


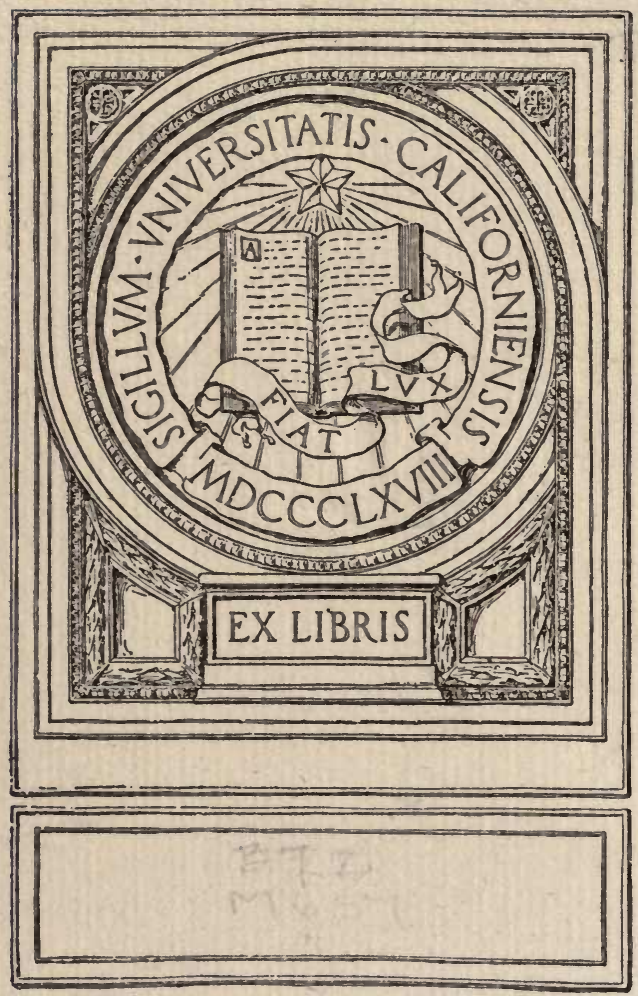



THE REALITIES OF MODERN SCIENCE 


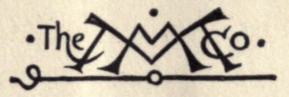

THE MACMILLAN COMPANY

NEW YORK - BOSTON - CHICAGO - DALLAS

ATLANTA - SAN FRANCISCO

MACMILLAN \& CO., Limited

LONDON - BOMBAY - CALCUTTA

MELBOURNE

THE MACMILLAN CO. OF CANADA, Ltd.

TORONTO 


\title{
THE REALITIES OF MODERN SCIENCE
}

\author{
AN INTRODUCTION FOR THE \\ GENERAL READER
}

\begin{abstract}
BY
JOHN MILLS

RESEARCH LABORATORIES, WESTERN ELECTRIC COMPANY, INC.; MEMBER, AMERICAN PHYSICAL SOCIETY ; AUTHOR OF

" RADIO COMMUNICATION," etc.
\end{abstract}

\author{
New Tork \\ THE MACMILLAN COMPANY \\ 1919
}

All rights reserved 
Copyright, 1919, BY THE MACMILLAN COMPANY.

Set up and electrotyped. Published May, rgrg.

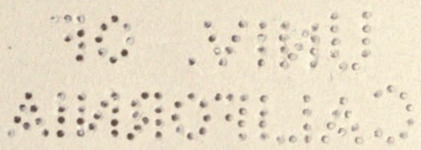

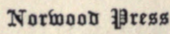

J. S. Cushing Co. - Berwick \& Smith Co.

Norwood, Mass., U.S.A. 
TO

IE. G. IIT. 
$$
\text { . }
$$ 


\section{PREFACE}

The present volume is intended for the general reader, interested in modern science, who finds few clews to recent advances in his memories of the formal instruction of school or college days.

During the last twenty years physical research has penetrated the mysteries of the chemical elements and has demonstrated that their atoms are granular in structure and electrical in nature. Transmutation - the dream of the alchemists - is to-day recognized as a natural process in the case of radioactive substances. An element common to all matter has been found in the electron which has been isolated and studied. It is a reality of modern science and in terms of it scientists are rapidly explaining the phenomena of all physical science, the essential unity of which its discovery has emphasized.

The existence of electrons and their determining effect in the composition of the chemical elements are easily demonstrable facts, compared to which the indestructibility of matter is a speculative assertion and the independence of mass and speed an exploded theory. Nevertheless our education is so constrained by established curricula and text-books adapted thereto, that a knowledge of these facts is usually acquired only by college students who elect the more advanced courses. Even in the subject of electricity most of vii 
the phenomena are treated in elementary courses without reference to the electron, the fundamental entity.

One difficulty seems to be that physical science is subdivided, classified, and named until the unity is completely obscured. Of each subdivision the accepted method of instruction assigns certain phenomena to high school or sophomore courses and others to junior work. The results of recent researches are postponed for consideration in graduate courses and "recent" often means since the graduation of the instructor. The selection of material for elementary courses is not always determined by whether or not the phenomena are fundamental and easily comprehensible, for it is largely traditional. For example, the writer remembers discussing a well-known text-book with a high school teacher, who said it was not adapted to his field because it introduced the "Brownian movement." The writer, however, believes that the Brownian movement is capable of simple presentation (cf. pp. 155 and 158) and should be discussed in order that the student may obtain satisfactory concepts upon which to base his future study.

So far as concerns college instruction one alternative is a general introductory course which cuts across the conventional divisions of subject matter, selecting to emphasize the unity. Nor should this introduction have the finality of the usual elementary course, for it should indicate the evolutionary character of science and lead up to present problems. It should also indicate the historical aspects and the social significance of modern science. In material it should be adapted 
to the future citizen rather than the future scientist, to general readers rather than technical students. The present book follows one of the many possible outlines for such an introduction and constitutes a suggestion as to one of the changes in teaching methods which our educational system seems to require.

The general reader is under no compulsion from a traditional curriculum and may pick and choose his sources of information. To the study of science he may, however, need an introduction and this need the present volume attempts to satisfy. The earlier chapters following an historical order develop without abstract formulations the fundamental concepts of modern science. By the time Chapter IX is reached the necessity of algebraic expression has become apparent and the three succeeding chapters illustrate its usefulness while developing the ideas of defining equations, rates, and the laws of motion. Not all these ideas are symbolized and the reader who feels an ineptitude for mathematical expressions is advised to give these chapters a cursory and mechanical reading in order to reach the important chapters on molecular and electronic motions.

The majority of readers will probably find no obstacles in the occasional formulas of the later text. For these the book may serve as an introduction to the general literature of physical science. To this end footnotes refer to books on special subjects, the greater portions of each of which the reader will find comprehensible in case he is interested in more detailed study.

The writer wishes to make an acknowledgment to the Physics Department of Mount Holyoke College. 
Professor Laird, the head of the Department, and Dr. Shields read this book in manuscript during the summer of 1918. Miss Shields has followed the general method and incorporated some of the material in a course for second year students. For this proximate use of the manuscript and for the suggestions which have arisen from it the writer expresses his thanks to Miss Shields. Thanks are also expressed to Dr. K. K. Darrow of the Western Electric Company, who has read the proof.

J. M.

Research Laboratories

The Western Electric Company, Inc.

March 1, 1919 


\section{CONTENTS}

CHAPTER

Preface . . . . . . . . . . . vii

I The Beginnings of Knowledge . $\quad$. . . 1

II The Machines of the Ancients . . . . 14

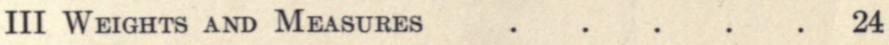

IV The Beginnings of Science . • • • . 35

V The Beginnings of Experimentation . . . 48

VI The Realities of Science . . . . $\quad$. 60

VII The Molecular Composition of Matter . . 70

VIII The Electron . • • • . . • • • 88

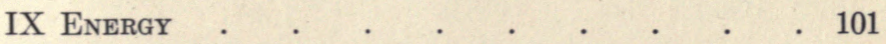

X Some Uses of Mathematics . . . . . 115

XI RAtes

XII Force, a Space Rate of Energy $\quad$ • $\quad . \quad 139$

XIII Molecular Motions and Temperature • 155

XIV Motions of Electrons . . . . . . . 173

XV The Interactions of Moving Electrons . 195

XVI The Continuity and Correspondence of Molec-

ular States $\quad . \quad . \quad . \quad . \quad . \quad . \quad . \quad 217$

XVII Molecular Mixtures . . . . . . . 234

XVIII Electrolytic Dissociation $\quad . \quad . \quad . \quad . \quad .244$

XIX Equilibria and Their Displacement . • . 257

XX Molecular Magnitudes . . . . . 270

XXI Molecular Energy $\quad . \quad$. $\quad . \quad . \quad .288$

XXII Electronic Magnitudes . . . . . . 304

$\operatorname{INDEX} . \quad . \quad . \quad . \quad . \quad . \quad . \quad . \quad . \quad . \quad 323$ 



\section{THE REALITIES OF MODERN SCIENCE}

\section{CHAPTER I}

\section{THE BEGINNINGS OF KNOWLEDGE}

MAN is sometimes distinguished as a "tool using" animal. Monkeys may be taught a few simple operations with tools, such as cracking nuts with a stone, but usually they merely mimic a man. Their hands, with five fingers instead of four and a thumb, are not suitable for picking up objects. Other animals have bodies the parts of which are convenient for various purposes, as horns for defense or claws for offense, but parts of the body, even though they serve a special purpose, are not tools. A tool is an object apart from its user.

Man's superiority as a tool user, partly physical in his ability to stand erect and use his hands, and partly mental, ultimately secured his position over the beasts of the world and enabled him to construct our material civilization. An instance of the mental difference is found in the attitude toward fire. The dog knows the pleasure on a cold day of curling up beside the fire. For thousands of years he has been man's companion and intelligent servant. Nevertheless, a dog, shivering before a dying fire, lacks the ability to foresee effects, 
which would lead him to push a new stick into the smoldering embers.

No one knows how man first learned to keep fire alive and how ages later he learned to make a fire. Many students of the relics of man in earlier geologic ages think that he first saw fire in the dry seasons when lightning had started it. Perhaps after a brush fire had been checked by a rain, some man, more adventurous and curious than his fellows, approached and picked up a burning stick. The man who was the first in the world to pick up a brand was not only brave but an important discoverer, in showing that fire could be safely handled. Nobody told him that although wood is combustible and if heated to the proper temperature will ignite with air and burn, still, when below this temperature, it is a very good heat insulator. The experimental fact preceded by ages its scientific description.

Probably other members of this discoverer's family imitated him, just as small boys around their first bonfire will soon follow the lead of the older boy who brandishes a flaming stick. From this time familiarity with fire increased, although the first fire-handlers may have died before they again saw fire, leaving the discovery to be remade by a later generation.

Perhaps, chilled by the rain which checked the spreading bush fire, our man may have discovered the pleasantness of warming his own body beside the embers. He may also have tasted roasted meat for the first time, driven by hunger to try the half burned body of some small animal which was caught in the fire. If so, it was a long time before he ate cooked 
meat again, for fires could only start in the dry season from lightning or from a volcanic eruption.

In the next dry season our man may have remembered his first taste of cooked meat. More probably he did not remember at all. Certainly his brain did not permit of his looking ahead and saying, "Next dry season, if there is a fire, I may find some roasted meat." His mind developed slowly, and the first experiment had to be performed many times by different members of the race before he was ready for his second step in the domestication of fire. History ${ }^{1}$ incompletely depicts these slow ages, the dark nights, the cold and rainy days, and the uncooked food.

How man learned to keep a fire alive is also a matter of surmise. Perhaps he noted that it lasted longest in large heaps of damp brush or in the trunks of rotten trees. At some such remains of a fire given by lightning from the heavens he may have cooked meats and noticed that the fire flared up under the breeze. Another discoverer may have carried home to his cave a glowing brand, which when thrown aside into the dry branches started a larger fire. By such a series of accidents the discovery may have been made that fire could be kept by furnishing it with fuel, and that it burned less fiercely and lasted longer if covered from the wind.

As yet no way was known of kindling a fire. If the fire died, the tribe had to beg or steal from another tribe or wait until a dry season when nature again provided fire. To-day we little realize the situation of

${ }^{1}$ An interesting sketch of this evolution is that of Migeod, "Earliest Man," Kegan Paul, London, 1916. 
mankind when its scientific knowledge was only sufficient to maintain a fire and not to start one. It is no wonder that religious rites grew up about the tribal fire and that special caretakers were dedicated to it.

While early man was learning some of the uses of fire and how to conserve and control it, he was also developing tools and through their use making advances in clothing and shelter. His first tool might have been a stone. Perhaps, while lying on the floor of his cave, he was frightened by the entrance of a wild beast and his hand closed over one of the small stones which he had earlier brushed aside to make a smoother bed. He fought blindly and the stone slipped from his grasp. A chance hit, the astonished beast turned tail, and he was saved.

The next time he was attacked he may have remembered the episode of the cave and used a stone again. If his brain was not sufficiently developed for him to connect the act with the flight of the beast he was probably eaten for his ignorance. Those families or tribes which quickest learned this use of stones were fittest to survive.

A peaceful use of stones as agricultural tools may or may not have preceded their use as weapons. Early man, we believe, dug for roots and in certain seasons these were the only succulent food which he could obtain. While burrowing with his hands he might strike a stone and instinctively grasping it continue the same digging motion. If the stone happened to be the right shape he found to his surprise that his work went faster and easier. Later he may have tried 
it again and found by bitter experience that round smooth stones retarded his operations. Still later some man may have broken a stone by throwing it against a rock, hoping to find among the pieces one suited to his needs.

In some such way there developed the idea of using tools and of forming them. Of course, it is only a small step from breaking the stone as just described and chipping off edges of the selected stone so as to form it more nearly to the desired shape. But this step may not have been taken for centuries. Even if some man did make this advance and his tribe learned it from him, accident or disease could have destroyed them all and with them the precious knowledge. There were as yet no records of past achievements to save a student the mistakes and trials through which ages of mankind accumulated and arranged its knowledge of the physical world.

If food became scarce in the region where lived a tribal group which had learned to preserve fire it may have wandered into other regions and so spread its special knowledge. This change from the old conditions and the necessity of meeting new ones would have stimulated it to new discoveries along other lines, as perhaps in the making of vessels for carrying fire and water on its travels. In this migration it may have met another tribe with other knowledge. If they fought the weaker tribe perished with its knowledge, or if they mingled the enlarged group enjoyed the knowledge common to its parts.

Except when tribes amalgamated the exchange of information must have been very slow because of the 
difficulties of language. At this time in the development of man he was just learning to talk. His few ideas and fewer words were concerned with concrete objects such as water, fire, food, sun, and moon or with his own sensations such as cold, hunger, and fatigue. He had no vocabulary for expressing abstract ideas. Imagine the difficulty of trying to tell a primitive man of the speed record of an automobile, of the efficiency of its engine, or of the refinement of its lines and upholstery.

Between the discovery of the method of conserving fire and its production by a simple machine many thousands of years must have intervened. A primitive method is that of rubbing a sharp stick back and forth in a groove cut in a block of hard wood. For this concrete case he had learned that his work in rubbing together two surfaces resulted in heat. The heat produced by his efforts did not diffuse rapidly and so make the entire block of wood a little warmer than it was before. Instead it was concentrated in the wood adjacent to the groove. If he rubbed hard enough, that is, if he did enough work, this part of the block would then rise rapidly in temperature, smoke, and finally set fire to dry wood dust or other tinder placed in the groove.

This simple device is not, however, a machine. It is merely a special tool for rubbing and a block to be rubbed. When primitive men arranged a combination where the rubbing tool was actuated by another part of the device, which part in turn was controlled by the operator, then he had a machine. In Fig. 1 is shown such a fire-making machine. It is of course a develop- 
ment of an earlier form, shown in Fig. 2, where a pointed stick or drill is twisted by the operator's hands.

Let us examine this primitive machine more closely. The operator, forcing the bow back and forth, causes its various points to move along parallel paths. There is no turning of the bow, so its motion is "translation." The machine then converts a motion of translation into one of rotation. The cord of the bow merely replaces

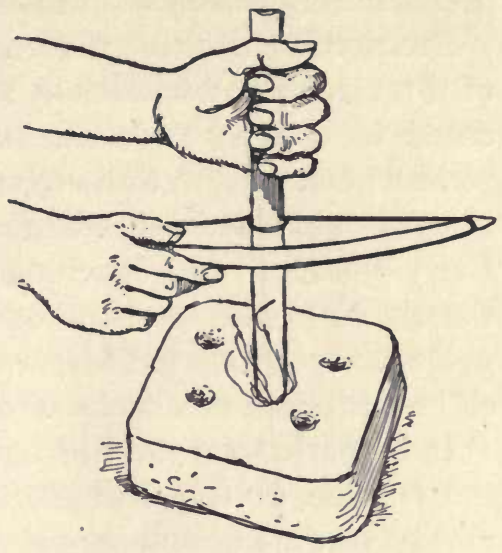

FIg. 1. the hands of the operator. In turning the drill of Fig. 2 through one complete revolution each hand

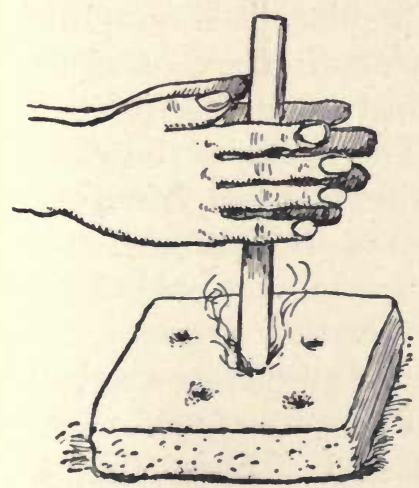

FIG. 2. comes in contact with every point of its circumference and moves a distance equal to the circumference. When the drill is operated by the bow, the latter must move through an equal distance. The operator may use only one hand with the bow, but, obviously, he must push or pull twice as hard since his other hand is not assisting. The advantage of the machine is not that it requires less work, but that it is more convenient, requiring only the simple 
motion of pushing and pulling. To operate the hand drill requires skill and practice, but to operate the machine requires less skill and the ability to work.

From this primitive design we can obtain a concept of a machine as a device in which a motion communicated to one part results in a different motion of a second part. Now, although this is a correct statement, it is one that is lacking in human interest or significance. Early man devised machines in his struggle against the rigors of the world about him. From our standpoint, as well as from his, we should consider the machine with reference to its effect on mankind.

It is. work to draw the bow back and forth against the friction of the drill and the block. We call the ability to do work "energy" and say that when work is done energy is expended. The machine requires energy from some source, and material upon which to operate. Push and pull, push and pull, is all that it requires, for in its sequence of motions it accomplishes the results of the most skilled craftsman. And this sequence of events is determined once and for all by the inventor of the machine. The needle of the sewing machine rises and falls on the material beneath it whether it be cloth or the hand of the operator. The loaded gun shoots friend and foe alike provided only the energy in its cartridge is released.

A machine, then, is a device for producing a definite sequence of motions provided the supply of energy necessary to operate it is released. Unless the machine is broken, in which case, of course, it is not a machine at all, man's only control of it is a permissive one, of allowing it to run or not, by controlling its 
supply of energy. In our modern life where machines for varied purposes are available this control is obtained by means of a switch or button, a faucet or a throttle. It is ours to say whether or not we shall release the energy, but otherwise the operation is inherent in the design of the machine except in so far as a counteracting machine, like a brake, may be available. In such a case, this too is controlled by its switch, throttle, or lever.

A machine, once started and supplied with energy, performs its characteristic series of operations without reference to their effects. In the inevitability of the sequence for which the machine is designed inhere its advantages and dangers. It is therefore vitally necessary that those who control machines or come within the range of their motions should bear in mind this fact. For this reason the old adage of "Look before you leap" has been replaced by the modern slogan of "Safety first."

The machine requires a source of energy, but does not demand an intelligence or skill on the part of the operator proportional to the results which it produces. While this permits the unskilled to produce the results of the skilled it does not offer the changing conditions which stimulate mental growth. There is a sameness to its operations which may make the human agents mere appendages of the machines they seem to control. The social and economic significance of the machine industry is only beginning to receive from economists and educators the consideration it deserves. Laws on manufacturing conditions and on child labor indicate a growing appreciation on the part of the 
public and its statesmen of a few of the problems involved.

With the control over fire, and the consequent ability to cook food and to maintain a comfortable living temperature, man's ascent toward civilization really began. During this time he devised and employed many simple machines, some of which we shall describe in a later chapter. From living in crude shelters of boughs and leaves or in caves he came to live in tents and houses. From being dependent on wild fruits and meats he advanced to agriculture. Animals of burden were used as machines with internal sources of energy. Boats were made and fitted with oars, which are of course simple machines, and also with sails by means of which the energy of the wind could be utilized. Larger groups of men could now exist in the same region, and cities and villages were formed. With the lessening of the struggle for existence man obtained more time for thought and mental development. The large empires of the ancient world and their civilizations were founded on these elementary advances in the knowledge of the physical world. Language and the arts had developed so that with two of these empires, Babylon and Egypt, history as we know it really began. With these there also began that arrangement and correlation of knowledge which we call science.

Both the Babylonians and the Egyptians were agricultural peoples, one living in the fertile valley of the Euphrates, the other on the banks of the Nile. What scientific advances they made were mostly along lines of immediate practical value. Thus, the Egyp- 
tians are believed to have learned mensuration and started the science of "earth measurements," or geometry, because of the necessity of marking anew each year the boundaries of fields flooded by the Nile. They did not carry their development, however, beyond the simple ideas necessary to lay off plots of ground and to compute areas and volumes. It was left for the Greeks to develop later the abstract ideas and general methods of reasoning which we know to-day as geometry.

Both these peoples were highly religious. With their lack of scientific knowledge it was but natural that they should be superstitious about the stars, and that their knowledge of astronomy should develop in connection with their religion. To the Babylonians we apparently owe the grouping of days into longer periods called weeks. Why seven days were chosen for the latter period is evident from our names for these days, which are traced in derivation to the sun, the moon, and the five planets, Jupiter, Mercury, Mars, Venus and Saturn. ${ }^{1}$ The lunar month was of course early noticed and measured by these astronomers. They had also progressed far enough to measure the year as $365 \frac{1}{4}$ days and to determine other astronomical facts.

These facts were developed in connection with their religion and their practical needs. In Babylonia, where stone was not easily obtainable and brick was used for building, one of the months was named for the brickbuilders. In this month, apparently, the

${ }^{1}$ Cf. Libby, "An Introduction to the History of Science," Houghton Mifflin Company, 1917. 
clay and the atmosphere best suited this work. In Egypt, on the other hand, great interest was taken in the various constellations in which the sun appeared at dawn. The heliacal rising of Sirius marked the annual inundation of the lands adjacent to the Nile and began the calendar year.

It is interesting to note, also, that the division of hours and minutes, each into sixty parts, may be traced to the Babylonians. Although they had a decimal system of numbers, they also had a sexagesimal system. In their system of weights, starting with a "shekel" equivalent to about half an ounce, they had a unit, the "mina," sixty times as large, and also a unit, the "talent," which was equal to sixty minas.

In general, both these early races were singularly lacking in curiosity as to the world in which they lived, as to its natural laws, its origin, and its composition. They did, however, invent new contrivances and thus showed a practical familiarity with some of the phenomena of nature. As early as 4000 B.c. the Egyptians had learned to melt iror oy using a bellows to make the fire burn hot enough.

In some respects their temperament was like our own. They were interested in practical applications and were unconcerned or even impatient of attempts to classify and coördinate their knowledge and to speculate upon the fundamental causes of the phenomena which they observed. They did not realize that practical devices follow and do not in general precede advances in scientific knowledge. In the case of the Egyptians this lack of speculative interest was combined with a feeling that in their religion they had reached a finality. As a result 
there was a long period in which they made small progress and during which they were passed by other races.

The rise of one of these, the Greek, is marked in its early stages by contributions from the Semitic race, of which the Babylonians and Egyptians were both members. The Island of Crete first received the culture of the Semites from the Egyptian, Assyrian, and Phœnician sailors and merchants. But the Greeks also were intrepid sailors and shrewd merchants, and they were shortly to be found in the older centers of learning. With one of these Greeks, an Ionian of Phœnician descent, Thales of the Island of Miletus, science as well as Greek philosophy is considered to have begun. This was about 585 B.c. 


\section{CHAPTER II}

\section{THE MACHINES OF THE ANCIENT WORLD}

In the homes of the earlier civilizations are buildings and monuments which have withstood the ravages of time and the waves of hostile invasion. Often these records of man's earlier activities are only restored to sight by excavation, for they have been covered by the dust of succeeding ages. The temples and palaces, the city walls, and the monuments of Egypt and Asia were of stone or brick, but the houses of the common people were usually of mud. When a conqueror razed a city, holes were broken in the walls to render it less easily defended; the monuments of the kings and the altars of the local gods were toppled over; and the houses of the common people were reduced to dust. The large buildings, of course, took years to restore, and the weakened and terrorized inhabitants may have hesitated to rebuild what had so recently been destroyed by their enemy. Thus in time the traces of a city were lost beneath the mud and rubbish of succeeding generations.

Such relics as we have, suggest to the engineer of to-day the question: How did the ancients, with their limited knowledge of physical science, succeed in erecting such enormous and high structures? The answer is to be seen partly in their knowledge of certain 
simple machines and partly in their organization of society. They were familiar, we know, with some or all of six mechanical contrivances, known as the six simple machines. These are the lever, the inclined plane, the wedge, the pulley, the screw, and the wheel and axle, conventionally illustrated in Fig. 3. Let us see what the advantages of these devices would be.

The lever consists of a bar. If the distance from the fulcrum, $c$, to the point $a$, where the force is applied,

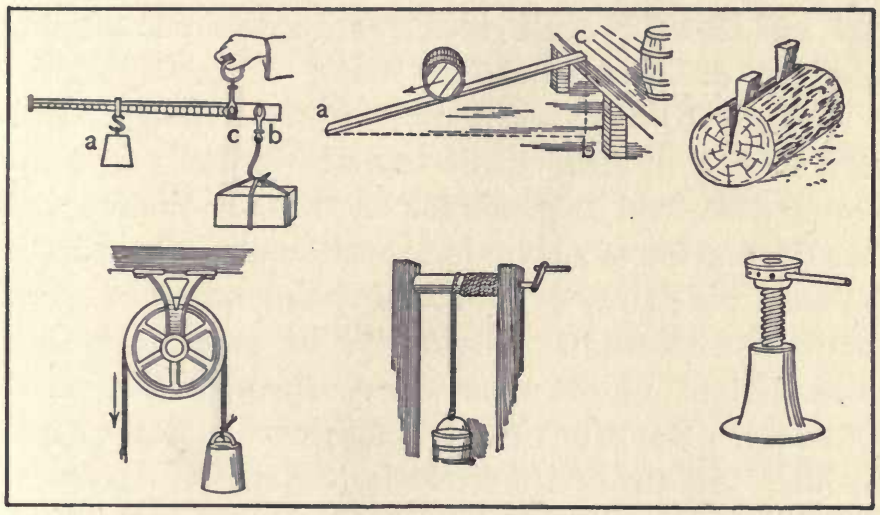

Fig. 3.

is larger than that to the point $b$, then, as we know, the lever gives a mechanical advantage. The force exerted at $b$ by the lever is as many times greater than the force applied at $a$ as the distance $a c$ is greater than $b c$. It was not until the time of Archimedes (died 212 B.c.) that men knew this rule. During preceding centuries, however, they must have had a very good working knowledge of the lever.

When a man wanted to raise the end of a block of 
stone he probably selected a bar which looked about long enough and tried. If it didn't work he pushed the fulcrum a little closer to the block and tried again. If the force he was capable of applying was still too small, he tried a longer lever. He thus made the lever arm of his force sufficiently greater than that of the weight he was trying to lift. Of course, if he chose too long a bar it may have bent in such a way as really to make his lever arm shorter. In some such manner the ancients probably obtained their knowledge of the lever and incidentally some ideas as to the bending and elasticity of beams.

We know to-day another property of the lever of which they made use, although it was not formally and completely described in words for centuries. We recognize that the motion of a lever is a rotation about its fulcrum, the path which any point travels being a part of a circle about the fulcrum. Obviously, in any motion, the more distant points must move through the greater distances. But the time it takes each point to move through the arc of its circle is the same. Hence the point that moves the farther must also move the faster. This is the property which we use whenever we want to strike faster than we can with the levers afforded us in the bones of our bodies, as in using an ax, a sword, or a golf club. The system of levers involved in an ordinary typewriter is an interesting illustration of a slow motion of the point where the force is applied producing a faster motion of another point of the system.

In the case of the lever, as of all machines, work is done by the machine only because work is done on it. 
Now, we know that when we push or pull, the work we do depends not only upon how hard but upon how far. When one pushes on the long arm of a lever and lifts a larger weight at the end of the short arm, he must push a correspondingly greater distance than the weight rises.

The inclined plane is strictly speaking not a machine. Its serviceability was probably evident to man fairly early in his development. He would have noticed that he could drag a burden up the smooth inclined face of a rock more easily than lift it through the same vertical distance. In his building operations he learned something of what builders to-day call the "angle of repose" of a loose material. When we try to make a pile of sand or gravel we notice that if the sides become too steep, what we put on slips down. If we do not exceed a certain steepness, that is, a certain angle of repose, then the friction which the surface offers prevents what we add to the pile from sliding down. The steeper the inclined plane, the more easily do things slide down and the greater the difficulty of dragging them up. For this reason the slope of the incline should be gradual. It is also desirable to reduce as much as possible the friction between the body and the surface of the incline. Of course, on roads this is usually accomplished by making the friction between the two surfaces rolling rather than sliding friction. With these ideas the ancients were familiar.

It is our common knowledge as to friction that it is greater the harder the two sliding surfaces are pressed together and the more irregularities there are upon 
them. Automobile tires have specially shaped surfaces or chains. Because of the fact that the amount of friction which will oppose the action of a sliding body depends upon the character of the two surfaces, it is easier when we wish to develop the law for an inclined plane to consider first a case where there is no friction. But such a case is impossible; even between the most highly polished and oiled surfaces there would be some friction. Nevertheless it is a method of science to consider first an "ideal problem," "the limiting case" of the general problem. Thus in the present instance, of all the possible cases of bodies on inclined planes, we decide to discuss first that case which lies just at the limit of the physically possible, where the friction is so small that we may entirely neglect it.

Consider the work of moving a body from one end $a$ to the other end $c$ of the inclined plane shown in Fig. 3. Experience tells us that as we push the body upward the plane supports part of its weight. If there is no frictional opposition to sliding, the work we do is that of lifting. In sliding it along the side $a c$ we do not have to push as hard, but we must push farther, so that we do just as much work as if we lifted the body vertically through the distance $b c$. In both the inclined plane and the lever the principle is the same, namely, a small force exerted for a long distance does the same work as a larger force for a shorter distance.

The wedge is a sort of double inclined plane. Of all the elementary machines it was probably the earliest, for it is really a cutting tool like a chisel. Some primitive man in trying to scrape a hole through a block of wood by using a sharp stone may have got it stuck in 
the wood and while pounding it out split the block. This use of a wedge for prying objects apart is so old as to be almost instinctive. Where a wedge is driven in by pounding, friction is very desirable, for if there were no friction it would drive in somewhat more easily but it would slip back and out following each blow.

If one cuts a long right triangle of stiff paper and then winds it about a pencil, he will see how a screw is but a special form of an inclined plane. Resting a finger nail lightly on the "thread" of the screw he may observe how turning the screw slides the finger up the spiraled incline. In practical applications of this principle the screw turns in a nut. If the nut is prevented from turning while the screw is turned the rotation of the screw will result in its translation relative to the nut. The screw offers a large mechanical advantage, to which friction, however, imposes a practical limit.

The pulley followed in the development of man's mechanical ability his invention of rope. For rope he may first have used long vines, and later, using two or more together to obtain greater strength, learned to twist rope. Considerable invention, however, was required to produce a pulley, although the idea of changing the direction in which a force is exerted by passing the rope over the limb of a tree was perhaps obtained by the easy accident of pulling at some vines which grew over a tree. Between such an observation as this and the idea of reducing the friction by allowing the bar over which the rope passed to roll, there is a large step. The idea that round objects roll more easily than they slide may have come from noticing 
pebbles and bowlders rolling down a hillside, or from the turning of bits of branches under foot. From the use of rollers to wheels was possibly the line evolution took. From wheels to pulleys is another possible step. A wheel, rolling along the ground, comes into contact with successive points, and the rotating axle moves forward. In the pulley successive points of the rope pass from one side to the other of a rotating axle. In both cases the rotation of the wheel about its axis is accompanied by a translation of the contacting surface relative to the axle.

The pulley was of special value in early building operations because there were no sources of energy, like steam engines, which could exert large forces. Large forces were derived from a large number of men; and a pulley allowed their combined force to be exerted in the desired direction. It is important to notice that with a single pulley the only effect is that of changing the direction of the force. With a combination of pulleys we may obtain mechanical advantage which was apparently unknown to the ancients. ${ }^{1}$ In such a case we arrange the system so that the weight to be lifted moves a smaller distance than the end of the rope which is being pulled. In this way we make use of the principle which applies to the lever and the inclined plane. This "work principle" states that in any machine the work of the acting force is equal to the work done against the resisting force. The work in each instance is measured by the product of the force and the distance.

1 The story of page 43 indicates that Archimedes was familiar with it, but this was much later than the building of the pyramids. 
The wheel and axle is something like a pulley. It permits a mechanical advantage, since the distance through which a point on the wheel moves may be large as compared to the corresponding distance through which the weight moves.

Of course, in the case of all these machines, some of the work of the operator is done against friction, and appears as heat at the point where the friction occurs. The work which the operator gets out of the machine is then less than he puts in. The ratio of the useful work to the input is the efficiency. In the ideal case it is $100 \%$, but no actual machines have efficiencies near this limiting value.

With these simple contrivances the buildings of the ancient world were constructed. We do not know the exact methods followed by their erectors, but it is possible that they used derricks to set the stones. In addition, as the building progressed, they used scaffolding. For the Babylonian structures, it appears, these scaffoldings were of brick. They would need to be quite substantial to support the large weights of men and materials necessary for such enormous buildings as we have seen in the figures. To-day frame scaffoldings may be made of comparatively light beams. Before man learned the underlying physical laws, strength and stability could be obtained only by massive construction, of which the Pyramids form perhaps the most striking illustration.

The energy to operate such machines and through them to rear such structures was not derived from natural sources through inanimate means. Of the use of winds the ancients had some knowledge, but except 
for sailing boats or for operations where continuity is not essential, wind is not a satisfactory source of energy. Horses, it is true, were available, but it is doubtful if they were much used for such purposes as these. They were not the property of the poorer classes, and were used for hunting and for warfare. For these buildings the energy was derived from men. Beside one of the large pyramids of Gizeh stand the quarters of the workmen, long chambers, capable of housing 4000 men. When we are told that the roof over the chamber in one of the pyramids was formed by three layers of cut stones, each piece weighing about 30 tons, we realize more fully the large amount of human energy which must have been expended in such a construction. The laborers who supplied this energy were slaves, usually members of subject races, who performed such tasks much as the Hebrews once made brick for the Egyptians.

It would be of interest to follow the development of slavery to its peak in the Roman Empire, its transition into feudalism, and the organization of society in medieval Europe. Through all the centuries from the earliest Egyptian records to the present time, under one form or another of slavery, men have supplied the energy for the monuments of dynasties. When man's development along scientific lines was yet too small to allow him to utilize the enormous stores of energy in the world about him, the main source of energy was in food, for the conversion of which into mechanical energy the human body is an efficient engine. But to-day man's growing scientific abilities are making possible grandeurs of buildings and comfort of builders 


\section{THE MACHINES OF THE ANCIENT WORLD 23}

far in excess of the dreams of the ancients, and his growing spirit of democracy is insisting that human energy shall not be wasted and that the energy of the material world shall be efficiently utilized for the comfort of all. 


\section{CHAPTER III}

\section{WEIGHTS AND MEASURES}

IT has been well said by one of the leading physicists of the 19th century that "when you can measure what you are speaking about and express it in numbers you know something about it, but when you can not, your knowledge is of a meager and unsatisfactory kind; it may be the beginning of knowledge, but you have scarcely in your thoughts advanced to the stage of science." In later chapters we shall see how science began, and learn something of the uses of mathematics.

To tell "how much," we must have some means for measuring, and a unit. For example, to measure a length we take some length as a unit, that is, call some definite length "one." We may then count how many times this unit goes into the unknown length. The unit we use for this purpose may be a length of any substance, as of string between two knots, for the material of the standard is unimportant provided it is not such as to change its length while we are measuring with it. If a boy wished a measure of how fast he was growing he might record his height each year on some upright. He would not, however, choose a poplar sapling.

This illustration makes the use of a variable standard 
seem very foolish, ${ }^{1}$ but such a possibility must always be guarded against, especially when precise measurement is desired. For example, a steel tape line varies in its length, increasing on hot days. In surveying over large areas, as in the case of the U. S. Coast and Geodetic Surveys, extreme precautions are taken in measuring a base line to compensate for such linear expansion. If a tape is used care is also taken that it shall always be under the same tension.

For the measurement of length it was natural that the earliest units should be connected with the human body. Thus lengths were measured in spans, in digits, in feet, or in the length of a step or pace. Longer distances were measured in terms of a day's march or journey. These units all differ from man to man, so that if two persons measure the same distance they will express it differently, because they will count different numbers of units.

Thus it came about when men wished to have a common understanding that they had to agree as to whose foot or pace should be used as the standard. Many times these lengths were referred to the body of a king or of a priest. In order that the chosen units should be commonly available for comparison, they were sometimes marked on the wall of the city or of a temple. This method of recording standards persisted until comparatively recently, for there are European cathedrals on the outer walls of which standards are marked.

1 The use in measurements of a standard which changes, without making proper allowance for such changes, we recognize as a form of mistake which is frequently made in the popular discussions of social and economic relations. 
The standards would sometimes be lost or destroyed, and then a new unit would have to be chosen. Perhaps the new unit was made practically of the same length as the old by reference to the walls of some building for which people remembered the lengths as expressed in the former unit. At any rate it is by this method that archeologists to-day obtain their ideas as to the length of the units used in ancient times.

Other units may be formed by taking multiples and submultiples of the adopted unit. This is also the custom to-day in the case of the so-called metric units, of which the meter is the unit of length. The multiple unit which occurs most frequently is formed by the prefix "kilo," meaning "one thousand." The submultiples are formed by using Latin prefixes instead of Greek, thus "centi" and "milli" for "one hundredth" and "one thousandth."

Different localities had different units, although there was a tendency toward the reduction of the number of units, due to the formation of large empires and to the usages of traders. Such a standardization ultimately resulted in greater simplicity and facilitated trade, for we all recognize the inconvenience attaching to the use of different systems, e.g. metric and English. The tendency to standardize was most marked in the case of units of weight. If money is to perform its proper service in the exchange of goods, then each piece of a given denomination must be as nearly as possible the same as any other. It was somewhat, probably, to insure the full payment of taxes and for reasons of pride, but largely to stabilize trade, that monarchs were especially concerned with weights and measures. 
Of course a dishonest monarch might debase his own currency by retaining the same form and markings for a coin but decreasing the amount of precious metal in it, and thus be enabled for a time to purchase from his own people or from unsuspecting traders a greater amount of goods for the same metal. Foreign traders, however, are usually alertly suspicious, so that only the full weight coin would circulate in foreign trade, as the reader realizes from his familiarity with Gresham's law.

For standards of weight, pieces of metal or stone were used. Sometimes these were in the form of animals, as the bronze lion of the Assyrians. In England one of the standards of weight was known from its material as "the stone." The use of this unit has persisted for years and is still evident in expressions for the weight of a man. To-day in England, in the British Commonwealth, except for India, and also in the United States the unit of weight is the pound. In the rest of the countries of the world the unit is the kilogram of the metric system. To the scientist this system is the more important.

While in the case of a measurement of length it is only necessary to set the standard beside the body of unknown length to make a direct comparison of the two, for measurement of weight special apparatus is required. For weighing it is necessary to have a set of weights, comprising multiples ${ }^{1}$ and submultiples

${ }^{1} \mathrm{~A}$ set of weights may be obtained as follows when one has ao cess to a balance and the standard weight. First it is usual to make a copy of the original standard, or "prototype," for use in place of it. This is made a little too heavy to start with and reduced until it is as nearly as possible equal to the standard. The copy is then 
of the unit weight. With these and a balance the unknown weight of a body may be determined in an obvious manner. The balance is merely a lever supported at the center. At the ends of the equal lever arms thus formed, pans are hung, in which the weights to be compared are placed. With this balance the ancients were familiar and Pythagoras in the sixth century B.c. notes that dishonest tradesmen used to shift the fulcrum slightly away from the pan containing what they were selling so that a false comparison resulted in their favor. Of course the check against such a fraud is to interchange the contents of the two pans, for then any inequality will be at once evident. In general, if the arms are unequal the true weight of the body may be obtained by observing the weights required to balance it, first in one pan and then in the other. This method is called "double weighing." (From these two weighings the true weight is obtainable as the geometric mean.)

Another method of obtaining the true weight of a body, even though the lever arms are unequal, is known as the "substitution method." The unknown body is placed in one pan and balanced by the addition to the other pan of lead shot, sand, or any convenient used for a standard and the prototype is preserved for occasional comparisons.

To obtain a weight of two units it is only necessary to make another weight like the copy and then to make a new weight which will just balance the other two. Two half units may be obtained in the following manner. Weights of approximately half a unit are made. These are balanced against each other and made equal. They are then kept equal and worked down until together they just balance the unit. In somewhat similar manner other submultiples may be obtained. 
substance. After a balance is obtained known weights are substituted for the unknown body until a balance is again obtained. It is evident that these known weights produce the same effect under the same conditions as does the body of unknown weight and hence that they are equivalent. The method requires that everything else which can in any way affect the actions to be compared must remain unchanged, or in the usual words, all other factors must be constant.

We are now ready to give a name to the method of direct comparison, illustrated by the use of the balance. If the lever arms are equal, equal weights produce equal and opposite effects which neutralize each other, so that there is no deflection of the beam. This is therefore called the "opposition method," the "zero deflection method," or the "null method" from the Latin "nullus." It is the method of no resultant effect.

These two methods, the opposition and the substitution, are the only ones by which we can compare two things, whether weights, electric currents, light intensities, or any of the other magnitudes which the scientist may have occasion to measure. The method of double weighing is evidently merely the opposition method used twice with the weights reversed, so that the effect of inequalities in the lever arms of the balance may be eliminated.

The advantages of the two methods are now evident. With the opposition method a direct comparison is obtained by one operation, while with the substitution method two operations are required. On the other hand, if the possible inequalities in the two parts of the 
apparatus, through which opposing effects are balanced, are to be eliminated by a reversal, as in double weighing, the number of operations required for equally accurate results in the two methods becomes the same. For many measurements, as for example in astronomy, it is impossible to apply the substitution method and results of marvelous accuracy are obtained by the opposition method.

Both the substitution method and the opposition method with reversals, are inconvenient because they take so much time, as is evident from the illustration of weighing. To-day the opposition method of weighing is used only where especially precise results are required, as for example, in chemical analysis, pharmaceutical work, and in the weighing of precious stones and metals. For ordinary purposes the use of spring scales makes possible a more convenient form of substitution method.

A spring scale depends for its operation upon elasticity, ${ }^{1}$ which is "the property by virtue of which a body requires the continued application of a deforming stress to prevent the recovery, entire or partial,

1 This definition, as the reader recognizes, is a good example of the expression of an abstract idea. Thus the use of the word "body" meaning a "definite amount of matter" does not limit the definition to any particular substance or form. Again in the word "deforming" we get away from the concrete by using a word expressing an abstract idea, for it covers stretching, bending, twisting, compressing, distending, in fact, any change in form. To stretch we must pull in opposite ways, to compress we push from opposite sides, to distend we push outward in every direction. A single force will not produce a deformation. To convey the idea of combinations of oppositely directed equal forces the physicist uses the word "stress." 
from deformation." The physicist also uses the word "strain," to represent the measure of the deformation which a stress produces. This happens to make it easier to remember the fundamental law of elasticity, namely: The ratio of stress to strain is constant.

In our definition for elasticity we see that the recovery when the deforming stress is removed may be "entire or partial." If it is entire the body is perfectly elastic. One of the best illustrations of perfect elasticity is the hairspring of a watch, which may coil and uncoil a million times without any permanent deformation. If, however, a body is deformed too far it does not return to its original form, although it may still show some ability to recover from the deforming stress. This is imperfect elasticity. When the stress becomes so large that the body does not recover entirely, the "elastic limit" is said to have been reached, and for greater stresses the alliterative law given above no longer holds. For some still larger stress the body breaks. This breaking stress measures the "ultimate strength" of the body.

With the quantitative applications of these principles of elasticity the maker of spring scales must be familiar. If no weights are applied to a spring scale greater than that corresponding to the elastic limit, the strain will always be proportioned to the weight. If then we mark the positions of the pointer when the scale pan is empty and when it carries $\mathrm{N}$ pounds, we may divide the total deflection, or distance between these two marks, into $\mathrm{N}$ equal spaces and number the dividing lines correspondingly. The process is that of calibration. Thereafter we may use it as a direct 
reading scale, remembering only that we must recalibrate if any doubt ever arises as to its accuracy.

We have so far considered only standards of length and of weight. Of course, units of area and of volume, e.g. the square foot and the cubic foot, may be formed upon the basis of a unit of length. Now it so happens that all the apparently complicated quantities ${ }^{1}$ which enter into science, such as the heat received from the sun, the intensity of a sound, the strength of an electrical current, can be expressed by the aid of measurements of length, weight (or more strictly mass), and time.

The idea of time is probably one of the first abstract ideas of mankind. We may think of time as flowing, like an endless stream. It is when we realize that it is slipping by and that changes are occurring that we become most interested in how fast they are occurring. In much of our study of physical science and of its application to human needs we are interested in the time-rate of change, that is, in "how fast." So important is this idea that a whole branch of mathematics was invented to deal with problems involving rates. This is known to-day as the "differential calculus," although as originally named by the inventor it was called "fluxions," that is, the mathematics which dealt with things that flowed.

An illustration not only of this idea of time as something which flows continuously but of the use of an unusual unit for measuring it, is found in the story of Galileo, a sixteenth-century scientist, and his study of the pendulum. In the cathedral at Pisa, he noticed

1 With the exception of two quantities, namely, the permeability $\mu$, and the specific inductivity $\mathrm{K}$, of the ether. 
that the lamps suspended by long chains from the ceiling swung to and fro. The question entered his head as to whether or not the period, i.e. time of one complete swing, depended upon the amplitude of the swing, that is, upon how far the swinging lamp departed from the vertical.

The problem then was to find out if the period changed as the motion damped down. The lengths of these pendula were comparatively long, so that their periods were matters of several seconds. Galileo timed the swings by counting his pulse. In the interval between pulse beats he had a convenient unit of time for his observations. Although the pulse rate varies from person to person and from time to time in the same person, for a few minutes, to determine which of two moving bodies is traveling its path in the shorter time, it might give a fair indication.

Up to this time pendulum clocks were unknown, and Galileo's discovery that the period was independent of the amplitude was the basis of Huyghens' later use of a pendulum to control the escapement and hence the rate of turning of the wheels of a clock. In a clock the springs or weights turn the wheels and the function of the pendulum is to allow only a definite part of a rotation for each swing, the amount depending upon the relation of the number of cogs on the wheels. The tendency of the motion of the pendulum to die out is cared for by arranging the mechanism so that as it passes through the middle point in its swing it receives a little kick which keeps it going and overcomes the friction of the bearing and of the air.

The earliest clocks were somewhat similar in prin- 
ciple to the familiar sandglass. They were large water bottles, and the unit of time was that required for the water to run out. In Greece, where public speaking reached perhaps its highest point in history, such clocks, called clepsydra, were used to time the speakers. In one of the orations of Demosthenes appear the words, "you, there, stop the water."

To-day the unit of time which is commonly adopted is the second, being the sixtieth part of a minute, which in turn is the sixtieth part of an hour, which is one twenty-fourth of a mean solar day. Now a solar day is to be found as follows. As the earth revolves the stars seem to an observer to revolve about an axis which is drawn from the center of the earth to a point very close to the so-called polestar, or North Star. A transit is set up so that the telescope lies in the plane formed by the axis of the celestial sphere, which we have just described, and the vertical line from the transit instrument to the center of the earth. This plane is the meridian plane at the location of the instrument. At noon the sun appears to cross this meridian. The time between two successive transits of the sun is called a solar day. Because the earth's movement about the sun is along an ellipse the solar day differs in duration from day to day. Its average duration is the fundamental unit of time from which we obtain the more convenient and shorter unit of the second. 


\section{CHAPTER IV}

\section{THE BEGINNINGS OF SCIENCE}

Science is said to have begun with Thales. Of Thales himself we know but little, and that through writers like Aristotle who lived two hundred years later. Specifically, he is credited by the latter with accounting for the attraction of iron by a lodestone, by assuming a cause inherent in the stone instead of supernatural influences, as did his contemporaries. With him our knowledge of magnetism begins.

Thales, also, felt the need of accounting for the various kinds of matter in terms of some common element. Twenty-four centuries passed between his suggestion and the common acceptance of the atomic theory which describes all matter in terms of a comparatively few elements in various proportion. But Thales envisaged a single element. This accords with the extension of the atomic theory, the "electron theory," which is accepted to-day. Atoms of all substances are now known to be composed of small particles of electricity, called electrons, which are all alike without regard to the chemical element from which they may be obtained.

All Thales really did was to direct men's attention to the problem, still incompletely solved, of the composition of matter. In the centuries since his time and more especially in the last, progress has been made 
toward a solution. The amazing productions of modern chemistry $^{1}$ have been made possible by the knowledge that any homogeneous ${ }^{2}$ substance is composed of small particles called molecules which are all alike in construction. The molecules themselves are formed by the combination of still smaller particles, the atoms, which were once thought to be indivisible. Of the atoms there are some ninety different kinds, each a chemical element. With the ways in which they combine, the properties of their compounds, and the methods by which elements may be extracted from compounds, modern chemistry is concerned.

Now Thales advanced a theory as to the composition of matter. Of course, his theory was all wrong because he had insufficient experimental data. He suggested that water was the single fundamental element. The progress of science is marked by theories which have been advanced by various scientists, accepted and held for a time by other scientists, and later superseded. Let us see what a scientist means when he speaks of a theory. He should mean that upon the assumption of certain things as true he can then explain in terms of these all the known facts of the subject of his theory. He does not mean that these assumptions are necessarily correct. If they help to form a picture of the mechanism of known phenomena they may enable him to predict what will happen under somewhat different conditions. 1911.

${ }^{1}$ Cf. Duncan, "Some Chemical Problems of To-day." Harpers,

2 The word "homogeneous" is also applied to substances which are mixtures in definite proportions of two or more kinds of molecules. 
If under new conditions what he predicts from his theory fails to happen, he knows that it is wrong somewhere. He therefore modifies it by changing some assumptions or adding new factors until he can account for the phenomenon which invalidated the theory. It may be that the theory is shown to be absolutely wrong, so that no modification can possibly make it explain the things that actually happened. In that case it must be discarded at once.

As time goes on new conditions arise and the theory is subjected to new tests. Sometimes it is not necessary to wait until new conditions arise naturally, for they may be devised and arranged. A scientist thus checks his theory by experiment. It may be that he can form a rule, expressing what to expect under any given set of conditions. This relation between cause and effect he states as a law. Sometimes the experiments will show unexpected relations, not inconsistent with the theory and yet not covered by it. The scientist may then verify this relation in other experiments and make a statement of it as a purely empirical law.

By theories formulated on the basis of experiment, by experiments devised to test them, and by their consequent verification, modification, or rejection, science has advanced. It has developed through a succession of theories. The man who furthers it, except by some accidental discovery, is the one who has imagination for the hidden processes by which natural phenomena occur.

The danger to science is not in the suggestion of new theories but in the failure of their adherents to follow 
the steps traced above. It sometimes happens that a theory is apparently completely verified and for generations commonly accepted by the scientifically trained. Later some experimental evidence may come to notice which explodes the existing theory. The new theory which arises to take into account the exceptions to the previously accepted theory must, however, fight its way against a natural conservatism and even against the opinions of scientists whose other achievements have entitled them to great influence. ${ }^{1}$

In the case of the Greek scientists or rather philosophers, the tendency was to advance broad general theories, like that of Thales, without applying to them the check of experiment. Of course, if by experiment we can learn how some natural phenomenon occurs, we no longer need a "theory" to account for it, nor need we build our explanation upon a "hypothesis." On the other hand, checking a theory by experiment does not indicate the correctness of all the assumptions but merely that they will account for all the observed facts of the experiment.

Forming theories is then one of our methods of learning the explanation of the phenomena which attract our attention. Without curiosity as to the "why" of the various aspects of the world about us we make but slight progress. The Greeks had an unflinching curiosity. Although most of their physical theories have since proved wrong, the curiosity which

${ }^{1}$ In the struggle between the wave theory of light and the preceding corpuscular theory the opinion of Newton greatly retarded the common acceptance of the former. The classical example is, of course, the astronomical theory of Ptolemy. 
urged their formulation initiated scientific investigation. It is not the contributions to the total of scientific facts which distinguishes them from the Babylonians and Egyptians but their contribution of method and of point of view.

We all recognize how necessary to success are a proper point of view and a good method. The selection of the best method has led, in manufacturing, to motion studies and the standardization alike of workmen and mechanical parts. This whole matter of efficiency ${ }^{1}$ is a fascinating and important study which concerns us all. Of course, a proper method of study is as important to the student as is an efficient method to the worker. To some extent the arrangement and facilities of a school and the formal instruction of teacher and textbook help the student. Very largely, however, it depends on the pupil, on his own critical attitude toward his mental processes, whether or not he ever forms an efficient method of studying, that is, of grasping and making his own new ideas. The student of science who fails to acquire the point of view of the physicist and a sympathy with his methods may be stuffed as full of facts as an encyclopedia and yet, like the latter, be unable to develop an original idea or to solve a new problem.

To the Greeks natural phenomena were question marks, stimulating their curiosity and demanding answers. Before the days of their philosophers, physical phenomena were explained in supernatural terms

${ }^{1}$ How best to employ such methods of efficiency without inhibiting the creative instinct is an interesting question. Cf. Helen Marot, "The Creative Instinct in Industry." 
as being the work of some spirit or deity. Thus on the island of Samothrace there was a "mystery," in charge of the priests, which attracted travelers from large distances. From the accounts it seems to have consisted of a lodestone and some iron rings which were attracted to this natural magnet and hung suspended from it. Thales got far enough scientifically to assign this attraction to something inherent in the stone itself rather than to any action of spirits. As a matter of fact, however, the simple laws of magnetism were not accurately stated until they were derived by Gilbert (1600) from long and careful experiment. The fact that the curiosity of the Greek philosophers did not falter before what was commonly considered supernatural is, however, illustrated by this case of Thales.

Of course, to-day we should not be prevented by superstitions ${ }^{1}$ from seeking the explanation of any phenomena which may attract our attention. But there was more to the Greek attitude than mere curiosity. They observed and classified phenomena. This correlation of phenomena, that is, the collection of those which are similar in principle, their description in abstract terms, the generalization of the underlying laws, and the formulation of theories, constitutes science. The influence of the Greek is evident to-day even in the words we use; for example, our word "principle" conveys an idea first expressed by Aristotle (384-322 в.c.).

The purpose of Aristotle illustrates the Greek point

${ }^{1}$ Many, however, have inhibitions against certain methods and fields of research, e.g. psychoanalysis. 
of view. It was "to comprehend, to define and to classify the phenomena of organic and inorganic nature, to systematize the knowledge of his own time. He pressed his way through the mass of things knowable and subjected its diversity to the power of his own thought. No wonder that for ages he was known as 'The Philosopher,' that is, master of those who know. His great systematizing intellect has left its impress on nearly every department of human knowledge. Physical astronomy, physical geography, meteorology, physics, chemistry, geology, botany, anatomy, physiology, embryology, and zoölogy were enriched by his teaching. It was through him that logic, ethics, psychology, rhetoric, æsthetics, political science, zoölogy (especially ichthyology) first received systematic treatment.'

These Greeks were keen observers. Aristotle asks such questions as "Why are vehicles with large wheels easier to move than those with small?" and "Why do objects in a whirlpool move toward the center?" $\mathrm{He}$ also reasoned that the earth is spherical because during an eclipse of the moon by the earth the edge of its shadow on the moon is an arc. He said that it was therefore possible "that the region about the Pillars of Hercules is connected with that of India, and that there is thus only one ocean." This idea, transmitted to Columbus through the writings of Roger Bacon, a Franciscan monk (1214-1294), influenced him to attempt his first voyage of discovery.

Many other Greeks of this golden age, or somewhat earlier, also contributed to the method and to the facts of science. There is the principle of Archimedes that bodies immersed in a fluid are buoyed up with a 
force equal to the weight of the fluid they displace. Of course, if a body is not entirely immersed it is buoyed up with a force equal to the weight of the fluid which the immersed portion of the body displaces. We speak of ships to-day in tons displacement, stating the weight of the water displaced and hence a measure of the total weight which the ship and cargo may have if its tendency to sink is to be neutralized by the buoyancy of the water.

The story of how Archimedes (287-212 B.c.) happened to arrive at his law is told by Vitruvius, the Roman engineer and architect who wrote about the time of Christ. "Though Archimedes discovered many curious matters that evidenced great intelligence, that which I am about to mention is the most extraordinary. Hiero, when he obtained the regal power of Syracuse, having, on the fortunate turn of his affairs, decreed to be placed in a certain temple a votive crown of gold to the immortal gods, commanded it to be made of great value, and assigned to the manufacturer for this purpose an appropriate weight of the metal. The latter in due time presented the work to the king. It was beautifully wrought and the weight appeared to correspond to that of the gold which had been assigned for it. But a report was circulated that some of the gold had been abstracted and that the deficiency thus caused had been supplied by silver. Hiero was indignant at the fraud, and unacquainted with a method by which the theft might be detected, requested Archimedes to give it his attention. While charged with this commission Archimedes went by chance to a bath. On getting into the water he noticed that 
just in proportion as his body was immersed did the water run out of the tub. From this he caught the method to be followed in the solution of his problem and immediately followed it up. He jumped out of the tub in his joy and ran home naked through the streets, crying in a loud voice 'Eureka,' meaning 'I have found it,' for he had found the method ${ }^{1}$ for which he was searching."

Another story as to Archimedes is told by Plutarch. While conversing with Hiero, Archimedes explained the principle of the lever by an illustration. He said that, given a lever and another world like our earth on which to stand, he could move our earth itself. Hiero was struck with amazement, and asked Archimedes to give a demonstration by moving some large weight on this earth. The latter arranged to draw out of the dock of the king's arsenal a heavily loaded ship which was otherwise only to be moved by many men with great effort. To accomplish this he used a system of pulleys and unaided drew the boat out of its dock.

How this "technical Yankee of antiquity," as he has been called by an eminent German historian,

${ }^{1}$ Suppose Archimedes weighed the crown first in air and then in water. When hung from the balance arm so as to be immersed in water it weighed less than before by an amount equal to that of the displaced water. Hence subtracting the two gave the weight of the displaced water. Now suppose he performed the same operations on a lump of gold. He would have found that the weight of the gold in air was 19.3 times the weight of the displaced water. If he used a lump of silver he found this ratio to be only 10.5. Hence if the crown was pure gold it should weigh 19.3 times as much in air as the water it displaced. On the other hand, if it was of pure silver this ratio would be 10.5. If it was a mixture of the two metals the ratio would lie between these two values. 
developed a water screw for pumping, which was used in Egypt for irrigation; how he invented machines, like catapults, for hurling huge stones, which were used in the defense of Syracuse against the Romans in 212 B.c. ; and how, when the Romans finally captured the city, he was killed by a Roman soldier whom he urged not to spoil the circles of the geometrical problem which he was diagraming on the sand, are interesting stories which the reader may find recorded in histories of science.

How Euclid, Archimedes, and other of these Greek philosophers developed geometry; how, for example, Archimedes arrived at the value of pi, $\pi$, the ratio of the circumference of a circle to its diameter, as being something between $3 \frac{1}{7}$ and $3 \frac{10}{71}$, and of their astronomical theories, the student will also find interesting reading. ${ }^{1}$

Despite, however, the many contributions of the Greeks to science, they frequently relied too much on their mental processes and not enough on experiment. The phenomena of nature had not at that time been sufficiently ${ }^{2}$ observed for correlation. They usually had too meager data on which to base conclusions. Of similar errors the popular science of to-day is occasionally guilty. The Greeks also made a distinction between theory and practice which had some re-

${ }^{1}$ Cf. Tyler and Sedgwick, "A Short History of Science." The Macmillan Company, 1917.

${ }^{2}$ But some Greeks recognized this, as is seen in a statement of Aristotle that "the phenomena are not yet sufficiently investigated; when they are, then one must trust more to observation than to speculation, and to the latter no further than it agrees with the phenomena." 
tarding effect on science in later ages, for the writings of these philosophers, particularly of Aristotle, were the textbooks of the middle ages. ${ }^{1}$

Our words "theory" and "practice" are derived from words introduced by them. These words were used to represent two opposite ideas, and this distinction and separation is the real fallacy in their philosophy as far as concerns natural science. We use the words in essentially the same way to-day, when we are speaking carelessly ; thus we say, "Oh, he doesn't know why it works; he is just a practical man," or "He may know it theoretically, but he is very impractical." To the Greeks, theory was rational and pure, while practice was irrational and base. One dealt with celestial matters while the other dealt with terrestrial. Theory was noble and practice was ignoble. This latter distinction was probably due largely to the existence of the institution of human slavery. The mechanical tasks, like mining and later agriculture, were largely performed by slave labor. This distinction between noble and servile persisted even after slavery had been replaced by feudalism, and persists to-day.

It was natural that, with this differentiation in mind, the Greeks, and those schoolmen of the middle ages who followed their methods, should rely too much on deductive reasoning, proceeding from broad and general premises to determine what should be true in specific cases. In the hands of the schoolmen science became a matter of a priori truths, independent of experience and experiment.

${ }^{1}$ From the decline of the Roman Empire to the Renaissance (about 300 to 1400 A.D.). 
An illustration is their reasoning as to the speed of falling bodies. They had probably noticed that a pebble falls faster than a feather, and they concluded that "bodies fall with velocities proportional to their weights." This conclusion was not tested by observing the fall of two bodies of different weights, but with essentially the same air resistance, until Galileo in 1590 actually tried the experiment. From the leaning tower of Pisa, a height of about 180 feet, he dropped balls of different materials and of different sizes. He found that they fell in almost the same times, and that light objects like pieces of paper fell more nearly like heavy balls when the paper was tightly wadded into a ball. Reasoning a posteriori he concluded that except for the resistance of the air all bodies would fall through the same height in the same time. Galileo could not perform the experiment under conditions where air friction and buoyancy were eliminated, for the air pump was not invented until about sixty years later. But since he found that the more nearly the effects of the air on two falling bodies were equalized, the more nearly did they fall through the same height in equal times, he reasoned for the limiting case that the two bodies would fall with equal velocities.

The importance in science of inductive reasoning was not fully appreciated until even after Galileo's time, although from the time of Roger Bacon there were men who advocated it. With the definitions of these two forms of reasoning in mind we may now see more clearly the method of science. From a mass of correlated information as to some class of natural phenomena, scientists reason inductively to obtain a 
general law for the relations which appear to exist in these phenomena.

Gilbert's experiments are an early instance of this method. He formed a small sphere of a magnetite (lodestone) and observed the behavior of small pieces of iron placed on the sphere. He found that a bit of iron tended to lie along a meridian line of this "terrella" just as does a compass needle on the surface of the earth. From these and other experiments he came to the conclusion that the terrestrial globe is itself a magnet. He found that the same end or pole always pointed to the same pole of the earth and hence that there was in each magnet a north seeking pole and a south seeking pole. By experiments with two magnets he found that their north seeking poles when placed in proximity are urged away from each other; similarly as to their south seeking poles. But a north seeking pole and the south seeking pole of the other magnet are urged toward each other. From these experiments he reached inductively the general law of the action of magnets, that like poles repel and unlike poles attract. To-day, there are other ways than those known to Gilbert for obtaining a magnetic effect; but no matter how it is produced, we may reason deductively from his general law.

The methods of science are thus seen to be both inductive and deductive. The former lead to extensions of the boundaries, the latter to extensions of application. 


\section{CHAPTER V}

\section{THE BEGINNINGS OF EXPERIMENTATION}

Two thousand years elapsed between the beginnings which the early Greeks made in the correlation of knowledge and the initiation of logical experimentation, which has made possible the science of to-day. Observation, and correlation based upon it, had indeed been considerable before the time of Gilbert and Galileo, whom we consider as the first experimenters in physics. In astronomy, experiments are impossible and progress is made from the classified data of many observations. The laws of other physical science have been obtained largely as the result of the observation of the phenomena taking place under conditions artificially prepared to facilitate such observations.

What civilizations followed the Greek and what were the peculiar characteristics of their bearers to make these years so unproductive? The widest-spread empire of the ancient world was, of course, the Roman, which by the time of Julius Cæsar had practically covered the then known world. But the genius of the Romans was essentially military and not scientific. Their achievements in thought were largely in the science of government. In the method of organizing their growing domains, in the enactment and codification of the necessary laws, and in the general development of legal procedure, they made their chief contri- 
butions to human knowledge. Their national spirit showed itself in the conquest and consolidation of alien territory. What developments they made in natural science were dictated by this spirit and its necessities, and were largely in the field of military engineering.

In this field they surpassed previous civilizations. To maintain their lines of military communication they made advances in the science of road building and bridge making. The etymology of the word "pontifex," which was the name of the highest priesthood, is immediately suggestive. Their aqueducts and public buildings are justly famous. Agriculture and forestry were held in good repute; and in early Rome the patrician was always a farmer. The work of the arts was not highly regarded, even before the enormous growth of slavery had attached its stigma to almost all productive work.

In medicine, or more particularly in surgery, the Romans made contributions. In the ruins of Pompeii, which was destroyed by Vesuvius in 79 A.D., many interesting surgical instruments have been found. It was this eruption of the volcano of which Pliny, the Elder (23-79 A.D.), in scientific curiosity, took too close a view. Pliny himself wrote a long book on "Natural History" which illustrates the practicality of the Roman interest in science.

How the Roman Empire gradually succumbed to the waves of invasion of rude strong tribes from northeastern Europe and how "dark ages" followed is one of the important stories of "medieval history." How all branches of learning and all forms of art suffered 
a practical death or cessation in these centuries, how between 1200 and 1600 they were revived, our histories tell us. But to the scientist there may well be particular interest in the events by which science was preserved and even fostered in its growth during these centuries.

In our Arabic numerals we have a trace and an example of the contributions ${ }^{1}$ of non-European races during the medieval ages. Through their capture of Alexandria in 641 A.D. the Arabs had become the custodians of the records of Greek learning. This city, founded at the mouth of the Nile by Alexander the Great in about 330 B.c., was the home of many famous scientists and mathematicians, whom it attracted by its museum and its libraries. Here lived Euclid (300 B.c.). Here also, about 150 A.D., the astronomer Ptolemy taught his theory of a geocentric celestial system, which was accepted until Copernicus (1473-1543) demonstrated that the sun was the center. About the same time Alexandria also produced the noted inventor Hiero, whose steam engine is a sort of anticipation of the modern steam turbine. To the records of these and other achievements, as well as to the entire field of Greek thought, the Arabs were appreciative heirs, while Europe suffered a decay of learning.

In the meantime Christianity had spread widely throughout Europe. The bishops of its various centers had become responsible to the bishop at Rome, who thus became the Pope. It had been accepted by the

${ }^{1}$ Algebra and trigonometry are of Arabic or at least of non-European origin. 
invading barbarians in whole armies. By the time of Charlemagne in 800 the union of Church and State had been formed which was to dictate the life of Europe for centuries.

This dictation entered into science as well as into religion. Of this the striking example is the astronomical system of Ptolemy. It is the easiest of which to persuade the ignorant, for it is the most obvious. In addition it had been elaborately and ingeniously supported by geometrical reasoning. How with the years it gathered authority, and even became so firmly held that disbelief of it was punished by the Christian Church, is an interesting illustration of Europe's attitude toward science in the medieval ages. ${ }^{1}$ How it was ultimately discarded in favor of the heliocentric system of Copernicus is one of the important stories of the Renaissance.

During the 14th and 15th centuries occurred those marked changes in the intellectual life of Europe that constitute the Renaissance. To some extent this was merely a revival of interest in the learning, that is, the literature, art, and philosophy, of the classical world. For centuries this pagan learning had for the most part been under the disapproval of the Christian Church, although some of it, e.g. the work of Aristotle, formed part of the education of the time. Such knowledge as medieval scholars had of the courageous intellectual life of the Greeks was frequently obtained from Latin translations, made by Jews, of Arabic

${ }^{1}$ Galileo in his last years was compelled to recant and deny the Copernican theories with which he had previously expressed his agreement. 
commentaries on Greek texts. In the spirit of the Renaissance, men went directly to the Greek manuscript and acquired something of the author's passion for knowledge and faith in reason. The invention about 1450 of the process of printing from movable type enormously increased the dissemination of this knowledge.

By the time of the Renaissance two important inventions of the Chinese had reached Europe. These were gunpowder and the magnetic compass. With the latter as a guide, Portuguese sailors had penetrated into strange water and explored long stretches of the African coast. They had sailed through the weedy terrors of the Sargasso Sea and rounded Cape Bojador. The old superstitions of a region of fire, and of gales that always blew the sailor away from home (the trade winds, probably), were yielding to exploration. Under such conditions there came to Columbus the opinion of Aristotle, that India might be reached by sailing westward.

This case of Columbus forms an interesting illustration of the cumulative effect of knowledge. The revival of learning, the growing familiarity with the compass, the invention of printing, the explorations of other navigators, all prepared his way. $\mathrm{He}$, in his turn, by his discoveries, pushed further out the boundaries of human knowledge. The more persons there are who know a given group of facts or theories the greater is the chance that one of the many may make the extension, to the possibility of which the rest are blind. Knowledge is more than power; it is the condition for growth. 
The first voyage of Columbus was an experiment. It is not always that experiments may be performed in the laboratory, for many of them must be on a national or world-wide scale, as is true to-day of many social experiments. Sometimes the by-products of an experiment are themselves of great value. An illustration of this is Columbus's discovery of the variation of the magnetic declination. ${ }^{1}$ Not always, of course, are the by-products of the main experiment so evident as they were in this case of Columbus's first voyage; nor are they so overshadowed by the importance of the main result. In such by-products may be the greatest value of the experiment. While the result of the main experiment is usually the reward of clear thinking and precise manipulation of the experimental apparatus, the by-products are usually the reward of a comprehending observation. They are frequently the basis of important inventions, but they are not obtained by the unobserving, who pass over their indications.

Three qualifications for an experimenter are thus suggested: (1) clear thinking, (2) accurate experimentation, and (3) careful observation. The first is required before the experiment, in order that experimental conditions may be devised which will permit of a definite answer to the question under examination. The second demands that the measurements be sufficiently precise not to obscure the desired results. There must also be a careful observation during the

${ }^{1}$ The angle between the direction assumed by a compass needle and the geographical meridian is called the magnetic declination of a locality. 
experiment and close scrutiny of the data obtained, so that new or unexpected phenomena may be detected. To-day it is possible, as a rule, to obtain from instrument makers apparatus with which very precise measurements may be made. The average experimenter does not have much difficulty in satisfying the second qualification. With the aid of accurate instruments and machines much of the experimental work of the commercial world of industry may be performed by assistants who lack the other two qualifications. The experiments are, however, planned and scrutinized by scientists who satisfy more fully these other conditions. In fact, without a large measure of ability of this character, the experimenter becomes but a human part of the machine which he operates. An experimenter who lacks the first and third qualifications bears to a true scientist the same relation as the driver of a locomotive which is guided by the rails and switches bears to those navigators like Columbus who sailed across uncharted seas.

Of the true scientist the seventeenth century furnishes many good examples. Of Gilbert and Galileo we have already learned. Of Torricelli (1608-1647), Pascal (1623-1662), Boyle (1627-1691), Hooke (1635-1703), and Newton (1642-1727) it is desirable to learn more, since various principles or laws of physics are known by the names of these discoverers. For example, the statement that stress is proportional to strain, is Hooke's Law.

Torricelli was a disciple of Galileo who devised the barometer. Now, the ancients had used pumps for lifting water, and had observed that in the pipe of a 
pump the water would never rise over 32 feet. The piston of an ordinary lift pump draws the air out of the pipe and thus creates a vacuum into which the water rushes, as was early recognized. It was Hiero who first attributed this phenomenon to "nature's abhorrence of a vacuum," and in default of any better explanation this was accepted until Torricelli investigated the subject experimentally.

The reasoning which led Torricelli to his famous experiment is as follows: If air has weight, then on the surface of the water in a well there is the downward pressure of the air. If the air is removed from a part of this surface, as for example that inclosed by the pipe of the pump, the pressure of the air on the rest of the surface of the water should force water up the pipe.

This, then, was Torricelli's theory to account for the action of a suction pump. How was he to test it? If the pressure of the air at the surface of the earth was the cause, and not some mysterious effect of a vacuum, then this pressure should support a column of mercury only one thirteenth of 32 feet, since mercury is thirteen times as dense. If this deduction corresponds with observed phenomena, the theory has been corroborated although not necessarily proven. To establish it a further experiment is necessary.

$\mathrm{He}$, therefore, selected a tube about 4 feet long and sealed one end. This he filled with mercury, closed the open end by his finger, and inverted the tube, immersing the unsealed end in a basin of mercury. When he removed his finger the mercury in the tube sank, thus forming a "Torricelli vacuum." This vacuum was evidently unable to hold the mercury, which 
fell away from the top of the tube until its column was about 30 inches high, i.e. about one thirteenth of 32 feet.

The theory received further support very shortly from an experiment by Pascal. He reasoned that if the barometer was carried up a mountain so as not to be so deep in the ocean of air at the bottom of which we live, then the pressure of the air should be smaller and it should be unable to sustain so high a column of mercury. At his suggestion his brother-in-law tried the experiment on Puy de Dôme, and wrote back to Pascal that he was "ravished with admiration and astonishment" when he found that after he had ascended the mountain for about three fifths of a mile the mercury column was three inches shorter. Of course, if an air pump had been available Torricelli's theory might have been checked as in classrooms to-day by surrounding both the tube and the basin of mercury by a glass vessel and then evacuating the latter. If the experiment is performed it will be found that as the air is removed the barometer column sinks until it is level with the surface of the mercury in the basin. As air is allowed to reënter the vessel the column rises to its original height. ${ }^{1}$

The balance, Torricelli's barometer, and the air pump, which followed shortly, are three of the scientific instruments which made possible much of the experimental work of the last 300 years. The microscope and the telescope, the latter invented by Galileo, have

1 Boyle performed this experiment in 1659 , five years after von Guericke invented the air pump. Cf. Moore, "History of Chemistry," McGraw-Hill Book Co., 1918. 
been important in biology and astronomy. The thermometer, also invented by Galileo, and the manometer complete the list of the most important. The last is an instrument for measuring the pressure of gases and is a development of the apparatus used by Boyle in his famous demonstration that air has elasticity of volume.

Boyle's experiments on the "spring of the air," as he called it, may be illustrated by the apparatus of Fig. 4. Some air is trapped in the short and sealed end of the U-shaped tube by pouring mercury into the long end. If the heights of the mercury in the two arms of the tube are the same, the air in the closed end is at atmospheric pressure. The column of atmosphere acting on the mercury of the open arm is equivalent to the column of mercury of a barometer. For convenience in describing the experiment let us assume that this is 30 inches.

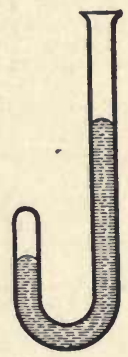

FIG. 4. If more mercury is poured into the long tube the levels are altered. The pressure on the trapped air is greater than atmospheric pressure by the amount which the column of mercury in the open tube exceeds that in the other. If this distance is 6 inches, the total pressure on the inclosed air is that of 36 vertical inches of mercury. The volume of this air is, of course, reduced. The new volume will be found to be $\frac{30}{36}$ of the original volume. In general, if the pressure is changed the volume is changed inversely, a fact known as Boyle's Law.

We now see that such a device may be used as a manometer by connecting its long arm to the container 
of the gas for which we wish to know the pressure. By Boyle's Law, then, we may calculate the pressure from the new volume of the air in the short arm.

In describing this experiment on Boyle's Law and its application to the construction of a manometer we have tacitly assumed that the temperature has been kept constant. As we shall see later, and as the reader realizes, changes in temperature will cause changes in the volume which the air occupies, apart from any change in pressure. We have also assumed that the tube is everywhere the same size.

If a tube like that of Fig. 5 is used the same experiment may be performed with identical results. Of

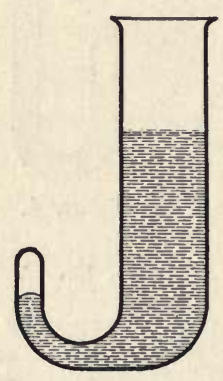

FIG. 5. course, more mercury needs to be added to produce the same difference of level. It is to Pascal that we owe the statement of the general principle which underlies this phenomenon. To understand it we distinguish between force and pressure, defining pressure ${ }^{1}$ as the force per unit area.

Now Pascal's Law states that fluids at rest transmit pressure equally in every direction. Is not this obviously the condition which must be met if a fluid is to be at rest? If a particle is to be at rest it must sustain pressures from the liquid about it which are the same in all directions, for if more pressure is transmitted to it from one side than the other it will move. Conversely, the particle

${ }^{1}$ If the pressure is the same on every square inch of cross-sectional area then the total force exerted is the product of the area and the pressure. 
itself is pushing equally in every direction, for if it did not react on the adjacent particle with an equal force there would be an unbalance of force which would cause motion. In other words, Pascal's Law means that in a liquid at rest any two adjacent particles of the liquid are acting on each other with equal and opposite forces. Consider now two adjacent particles in the horizontal portion of the tube of Fig. 5. Since the liquid is at rest the pressure transmitted from the right must be equal to that from the left. The pressure exerted by the fluid in the long tube is then equal and opposite to that of the fluid in the short tube.

The total downward force exerted by the liquid in the right-hand tube is as many times greater than that of the left-hand as the area of the right tube is greater than the area of the left tube. A mechanical advantage may therefore be obtained by utilizing this property of a liquid. This is illustrated by the hydraulic press in which a small force acting on a piston of small area produces the same pressure as does a larger force applied to a correspondingly larger piston. As a consequence of the incompressibility of liquids, the distances through which the acting and resisting forces are exerted are inversely as the forces, as the "work principle" requires. 


\section{CHAPTER VI}

\section{THE REALITIES OF SCIENCE}

IN the classification of the phenomena which are physical rather than chemical, it was natural to correlate them according to the senses by which they are perceived. The subjects into which physics has usually been divided are mechanies, heat, sound, light, and electricity and magnetism. Thus under "light" and "sound" were classed those natural phenomena which affected the optic and the auditory nerves. "Heat" included those affecting what has been called the "temperature sense." "Mechanics" included phenomena of motion and of forces. Electricity and magnetism, which are now grouped together, were for a long time considered separate divisions. They dealt with the motions and forces of which electricity and magnetism are the causes.

A classification according to senses is unsatisfactory. Light does not exist for one who is blind, nor sound for one who is totally deaf. Either exists only in so far as we ourselves are concerned and have certain nerves. For the color-blind, as for example those who fail to perceive the greens, light of this color does not exist, although it may for others. Those of normal vision may have a sensation which they call green light, but this means not that green light is real but only that an impression is real to them. Light is not an objective but a subjective reality. 
What are the causes of the sensations which we call light? What is the objective reality of such phenomena? Let us attempt to answer these questions by considering in detail an illustration of sound, a similar subjective reality.

We are all familiar with some musical instrument and know that sound is produced from a stringed instrument by setting the string in motion. Its natural motion is periodic, for it takes the same time for each swing back and forth through the position of rest from which it is displaced. The smaller the period of this vibration, the higher is the pitch of the musical note which we recognize.

The phenomena are most easily observed if produced in a slightly different manner. Let a visiting card be held so as to touch the teeth of a rotating gear wheel. The card is pushed away and flaps back, that is, vibrates, once for every tooth which comes in contact with it. If the wheel is turning very slowly we recognize the flapping of the card as a regular or rhythmic noise. As the speed of the wheel increases this becomes a musical note of rising pitch. The number of complete vibrations which the card makes in each second is called its "vibration frequency" and is the measure of the pitch.

Consider now the means by which the motion of the sounding body reaches the ear of the listener. The intervening air consists of small discrete particles or molecules. As the vibrating card is pushed out by a tooth it forces ahead of it the adjacent layer of molecules, which in turn push against those adjacent to them. A city crowd, gathered around some object of interest, as it surges away under the commands and 
shoves of the policemen at the center, pictures a somewhat similar action. The push or pulse, started at the center, travels outward through the crowd. Figure 6

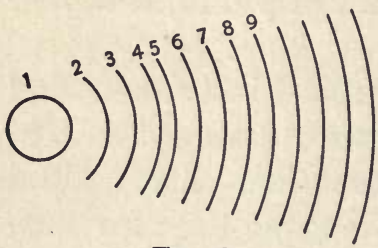

FIG. 6. represents a series of layers. When the pulse, which originates at the center, reaches a layer, as 6 of the figure, it results in a momentary crowding of this layer against the next outer one. The layer 6 is thus crowded or condensed between layer 5 which is moving outward and layer 7 which has not yet started to move, and we speak of this pulse as one of condensation.

Now suppose that, just after those at the center have started to push out, conditions change so that they may again move in. They do so, increasing the distance between their layer and the next. This layer in its turn moves inward, and successively the other layers adjust themselves to the new condition. Whereas before we had a con-

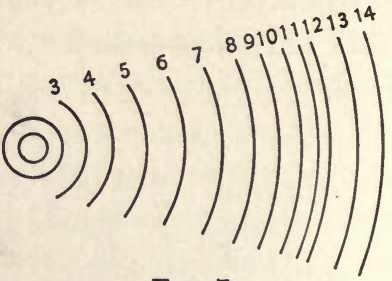

FIG. 7. densation we now have a pulse of rarefaction spreading outward from the center, as shown in Fig. 7 by the relative positions of the layers when the pulse has reached 7. In the figure the previous pulse of condensation is shown as just reaching layer 13. The vibrating card gives rise in the surrounding air to a succession of alternate condensations and rarefactions which travel outward to the ear of the listener. The thin_drum of the ear is pushed in by each pulse of 
condensation which reaches it and allowed to move out by each succeeding rarefaction.

A musical note is seen to be the impression of a listener whose eardrum is moved back and forth periodically. Such a motion may be obtained from a vibrating body through the medium ${ }^{1}$ of the intervening air. The note depends for its pitch upon the frequency. The "international pitch" $\mathrm{A}$ is a note of 435 vibrations per second. When the frequency is above about 20,000 per second many persons are incapable of hearing it. Frequencies of 30,000 or more are inaudible to most persons. These high notes may be produced by small organ pipes, by whistles, by vibrating rods which are very stiff and short, and by other means similar to those used to produce the notes of music. The vibrations from such bodies are transmitted to the ear through the air in the same way as are those of lower frequency. In one case we say there is the sound of a musical note; in the other we hear nothing. The difference is in our own brains, for sound is a subjective reality.

What is the objective reality with which we have to deal, which is present in both cases, whether we hear the sound or not? The most obvious reality is matter, both in the case of the vibrating body and in the air which transmits these vibrations. Then there is the motion of the vibrating body and of the surrounding air. Shall we take motion ${ }^{2}$ as the other reality? Before we decide let us see what we mean by motion.

${ }^{1}$ In elementary courses on physics it is usual to demonstrate the function of the air by inclosing the source of sound in a chamber which is then evacuated.

2 "Motion" is here used in its root significance and with no connotation of "momentum." 
In speaking of motion we refer the position of one body to that of another. Consider the case of two railroad trains at rest on parallel tracks. We know that it is difficult for a passenger in one train to tell by looking at the other whether his own is starting or not. He may see the other apparently sliding by, but he cannot decide, on visual evidence alone, as to his own motion unless he can see the ground. Even if he is told that he is actually in motion he cannot determine the direction. Visually he can decide only as to whether or not there is a relative motion of the two adjacent trains. This fact may be illustrated by placing two pencils side by side, making a mark on each, and seeing in how many ways one or both may be moved so as to produce the same motion of one mark relative to the other.

The idea of motion is best expressed more abstractly. Let two points be always connected by a straight line ; if this line changes in length or direction there is a relative motion ${ }^{1}$ of the two points. It is always with relative motions that we deal, as in the case of a body falling with reference to the earth. If we knew two fixed and intersecting lines in the universe we could refer to these the positions and motions of all bodies. But what do we mean? fixed with reference to what? We reply, "Why, absolutely fixed," and use "absolutely" in its technical sense. It is, however, preferable to consider all motion as relative.

Recognizing that motion is relative, let us imagine

${ }^{1}$ An interesting exposition of the historical and philosophical aspects of mechanies is that of Mach, "The Science of Mechanies," Open Court Publishing Co., 1907. 
that a listener sways his head from side to side just in time with the motion of the layer of air adjacent to his eardrum. It was the presence of this air, moving the drum periodically, which we saw to be the cause of his auditory impressions. With reference to the ground the motion of his eardrum will be made just what it was when he was hearing the sound, but now there will be no relative motion of the eardrum and the skull. A relative motion of these is required to produce an effect on his auditory nerves, so that he now hears no sound although the conditions of the source and of the intervening air are just what they were before.

Another illustration which shows both the subjectivity of sound and the relativity of motion is a matter of common observation. The pitch of an automobile horn or of a locomotive whistle is higher if the machine is approaching than when it is stationary. The principle of this phenomenon, which occurs in light as well as in sound, is known as Doppler's. Conversely, if the whistle is receding from the listener the pitch is lower. The vibration frequency of the horn does not depend upon which direction the machine is going with reference to the listener. Why should the pitch be different? The number of pulses reaching the ear each second is greater when there is a relative motion of the listener toward the machine. This is most evident if we think in terms of a train. In fact we usually speak of a condensation and its succeeding rarefaction as a "wave" and of the succession of these as a "train of waves." Any one who ever watched a long freight train realizes that more cars per minute 
pass him if he walks toward the point from which the train is coming.

In trying to determine what are the objective realities in the case of sound we have so far recognized that one reality is matter. The other apparently involves motion, but because motion is relative, it has seemed preferable to look further. The other reality in sound we shall now see to be energy, the ability to do work. In order to show this we shall consider in more detail the vibratory motion of a sounding string.

The string, originally at rest, is set in vibration by momentarily deforming it, as by picking it. Elasticity is called into play; and when the stress is removed the string flies back to its original position. It passes through this position, bowing out in the opposite direction. Elastic forces are now operative just as they were in the case of the original deformation. The string, therefore, swings back through its center of vibration and assumes a symmetrical form on the other side.

In producing the original deformation, work is done against the elastic forces, and the stretched string acquires an ability to do work. This principle was early applied practically, in the bow of the ancients, where the energy was used to impart motion to an arrow. If the vibrating string is a source of sound, the matter, to which motion is imparted, consists of the adjacent molecules of air and also of the molecules of the string itself. With each vibration of the string some of the original energy is imparted to adjacent molecules and transmitted by successive layers of molecules away from the vibrating string. The 
spherical layers are successively larger and consist of a successively greater number of molecules. Since a larger number must be set in motion, the motion imparted to each molecule is smaller the farther it is away from the vibrating source. This decrease means a decrease in the possible motion of the eardrum and hence in the intensity of the sound as a listener assumes positions farther away from the source. At any instant, however, the energy imparted by the previous vibrations of the string is associated with all the molecules between the string and that most distant spherical surface, which the first pulse has just reached.

This is why the vibrations gradually decrease and finally cease. The work done in producing the original deformation is gradually passed on by the string to the air molecules. Since the string in each swing must push ahead of it the air molecules, it will not swing quite as far as if there were no work to be done in moving the air. The amplitude of the vibration then damps down just as in the case of the swinging pendulum. In fact, the string and the pendulum are but two illustrations of a type known as simple harmonic motion.

We passed over the question of why the string, when released from the initial deforming stress, should fly through its center of rest. As an elastic body it should return to this position, for each molecule of the string is urged toward its unstressed position. In this position, of course, the restoring force of elasticity is zero and does not affect the motion which has been imparted to the string. The fact that the latter continues in 
motion through the unstressed position is a characteristic of bodies which we describe by saying that they have inertia.

We know by experience that it takes work to set a body into motion, to make a body which is already in motion move in a different direction, or to stop it. In deforming the string against the elastic forces we give it the ability to do work, which it does in setting its particles into motion toward their original positions. When, however, these particles arrive at this position they are in rapid motion and thus in turn have the ability to do work. This they do against the elastic force of the string, which becomes effective the moment the latter passes through its unstressed position. A deformation opposite to the original one is thus brought about. It is also smaller, for the particles cannot do quite as much work in assuming it, since some of the original energy has been transmitted away by the air and some dissipated in the frictional motions of the particles of the string itself. For this reason the vibration is damped.

If a vibrating source is surrounded by some other medium, as for example by water, similar phenomena would occur, although the wave train would not travel at the same speed and the source would damp down more quickly. All phenomena, comprising a vibrating source and an elastic medium, by the vibrations of the molecules of which energy is transmitted away from the source, should be classified as sound, although only under special conditions can the vibrations be detected by a human ear.

The realities, for which we have searched in con- 
sidering the phenomena of sound, are now seen to be matter and energy. With these science is concerned and about them we shall group our remaining discussion. They are the realities of mechanics and of light, although in the latter case the medium is not molecular and the vibrating bodies are electrons. We shall find them the same for the other subdivisions of physics and for all physical science, including chemistry. 


\section{CHAPTER VII}

\section{THE MOLECULAR COMPOSITION OF MATTER}

ThAт the realities with which science deals are matter and energy was not appreciated until comparatively recently. In 1777 the indestructibility of matter was established by experiments of Lavoisier, a French chemist. In 1843 experiments of Joule established the indestructibility of energy. The experiments of the former will be considered in this chapter, and those of the latter in a later chapter. It is upon the basis of the indestructibility of these entities, energy and matter, that we are entitled to consider them the realities of science.

A body of any kind of matter may be divided into very fine particles, as we all know, just as a lump of stone may be crushed under water until its particles float away undiscernible to the human eye. Pulverizing stone gives merely small particles of stone and does not produce any change except of size. The particles of water vapor in the air about us are even smaller than anything which can be seen with the best microscope, but still they are unaltered in kind. In the past it has sometimes been argued that there was no limit to such divisibility of matter, that matter in fact was "infinitely divisible." On the other hand, there were philosophers like Democritus (420 B.c.) who held that it is granular in its composition, consisting of small 
similar parts which cannot be further divided, as is indicated by the name "atoms."

The present-day concept of the structure of matter was not firmly established until about 1860 . According to the ideas accepted since that date matter may be subdivided into small similar parts, called molecules, which are the limit of divisibility for that kind of matter. To subdivide any kind of matter into parts smaller than this perfectly definite particle, is to alter the kind of matter.

The molecule of starch is one of the largest of which we know, and yet it is so small that the most powerful microscope will not permit us to observe it by eye. We do not know what its shape may be, but if we imagine it inclosed in a sphere we do know that the diameter of this sphere is about one two-hundredth part of the diameter of the smallest particle which we can see with the microscope. The molecule of sugar, which is much larger than many of the other kinds of molecules, is only about one ninth the diameter of the starch molecule. The diameter of the molecular spheres for the molecules of the gases which compose the air we breathe is different for each kind, but is about $2 \times 10^{-8}$ cm. ${ }^{1}$ How these dimensions may be obtained we shall see in Chapter XX.

Matter of most kinds may be divided into particles even smaller than its molecules, but whenever such division takes place the kind of matter is changed.

${ }^{1}$ The symbol $10^{-8}$ means $\frac{1}{10^{8}}$, i.e. $0.000,000,01$. Very large or very small numbers are conveniently expressed "in powers of ten." Since $1 \mathrm{~cm}$. is $0.394 \mathrm{in}$., it follows that the molecular diameter is about $8 \times 10^{-\rightarrow}$ inch or eight thousandths of one millionth of an inch. 
Thus the molecule of water may be divided into three smaller parts, of which two are similar particles of hydrogen and one is a particle of oxygen. In the same way common salt is divisible, each molecule giving one particle of a metal known as sodium and one of chlorine. The latter we know as a green poisonous gas, but in this form each molecule of it consists of two of the smaller particles which enter into the molecule of salt. These particles into which the molecule is divisible or of which the molecule is composed are called atoms. Of the atoms there are about ninety different kinds. These different kinds of matter, which cannot be further decomposed into other kinds, the elementary substances, are spoken of as "the elements."

This concept of an atomic composition was foreshadowed by the early Greek philosophers but was not confirmed until about 1802, when it was set forth with experimental evidence by John Dalton. During the preceding centuries the natural desire of men to explain matter had found its outlet in theories untested by experiment. Matter had been classified by its properties and its apparent similarities rather than by its experimentally determined composition. The four qualities by which it was generally compared were those of fire, earth, water, and air. Any chemical change was regarded as due to the proportion of these "elements" or "principles" which were added to the original substance. But as to the concept of the "essence" to which these principles were added, opinion was divided; some of these ancient and medieval philosophers held that it was a material substance and others that it was "ethereal." 
There is some reason to believe that the thinkers of the school which considered the essence material and hence sought for it by experiment either formed or were among the early alchemists. The origin of alchemy and even the derivation of the name itself are, however, matters as to which historians are in doubt. By the fourth century of this era, historical evidence seems to show that the attention of the alchemists had become centered upon the problem of the transformation of baser metals into gold and silver. This they attempted to accomplish by adding or subtracting some of the elementary principles mentioned above. Their experiments thus led to the discovery of some new compounds and also to methods for separating different substances. Alchemy was largely in the hands of the Arabs until the 11th century, when it became European. Although it was experimental it was essentially only descriptive. Its theory was also incoherent and mystical.

Throughout the centuries during which chemistry was a mystical art rather than a science, progress was, of course, made in the processes of industrial chemistry by "cut and try" methods. The metallurgical operations of smelting and refining advanced. The art of healing progressed during this same period and by the 15 th century chemical preparations in medicine had become of considerable popular importance. The attention of the alchemists, therefore, turned from their unsuccessful search for gold to a search for new medicines. But medicine was also a science in its infancy, one of superstitions, mysteries, and untried theories. Thus as late as 1800 Davy, famous to-day 
for his miner's safety lamp, demonstrated by breathing nitrous oxide, that is, "laughing gas," that it was not the "principle of contagion" which the medical men of his day considered it.

The development of chemistry, as medicine, extended only from the 15 th to the 17 th century. During the 17 th and 18th centuries the influence of the alchemistic theories was decreasing. With the discoveries of Black, Priestley, Cavendish, Scheele and others in the second half of the 18th century the mystical character disappeared and it was possible for Lavoisier and Dalton to lay the foundation of modern chemistry.

The revolt against the doctrines of the medieval ages was really started by Robert Boyle. In 1662 he published his "Skeptical Chemist." In this he denied the accepted theory and stated that all substances were either elements, which could not be further decomposed, or else compounds of two or more such elements. Compounds, according to his hypothesis, were formed by the coalescence of small particles of the elements concerned. The corpuscles of any one kind he considered to have an affinity for the corpuscles of another kind, and this affinity was the cause of the formation of the compound corpuscles. The affinities postulated by Boyle were not, however, the likes and dislikes and other mental attributes sometimes used by his contemporaries or predecessors to explain chemical reactions.

For centuries the theory of the four elements had failed to account, even to its adherents, for the formation of the known products of chemical reaction. Additional principles had, therefore, been accepted as capable of modifying the nature of matter. Mercury 
was supposed to add luster and to make the substance volatile. Salt conferred fixity rather than volatility in the presence of fire. Sulphur added combustibility. Later the "principle of combustibility" was assumed to be due to other causes than the addition of sulphur, so that a more inclusive term came to be desirable and in $\mathbf{1 6 9 0}$ the principle was named "phlogiston."

According to the phlogiston theory, combustion meant the liberation of phlogiston, and those substances which burned most readily released the larger quantities. Charcoal, wood, and coal were thus assumed to be nearly pure phlogiston. Now, metals exposed to fire tarnish and in time form earthy powders. These we call oxides. The familiar red rust of iron is an oxide formed by a reaction with water and air. Some of the iron ores are oxides. The method of reducing metallic oxides by heating them with charcoal had been used for centuries. The reaction which takes place is one of combustion of the charcoal and the oxygen of the metallic oxide. Carbon oxides, the usual products of combustion, with which we are all familiar, are thus formed and a residue of pure metal and charcoal ash is left. The advocates of the phlogiston theory curiously inverted this idea of combustion. They assumed that phlogiston left the charcoal and entered the oxide, the earthy powder which they called "calx." The calx thus became a metal by the addition of phlogiston. Conversely, when a metal was burned it was dephlogisticated and a calx resulted.

The opponents of the phlogiston theory pointed out that the calx was heavier before it became a metal by the addition of phlogiston. Any such objection was, 
of course, easily to be met, if one's science was a matter of qualities and principles, by describing phlogiston as a "principle of levity" such that it decreased the weight of the body into which it entered. In the choice of such additional principles the advocates of this theory were not always consistent.

The problem of combustion was not, however, to be solved until it was shown that air was a mixture of dissimilar gases. That gases did differ in kind and in density, that is, mass per unit volume, was definitely established by Black's experiments in 1752 on carbonic acid (carbon dioxide and water). Black, who was a Scot and a student of medicine, was interested early in his life in the medicinal properties of mineral waters. In his study of limewater he found that limestone (now known as a compound of calcium, carbon, and oxygen, $\mathrm{CaCO}_{3}$ ) when heated lost a gas (carbon dioxide, $\mathrm{CO}_{2}$ ). The weight of the gas thus produced he found by the balance to be equal to the loss in weight of the stone. He also brought about the reverse reaction, obtaining calcium carbonate from lime (calcium oxide) and carbonic acid, and demonstrated for this reaction the conservation of mass.

In 1773 Scheele, a Swedish chemist, discovered oxygen as a constituent of air. The succeeding year Priestley also discovered oxygen. The name, however, was suggested later by Lavoisier. Priestley obtained oxygen by heating a tube of red oxide of mercury by focusing the sun's rays upon it with a burning-glass. The gas thus liberated was found to support combustion better than did ordinary air. For example, a glowing ember thrust into a vessel containing oxygen 
will throw out sparks and burst into flame. Priestley was also the first to notice the exhilarating effect of breathing pure oxygen, although he preceded the experiment upon himself by trying the gas on two mice.

The experiments of Lavoisier extended over several years. His final conclusion as to air was reached in 1777. It consists of a mixture of two gases, one capable of supporting combustion and the other incapable, oxygen and nitrogen, respectively. By this time he had coördinated and extended the researches of his contemporaries, reaching a conclusion in accord with their experimental results but not always with their theories, for many of them were phlogistists. His demonstration of the fallacy of the phlogiston theory occurred earlier (1772). He burned phosphorus in a closed vessel and showed that when all the phosphorus which could be made to burn had been consumed, (1) about one fifth of the air had disappeared (the oxygen); (2) the loss in weight of the air was practically equal to the difference in weight of the resultant white solid and the original phosphorus ; and (3) the density of the residual air was now less than that of the original air. An effective demonstration of the conservation of matter was thus made by Lavoisier. The progress of the "science of the composition of substances," as Boyle had defined chemistry, thereafter proceeded with great rapidity.

The discovery of the chemical composition of the atmosphere as one volume of oxygen to each four volumes of atmospheric nitrogen ${ }^{1}$ gave no immediate

${ }^{1}$ Nitrogen and traces of some other gases. 
clew to its physical structure. The union of oxygen and nitrogen was supposed by many scientists to be chemical, one substance dissolving the other. When water evaporated into the air it, also, was supposed to be dissolved by the existing compound of nitrogen and oxygen. This idea was incomprehensible to Dalton. He tried to visualize such a mixture in terms of small particles which he called atoms, adopting the ideas of a granular structure. The difficulty in his mind was that the compound particles would be of different masses and should ultimately settle toward the surface of the earth, resulting in a stratified atmosphere just as two liquids of different density will separate under gravity. It had been found, however, by testing air, obtained at various altitudes, that the proportions of oxygen and nitrogen were essentially constant and hence that no such phenomenon of stratification occurred. Such a chemical theory could not be reconciled with the observed facts, and yet Dalton felt the need of picturing the phenomenon in terms of corpuscles. At first it seemed to him equally inconceivable that the air should be merely a mechanical mixture of particles of the two gases just as we might make a mixture of baseballs and tennis balls.

The pressure of a contained gas had been shown by Boyle to be due to its "spring" or elasticity. Bernouilli in 1738 had suggested that the cause of the pressure was the impacts upon the surface of the container of the small particles of the air. The kinetic theory, which explains such pressure as due to molecular impacts and the motions of the molecules as due to the energy which they possess, was not, however, 
advanced in an acceptable form until the work of Clausius in 1857. In Dalton's day the effect which Boyle had noticed was explained on the basis of forces. This was largely, of course, because of the influence of Newton's concept of forces. ${ }^{1}$ For the present it is only necessary to note that the pressure was supposed to be due to the interactions of the various corpuscles. These were said to repel each other with a force which became smaller as the separation between the particles increased. If both kinds of particles repelled then stratification was still possible. But if the only actions were between similar particles then each gas would tend to expand and fill any available space. Dalton, therefore, assumed that each gas acted as a vacuum so far as the other gas was concerned.

This, as we shall see, is also the modern view, but we recognize to-day that it is only approximately true and depends upon the actual amounts of the gases as compared to the volume of the container. If, compared to this latter volume, the space occupied by the gas molecules is small, then their motions are practically independent of each other's presence. The phenomenon has a parallel in the case of a dancing-floor. If the space occupied by the couples while at rest is small as compared to the floor area, their motions in dancing will be uninfluenced by each other's presence.

For pressures not greater than a few atmospheres Dalton's assumption would be true. He verified it experimentally and announced his law of partial pressures, that the pressure exerted by a contained

1 The laws of Newton and the modern theory as to gas pressures will be considered in Chapters XII and XIII, respectively. 
volume of air or other mixture is the sum of the pressures which each component gas would exert if contained alone in a similar volume. Dalton was, therefore, able to visualize a mixture of gases as a purely mechanical mixture of small particles, all those of each constituent gas being alike.

He called all such particles "atoms" and failed to make the modern distinction between the molecular and atomic particles. Such a distinction was first pointed out by Avogadro in 1811. The classification of Avogadro, however, was not generally accepted during the next few years, and considerable confusion resulted. In fact, the confusion as to the concepts of atom, molecule, and atomic weight gave rise to such conflicting theories and methods of expressing chemical composition that the development of the science was impeded. A conference was therefore called at Karlsruhe in 1860 to discuss the various hypotheses. A paper containing the researches and theories of Cannizzaro, a professor at Rome, which had been published in 1858, was brought to attention. With the acceptance of his conclusions modern chemistry became established.

If we accept the idea that the molecules of any kind of matter are similar and are formed by the combination of atoms of different elements, all the atoms of any element being alike, we reach at once certain conclusions. Thus, suppose that we ask what possible compounds may be formed of two elements, say A and B. The simplest molecule would be formed by one atom of $\mathrm{A}$ and one of $\mathrm{B}$. Such a compound molecule we might then symbolize as $\mathrm{AB}$. The molecule might be formed of one atom of $A$ and two of $B$, in which case 
it would be represented by $\mathrm{AB}_{2}$, where the subscript represents the number of atoms, of the kind indicated by the letter, which enter into the formation of the molecule. Other possible combinations are $\mathrm{A}_{2} \mathrm{~B}, \mathrm{~A}_{2} \mathrm{~B}_{2}$, $A_{2} B_{3}, A_{3} B, A_{3} B_{2}$, and so on. Whether or not any particular one of the compound molecules which we have represented can be formed will depend upon the mechanism by which the atoms of a molecule are held together. This we shall discuss in the next chapter.

Let us now see what experiment Dalton performed to test such an assumption as to molecular composition. In 1802 he discovered that if he mixed 100 parts of common air with 36 parts of nitric oxide he could obtain a combination of all the oxygen of the air with this oxide, leaving a residue of 79 parts of atmospheric nitrogen. Such a combination ${ }^{1}$ occurred if the mixture was made in a narrow vessel or tube. On the other hand, if the combination took place in a large vessel over water, in which case it would be very rapid, a different compound ${ }^{2}$ was obtained. In this case he could mix 100 parts of air with 72 parts of nitric oxide and all the oxygen would enter into combination, as would be evidenced by the reduction of the air to 79 parts as before. Evidently the same amount of oxygen could enter into combination with a definite amount of nitric oxide or with twice that amount. But Dalton

${ }^{1}$ Nitric oxide is NO. This compound is nitric peroxide, or in symbols $\mathrm{NO}_{2}$. Thus $2 \mathrm{NO}+\mathrm{O}_{2}=2 \mathrm{NO}_{2}$.

2 The compound thus formed was nitrous anhydride or $\mathrm{N}_{2} \mathrm{O}_{3}$. Four molecules of $\mathrm{NO}$ combine with one of oxygen, containing two atoms, as may be expressed in the equation $4 \mathrm{NO}+\mathrm{O}_{2}=2 \mathrm{~N}_{2} \mathrm{O}_{3}$. Other compounds which may be formed are $\mathrm{N}_{2} \mathrm{O}$ or nitrous oxide, and $\mathrm{N}_{2} \mathrm{O}_{5}$ or nitric anhydride. 
showed that it had to be either one or the other. Thus if he supplied more than 72 parts of nitric oxide to 100 parts of air there was a corresponding residue of nitric oxide as well as of nitrogen. Similarly if less than 72 parts were employed the residue contained oxygen, indicating that the amount of nitric oxide available was insufficient to form compound particles with all the particles of the 21 parts of oxygen.

By this and other similar experiments Dalton established the granular composition of matter. He summarized these phenomena in his law of "multiple proportions," the value of which to-day is largely historical. It was the first satisfactory evidence as to the molecular and atomic structure of matter. If we start our study by accepting the concept of atoms and molecules we need not burden our minds with its formal expression. Combinations of atoms into molecules must always involve whole numbers of atoms. Molecules which differ in the number of similar atoms which they contain must differ in properties both physical and chemical. The converse is, however, not always true. It may happen, particularly in the case of molecules involving many similar atoms, that different substances may be formed by the same combination of atoms, just as different words may be formed by the same combination of letters. The same combination of atoms as forms the molecule of alcohol may also be formed into a molecule of "methyl ether," an ether somewhat like the anæsthetic.

After the molecular composition of matter had been demonstrated by Dalton it was natural to assume that equal volumes of dissimilar gases would contain, under 
similar conditions of pressure and temperature, equal numbers of molecules. As a matter of fact, GayLussac found that gases combined in simple proportions by volume. He was unable, however, to reach the conclusion that the number of molecules in equal volumes were equal, because of apparently conflicting experimental evidence. For example, if equal volumes of hydrogen and chlorine gas are combined the resulting volume under the same conditions of pressure and temperature is found to be the sum of the original volumes. If each hydrogen molecule combined with a chlorine molecule there should be only as many molecules as there were originally of either chlorine or hydrogen, and hence we should expect the combination to occupy only the volume originally occupied by either.

Avogadro, however, assumed that the number of molecules must be proportional to the volume and, since the volume of the compound was twice that of each constituent, that there were twice as many molecules of hydrochloric acid. But, since a molecule of hydrochloric acid must contain a particle of hydrogen and a particle of chlorine, there must have been originally twice as many particles of both hydrogen and chlorine as there appeared to be from the volume they occupied. If each particle of hydrogen really consisted of two smaller particles, and similarly for chlorine, then the experimental facts of the formation of hydrochloric acid ${ }^{1}$ would not be contradictory to his

1 In chemical notation the formation of hydrochloric acid is expressed as $\mathrm{H}_{2}+\mathrm{Cl}_{2}=2 \mathrm{HCl}$, indicating that each molecule of hydrogen and of chlorine is diatomic and that the combination of a molecule of each kind results in two molecules of hydrochloric acid. 
assumption. He, therefore, announced that equal volumes of different gases at equal pressures and temperatures contained equal numbers of molecules. He also postulated the modern distinction between atoms and molecules and stated that the molecules of an element might be compounds of the atoms of the element.

Avogadro's assumption as to numbers of molecules offered a very convenient method for comparing the masses of the molecules or atoms of different substances provided they were in the gaseous form. ${ }^{1}$ It is possible to make comparisons only, so the mass of the molecule or atom of some gas must be taken as a standard. Hydrogen as the lightest gas was so chosen. Confusion, however, resulted until Cannizzaro's work, because some investigators compared with the atom and others with the molecule. Berzelius, a chemist of influence, who investigated relative atomic weights, denied Avogadro's idea, which conflicted with his own assumptions of an electrical attraction between the particles which combine in a chemical reaction. His theories along this line have since proved to be erroneous and need not be discussed.

The atomic weight of hydrogen was chosen as the standard and called unity. Upon this basis the molecular weight of hydrogen gas is 2. Oxygen was found to be approximately 16 times heavier than hydrogen, so that its molecular and atomic weights are about 32 and 16, respectively. Later it was agreed to express

${ }^{1}$ The atomic weights of non-gaseous elements are obtained by weighing the constituents and the products of various chemical reactions. 
all atomic weights in terms of oxygen taken as 16 rather than hydrogen as 1 . The atomic'weight of hydrogen as expressed on this scale is 1.008 .

If we wish to deal always with the same number of molecules we may do so, then, by taking of each substance a number of grams equal to its molecular weight. Thus 32 grams of oxygen and 2.016 grams of hydrogen contain the same number of molecules. Such an amount of any substance is known as " 1 gram-molecule," or by abbreviation as "1. gm.-mole," or more simply as " 1 mole."

The combination of atoms in groups, which we symbolized in terms of A and B earlier in this chapter, represent of course but a few of the combinations which we can imagine. Why do some of these combinations occur in chemical reactions and not others? Why, for example, does one hydrogen atom combine with one chlorine atom to form hydrochloric acid, $\mathrm{HCl}$, but two hydrogen atoms combine with one of oxygen to form water, $\mathrm{H}_{2} \mathrm{O}$ ? Why do we not obtain a compound like $\mathrm{HCl}_{2}$ or $\mathrm{H}_{2} \mathrm{Cl}$ ? What is the cause of such combinations?

- Speculations as to the cause have been made since the time of the early Greek philosophers. Hippocrates assumed that "like draws to like" and that substances which combined had something in common. The early Greek atomists personified the atoms, attributing to them loves and hates. The medieval alchemists were more picturesque in their ideas. They assumed that the combinations were due to differences in the forms of the particles of substances. They pictured acids as composed of sharp particles like 
needles or spears, which transfixed the particles of the substances upon which the acid acted. Newton explained the actions in terms of forces of attraction which were negligible except when the atoms between which they acted were very close to each other. With the discovery of Volta ${ }^{1}$ in 1800 of a relation between chemistry and electricity, theories like that of Berzelius arose. Although, as we shall see in the next chapter, present theories point to an electrical cause, the details of the mechanism are largely unknown.

It became convenient to speak of the combining ability of atoms without particular reference to any theory of affinity. The term "valence" thus came into use. One atom of chlorine combines with one of hydrogen, and no combinations have been formed, the molecules of which contain only hydrogen and chlorine atoms, in which more than one atom of each element was involved. These two substances are said to have similar power of combination or valence. Oxygen has twice the valence of hydrogen or chlorine, for one atom of oxygen combines with two of hydrogen.

Valence is always referred to that of hydrogen, which is taken as unity. Chlorine is thus seen to be monovalent while oxygen is divalent. A monovalent atom may for the moment be likened to a one-armed man who may grasp the hand of another one-armed man, as in $\mathrm{HCl}$. An oxygen atom in such a picture has two hands and may grasp those of two monovalent atoms such as hydrogen. Carbon has four bonds. When it burns incompletely we have the formation of the extremely poisonous carbon monoxide, $\mathrm{CO}$. Two of 1 Cf. Chapter XIV. 
the bonds of the carbon are satisfied by the two of the oxygen atom, but the remaining two are available for other combinations. This is apparently the cause of its effects when inhaled. On the other hand, if the combustion of the carbon is complete all four bonds are satisfied by two atoms of oxygen and the resulting compound is carbon dioxide, $\mathrm{CO}_{2}$. 


\section{CHAPTER VIII}

\section{THE ELECTRON}

The electron, discovered in the last years of the 19th century, has indicated the electrical composition of matter. Although we spoke of the realities of science as matter and energy, we might equally well speak of electricity and energy, as we shall see in succeeding chapters. The concept of the electron has already explained many perplexing phenomena and, of course, raised new questions itself. The atoms of chemistry are no longer regarded as indivisible particles. An atom, we have reason to believe, always consists of a number of electrons and another part which is called the "nucleus." These electrons are little bits of electricity. ${ }^{1}$

Further than to say that electrons are electricity we cannot go. We can say that matter is molecular, that molecules are composed of atoms, and that atoms are formed of electrons. In finding how the matter of the universe is composed scientists have at last reached the electron. In terms of it they can explain

${ }^{1}$ But what is electricity? Sometimes it is supplied to us over wires from a power plant and utilized in a wire device like an electric lamp. What then happens is, that the power plant pumps, or forces, a procession of these electrons through the wires, making them hot and that of the lamp white hot. The heat comes from the work done by the stream of electrons in their passage through the wire. 
fairly well everything else, or at least there is promise that ultimately everything else will be so explained. But as to the electron itself no explanation can be given. If any explanation is ever obtained it will be in terms of something else which in its turn will be unexplainable and have to be accepted as the fundamental element or beginning from which all other explanations start. The electron is the fundamental entity with which modern science starts.

But what is the nucleus? That we do not as yet know. To learn what we do know of it we must consider further the behavior of electrons. These are, so far as we know, all alike without regard to the atoms from which they are derived. An electron from a hydrogen atom is just the same as one from an atom of copper or one from an atom of radium. They are very small $^{1}$ as compared to an atom although they are for their size much heavier. When it comes to moving an electron, as for example starting one, it is found that it has about $\frac{1}{1845}$ of the inertia of the hydrogen atom. If you realize that it takes about $1.70 \times 10^{25}$ hydrogen atoms to weigh an ounce you will see how small is the mass of an electron.

Now, electrons have a peculiar property of repelling each other. Two electrons always exert a force pushing each other apart even though they may not be in contact. How can an electron which is not touching another, push on it, urging the second electron away from itself? Again the answer is that we do not know. They must act on each other through a "medium," a "something between." Such a medium the physicist

1 What we mean by "size" is discussed a little later. 
must assume, for of the repulsion he has positive proof. He, therefore, postulates a medium which he calls the "aether," or, as now spelled, "ether." The word, derived from the Greek "belonging to the upper air," was originally applied to the medium between the earth and the heavenly bodies. The ether is imponderable and intangible and we cannot detect its existence by our senses.

When the physicist speaks of a vacuum he means a space free from matter, but through it electrical repulsions are exerted and light, heat, and radio-telegraph waves may pass. Through such ethereal spaces the light of the sun and the stars reaches our earth. To the modern physicist, these vacua are empty only as far as concerns matter, that is, molecules, atoms, and dislodged electrons. According to his ideas a vacuum is full of ether. In fact, he considers all space throughout the universe to be filled continuously by this ether, like an enormous ocean, in which exist as specks the electrons and the atoms which they form. That the electrons are really mere specks in this universe of ether we realize readily from the statement that the radius of an electron is probably not larger than $2 \times 10^{-13}$ $\mathrm{cm}$. and that of a hydrogen atom is about $2 \times 10^{-8} \mathrm{~cm}$. The whole atom is perhaps 100,000 times as large in diameter as the electron. In other words, the radius of the electron is about as large, compared to the radius of the atom, as is the radius of our earth as compared to the radius of the orbit in which it travels around the sun.

We may consider the size of our solar system to be as large as the orbit traveled by the most remote planet. 


\section{TABLE I}

THE ELEMENTS, THEIR ATOMIC NUMBERS, ATOMIC WEIGHTS, AND POSITIONS IN THE PERIODIC SERIES

The atomic number appears at the left of the symbol for each element, the atomic weight below; where the latter are not in the order of the atomic numbers they are in italics. $1 \mathrm{H}$

1.008

\begin{tabular}{|c|c|c|c|c|c|c|c|c|}
\hline 0 & I & II & III & IV & $\mathbf{V}$ & VI & VII & VIII \\
\hline $\begin{array}{l}2 \mathrm{He} \\
3.99\end{array}$ & $\begin{array}{l}3 \mathrm{Li} \\
6.94\end{array}$ & $\begin{array}{c}4 \mathrm{Be} \\
9.1 \\
\end{array}$ & $\begin{array}{l}5 \mathrm{~B} \\
11.0\end{array}$ & $\begin{array}{c}6 \mathrm{C} \\
12.00\end{array}$ & $\begin{array}{r}7 \mathrm{~N} \\
14.01\end{array}$ & $\begin{array}{c}80 \\
16.00\end{array}$ & $\begin{array}{l}9 \mathrm{~F} \\
19.0\end{array}$ & \\
\hline $\begin{array}{l}10 \mathrm{Ne} \\
20.2\end{array}$ & $\begin{array}{l}11 \mathrm{Na} \\
23.00\end{array}$ & $\begin{array}{c}12 \mathrm{Mg} \\
24.32\end{array}$ & $\begin{array}{c}13 \mathrm{Al} \\
27.1\end{array}$ & $\begin{array}{l}14 \mathrm{Si} \\
28.3\end{array}$ & $\begin{array}{l}15 \mathrm{P} \\
31.04\end{array}$ & $\begin{array}{c}16 \mathrm{~S} \\
32.06\end{array}$ & $\begin{array}{l}17 \mathrm{Cl} \\
35.46\end{array}$ & \\
\hline $\begin{array}{l}18 \mathrm{~A} \\
39.88\end{array}$ & $\begin{array}{l}19 \mathrm{~K} \\
\$ 9.10\end{array}$ & $\begin{array}{l}20 \mathrm{Ca} \\
40.07 \\
\end{array}$ & $\begin{array}{l}21 \mathrm{Sc} \\
44.1\end{array}$ & $\begin{array}{l}22 \mathrm{Ti} \\
48.1\end{array}$ & $\begin{array}{l}23 \mathrm{~V} \\
51.0\end{array}$ & $\begin{array}{l}24 \mathrm{Cr} \\
52.0\end{array}$ & $\begin{array}{c}25 \mathrm{Mn} \\
54.93 \\
\end{array}$ & $\begin{array}{lll}26 \mathrm{Fe} & 27 \mathrm{Co} 28 \mathrm{Ni} \\
55.84 & 58.97 & 58.68\end{array}$ \\
\hline $\begin{array}{c}\ldots \ldots \\
\ldots \ldots \\
\end{array}$ & $\begin{array}{l}29 \mathrm{Cu} \\
63.57 \\
\end{array}$ & $\begin{array}{l}30 \mathrm{Zn} \\
65.37 \\
\end{array}$ & $\begin{array}{c}31 \mathrm{Ga} \\
69.9\end{array}$ & $\begin{array}{c}32 \mathrm{Ge} \\
72.5\end{array}$ & $\begin{array}{l}33 \mathrm{As} \\
74.96\end{array}$ & $\begin{array}{c}34 \mathrm{Se}^{\circ} \\
79.2\end{array}$ & $\begin{array}{l}35 \mathrm{Br} \\
79.92\end{array}$ & \\
\hline $\begin{array}{l}36 \mathrm{Kr} \\
82.92\end{array}$ & $\begin{array}{l}37 \mathrm{Rb} \\
85.45\end{array}$ & $\begin{array}{l}38 \mathrm{Sr} \\
87.63\end{array}$ & $\begin{array}{l}39 \mathrm{Y} \\
88.7\end{array}$ & $\begin{array}{c}40 \mathrm{Zr} \\
90.6\end{array}$ & $\begin{array}{c}41 \mathrm{Nb} \\
93.5\end{array}$ & $\begin{array}{c}42 \text { Mo } \\
96.0\end{array}$ & $\begin{array}{c}43- \\
\ldots \ldots\end{array}$ & $\begin{array}{rrrr}44 \mathrm{Ru} & 45 \mathrm{Rh} & 46 \mathrm{Pd} \\
101.7 & 102.9 & 106.7 \\
\end{array}$ \\
\hline $\begin{array}{c}\ldots \ldots \\
\ldots \ldots \\
\cdots\end{array}$ & $\begin{array}{l}47 \mathrm{Ag} \\
107.83 \\
\end{array}$ & $\begin{array}{l}48 \mathrm{Cd} \\
112.40 \\
\end{array}$ & $\begin{array}{l}49 \text { In } \\
114.8\end{array}$ & $\begin{array}{l}50 \mathrm{Sn} \\
118.7\end{array}$ & $\begin{array}{l}51 \mathrm{Sb} \\
120.2\end{array}$ & $\begin{array}{l}52 \mathrm{Te} \\
127.5\end{array}$ & $\begin{array}{c}531 \\
126.92 \\
\end{array}$ & \\
\hline $\begin{array}{l}54 \mathrm{X} \\
130.2\end{array}$ & $\begin{array}{l}55 \mathrm{Cs} \\
132.81\end{array}$ & $\begin{array}{l}56 \mathrm{Ba} \\
137.37 \\
\end{array}$ & $\begin{array}{l}57 \mathrm{La} \\
139.0\end{array}$ & $\begin{array}{l}\text { See } \\
\text { Note }\end{array}$ & $\begin{array}{l}73 \mathrm{Ta} \\
181.5\end{array}$ & $\begin{array}{l}74 W \\
184.0\end{array}$ & $\begin{array}{c}75- \\
\ldots \ldots\end{array}$ & $\begin{array}{llll}76 & \mathrm{Os} & 77 \mathrm{Ir} & 78 \mathrm{Pt} \\
190.9 & 193.1 & 195.2\end{array}$ \\
\hline$\cdots$ & $\begin{array}{l}79 \mathrm{Au} \\
197.2\end{array}$ & $\begin{array}{l}80 \mathrm{Hg} \\
200.6\end{array}$ & $\begin{array}{l}81 \mathrm{Tl} \\
204.0\end{array}$ & $\begin{array}{l}82 \mathrm{~Pb} \\
207.20 \\
\end{array}$ & $\begin{array}{l}83 \mathrm{Bi} \\
208.0\end{array}$ & $\begin{array}{l}84 \mathrm{Po} \\
(210.0)\end{array}$ & $\begin{array}{c}55- \\
\ldots \ldots\end{array}$ & \\
\hline $\begin{array}{l}86 \mathrm{Nt} \\
(222.0)\end{array}$ & $\begin{array}{c}87- \\
\ldots \ldots\end{array}$ & $\begin{array}{l}88 \mathrm{Ra} \\
226.0\end{array}$ & $\begin{array}{l}89 \mathrm{Ac} \\
(227)\end{array}$ & $\begin{array}{l}90 \mathrm{Th} \\
232.15\end{array}$ & $\begin{array}{l}\text { UrX2 } \\
(234)\end{array}$ & $\begin{array}{l}92 \mathrm{Ur} \\
238.2\end{array}$ & $\cdots$ & \\
\hline
\end{tabular}

Norz. Each vertical column forms a "group" the elements of which have the valencies indicated by the Roman numerals or else form similar compounds with other elements like hydrogen and oxygen. Each row is a "period." Corresponding to the atomic number 58 is the rare metallic element cerium. For simplicity an entire period of rare earths, following cerium, is omitted from the table of positions although they are included in the list of elements.

The List of Euements in the Order of Atomic Numbers:

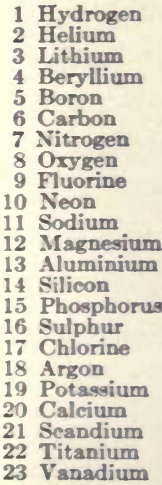

24 Chromium
25 Manganese
26 Iron
27 Cobalt
28 Nickel
29 Copper
30 Zinc
31 Gallium
32 Germanium
33 Arsenic
34 Selenium
35 Bromine
36 Krypton
37 Rubidium
38 Strontium
39 Yttrium
40 Zirconium
41 Niobium
42 Molybdenum
43 Ruthenium
44 Rhodium
45 Palladium

47 Silver
48 Cadmium
49 Indium
50 Tin
51 Antimony
52 Tellurium
53 Iodine
54 Xenon
55 Caesium
56 Barium
57 Lanthanum
58 Cerium
59 Praseodymium
60 Neodymium
61 Samarium
62 Europium
63 Eudolinium
64 Gadoium
65 Terbium
66 Dysprosium
67 Holmium
68 Erbium
69 Thulium

70 Ytterbium

71 Lutecium

72

73 Tantalum

74 Tungsten

75

76 Osmium

77 Iridium

78 Platinum

79 Gold

80 Mercury

81 Thallium

82 Lead

83 Bismuth

84 Polonium

85

86 Niton

87

88 Radium

89 Actinium

90 Thorium

91 Uranium X 2

92 Uranium 
If then, as there seems reason to believe, the hydrogen atom consists of a nucleus and one electron revolving about it, the size of both may well be very small as compared to what we should measure as the size of the atom or of its inclosing sphere. Although the relations of size in the atom are much like those of our earth and its orbit, the nucleus is very much smaller in proportion than is our sun.

In the case of atoms there are two ways, which we shall discuss more fully later, in which electrons may be obtained. In the first case we may jar electrons loose from the atom. In the second case the electron may be thrown off by some disturbance which has its origin in the atom itself. In this second case we call the substance "radioactive." Of such substances radium, discovered in 1897 by Monsieur and Madame Curie, is the best example. Other radioactive substances are uranium, thorium, actinium, and polonium. The atoms of such substances appear to be disrupting; not that all of them do so at once, but of a bit of such a substance some of the atoms are always breaking down in this way. In such a breakdown electrons are shot out or other changes take place and the result is new elements. ${ }^{1}$

Uranium, which is the heaviest known atom, has at least 92 electrons, ${ }^{2}$ that is, it has 92 electrons exclusive of any which may be contained in the nucleus, the construction of which we are about to consider. Between

${ }^{1}$ Radium is believed to be a product due to the disintegration of uranium, and this may later be found true of the other radioactive elements.

2 The determination of "atomic numbers" is discussed in Chapter XXII. 
hydrogen, with only one electron, and the unstable uranium, with its 92 , lie all the possible elements. If one considers that an atom must have a whole number of electrons it will appear that the other 84 known elements may fit in between hydrogen and uranium and still leave six yet to be discovered. The names of the elements with their numbers of electrons are given in Table I. The spaces indicate possible elements which have not yet been discovered. These may some day be discovered in the composition of some distant star or perhaps in some rare earth.

What is the character of the nucleus and why if electrons repel each other, are they not all dispelled and all atoms disrupted? The answer is that the character of the nucleus is such as to attract towards itself and in general to hold within the atomic radius the various electrons of the atom. We may say, then, that the nucleus is itself electricity, but of a different kind from that of the electron. For convenience and for reasons connected with the history of the science, we call the electricity of the electron "negative" and that of the nucleus "positive."

The names were introduced by Benjamin Franklin about 1756, long before the electron was known, for our knowledge of the latter has all developed since Röntgen's discovery in 1895 of X-rays. ${ }^{1}$ In Franklin's time it was known that if a glass rod is rubbed with silk it is electrified, that is, acquires the ability to attract light particles, as bits of paper or pith balls. Two

1 The reader probably knows most of $\mathrm{X}$-rays as a means of taking pictures of bones or teeth for surgical diagnosis. The phenomenon is discussed further in Chapter XIV. 
pith balls electrified by contact with the rod are found to repel each other. On the other hand, a rod of sealing wax, which has been electrified by rubbing it with cat's fur, will produce effects similar to those of the glass rod. But there is an important difference. A pith ball charged by the glass rod and one charged by the sealing wax will attract each other. These phenomena may be summarized in a simple law, namely : like electricities repel and unlike attract. To the electricity of the glass rod Franklin gave the name "positive" and to that of the sealing wax, the name "negative." However charges of electricity are produced to-day, we still use these names.

Before returning to the question of atomic composition we shall need to describe further the phenomenon of electrification. It will be found by test that the silk is negatively charged, when the glass rod is positively charged. Furthermore, until the two dissimilar substances are brought into intimate contact, as by rubbing, they are not electrified. The normal condition of matter, in other words, gives no evidence of electricity. This may be tested by presenting the silk and the glass together to a pith ball, which has been charged, and noting that the latter is neither repelled nor attracted. After the two substances are electrified, if they are held close together and tested by a charged pith ball, they will produce no effect, because their positive and negative electricities neutralize in their effects. Because of this equal effect we conclude that unlike electricities always appear in equal amounts.

We notice also from such an experiment that when a body gives no evidence of electrification, it may never- 
theless have in it equal and unlike electricities. With this in mind we now see how an atom or a molecule may normally appear uncharged and yet have within it equal and unlike electricities.

Recognizing, then, that the atom is composed of a nucleus of positive electricity and of electrons we may now explain the electrification which is produced by rubbing the glass with silk. During the intimate contact some of the electrons which are not very firmly held in their respective atoms become attached to other atoms. During this rearrangement ${ }^{1}$ of the electrons the glass loses electrons to the silk. The silk has more than its usual number. Conversely, the glass rod has less than its normal number of electrons and therefore appears positively charged. In other words, for the glass rod there are not sufficient electrons to neutralize in effect the positive nuclei of its atoms. The positively charged glass rod will attract the negative silk with which it was rubbed, and it is against this attraction that we do work in separating the two dissimilar substances in the act of producing electrification.

We may also ask why a charged glass rod attracts an uncharged pith ball, for it was this phenomenon which first called attention to electricity. The mechanism is simple. The rod, being positive, draws toward itself

${ }^{1}$ We may imagine a very simple parallel case to illustrate how this happens. Consider two trains which meet at a railroad siding. Some of the men wander about from car to car, either of their own train or of the other. But the men of train 1 stick more closely to their own cars than do those of train 2. When the whistle blows for departure the first train will have more and the second train less men than when they pulled in. If we picture the cars as atoms and the men as electrons we have qualitatively the process of "electrification by friction." 
some of the electrons of the pith ball. The side of the ball near the rod has more and the opposite side less than its normal number of electrons. The nearer side is negative and the more distant positive. The attraction of the rod for the nearer side is greater than its repulsion of the more distant side, with the result that the pith ball is urged toward the rod.

Returning to our consideration of the atom we may now summarize as follows: (1) the normal state of an atom is uncharged; (2) the atom consists of a number of electrons, and a nucleus which has a positive charge just equal to the negative electricity of the electrons; (3) the operation of charging a body with electricity consists in causing either an excess or a deficiency in the number of electrons in the body.

The nucleus attracts the electrons and they are in general very firmly held in the atomic radius. But why doesn't the attraction which exists between the positive nucleus and the negative electrons draw them together? To this question the scientist has as yet been unable to obtain an entirely satisfactory answer. For this and other questions we must await either further theories or more experimental evidence. The statements, however, which we have so far made as to the nature of the atom are supported by experimental evidence and are commonly accepted.

The nucleus we recognize as positive electricity, but we mean thereby merely that it has an excess of positive electricity over any negative which it may also include. In fact there is evidence that the nucleus itself contains some electrons. In the case of radioactive substances we find that electrons are shot off and 
also atoms which we recognize to be helium. Helium is a light monatomic gas, twice as heavy as diatomic hydrogen. Its atom consists of a nucleus and two electrons.

Since such an atom is shot off from radium it appears to mean that the nucleus of the radium atom contains, or possibly is made up of, helium atoms. It is also possible that these helium atoms are themselves made up of hydrogen atoms. If this is the case, the nucleus of each helium atom should consist of ofour nuclei, like that of the hydrogen atom, and two electrons. This helium nucleus would then require two external electrons in order to be neutral. That the helium atom has two electrons external to the nucleus, we know, but we are as yet in the dark as to whether or not the nucleus is formed as suggested above. The point to be noted is that, even though scientists are not yet able to speak definitely of the composition of the nucleus, there is sufficient evidence to warrant our bearing in mind the possibility that the nuclei of all the atoms may some day be found to be formed by the combination of electrons and a number of positive elemental charges ${ }^{1}$ all just like the positive nucleus of the hydrogen atom.

1If we use the term "electron" to mean an element of electricity we must distinguish between this positive electron and the negative electron with which we have previously dealt. This is the practice of such pioneers in electron physics as J. J. Thomson, Millikan, and Rutherford. Unfortunately the Century Dictionary has not recorded this usage. It happens, however, that our further discussions concern only the negative electron, and for convenience we shall continue to use the term without qualification to represent the elementary negative charge. 
The question of how the electrons of an atom group themselves under the action of their mutually repellent forces and the attraction of the nucleus is a difficult problem of mathematical physics. An interesting study has been made, however, of the manner in which a number of similar particles, which repel each other, would group themselves in a plane, under the action of a centrally located source of attraction. A number of small magnetic needles were mounted vertically through small corks and thus floated on the surface of a vessel of water. Similar poles of the needles projected upward through the corks. A long magnet was suspended vertically above the vessel so that a pole of opposite character to those of the needles might act as a center of attraction. It was found that the configurations into which the floating poles grouped themselves depended upon their number. Thus three poles placed themselves at the corners of an equilateral triangle, the center of which was just below the attracting magnet. Similarly four magnets group at the corners of a square and five at the vertices of a regular pentagon.

When six magnets enter into the configuration one goes to the center, immediately below the pole of the large magnet, the other five forming a pentagon. With seven and eight similar figures are formed with one magnet at the center. With nine there are two in the center and seven in the outside ring. With ten or eleven there is an inner triangle and an outer ring of either seven or eight. The number in the center increases until, when the total is fourteen, there is a pentagon inside and a ring of nine outside. In other words, as the number entering into the configuration is in- 
creased, certain arrangements recur. When the number is increased to fifteen there is an outer ring of nine, an inside ring of five, and in the center of this a single magnet. As the number of magnets increases certain configurations appear more or less periodically, that is, at definite intervals.

It is reasonable, therefore, to expect, as prominent scientists $^{1}$ have done, that whatever the positive nucleus of the atom may be, atoms differing in their compositions by definite numbers of electrons may in part have similar configurations for their electrons. In so far as the electron configuration as well as the number determines the characteristics, such atoms should have certain similarities in chemical properties. If a list is made of atoms in the order of the number of electrons they contain, those of similar properties might be expected to occur periodically in the list.

To some extent this is reasoning after the fact. That there is such a periodicity to a list of the elements, arranged in order of their atomic weights, was noticed years before the electron was discovered. Also, some chemical elements are similar in their properties, e.g. lithium and sodium are both soft white metals. They form chlorides, $\mathrm{LiCl}$ and $\mathrm{NaCl}$, respectively, which have quite similar properties. Potassium is also very similar to these two elements. We find such a similarity between the compounds of sodium and potassium; thus we are all familiar with the similarity of caustic soda and caustic potash, $\mathrm{NaOH}$ and $\mathrm{KOH}$, respectively. The atomic weights of lithium, sodium, and potassium

${ }^{1}$ Cf. J. J. Thomson, "The Corpuscular Theory of Matter," Chap. VI, Charles Scribner's Sons, 1907. 
are 7,23 , and 39 , respectively; hence the difference between sodium and lithium is the same as that between potassium and sodium. (Table I shows equal differences in the number of electrons.)

The classification of elements according to atomic weights was first worked out by Newlands in 1864 . It was, however, much extended and elaborated by Mendelejeff in 1869. Finding in one of the periods a place where an element was apparently missing, Mendelejeff predicted that an element of about a certain atomic weight, with a certain valence, which should form certain compounds typical of its group, might later be discovered. He made two other predictions of this character. The three elements, gallium, scandium, and germanium, were discovered during the next twenty years and found to have essentially all the properties which had been predicted for them.

The characteristics of the atoms of the elements are believed to-day to be due to the number and configuration of the electrons. The power of combination is undoubtedly to be explained in terms of the forces existing between the electrical charges of atoms which are brought close together. Although positive and negative electricities in the atoms are equal, their distribution might well be such that a net force would act between two dissimilar atoms if they were very close together. The cause of attraction would then be somewhat similar to that discussed on page 95 , the resultant force being due to the fact that the attracting electricities of the two atoms were on the average closer to each other than were the repelling electricities. 


\section{CHAPTER IX}

\section{ENERGY}

IN the preceding chapters certain facts as to the composition of matter have been stated, which may be summarized in the statement that matter is granular in structure and electrical in nature. In all matter we have reason to believe that the constituent parts are in motion. By the motion of electrons the phenomenon of contact electrification (cf. page 95) was explained. In later chapters we shall discuss further the motions of the electronic constituents and also of the atomic aggregates which compose the molecules of matter. Of the motions of the molecules themselves, at least in the case of liquids and gases, there is familiar evidence in the phenomenon of diffusion, that is, the unaided mixing of two different substances, of which the diffusion of an odor through air is an example.

Because of the characteristic of inertia (cf. page 68) there is associated with all the motions of these constituents of matter an ability to do work, which we call energy. To say that all bodies in the universe have inertia is to say, in effect, that all moving bodies possess energy, but offers no explanation of the original cause, the energy source of the universe. All the physical explanations of the origin of our earth, or our astronomical system, must start from an assumed con101 
dition, or reach a possible initial condition, in which there was present a sufficient amount of energy to account for the present distribution of energy among the component parts.

Although in this chapter we shall state the fundamental ideas as to energy in connection with visible and tangible bodies, e.g. stones or a baseball, this should not mislead as to the relative importance of the energy associated with groups of molecules as compared to that of the molecules themselves or their component parts. The energy which is most important in nature is not that of bodies like trains and bullets, hammers and fists, but the interatomic and molecular energy. The interatomic energy of the sun, transmitted to the earth, is recognized as heat and light, and is the cause of the chemical synthesis in growing plants. It is interatomic energy which causes the heat evolved by some chemical changes, as that of combustion. (The heat itself we shall find to be molecular energy of the body which is heated.) The energy of organic life is the result of innumerable small contributions of interatomic energy and to some extent of molecular energy. The rise of sap in plants is a phenomenon of molecular energy.

As has been indicated above, energy may be associated with the component parts of the atom, with the molecules and atoms themselves, or with bodies of more than molecular size. Of the kinds of energy we distinguish, however, only two, namely "potential" and "kinetic," the latter due to motion and the former existing only in possibility. Whenever a body is given the ability to do work as a result of the motion 
which is communicated to it, it is said to possess kinetic energy. Of this a moving bullet, the falling weight of a pile driver, and the rotating flywheel of an automobile engine are examples. In the same way moving molecules or the moving electrons of their atoms possess kinetic energy.

Kinetic energy is the only kind of which we may be conscious, for there is no motion in the case of potential energy. In the wood beside the fireplace and the oxygen in the room there exists a possible source of energy, the potential energy of separation of two chemical compounds, which is only manifested when they are allowed to unite. In the raised weight of a pile driver, in the coiled spring of a watch, in the powder of a cartridge, in the water of lakes and reservoirs which are above the surrounding ground, there is potential energy.

The weight of a pile driver possesses potential energy because it may fall toward the earth, and hence it is not the weight itself, but rather the system, of the weight and the earth which attracts it, which possesses this energy. In the same way the water of an elevated reservoir does not itself possess the potential energy, but rather the system of which it is a part. Potential energy is due to the position or separation of the parts of a system. In the case of the explosive mixture of the cartridge this is also true, and the energy is released by allowing the combination of the separated parts to take place.

But where is the separation in the case of the coiled watch spring? If anything, the parts appear to be closer together when the spring is wound than when it 
is unwound. The uncoiled position is normal for the spring, since to wind it requires work. In this condition the various molecules of which it is composed have definite positions with reference to each other. When, however, we bend the spring, as in winding, we force them to assume a new configuration. Now, whether in the act of bending we pull two adjacent molecules farther apart or push them closer together we change their separations and potential energy. The proof, however, is not in the separation but in the subsequent ability of the system to do work.

In the case of the spring the system is molecular. In that of the explosive mixture in the cartridge it consists of a large number of atoms, grouped into molecules of two or more chemical compounds. The atoms which form these compounds are, of course, capable of forming other compounds, the products of the explosion. (If the explosive is a single compound it must be an unstable one from which the component atoms form more stable compounds.) In the case of the pile driver and the earth, we have recognized a separation of the parts, not of individual molecules or atoms, but of molecules in the bulk. The bulk of molecules forming the weight are separated from the bulk of those which form the earth.

These are illustrations not only of the energy of separation, but of the three different types of separation. In the system of pile driver and earth the separation is of more than molecular magnitude, that is, too large for forces between molecules to come into play. In the coiled spring the separations are small enough for molecules to exert forces upon each other. 
In the explosive mixture the separations are even smaller in size and concern the electrons and the nuclei of the atoms, which come together into new combinations when explosion occurs.

Potential energy, then, is the ability of a system to do work as the result of the displacement of its parts, while kinetic energy is its ability as a result of their motions. If the motions are those of whole atoms or molecules the energy is molecular kinetic energy. When we realize that every moving electron, atom, or molecule in the universe possesses kinetic energy, and that wherever there are separations which tend to change there is potential energy, we recognize what an enormous store of energy there is in the universe in which we live. The questions this realization suggests are: How much of this energy is available? and How may the available energy be utilized?

To obtain the idea which is involved in the word "available" let us consider the case of the attraction of the earth for parts of itself. If we lift a shovelful of earth from the surface we do so against the attraction of the rest of the earth. In this separation work is done and potential energy is given to the system composed of the earth and the shovelful, which we are holding apart. As another example note that each particle of a mountain forms with the rest of the earth a system with potential energy, for it is only necessary to start a stone to have it roll crashing down the mountain side. But suppose that we stand on relatively flat country beside a deep well or a mine shaft. If we start a stone it will fall down the shaft, for in this case also the system possesses potential energy. In 
both cases the energy is available, for it is possible to decrease the separation, since in both cases the stone has some place to which it may fall. But if the mine shaft is filled up so that the stone has no place to fall the conditions are not different as to the energy which the system possesses, for there is still the same separation existing between the attracting bodies. As to availability, however, the conditions are different, for the energy is no longer available.

Consider now the energy of the system which the water of the ocean forms with the earth. All the drops which have the same separation from the center of the earth form with the latter systems having the same potential energy. The energy, however, of all these systems is not available. A drop of water on a cliff above the ocean possesses more potential energy, for it may fall to the level of the surface of the sea. Of its total potential energy a part is obviously available, and this part is the difference between the energy it has on the cliff and the energy which any drop has on the surface of the ocean. Since the amount of the energy which is available depends upon the distance above sea level, we might speak of water at sea level as having zero available potential energy and measure the available potential energy of water at higher levels by the distance. We might further speak of sea level as being the level of zero gravitational potential, allowing the word "energy" to be understood.

Let us follow this idea a little further and see where it leads. We did not call attention to the drops of water but rather to their "locus," namely the surface of the sea. We spoke, in other words, of a locus of 
zero potential. Since the potential energy of a drop of water depends upon where it is, that is, upon the point which we are considering, we are justified in speaking of the gravitational potential of any point as meaning the available potential energy of a drop of water placed at that point. All the points about the earth where such a drop of water would have the same potential energy form an equipotential surface. For example, if we consider a point a foot above sea level it will have a certain potential, but every other point which is one foot above sea level will have the same potential. Through these we may think of a surface as existing, not a real surface like that of the sea itself, but an abstract one like those which are considered in geometry. Similarly, other equipotential surfaces may be imagined.

This idea of potential is of peculiar value in the study of electricity, but we are limiting our present discussion to gravitational potential. Although this terminology is largely used only in such study, equipotential surfaces are frequently dealt with. The surveyor, locating a railroad route, endeavors as far as possible to find it on an equipotential surface. He does not call it that, for he usually says he wishes to obtain a level line or else a line of low grades. In passing from a point of lower to one of higher potential, that is, from one nearer to the center of the earth to one farther therefrom, work must be done in moving a body; and as far as possible the engineer wishes the only work to be that required to overcome the friction of the moving train. Of course, if his road was going to carry freight only one way, he would seek for a 
route which led from a high potential to a low potential.

Returning to our idea of the gravitational potential of a point as the potential energy of a drop of water at that point, the reader has doubtless felt that the drop of water forms an unsatisfactory unit. With this we agree and suggest that we speak of a pound of water or preferably a gram of water, and then abstracting the water leave merely the mass. The gravitational potential of a point is the potential energy of a gram at the point.

In case we use grams we should use the centimeter as the unit of distance. The potential of the surface which is one centimeter above sea level we shall call one gram-centimeter $(1 \mathrm{~g} . \mathrm{cm}$.). The amount of work, then, which one gram can do in falling from a point one centimeter above sea level to sea level is a gramcentimeter. Conversely, it would require one gramcentimeter to lift a gram from sea level to a point one centimeter above it.

Whenever we pass from a point of lower potential to one of higher potential, work is required, that is, energy must be supplied. Similarly, in passing from a point of higher to one of lower potential, energy is released. When we supply energy we do work, that is, we exert a force through a distance. On the other hand, when energy is released, work is done for us. In both cases a force comes into play when the potential is changed. If the potential is increased a force must be applied to the system. On the other hand, if the potential is decreased the acting force is supplied by the system under consideration. In a later chapter 
we shall define "force" quantitatively in terms of the change in energy.

When we move a body from a point of lower to one of higher gravitational potential we must supply a force and we do work. Potential energy is thus stored in the system. But when a body is allowed to pass from a point of higher to one of lower potential, e.g. to fall, what becomes of the potential energy which it possessed? We know that the body moves faster and faster as it falls. An acceleration is the result when its potential energy is allowed to decrease. We shall postpone the quantitative definition of acceleration to the chapter on "Rates" and be content at this point with the qualitative definition implied above. The very fact that the body falls, that is, is set into motion, means that it is given kinetic energy. The farther it falls the more potential energy the system has expended. But the farther it falls the greater is its speed, the larger its kinetic energy, and the smaller its potential energy.

Suppose we consider a numerical case of a body of one pound lifted 20 feet above sea level. It has a potential energy of $20 \mathrm{ft}$. lbs. Of course, if the body was two pounds it would have twice as much energy. In fact the potential of the point to which it is lifted is the potential energy possessed by each pound of the body, or as we say the potential of this point is the energy per pound of a body placed there. Allow the body to fall. When it is at a point 19 feet above the zero of potential it has $19 \mathrm{ft}$. lbs. of potential per pound. How much kinetic energy has it? If none of the energy of the system has been given up to other 
systems, as for example, to the molecules of the air through which the body falls, then its kinetic energy is $1 \mathrm{ft}$. lb. for each pound of the body. When it has fallen to a point 18 feet above the zero of potential, it has 2 ft. lbs. of kinetic energy for each pound of the body. The decrease in potential energy is always equal to the increase in kinetic energy, provided that none of the available energy is allowed to get away from the system. There is a change in the kind of energy going on steadily as the body falls, but no change in the total amount of energy possessed by the system. Such a system, where energy is neither added nor subtracted by some outside system, is called "conservative."

In practice, however, we do not find conservative systems. All the systems with which we have to do either lose or gain energy from other systems. In the case of a body falling through air some of the energy is imparted to the molecules of the air which the body pushes aside in falling. These air molecules are set into motion; that is, they are given kinetic energy. The energy given to them is subtracted from the system which we are considering. The system of earth and body is not, then, a conservative system. If, however, we consider the system to be composed not only of the earth and the body but also of the molecules of the air we do have a conservative system.

In the story of Galileo's experiment we saw that a falling body does not fall as quickly if there is friction. We now see from our knowledge of energy why this is so. In falling through any given distance a certain definite amount of energy is released. If all this energy is available for accelerating the body, it 
will acquire a greater speed and hence take less time to fall than if part of the energy must be expended in accelerating the molecules of air which are adjacent to its path.

The greater the amount of energy which friction subtracts from the system, the smaller the kinetic energy imparted to the body and hence the more slowly does it move. Now, it is possible to arrange the friction which a falling body must overcome so as to subtract all of its energy. When this is done, the body, of course, descends so slowly and uniformly that it is scarcely moving when it reaches its final resting place. We accomplish this every day without realizing the physics of it. When one sets a glass of water on a table he does so in such a way that it doesn't bump; that is, he makes sure that it has no kinetic energy, retarding its fall by absorbing into his own muscles the energy which is released as the glass descends from a point of higher to one of lower potential.

Perhaps the most striking illustration, however, is the parachute which was used in the War for escaping from observation balloons. This is merely a huge silk umbrella without ribs. In the top is a small hole through which the air can escape slowly and with considerable friction. When the parachute is released from the balloon it falls very rapidly, until the air has opened it. Thereafter its descent is quite gradual. When the parachute is working properly the balloonist arrives at the earth without an unfortunate amount of kinetic energy, for the energy which he possessed at the higher altitude has been entirely converted into molecular kinetic energy of the air. 
What, however, is the effect of increasing the kinetic energy of the molecules of a substance? An experiment which was performed by the Englishman, Joule, in about 1843 not only answered this question but is the basis of the reasoning as to energy which we are able to follow to-day. He arranged a falling weight so that it turned a paddle wheel in a vessel of water as shown in Fig. 8. The motion of the falling weight

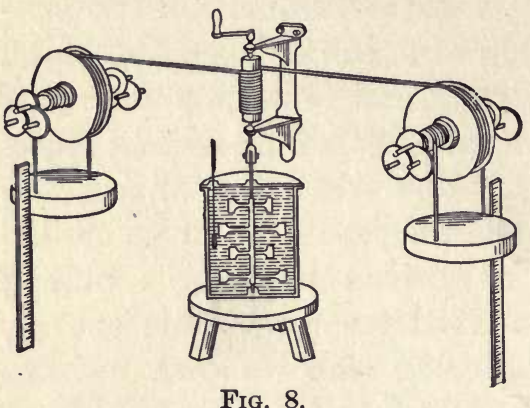

Fig. 8. is retarded in part by the friction of the paddle wheels and water and in part by a second weight which it lifts. This second weight was increased until its retarding effect plus that of the paddles was just sufficient to insure that the first weight fell so gradually as practically to have no kinetic energy. The first weight, being greater than the second, lost potential energy while the latter gained. The total loss in potential energy of the system formed by the earth and the two weights was the same as if a single weight, equal to the difference of the two, had fallen through the distance through which the first weight fell.

Joule found that the rapidly revolving paddle wheels heated the water, and he measured the rise in its temperature with a thermometer. He made several trials and he found that for every $42,700 \mathrm{~g}$. cm. of potential energy which the weights lost there was an equivalent rise of temperature of one degree Centi- 
grade $^{1}$ for one gram of the water. In other words, he found that energy, which was apparently lost, was not lost, as had been believed up to that time, but was converted into molecular energy and manifested as heat. He also found the numerical relation between temperature and the molecular energy of water. $\mathrm{He}$ is usually said to have determined the "mechanical equivalent of heat." This term, however, is misleading, and we shall discuss it later. ${ }^{2}$

Joule's experiments extended through several years and covered a wide range of possible cases, of which the one described above is merely the simplest for such a discussion as ours. In all cases he found that when energy, which was associated with ponderable bodies, disappeared there was to be measured a perfectly definite amount of increase in heat in the parts of the system with which he was working. Of course, his laboratory methods were not always as precise as they might be made to-day ; and some of them do not permit of very accurate observations. His experiments, however, satisfied the scientific world of the truth of his idea that energy is never destroyed but merely changed in kind or in location.

This fundamental fact of physical science, which Joule demonstrated is known to-day as the Principle of the Conservation of Energy, but is better expressed as the Principle of the Indestructibility of Energy.

Energy and matter are both indestructible. Energy, as we have seen, may change its form and its location,

${ }^{1}$ One degree centigrade is 1.8 degrees on the Fahrenheit scale of temperatures. Also $0^{\circ} \mathrm{C}$. is the same temperature as $32^{\circ} \mathrm{F}$.

${ }^{2}$ Cf. Chapter XXI. 
but its amount remains unchanged. Matter may change its form, being solid, liquid or aëriform. We cannot, however, either create or destroy matter. Nor are there any processes of nature whereby it may be done. It may undergo transformations, appearing to us now as one chemical substance and now as another, but the total amount of matter in the universe remains unaltered.

Matter and Energy, two indestructibles of the universe, are the entities in terms of which we must explain all physical phenomena. They are the realities of modern science. In connection with the first, we must always bear in mind the granular and electrical composition. In connection with the second, we shall need a further law as to availability. Some ideas as to this have been given in this chapter. A general statement is contained in what is known as the "Second Law of Thermodynamics." Thermodynamics, as a division of science dealing with the forces due to heat, was established before scientists appreciated the unity of physical science. Its first law, embodying the relation which was discovered by Joule, is essentially the principle of the conservation of energy. Its second law states the limits of the availability of energy.

To-day we realize that these laws are not limited in their application to a particular division of science but are fundamental. In fact, it would be preferable if they could be spoken of as the first and second laws of Energy, but we must use the names which were attached to them at the time they were formulated. 


\section{CHAPTER $\mathrm{X}$}

\section{SOME USES OF MATHEMATICS}

$\mathrm{WE}$ are all familiar with the convenience of abbreviating words by single letters. Certain cases are found in dictionaries and are taught in schools so that their use is practically universal within the limits of the particular language. The letter is used as a symbol for the word just as the word is itself a symbol for the idea. The convenience is, of course, one of brevity in writing. In mathematics symbols are used which are universally recognized without regard to the language of the student. This is a convenience, but the chief advantage which mathematics offers to science is its methods of handling symbolized ideas so as to reach conclusions which in some instances would be practically unattainable by any other form of reasoning. In fact, mathematics, usually defined as "the science concerned with the logical deduction of consequences from general premises," may be concisely defined as "symbolized logic." Let us then examine a few illustrations which will show this convenience of abbreviation and also in a very elementary way the logical deduction of consequences from assumed premises.

In determining the area of a rectangle we multiply the length by the breadth. Thus if the sides are 3 and 4 inches we say the area is 12 square inches since 
$3 \times 4=12$. The general rule for finding the area would be as follows: Measure the length and the breadth in the same units (e.g. both in inches) and multiply the number of units expressing the length by the number expressing the breadth; the product will be the number of times the square unit of area is contained in the rectangle.

Such a familar rule may be more concisely stated in symbols as follows: If $L, B$, and $A$ express the length, breadth, and area of any rectangle then

$$
A=L B
$$

This equation states the relation of the three magnitudes $L, B$, and $A$. Divide both sides of this equality by $B$ and we obtain

$$
L=\frac{A}{B}
$$

This new form of the relation indicates what of course we have known since our early study of arithmetic, namely, that the length of a rectangle is to be found by dividing its area by its breadth. Similarly dividing both sides of the equality (1) by $L$ gives

$$
B=\frac{A}{L}
$$

which states a similar relation for the breadth of a rectangle.

Equations (1), (2), and (3) are obviously all the forms in which the relationship of the sides and area of a rectangle may be explicitly expressed. ${ }^{1}$ We need to

1 The relation $\frac{L B}{A}=1$ is the general but implicit expression of the relationships of equations (1), (2), and (3). 
remember but one of them, since any one is obtainable from another by the simplest algebraic process. In passing from one form to another we have reasoned mathematically.

In the case of any law of science which may be expressed in the form $Z=X Y$ where $X, Y$, and $Z$ are the magnitudes with which the law deals we may always reason by the same mathematical processes as we employed above and arrive at the results of $X=\frac{Z}{Y}$ and $Y=\frac{Z}{X}$. Now, it happens that in an ordinary elementary course in physics, such as that of a high school, the student meets about forty physical laws which are expressible by just this simple relation. In our discussion we have arrived quickly at the general and abstract case. Partly because of the immaturity of high-school students and partly because of certain traditions and inhibitions of their teachers it too frequently happens that each of these laws is dealt with as a special concrete case. The result is that the simple mathematical transformations which we have indicated above occasion what is perhaps undue difficulty, and overemphasize what are popularly considered the mathematical difficulties of the subject.

There are two reasons why this typical equation should be carefully studied. The first is the obvious one that it would make the subsequent work of the student much easier, for whenever he meets a law expressible in this form he knows that he may apply the same mathematical processes of reasoning with similar results. The second advantage is that he may 
then concentrate his attention more on the physics of the relation and not so much on the mathematics.

In other words, mathematics to the scientist or engineer is merely a tool, which he should use like a good workman almost by second nature, thinking not of the tool but of the work which he wishes to do. Of course, a workman selects the tool required for the particular job which he has in mind, but he does so as the result of previous knowledge as to how the work is to be done and of previous experience with his tools. In this chapter we shall consider briefly relations symbolized by equations of the form $Z=X Y$, which proves so troublesome to the high-school student, and in the next chapter we shall consider another illustration of mathematics which frequently proves unnecessarily difficult to his college brother.

One familiar case of the relationship $Z=X Y$ has been illustrated by the area of a rectangle. Let us consider another in the expression of the law for the volume of a rectangular box. We derive the law for the volume by noticing that if the area of the base is increased, e.g. doubled, the volume is proportionately increased, e.g. doubled. Symbolizing the volume by $V$ and the area as before, we express this fact as

$$
V \propto A^{1}
$$

Similarly, if the area of the base is kept constant and the height changed the volume is altered proportionately ; thus, representing height by $H$

$$
V \propto H
$$

1 The symbol $\propto$ obviously means "is proportional to." 
Now these two facts may be expressed in the single relation

$$
V \propto A H
$$

This is the law for the volume of a rectangular parallelepiped. It is not yet in the form for numerical calculation because we have not yet decided upon the units in which the three magnitudes, $V, H$, and $A$ are to be measured or expressed.

We recognize that any magnitude, e.g. an amount of money, is expressed by a number, a "numeric," as we say, and a unit. The numeric indicates how many times the chosen unit is contained in the given magnitude. The greater the unit, the smaller, of course, the corresponding numeric. Thus

$$
\begin{gathered}
\$ 3=300 \& \text {, that is } 3(1 \text { dollar })=300(1 \text { cent }) \\
\text { or } \frac{1 \text { dollar }}{1 \text { cent }}=\frac{300}{3}=\frac{100}{1}
\end{gathered}
$$

In the expression of any given magnitude the numeric is inversely as the unit.

The numeric expressing the volume depends upon the choice of unit for measuring volume. Similarly, the product $A H$ will depend upon the units in which these two magnitudes are expressed. Consider for example the concrete numerical problem of a corncrib of area $10 \mathrm{sq}$. ft. and height $4 \mathrm{ft}$. For this case $A H$ is obviously 40 cubic feet. But if we measured the volume by pouring in corn we should find it to be about 32 bushels. That is, in bushels the numeric of the volume, $V$, is 32 . By selecting the unit we may make the numeric anything we please. It would, however, be a convenience to choose the unit expressing 
the volume so that the corresponding numeric would be the same as that expressing the product $A H$.

Of course, in this concrete numerical problem we recognize that the unit we should use is the cubic foot, since we are expressing the area in square feet and the height in feet. But we are dealing with an evident problem so that the method which we are employing may not be obscured by incidental difficulties. Let us represent the desired and supposedly unknown unit for volume by $(v)$; then, since the numeric corresponding to $A H$ is $10 \times 4$ we write

$$
\text { or } \quad \begin{array}{rlrl}
40(v) & =10(1 \text { sq. } \mathrm{ft} .) \times 4(1 \mathrm{ft} .) \\
& \quad(v) & =(1 \text { sq. } \mathrm{ft} .)(1 \mathrm{ft} .) .
\end{array}
$$

That is, the unit of volume is that of a rectangular parallelepiped for which the base is one unit of area ( $1 \mathrm{sq}$. ft.) and the height is one unit of length ( $1 \mathrm{ft}$.$) .$

So far our reasoning has dealt mostly with a concrete numerical example. Concrete numerical illustration, without an expression or development of the general principle involved, was the method of the first textbook of science of which we know, the Ahmes papyrus. This was the work of an Egyptian priest about 1700 B.c. and was based upon an earlier text of which no portions have been found, which antedated it by 500 years at least. The manuscript describes itself as "Instructions for arriving at the knowledge of all things, and of things obscure, and of all mysteries." If one is satisfied in science with a concrete case and does not go on to abstract the general principle, his attitude will be about that of the ancient Egyptian. It was the Greeks, as we saw, who started science 
about 600 B.c., by their ability to express and reason with abstract ideas. If one catches up with them he is only about 400 years behind the times in point of view, for Greek thought dominated such scientific spirit as was shown in the medieval ages, until Galileo in the 17 th century connected theory and practice through experimentation. To catch up with the present-day trend is not, however, as hard a task as these dates would seem to imply, for, if we accept the inheritance, we are heirs to the successes, not the failures and trials, of our scientific forebears.

Returning to our concrete problem we may now make a general statement. If a law ${ }^{1}$ is expressed as $Z \propto X Y$, then $Z=X Y$ if the units $(x),(y)$, and $(z)$ are so chosen that they are related as $(z)=(x)(y)$. In the case of a rectangular area, if the sides are measured in feet $(x)=1 \mathrm{ft}$. and $(y)=1 \mathrm{ft}$., hence $(z)=(1 \mathrm{ft}).(1 \mathrm{ft}$.$) or \overline{1 \mathrm{ft} .}{ }^{2}$ More generally, if the unit of length which we adopt is symbolized by $(\mathrm{L})$ the unit of area will be $(\mathrm{L})^{2}$ and the unit of volume will be $(\mathrm{L})^{3}$ e.g. $\overline{1 \mathrm{ft}}^{3}$

Starting with a chosen unit of length we derive, as a consequence of the law of area, a unit of area which is expressed in terms of our fundamental unit. Similarly, from the law of volume we derive a unit of volume which is expressed in terms of the unit of length.

In the sense of being derived from some other unit, the unit of length is not itself a derived unit. It is a fundamental unit, as we have implied above. Such

1 More generally if $Z \propto X Y$ then $Z=k X Y$, where $k$ is a factor of proportionality. This is the defining equation of $Z$ in terms of $X$ and $Y$, and $k$ depends upon the choice of units. 
units have all been more or less arbitrarily chosen. When the French, at the time of their Revolution, by adopting the metric units, laid the basis of the present system of derived units, for the measurements of all the magnitudes with which science deals, they attempted to obtain a unit which would not be dependent on an arbitrarily chosen standard, as was the English "yard," and would have a physical significance. There was thus chosen the one ten-millionth part of the distance from the equator to the pole along the meridian passing through Paris. Obviously, the determination of this distance was a matter of astronomical observations rather than of direct measurement. The distance as finally determined was marked off by two fine lines on a long platinum bar. This distance is the "meter."

As a matter of fact, later measurements showed that it is not exactly the desired fraction of the earth's quadrant. The distance is nevertheless the accepted standard of length for all scientific as well as for many commercial purposes.

Even if the meter had been the desired fraction of the earth's quadrant it would not have been a derived unit but merely a submultiple of an arbitrarily chosen length. The choice of a ten-millionth as the submultiple made a unit of convenient size, a matter of 39.37 inches or about 10 per cent more than our familiar unit of the yard. Of course, one idea in basing the length of the unit on that of the earth's surface was to obtain a unit which would be permanent and reproducible without reference to a standard if the latter were destroyed. A more logical choice of unit could be made 
to-day as a result of our greater knowledge of physical magnitudes. A secondary standard was suggested by Michelson, ${ }^{1}$ the recipient in 1907 of the Nobel prize. He suggested the wave length of light, choosing for that purpose the red light emitted by cadmium vapor when an electrical discharge passes through it. In terms of this wave length he made a remarkably accurate measurement of the meter, working, of course, with the prototype at Paris. The distance represented by the meter is, therefore, very precisely known to-day in terms of an absolutely stable physical magnitude which may be reproduced by any scientist in his laboratory.

The remaining fundamental units from which the scientist derives all the other units are those of mass and time. The unit for mass, or quantity of ponderable matter, is the gram which is the thousandth part of the kilogram. The latter was originally intended to be the mass of a cube of water, one tenth of a meter on a side, at its greatest density. Although more recent measurements have shown that it is not accurately this mass, the kilogram is the accepted standard. The unit of time, the second, has been discussed in Chapter III. The second, the hundredth part of the meter $(1 \mathrm{~cm}$.$) , and the thousandth part of the kilo-$ gram ( 1 g.) are the fundamental units for scientific purposes.

In terms of these fundamental units the other units are easily obtained when once the laws are known. Such units are said to be derived units of the C. G. S. system.

\footnotetext{
1 Cf. Michelson, "Light Waves and their Uses " Univiv. of Chicago Press, 1907.
} 
Some of them are obtained by relations of the general form $Z=X Y$, which are not physical laws but defining equations. For example, the velocity with which a body moves is the ratio of the space traversed to the time consumed. Hence the defining equation is $V=S / T$. The unit of velocity is then $1 \mathrm{~cm} . / 1 \mathrm{sec}$, or $1 \mathrm{~cm}$. per sec. as it is usually read.

Similarly if the velocity changes, that is, if the motion is accelerated, the measure of the acceleration is defined as the rate of change of velocity, and is a change in velocity (expressed in $\mathrm{cm}$. per sec.) occurring in 1 second. Of this we shall have occasion to treat more fully in the next chapter when we consider "rates."

Before doing so it may be of interest to note two illustrations of the importance of mathematics to the student of science. In the development of our knowledge of mechanics and hence of astronomy, which deals with celestial mechanics, there came a time about 1600 A.D. when further progress had to wait until new mathematical tools were developed. These tools were supplied by Newton, who invented a mathematical method of studying problems which involve motion. This is the method mentioned on page 32. Similar methods were developed independently by Leibnitz, for this was a remarkable age in mathematics.

The second illustration concerns the discovery of wireless telegraphy. In 1873 Maxwell, who was a prominent physicist, highly trained in the use of mathematical tools, announced that light was an electrical phenomenon and traveled as an electromagnetic wave. He further stated the possibility of there being other electromagnetic waves which would not produce the 
effect of light but would travel just as light waves travel.

In $1887 \mathrm{Hertz}$ verified this prophecy of Maxwell and announced the discovery of electromagnetic waves. Hertz studied their properties or characteristics. He showed how they could be produced, how they traveled through the walls of buildings and were not affected by obstacles which would completely obstruct the passage of light, and also how they could be detected, since they do not affect the eyes as does light.

In 1896 Marconi showed how these waves could be utilized for telegraphy, by inventing an antenna from which they might start out and by which they might be received.

It may look like a very long time between the three steps taken by Maxwell, by Hertz, and by Marconi. But one must remember that the problem which confronted Hertz was that of producing some waves in space which would travel like light although they were not light and so could not be detected by the human eye. Some instrument had to be devised which would act toward these waves just as the eye does toward light waves, that is, which would indicate their presence. And, after what one thought would serve for an "eye" had been made, how could one tell, if it did not work, whether the fault was with the eye or with the apparatus which was expected to produce the waves?

It is interesting to note that the three steps were taken by men whose interests and abilities in physics were perhaps not so much different in amount as in kind. Maxwell was interested in developing a complete theory, which naturally took a mathematical 
form, for explaining electricity and magnetism. He wanted to know the general principles and laws and to put them into such form that men might predict what would happen under any set of conditions which they might imagine. That he succeeded very well is evident from his contribution to radiotelegraphy. Maxwell was a "mathematical physicist."

Hertz although well trained in mathematics was a "research physicist." He was perhaps most interested in experimental attempts to extend the body of scientific knowledge. He was not immediately concerned with the application of this knowledge to the uses of mankind. He probably knew that all knowledge is ultimately of use and that his contributions to the sum total of general knowledge would interest, inform, and inspire others, some of whom might make practical applications.

Marconi was the inventor and the engineer. Without his vision of the possibilities of Hertz's discovery this new art would not have developed until some time later. He contributed some of the means for the practical application.

We notice that all three types were necessary for the complete development. Sometimes the mental qualifications are combined in one man, but in most cases a man's best ability lies along only one of these lines. If we see the importance in the progress of science of each type, we may appraise more accurately their contributions and thus avoid the popular error of attaching too much credit to the inventor or the converse academic error of failing to give him sufficient credit. 
The illustration in question indicates well the manner by which science grows, that is, by accretions or contributions. These have been made in the history of science by many men whose names have long been forgotten or, as in the case of some of the earliest discoverers, by men who probably had no names at all. Such contributions have been made by men of all races and nationalities. In the case of radio-telegraphy it is to be recalled that Maxwell was an Englishman, Hertz a German, and Marconi an Italian.

While the individual who makes any advance in science is deserving of great credit it must not be forgotten that such discoveries are rarely if ever made until the time is ripe for them, that is, until the whole body of scientific knowledge and methods has prepared the way for the discovery of genius or of accident, as the case may be. The man who actually makes the discovery is usually but a little time ahead of his foremost contemporaries.

In our illustration this is true and was so recognized, for example, by Hertz. In the preface to the collected papers on his work, which were published some years later, he generously but truly states that if he had not happened to make the discovery, some other scientist would have done so shortly. He mentions Lodge, the English scientist, who was then working along somewhat similar lines, as most likely to have made the advance. 


\section{CHAPTER XI}

\section{RATES}

WHEN one speaks of the speed of a passing automobile as so many miles, say thirty, per hour, he is expressing his estimate of an instantaneous rate, for he does not mean that the machine will travel thirty miles in the hour but that at the given instant its motion is such that a continuance at this rate would result in this displacement. The estimate is the result of previous experiences, conscious or otherwise, in estimating distances and times. Although the observer does not make actual measurements of these two magnitudes and then perform an arithmetical operation upon them, the method is fundamentally that which was applied in the "speed traps" of the earlier days of automobiles. In such traps two observation stations were established along the roadway at measured distances apart and telephone connections were provided between the observers. The time consumed by any machine in traversing the known distance could then be obtained and hence the speed in miles per hour, by taking the ratio of the distance in miles to the time in hours.

The method admitted of a determination only of the average speed through the trapped distance. Stories were told, therefore, of drivers who astonished the 
observers by speeding past their posts, but, because the machines were slowed down in the intervening distance, the actual figures indicated compliance with the law. The average speed was only necessarily the actual instantaneous speed at each observation post in case the car traversed the entire distance at a uniform rate. By shortening the distance for which the car is timed a result more nearly approximating the actual speed at either post is obtained, but this is because in the correspondingly reduced time only a negligible change in speed can occur, and hence the observer is dealing with an essentially uniform speed throughout the measured distance.

The general method which is indicated for obtaining the actual, that is, instantaneous, speed at any point on the path of a moving body is as follows: Establish an observation station at the point in question and a second station as near as possible ${ }^{1}$ to the first. Observe the time required for the body to traverse this distance and find the ratio of the distance to the time.

We recognize that this method requires that we shall go the limit in reducing the separation of the two stations. Now, our observations are separated not only in space but also in time, and it is usual to empha-

${ }_{1}$ Of course, in practice other sources of error than the change in velocity must be taken into account. The first source of error occurs in the observation of the coincidences of the moving body with the two reference points, and the second is found in the measurements of the distance and the corresponding time interval. Whatever means we may employ we only approximate the magnitude, and hence in exactness we should always express each measured magnitude as a definite amount, plus or minus a limiting error. 
size the latter separation by saying that we measure the distance traversed between two points in time. The ratio of the distance to the time interval is the average velocity. As the time interval is reduced this ratio becomes more and more nearly representative of the instantaneous rate. Its value, in other words, approaches the value of the instantaneous rate as a limit, while the time interval is caused to approach zero as a limit.

As the time interval between observations is reduced the distance traversed is also reduced. The fact that both the numerator and the denominator of the ratio are thus made "infinitesimals" does not mean that the ratio may not have a perfectly definite and finite value. Of this idea, that a ratio of two magnitudes may be finite even though the magnitudes concerned are physically very small, we have previously had an illustration in our comparison of the distance ratios in the solar system to the distance ratios of the electronic systems of molecules. Physically speaking, with reference to the diameter of the earth the diameter of an electron is infinitesimal. To a mathematician, however, an infinitesimal is an abstraction, representing a quantity indefinitely small, which approaches zero as its limiting value.

The fundamental ideas involved in the concept of a rate are conveniently illustrated also in the case of the slope or grade of a road. Such a slope is usually expressed as a ratio of the vertical distance to the corresponding horizontal distance, e.g. as a two per cent grade. It is obviously the rate at which one ascends with respect to his horizontal displacement. 
The analytical processes, involved in the study of rates, follow from a consideration of this case.

In Fig. 9 is given the cross section of a road. Axes, $\mathrm{OH}$ and $\mathrm{OV}$, permit the expression of the location of any point of the road with reference to their intersection. For convenience we shall denote distances measured along $\mathrm{OH}$ and $\mathrm{OV}$ by $H$ and $V$, respectively. Corresponding to any chosen

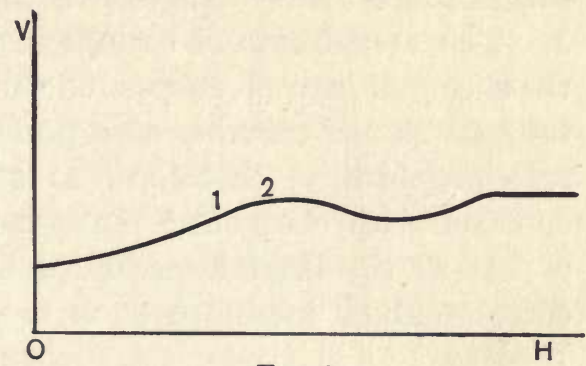

FIg. 9. value of $H$, or, as we may say, to any value which $H$ may assume, there is a value of $V$ which satisfies the condition that the point determined by these "coördinates" lies on the curve representing the road. In

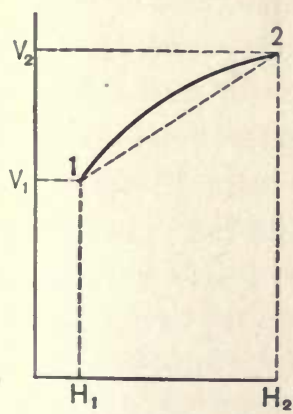

Fig. 10. other words, as $H$ varies, $V$ also varies, being dependent for its value upon $H$. It is usual, therefore, to say that $H$ is an independent variable and that $V$, the dependent variable, is a function of $H$. In the particular case shown in the figure it is evident that the slope varies from point to point, that is, that the slope itself is a function of $H$.

Between any two points, as 1 and 2, represented in the enlargement of Fig. 10 by the coördinates $H_{1}, V_{1}$, and $H_{2}, V_{2}$, respectively, the average slope is the 
quotient of $V_{2}-V_{1}$ and $H_{2}-H_{1}$. This is evidently the slope of the dotted line extending from 1 to 2 . As the point 2 is chosen closer to 1 (that is, as the increment, $H_{2}-H_{1}$, approaches zero), the dotted line becomes more nearly tangent to the curve at the point 1. The actual rate of change of $V$ with respect to $H$, therefore, at any given point is the average slope of a tangent to the curve at this point. We may find the rate graphically, therefore, as accurately as we can construct the tangent. ${ }^{1}$ In general, we may define a rate as the limit approached by the ratio between corresponding increments, in the dependent and in-

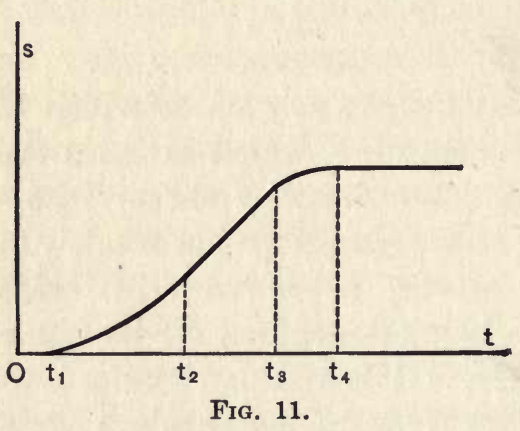
dependent variables respectively, as the increment of the latter approaches zero.

In this particular case of the slope of a road the variables are both distances, which are measured and plotted with reference to a common reference point. A similar plot may be made for a case involving unlike variables, e.g. that of the moving automobile. For this we must assume reference points both in time and in space. Corresponding to any time, say $t$, subsequent to our assumed zero of time, the auto-

1 Analytical methods of absolute accuracy are possible if the form of the function, which one variable is of the other, may be expressed in symbols. The methods are those of the calculus. For example, in a function like $s=a t^{2} / 2$ the rate of change of $s$ with respect to $t$ (usually symbolized as $d s / d t$ ) may be shown to be at. 
mobile would be separated by a distance $s$ from the reference point in space. A plot may, therefore, be constructed as in Fig. 11. The rate of change of position with respect to a change in time, that is, the speed of the car, is given at each instant of time by the slope of a tangent to the corresponding point of the curve. It is therefore evident that for the concrete case of the figure the car is originally at rest and so remains until a time $t_{1}$ has elapsed. At a time $t_{2}$ the maximum speed is attained. This speed is maintained until $t_{3}$, following which the car is brought gradually to rest at $t_{4}$. It remains at rest for the balance of the time indicated by the plot.

This slope, involving unlike magnitudes, may be termed a physical rate as distinct from the geometrical rate, illustrated by the slope of a road. The only difference is that of units, for geometrical rates are pure numbers but a physical rate is expressed by a numeric and a compound unit. Thus the unit of speed is the quotient of unit length and unit time, e.g. $1 \mathrm{~cm} . / 1 \mathrm{sec}$.

The most familiar rates of everyday life are those of speed and interest, both time-rates, if we name them for their independent variables. For the scientist, of course, there are as many different kinds of rates as there are physical magnitudes which may be considered independent variables. For example, he may be concerned with a rate of expansion with respect to temperature, with a rate of increase of electric current with electromotive force, or with a rate of change of energy with respect to space. In the following chapter we shall see how force is a space rate of change 
of energy. For that discussion we shall need a relationship between the velocity acquired by a body which is uniformly accelerated and the space over which it passes.

The scientist uses the word "velocity" to represent speed in a definite direction. For example, a point on a uniformly rotating wheel is moving with constant speed, but its velocity is constantly changing, for the direction of motion is constantly changing. If we are dealing, however, only with motion in a straight line, velocity and speed are identical. Just as velocity is defined as the time-rate of change of position, so acceleration is defined as the time-rate of change of velocity. (In the illustration of the rotating wheel it is evident that each point is constantly accelerated toward the center.)

The simplest case for analysis is that of a body moving with constant velocity. If the velocity is $v$ it will travel in a time, $t$, a distance, $s$, such that $s=v t$. If the velocity is not constant the simplest case occurs when the acceleration is uniform, that is, when the velocity increases the same number of units of velocity in each unit of time. Let $a$ represent the acceleration, then if the initial velocity is zero the velocity at the end of $t$ seconds is expressed as $u=a t$. (In general, ${ }^{1}$ if the initial velocity is not zero but is $v_{0}$, then the velocity at the end of $t$ seconds is $v=v_{0}+a t$.)

Because the velocity increases uniformly it follows that the body is moving with its average velocity at

1 In an ordinary elementary course in physies there occur about twenty physical relations which are entirely analogous to this expression and are represented by similar equations. 
the middle of the interval, $t$, and also that for each instantaneous velocity below this average there is a corresponding velocity equally above the average. So far as concerns the total distance traversed in the time $t$ the result is the same as if the body moved with a uniform velocity, $\bar{v}$, equal to the average value. Consider then the case of a body uniformly accelerated from rest. The average velocity is half the sum of the initial and final velocities, that is $\bar{v}=a t / 2$. The distance traversed is $s=\bar{v} t$ and hence $s=a t^{2} / 2$. (For example, in the case of a body falling freely from rest the acceleration is of value " $g$ " and $s=g t^{2} / 2$.) The distance is therefore proportional to the square of the time.

For our later purposes, however, we wish to express the relation between the total space traversed and the final velocity which the body has acquired. This velocity is $v=a t$ and hence $t=v / a$. Substituting $v^{2} / a^{2}$ for $t^{2}$ in $s=a t^{2} / 2$ gives $s=v^{2} / 2 a$ or $v^{2}=2 a s$, as the desired relation. The distance, therefore, increases as the square of the velocity.

The three relations for free fall from rest, namely, $v=g t, s=g t^{2} / 2$ and $v^{2}=2 g s$ were derived by Galileo, whose experiments from the leaning tower of Pisa were more spectacular but less fruitful in scientific development than those of his other methods. His study followed the line of assumption and experimentation. Several assumptions he disproved himself by further analysis before he hit upon the correct one, for in his day acceleration was unknown and its concept is due to him. Starting, finally, with the assumption that if two bodies are allowed to fall from rest, one, 
falling for twice the time of the other, will acquire twice the velocity, he formulated the necessary relations for $s$ and $t$. He had to deal with $s$ and $t$ instead of $v$ and $t$ because he had no means for measuring instantaneous velocities. His reasoning has been followed in the preceding analysis, where it was shown that the total distance traversed should be proportional to the square of the time during which motion occurs.

This conclusion from his fundamental assumption he set himself to test. Clocks and chronographs were, of course, unknown and only water clocks or sandglasses were available. With such crude devices it would ordinarily be impossible to determine the time of descent of a freely falling body with sufficient accuracy to check the conclusion. He sought first, therefore, to retard the descent so that it might be more accurately observed. For this reason he studied the motion of balls rolling down grooves in an inclined plane. A further assumption was therefore required to the effect that the form of the relationship between $s$ and $t$ would not be altered. Measuring distances from the upper extremity of the plane he marked off lengths of $1,4,9$, and 16 arbitrary units. The corresponding times of descent should be found to be as $1,2,3$, and 4 .

He next sought an improvement in methods of timing. For the means he used a vessel of water, with a large transverse area, in the bottom of which there was a minute orifice which he could close by his finger. Such a vessel will have a practically constant "pressure head" while a small amount of water is being discharged, and hence the weights of water 
discharged will be proportional to the time of flow. ${ }^{1}$ With this apparatus he confirmed his assumptions.

Further studies by Galileo of the kinematics of uniformly accelerated bodies contributed much to that base of accumulated knowledge upon which his successors, and especially Newton, built the classical system of mechanics. The modern concept of energy upon which science rests to-day was frequently approached but apparently never firmly grasped by these natural philosophers. For example, Galileo studied the relations which must subsist between free descent and motion on an inclined plane. As he had shown previously, the velocity of a freely falling body is increased proportionally to the time of descent. He therefore reasoned that if its direction of motion should be reversed at any instant, as by a reflection, the velocity would then be diminished proportionally to the time of ascent. The body should, therefore, rise through the same distance as it had previously fallen. If, then, a body is allowed to roll down an inclined plane and up another it cannot rise to a point higher than that from which it started. In the limiting case it will just attain this height. If it could exceed this height it would be possible to arrange inclined planes so as to effect the elevation of bodies by gravity alone. The velocity acquired in frictionless descent along an inclined plane depends, then, only upon the

${ }^{1}$ It was Torricelli, somewhat later, who perceived the analogy between freely falling bodies and the flow of liquids under a gravity feed. He showed that, neglecting all frictional resistances, the velocity of efflux from an orifice, a distance of $h$ below the surface, is given by $v^{2}=2 g h$. Hence if the head, $h$, is constant the velocity is constant and the discharge is proportional to the time. 
vertical height and not upon the slope of the plane. As Mach $^{1}$ points out there is contained in Galileo's assumption "the uncontradictory apprehension and recognition of the fact that heavy bodies do not possess the tendency to rise but only to fall." The ideas involved, however, are really those of energy, for obviously the energy acquired in falling must be equal in a conservative system to the gain in energy which would be consequent to a reversal of the displacement.

1 Mach, "Science of Mechanics," pp. 134 et seq. 


\section{CHAPTER XII}

\section{FORCE, A SPACE RATE OF ENERGY}

IN our earlier discussion we have used the word "force" without definition, since we all have a concept acquired by our own muscular experiences. The physicist, however, has given to this term a technical meaning. Thus as one of the definitions in the Century Dictionary there is "the immediate cause of a change in the velocity or direction of motion of a body." This concept originated in 1647 with Newton, who stated three fundamental laws as to the motion of bodies, which he had deduced from the facts of astronomy and from various experiments. His first law says that "every body continues in a state of rest or of uniform motion in a straight line except in so far as compelled by force to change that state." This statement defines force, and implies a characteristic of all bodies, inertia. Bodies are inert.

That this statement of Newton is really a law we all believe although we cannot prove it. We know that bodies at rest remain at rest unless they are forcibly moved and that it requires force to change the direction of motion of a body. As to the idea that a body would continue in uniform motion in a straight line if no force were exerted upon it we have no proof. If we start a body it comes to rest, sooner 
or later, because of the "frictional forces." If the friction is reduced the body maintains a state of motion for a longer time. We, therefore, reason that if all opposing forces could be removed the body would continue to move with uniform velocity.

This law was stated about two centuries before the reality of energy had been recognized. Changes in energy are the concomitants of changes in motion and to-day many scientists consider the former to be the causes of the latter. We have seen that energy may be either potential or kinetic and also that decreases in potential energy result in increases in kinetic energy or vice versa.

A body in motion or one at rest will have the same kinetic energy indefinitely unless it acquires more at the expense of some source of energy or unless it imparts its energy to other bodies or to parts of itself. The latter happens when there is friction, for the body then transfers some of the kinetic energy, which it has as a bulk, to its own and adjacent molecules.

A moving body is retarded if its motion is in such a direction as to increase the potential of the system which it forms with another body. As a body which is thrown into the air moves away from the earth the potential energy of the system increases. The kinetic energy of the body is thus converted into potential energy, and at the instant when the conversion is just completed the body is at rest. ${ }^{1}$ It then falls and the

1 Of course, if the kinetic energy is greater than the greatest amount of potential energy which the body can add to the system by moving to any distance whatever, then it cannot thus come to rest. This is the case for comets. 
potential energy is in turn converted into kinetic energy.

During the centuries, however, which followed Newton and before the modern ideas of energy were accepted, the word "force" in the Newtonian sense became firmly fixed in scientific language. Thus scientists to-day speak of frictional forces as if these were the causes of the slowing down of a moving body even though they realize that changes in the form and location of its energy are the real causes.

In the case of the gravitation of bodies toward the earth we still speak of the "force" of gravitation instead of saying that the earth and any other body form a system, the potential energy of which decreases as they approach one another. The reader will find this phenomenon almost always described in terms of force as a cause. In part this is due to the form in which Newton expressed his so-called Law of Universal Gravitation. This states that any two bodies (or strictly "particles") attract each other with a force which is proportional to the product of their masses and inversely as the square of the distance between their centers. ${ }^{1}$ If Newton had lived after the Principle of the Conservation of Energy had been accepted it is quite probable that he would have expressed his law of gravitation in terms of energy instead of force. Later we shall see how nearly he came to recognizing

${ }^{1}$ If the masses are $m_{1}$ and $m_{2}$ and the distance between centers is $r$, then the force, $f$, is

$$
f \propto \frac{m_{1} m_{2}}{r^{2}} \text { or } f=\frac{k m_{1} m_{2}}{r^{2}}
$$


in his third law of motion the idea of the conservation of energy.

The Law of Universal Gravitation may be stated as follows: Any two bodies form a system the potential energy of which tends to decrease and is always less than it would be if the bodies were infinitely far apart by an amount proportional to the product of the masses and inversely as the distance between centers. Thus let $P_{\infty}$ represent the potential energy when the bodies are at an infinite distance from each other, and $P_{r}$ the potential energy when they are separated by some finite distance, $r$. Let $m_{1}$ and $m_{2}$ be the masses of the two bodies, then

$$
P_{r}=P_{\infty}-k \frac{m_{1} m_{2}}{r}
$$

where $k$ is a factor which reduces $\frac{m_{1} m_{2}}{r}$ to the same units as are used in expressing $P_{r}$ and $P_{\infty}$.

As a special case consider a body of mass $m$ resting on the surface of the earth. Represent the mass and radius of the earth by $M$ and $R$ respectively. Then the potential energy of the system is

$$
P_{R}=P_{\infty}-k \frac{M m}{R}
$$

If the mass $m$ is raised a distance $x$ above the surface the distance $r$ of equation (2) is no longer $R$ but is $R+x$, and hence

$$
P_{R+x}=P_{\infty}-k \frac{M m}{R+x}
$$

The increase in potential energy occasioned by raising the body is found by subtracting (3) from (4) thus 


$$
P_{R+x}-P_{R}=\frac{k M m}{R}-\frac{k M m}{R+x}=\frac{k M m}{R}\left(\frac{x}{R+x}\right)
$$

Now $R$ is about 3960 miles. If we are concerned only with separations which are small as compared to 3960 miles we have $R+x$ approximately equal to $R$ and hence we may obtain from equation (5) an approximate ${ }^{1}$ value.

$$
P_{R+x}-P_{R}=\frac{k M m x}{R^{2}}
$$

It follows that near the surface of the earth the increase in potential energy is directly proportional to the increase in separation. Dividing this increase by the distance $x$ we obtain as the rate ${ }^{2}$ at which the p.e. increases with distance, $k M m / R^{2}$. In other words, the p.e. of the system formed by the earth and a mass $m$ increases $k M m / R^{2}$ energy units for each unit of length by which the separation increases.

Now the earth is an oblate sphere with its larger radius at the equator. Raising a given mass a given distance would produce a smaller increase in p.e. at the equator than at the poles since $R$ would be greater at the equator. In general the change in p.e. corresponding to the vertical movement of one gram through one centimeter, will depend upon the region of the earth's surface where this displacement takes place. The gravitational unit of energy, the gram

${ }^{1}$ For example if $x$ is 1 mile the increase in potential energy as given by equation (6) is about one quarter of a per cent larger than as given by (5).

2 The space rate of change of p.e. is then of the form $\frac{k m_{1} m_{2}}{R^{2}}$ which is the foree according to Newton's definition. Cf. footnote p. 141. 
centimeter which we used in Chapter IX, is consequently not invariable. We need an absolute unit, and we shall now derive it from the three fundamental units of length, mass and time.

Since the p.e. which is available for conversion into kinetic energy when 1 gram falls $1 \mathrm{~cm}$. depends upon the locality, the k.e. which is acquired is similarly dependent. If a gram in falling $1 \mathrm{~cm}$. acquires a greater k.e. in one locality than in another it must also have acquired a greater velocity. That is, it is accelerated more and the value of $g$ should be higher. Let us therefore measure energy in such a unit that the numeric expressing $1 \mathrm{gram}-\mathrm{cm}$. shall be proportional to the acceleration at the given locality. We have already seen that the increase in energy is proportional to the total distance traversed and to the mass of the displaced body. Hence, let us write as the defining equation of the unit of energy

$$
W_{s}-W_{o}=\text { mas }
$$

when $W_{o}$ is the initial energy of a body of mass $m$ which, after traveling a distance $s$ with a uniform acceleration of $a$, has a final energy $W_{s}$.

We now apply the method of Chapter $\mathrm{X}$ by placing $m=1 \mathrm{gram}, s=1 \mathrm{~cm}$., and $a=1 \mathrm{~cm} . / 1 \overline{\mathrm{sec}}^{2}$, then $W_{s}-W_{o}$ is one unit of energy. Unit energy is that expended upon (and hence that acquired by) 1 gram in moving $1 \mathrm{~cm}$. with an acceleration of $1 \mathrm{~cm}$. per sec. per sec. This unit is so frequently used that it has been given a convenient name, viz. the "erg" from the same Greek root as "energy."

If $a$ in equation (7) has the special value of $g$ then 
for $m=1 \mathrm{~g}$. and $s=1 \mathrm{~cm}$. the change in energy is $g$ ergs. Since $g$ is about $980 \mathrm{~cm}$. / $\overline{\mathrm{sec}}^{2}$ it follows that 1 gram-centimeter is about 980 ergs. $^{1}$

Considering equation ( 7 ) we see that

$$
\frac{W_{s}-W_{0}}{s}=m a
$$

states the rate at which the energy changes as the separation $s$ is altered. This space ${ }^{2}$ rate of change of energy is defined as the force. The unit of energy being the erg, the unit of force is $1 \mathrm{erg}$ per $\mathrm{cm}$. This unit is called the "dyne" from the root which we recognize in our word "dynamic." It is also evident that the dyne is the force which will accelerate $1 \mathrm{~g}$. unit amount, that is, change the velocity unit amount ( $1 \mathrm{~cm}$. per sec.) each second.

According to this definition forces are called into

1 A pound is $454 \mathrm{~g}$. and a foot is $30.5 \mathrm{~cm}$. It therefore follows that $1 \mathrm{ft}$. lb. of work is (980) (454) (30.5) or $13,600,000$ ergs. The erg is obviously too small a unit for practical purposes. A multiple known as the "joule" and equal to ten million $\left(10^{7}\right)$ ergs is therefore used.

${ }^{2}$ Distinguish between the space rate of energy, which is force, and the time rate, which is power.

Frequently we are interested in the time rate at which energy is expended. The unit of $1 \mathrm{erg}$ per second is inconveniently small and the practical unit of one joule per second is known as the watt. A thousand joules per second ( $\left.10^{10} \mathrm{ergs}\right)$ is the kilowatt, which is familiar to all purchasers of electrical energy. In the 3600 seconds of an hour during which energy is received at the rate of 1 kilowatt there is received a total of 3.6 million joules or 36 million million ergs. In such units one's household consumption of electrical energy appears enormous. It might be noted, however, that the energy released by the combustion of one pound of coal (and the necessary air) is about 13 million joules or enough for almost $4 \mathrm{kw}$. hrs. if there were no dissipation in the transformation. 
play only when changes occur in the energy of a system, either in its total amount or in its kind or location. From this viewpoint a table does no work in keeping a book from falling, for there is no change in the energy of the book and the ground and hence no force is exerted by the table. The difficulty in which this definition of force involves us is obvious. The trouble, however, is not due to our present definition but to the fact that our scientific language lacks as yet adequate terminology. What we actually do is to use the word in the above rigorous sense and also in the less technical sense of our earlier chapters.

We recognize that if the supporting table is withdrawn the book will fall and a force will be exerted in accelerating it. But the book falls not because of a force but rather because of the partial conversion of its potential energy into kinetic energy. We do not as yet know why such a change in energy occurs but it is a phenomenon of nature that it does unless some obstacle like the table intervenes. We have no word to express this. idea, although the word "tractate" has been proposed.1 Similarly "pellate" has been suggested to describe the natural motion of bodies away from each other. For example, like electrical charges pellate, unlike tractate.

In the case of a falling body $m g$ dynes is the force exerted when it falls freely. (This follows at once from equation (8) by substituting $g$ for $a$.) If the energy released as it falls is not available for acceleration then the space rate of change of the energy available

${ }^{1}$ By Frederick Soddy in "Matter and Energy," Holt, Home Univ. Library, pp. 110-111. 
for accelerating the body will be less than $m g$ and may even be zero, as was the case in the experiment of Joule described on page 112 . The value $m g$ is thus the maximum force which can be called into play by allowing the potential energy to decrease. This maximum force which a body can exert in free fall is called its weight. The weight of 1 gram is then $g$ dynes, or approximately 980 dynes, depending upon the locality.

This inexact use of the word "force" as meaning "weight," that is, the maximum space rate at which energy will be released if gravitational tractation is allowed, persists in the language of physics. There is no serious objection to this use provided that it does not encourage an attitude of considering force as a cause instead of a rate. Energy is the cause in terms of which we must seek to explain all physical phenomena.

The rigorous quantitative meaning which modern physics has given to "force" leads to the same numerical measure as Newton selected and stated in his second law. This law says that "rate of change of quantity of motion is proportional to the force and takes place in the straight line in which the force acts." Today "quantity of motion" is called "momentum." It is measured by the product of mass and velocity. Since only the velocity changes and since the rate of change of velocity is acceleration, the rate of change of momentum is the product of mass and acceleration. From equation (8) it is evident that the two definitions are equivalent, for the left-hand member expresses our present definition and the right-hand the Newtonian definition. 
Newton recognized that the change in the momentum of a body, which takes place when it is acted upon by a force, is merely one aspect of the phenomenon. He reached a conclusion, partly by experiment and partly by inference, that in all such cases an equal and opposite change in momentum must occur in some other body. ${ }^{1}$ As he stated it in his third law of motion: "Action and reaction are equal and opposite; or in other words, the mutual actions of two bodies are always equal and oppositely directed." We recognize this fact in such cases as that of a man jumping from a. small boat. As the man jumps forward, he kicks the boat backward. The man and the boat are put into motion in opposite directions. According to Newton, the momentum of the man, that is, the product of his mass and his velocity, is equal to the momentum of the boat. If, then, the boat has a large mass it will acquire only a small velocity. If its mass is very large

'It is therefore usual to say that there is a "conservation" of momentum. The use of the term is unfortunate, particularly in elementary textbooks, for it implies that momentum is an indestructible in the same sense as is energy. To readers who remember the emphasis in such texts it may have appeared that momentum is a reality like energy. The principle of the conservation of momentum is a recognition of the characteristic inertia of matter which is implied in Newton's first law of motion. The parts of a system cannot of themselves alter the location of their center of mass. For example, at any instant after the explosion of a shell the configuration of the fragments will be such that their center of mass occupies the position in space which the center of mass of the shell would have occupied at that instant if the explosion had not occurred. The principle is equivalent to that of the "conservation of the center of mass." Both are implicit consequences of inertia, the distinctive quality of bodies which may acquire kinetic energy. Momentum is not, therefore, to be considered a reality in the sense in which the word has been applied to matter and to energy. 
as compared to that of the man this velocity may well be both imperceptible and negligible.

That actions occur in pairs, equal and opposite, we recognize in our daily acts. Thus if one wishes to exert a force he braces himself against some firm backing, that is, something of such mass that the momentum he imparts to it will produce but a negligible velocity. The firmest backing is, of course, the earth. Its mass is so large that any motion which we can impart to it, as for example by shooting a shell from a howitzer, is so small that we frequently overlook the fact that the action is similar to that of the man jumping from the boat.

Consider the stresses in the case of a man lifting a mass from the earth. As he pushes up he also pushes down on the earth. There are then two pairs of mutual actions, namely those between the man and the mass and those between the man and the earth. The man pushes up on the body, its reaction is down on him. He pushes down on the earth, which reacts on him, pushing up. These actions and reactions are represented in Fig. 12 by the arrows.

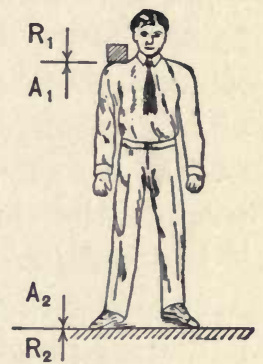

Frg. 12.

We may consider either force of a pair as the action and the other as the reaction. Thus in the present figure we consider $A_{1}$ to be the action of the man on the body and $R_{1}$ to be its reaction on him. We are thus viewing the action from the standpoint of the man. On the other hand, consider the crushing effect of the weight which the man is trying to support. We now 
view $R_{1}$ as the action and $A_{1}$ as the man's reaction. Which one of a pair we consider the action is merely a matter of point of view.

When we consider the forces $R_{1}$ and $R_{2}$ of the figure we notice that the man is subjected to equal and opposite forces. This pair of equal and opposite forces also constitute a stress. Similarly the forces $A_{1}$ and $A_{2}$ constitute a stress. The man is exerting a pair of equal and opposite forces, in other words, a stress. From the other point of view he is subjected to a stress. In all cases of the mutual actions of bodies stresses occur.

For bodies at rest this idea is very evident when described in terms of force with the loose meaning which we have discussed above. Thus a body at rest on a table acts downward on the table and is supported by the upward reaction. When, however, a body in motion is considered, the idea meets an instinctive objection on one's part. Thus one says, "But if A pushes B away, must not A push harder than B? If the reaction is just equal to the action, why doesn't it just balance it and prevent any motion?"

Consider first the case of a man acting on a bowling ball instead of upon another man. If the ball is of small mass it does not require as great an action upon the man's part to give to it a definite acceleration. In fact, neglecting air friction, the force which he is conscious of exerting depends upon the mass and acceleration. These determine the resistance which his arm meets in swinging the ball. If it was a gun which was shooting the ball, the reaction of the ball on the gun would be evidenced by the recoil. Why is there no 
recoil to the man as the ball leaves his fingers? Obviously because he serves only as a medium which transmits the reaction of the ball to the earth.

The action of the man is upon the ball and its motion depends only upon its mass and the force which he exerts. Similarly the reaction of the ball on the man is not a matter which has a further concern with the motion of the ball. If there were no stress between the man and the earth his momentum would be equal and opposite to that of the ball. Whether he takes up the momentum himself or merely transmits it to the earth does not alter the equality of the action and the reaction.

Now consider the case of $\mathrm{A}$ pushing upon $\mathrm{B}$, who in turn braces against the ground. As long as B's body will stand the stress, to which it is subjected between A and the earth, there is no motion. When it will no longer, or when his feet slip, then he moves. So far as his motion is concerned he is to all intents and purposes a bowling ball. His reaction on A makes no difference whatever in his own motion, although it will determine the motion of A unless the latter succeeds in imparting it to the earth. That this is so, is readily to be grasped in case one pictures A and B as engaged in their struggle on a polished frictionless floor. Then if A grasps B he may thrust the latter away from himself. As he does so, however, there is a reaction of $B$ on him. The result is that both $A$ and $\mathrm{B}$ move with equal momenta but in opposite directions exactly as in the case of the man and the boat. If the floor does not have a negligible friction the heavier man, of course, has the advantage, for he will transmit 
to the earth more of his momentum than will the lighter man.

Newton demonstrated the equality of the components of a stress as follows. He floated two bowls in a large vessel of water. In one was a magnet and in the other a piece of iron. The magnet attracts the iron. The iron reacts on the magnet. The two bowls, therefore, float together. If, however, the action is greater than the reaction the magnet will keep pulling the iron along and the combination will move Conversely, if the reaction is greater the two bowls will move in the opposite direction. Since neither bowl propels the other, action and reaction must be equal and opposite.

If one could propel the other there would be a violation of the principle of the conservation of energy. We could arrange a circular water path and allow the magnet to propel the iron around this path. Connecting the rim of a wheel to the magnet, we could obtain useful work. The result would be a "perpetual motion" machine.

Perpetual motion machines are those which will do useful work without requiring that at least an equal amount of work shall be done upon them, that is, machines which will create energy. In the early days of experimental science there were many seekers after a machine of this type, and ingenious were the fallacies by which they persuaded themselves that their designs followed known laws of physical science. While the search was fruitless, the experimentation served some purpose in advancing science just as did the equally fruitless search of the alchemists.

To that master philosopher, Newton, such quests 
seemed futile, for he stated as a scholium to his third law what we know to-day as the "work principle." What he said may be expressed in our modern terms as follows: "In any machine or combination of machines the work of the acting forces is equal to the work of the resisting forces." If we understand the "work of resisting forces" to include not only the useful work but also the work done against frictional forces, we have a statement conforming to our present ideas of energy.

To-day the goal of the scientist is not an impossible perpetual motion machine but rather the efficient utilization of the available energy of the universe and that increase in availability which may follow further knowledge as to the composition of matter. Scientifically the aims are radically different, but socially they are identical, for in both cases the aim is to lift man above the struggle for existence.

To understand more fully the present limitations which the scientist encounters in making available for man some of the untouched sources of energy in the universe, we need to consider the energy of molecules and electrons. In so far as the energy they possess is potential we are in ignorance of its very existence except in those cases where we have already learned to release it, as in various chemical or electrical actions. In so far as it is kinetic energy we may measure its amount even in cases where we do not as yet know how to utilize it. On the part of the molecules of a substance such a measurement is possible because the energy is manifested as heat.

The kinetic energy of translation of any body may be expressed in terms of its velocity and its mass. 
From equation (7) we see that the energy expended in accelerating a body of mass $m$ is mas. For as we may, however, substitute $v^{2} / 2$ from the equation $v^{2}=2 a s$, which was derived on page 135 . Hence the energy due to translation is $m v^{2} / 2$, where $v$ is the velocity at the moment of our consideration. This important relation is entirely general and is applicable to moving molecules. 


\section{CHAPTER XIII}

\section{MOLECULAR MOTIONS AND TEMPERATURE}

IN any of the three forms, solid, liquid, or aëriform, in which we are familiar with matter, we now know that the molecules are in rapid motion. In solids under normal condition the molecules do not move beyond the bounding surfaces of the body. In liquids moving molecules may escape from the surface, as in the familiar case of the evaporation of water from an open vessel. The molecules which have escaped move about in the space above the vessel, unrestricted except for such other surfaces, liquid or solid, as may be in the neighborhood. For all substances which are in an aëriform state such unrestricted motion of the molecules is characteristic.

The molecular motions of the latter state are comparable to those of the gnats in a swarm, such as one sometimes meets of a summer evening in the space below a street lamp. Their motions are haphazard and irregular. Individual gnats approach or recede from one another, flying now in one direction and now in another. They picture to us fairly well the natural motions of individual molecules. The entire swarm may be given a motion in the same direction, as by waving them aside with a paper. Even when they have such a motion as a group, they still have their 
irregular natural motions. In the case of wind the motions of the molecules of the air are similar in that they consist of these natural haphazard motions and of a forced motion, essentially the same for all the molecules, which is superimposed upon the natural motion.

If one thrusts a paper into a swarm of gnats he will recognize that, at whatever angle he may hold it, there will be about as many gnats striking it each moment, for at any instant in their haphazard motions there are about as many flying in any one direction as in any other. Imagine the gnats to be inclosed in a box. There should be about as many striking any square centimeter of its inner wall in a second as there are striking any other equal area. Their impacts, therefore, should exert the same pressure on all the containing walls. That a large number of such small blows produces the effect of a steady force is well illustrated by the force exerted on an umbrella by the raindrops of a heavy summer shower. About the same number strike each second, and the umbrella must be supported against a constant force.

Suppose that the volume of the box is halved by pushing the cover down and thus crowding the gnats closer together. They continue to fly as before, but the distance between top and bottom is only half as great, and therefore they require but half the time to make the trip. There should then be twice as many impacts per second as before, and the pressure on the top and bottom should be doubled.

The area of the sides of the box has been reduced to one half by decreasing the height. Since for each 
side there will be the same number of impacts per second as before, the number on each unit of area and hence the pressure on the sides, also, will be.doubled. We notice, then, that as the volume is halved the pressure is doubled; in other words, the pressure exerted by the moving gnats and the volume of their container will vary inversely, exactly as Boyle found was true for a definite volume of air.

Suppose that we keep the volume constant but introduce an additional number of gnats. If there were originally $N$ gnats, or rather let us say molecules, and this number is increased to $N^{\prime}$ then the number of impacts occurring each second should be $N^{\prime} / N$ times as many as originally. The pressure will be proportionately increased. Thus, if it was initially $P$ it will be $P^{\prime}$, where $P^{\prime} / P=N^{\prime} / N$. Let $V$ be the volume. It has not changed while more molecules were added. If we now increase the volume until the pressure is restored to its original value of $P$ we shall find the new volume, $V^{\prime}$, to be greater than $V$ in the same proportion as $P^{\prime}$ bore to $P$. Hence we have $V^{\prime} / V=N^{\prime} / N$. Therefore, equal volumes at equal pressures will contain equal numbers of molecules. Or, in general, if the volumes are equal, the pressures will be directly as the number of molecules. Similarly, if the pressures are equal, the volumes will be directly as the number of molecules.

Consider again the original illustration of a swarm of gnats. A person with poor eyesight who failed to see the swarm might, nevertheless, feel the pressure of their impacts. Suppose that some light object, larger than a gnat, as for example a small bit of very thin tissue 
paper, was thrown into the swarm. It wouldn't fall very quickly, for it would be buffeted first one way and then another, now up and now down, by the impacts of the various gnats which collided with it. Such a piece of paper might be made so small that only rarely would two or more gnats happen to collide with it simultaneously. The observer while unable to see the gnats would then see this paper moving in space, irregularly and jerkily, as it was jostled by individual gnats.

Now this is almost what actually happens in the case of molecules. The human eye is adapted by ages of evolution to see large objects which are of interest to human beings. Even with the aid of the best possible microscope it can never see directly objects smaller than a certain definite size determined by the color of light with which they are illuminated. This size is, however, much larger than the largest known molecule. In 1827 a botanist, Robert Brown, observed through the microscope the continual movements of some minute particles which were suspended in the liquid which he was examining. The movements of small bodies due to the impacts of molecules are, therefore, known to-day as "Brownian Movements." For years no use was made of this discovery, although the bacteriologists learned to distinguish between these movements of small suspended particles and those of the bacteria for which they were searching with microscopes. In recent years many very important ideas as to molecular movements and also as to electronic movements have been obtained by applications of this phenomenon. 
Although the Brownian movement enables scientists to observe by their effects the actions of individual molecules and has thus extended our knowledge of molecular physics, we shall direct our present attention to the average behavior of a large number of molecules. In other words, we shall treat the problem which these haphazard motions present according to what is called the "statistical method." You know, for example, that if you flip a coin it is just as likely to be "heads" as "tails." There are only two possible "events," as they are called, and the chance or probability of one is the same as that of the other. In the same way the chance that you are taller than the average for your age and sex is equal to the chance that you are shorter than the average. If one assumes that you are taller his probability of being right is one chance in two, or one half. On the other hand, what is the probability that you are taller than your two closest friends? There are three possible events, namely, tallest, taller than one, or shortest, which are all equally probable. The probability of any one of them is $1 / 3$.

Consider then $N$ molecules of a gas in a rectangular box, of dimensions $a, b$, and $c$ centimeters. (See Fig. 13.) What is the probability that any particular molecule is moving more in the direction of the $a$ dimension than along the lines of $b$ or $c$ ? The events are all equally likely and the probability of each is $1 / 3$. Of the $N$ molecules, $N / 3$ may be thought of as moving in the direction of $a$.

Not all the molecules, however, are moving with the same velocity. It is just as probable, however, 
that any individual molecule is moving with a higher velocity as that it is moving with a lower velocity than the average. We may therefore deal with the average velocity.

What is the effect of a molecular impact against the box? If the molecules were inelastic like lumps of putty they would not bound back from the walls of the box. Their kinetic energy would be imparted to the molecules of the walls and they would cease to move, dropping under gravitation to the bottom of the box. The pressure they exert would then decrease to zero. If they are elastic they bounce back. In order, however, that the pressure shall remain constant as time goes on they must maintain the same average velocity, and hence on the average they must bounce back with a velocity numerically equal to that of their approach. Otherwise the phenomenon would be like that taking place if the door of a room were opened while a large number of tennis balls were thrown in. The door might then be closed and the balls left to bounce back and forth. As one strikes the wall, however, it does not bounce with its original velocity, because some of its kinetic energy is converted into molecular motions in itself and in the wall. The temperature of the balls and the walls then rises as the bulk motion of the balls ceases. That the kinetic energy which is subtracted from a moving body by a collision is manifested as heat is well illustrated by the rise in temperature which occurs when a piece of metal, e.g. a nail, is pounded with a hammer.

If the average velocity of the rapidly moving molecules of an inclosed gas is not to change, two conditions 
must be satisfied. First, there must be no subtraction from their energy or no addition to it by the walls of the box; and second, there must be no similar subtraction or addition on the part of the component parts of the molecules.

The first of these conditions requires that on the average there shall be no interchange of molecular energy, that is, heat, between the walls and the molecules. In other words, they must be at the same temperature. This does not mean that individual molecules may not rebound with greater or less velocity, but means that on the average the value of the kinetic energy of a molecule, represented by $m v^{2} / 2$, must remain constant. Individual molecules may lose energy to the molecules of the walls, but in the succeeding impacts other gas molecules must receive equivalent additions of energy from the walls. This condition requires, therefore, that on the average the kinetic energy of the molecules constituting the walls, and hence their velocities and momenta, must be such that in their collisions with the molecules of the contained gas there shall be no net interchanges of energy.

If, however, the walls are not at the same temperature such transfers of energy will occur until the partition or division of the total energy possessed by the two sets of molecules satisfies the above condition. It is by such exchanges that two bodies which are at different temperatures arrive at the same temperature, when placed in contact, one cooling and the other heating. This process, incidentally, is usually spoken of as a transfer of heat by conduction.

It is important to note that while we started with 
the idea of average velocity what we really are concerned with is the average square of the velocity, since this measures the average kinetic energy.

Let us now consider the second condition which must be satisfied if the average velocity of the molecules before and after mutual collisions shall remain constant. We recognize two types of motion which the atoms composing a molecule may have. They may move with reference to each other, just as two persons in walking together may vary somewhat their relative positions. They may, however, preserve the same relative distances apart and yet rotate, one around the other or both about some common point, just as two dancers in waltzing. They may, of course, have a motion which is a sort of a combination of these two internal motions. The pressure on the walls of the container is due to the motion of translation which the molecules have and not to the internal motions of their component atoms. As the molecules collide there might occur transformations of energy whereby these internal motions gained at the expense of the motion of the molecule as a whole. We all have seen illustrations of this phenomenon, as, for example, two skaters, colliding at high speed, may be set spinning if they do not meet head on. If the average velocity of the molecules is not to be altered by such collisions then there must, on the average, be some definite partition of the total kinetic energy of the molecules between translation and internal motions.

As long as there is no alteration in the total energy of the molecules, such as would occur if the walls of the container were at a different temperature, the 
pressure of the gas remains constant unless the volume is changed. This is the experimentally observed phenomenon of which Boyle's Law describes the general case. Hence the average kinetic energy of the molecules must remain constant and also the average internal energy of its atoms. The molecules, therefore, must rebound, either from mutual collisions or from impacts against the walls, with the same average (squared) velocity.

We are now ready to answer the question of page 160 as to the effect of an impact ${ }^{1}$ with the walls. During it the molecule is first stopped and then started in the opposite direction with an equal velocity. If its mass is $m$ and this velocity is $v$ there is a change of momentum of $m v$ in stopping it and another of equal amount in imparting to it the opposite velocity. The total change in momentum accompanying each impact is then $2 m v$.

An expression may now be obtained for the pressure which these molecular impacts exert on the end $b c$ of the box of Fig. 13 . If we

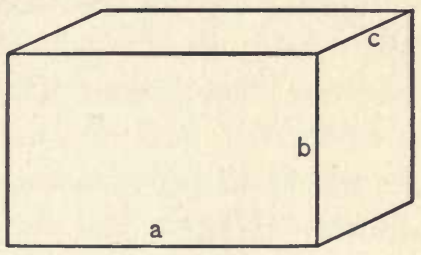

FIg. 13. multiply the change in momentum per impact (i.e. $2 m v$ ) by the number of impacts per second we obtain the total change of momentum per second, that is, the force exerted. Dividing this force by the area $b c$ gives force per unit area, that is, the pressure.

${ }^{1}$ Bernouilli in 1738 was the first to suggest that the molecules of a gas were in constant motion and that their impacts resulted in a pressure. 
Let $v$ represent the average velocity of the molecules in the direction of the dimension $a$ of the box. So far as concerns the impacts of any of these molecules on the end $b c$ it is evident that there will be one impact for every time a molecule, moving with this velocity, would make one round trip ${ }^{1}$ between this end and the opposite one That is, for every $2 a \mathrm{~cm}$. which it travels in the $a$ direction it will strike the end $b c$. Since it travels $v \mathrm{~cm}$. per second it will make $v / 2 a$ impacts per second. Since there are $N / 3$ molecules which are in effect traveling in this direction there will be a total of $N v / 6 a$ impacts per second. The force exerted on $b c$ is therefore

$$
\frac{N v}{6 a}(2 m v) \text { or } \frac{2 N}{3 a}\left(\frac{m v^{2}}{2}\right)
$$

Dividing by the area $b c$ gives the pressure, $P$, as

$$
P=\frac{2 N}{3 a b c}\left(\frac{m v^{2}}{2}\right)
$$

in which the product $a b c$ is the volume $V$ of the container. Hence

$$
P V=\frac{2}{3} N\left(\frac{m v^{2}}{2}\right)
$$

We have thus obtained a relation which indicates that, provided the average kinetic energy of translation, $N\left(m v^{2} / 2\right)$, of a group of $N$ molecules is not altered, the product of the pressure and volume is constant. In

${ }^{1}$ Actually, of course, any particular molecule may collide with another and bounce back. The other molecule also bounces back. The net effect so far as concerns impacts on the walls is just the same as if the molecules had passed by or through each other. 
other words, we have obtained an expression which states the facts of Boyle's Law.

The molecules, considering their motions of translation only, have what is called three "degrees of freedom." A railroad train has only one degree of freedom. It may move back and forth along only one direction, namely that of its track. A pedestrian has two degrees, for he may move along a north and south direction and also along an east and west direction. Having these two degrees of freedom he may, of course, move anywhere in the plane of the earth's surface at his locality. Thus, if he moves northeast, we may think of each small displacement in that direction as the result of small displacements to the north and to the east. An aviator, on the other hand, has three degrees of freedom. He is not restricted to motion in a line or in a plane, but may move through space. So far as concerns his motion to any point we may think of it as the result of component motions along three directions, as N-S, E-W, and Up-Down.

In the same way we may think of the total kinetic energy of the molecules of a gas as energy of motion in each of three rectangular directions. The kinetic energy due to motions along any one of these directions or axes, is on the average just as much as that due to motions along any other. In other words, if the total kinetic energy of translation is thought of in terms of the degrees of freedom, it is evident that it should be equally divided among them. That is, there is an equipartition of energy, each of the degrees of freedom having one third of the energy.

As is evident from the equation (1), if we keep the 
volume $V$ constant and vary the average kinetic energy of the molecules the pressure varies proportionately, that is, directly. Similarly, the equation shows that, if we keep the pressure constant, the volume varies directly as the average kinetic energy of the molecules. Alterations in this kinetic energy are made by adding or subtracting energy, that is, by either heating or cooling the body under consideration. If any body, when placed in contact with the gas (or with the thin walls of its container), does not cause a change in the product of gaseous pressure and volume there is no net change in the average kinetic energy of the molecules and we say that the body has the same temperature as the gas.

It was upon exactly this principle that the first thermometer operated. This was made by Galileo in 1597, over two hundred years before the

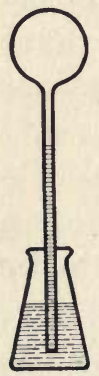

kinetic theory of gases was first formulated. The instrument was essentially of the form shown in Fig. 14. You see at once how it may be used by the substitution method to indicate when two bodies are at the same temperature. If first one and then the other is brought into contact with the bulb, then, the fact of an equality of temperature will be indicated by the same Fig. 14. position ${ }^{1}$ in both cases for the liquid in the stem.

A possible source of error in such use of a thermometer may be mentioned. Suppose the two bodies, $A$ and $B$, are very different in mass, e.g. that $A$ comprises a smaller number of molecules than $B$. It requires a greater addition of energy to $B$ than to $A$ to produce the same increase in the average kinetic energy. Body $B$ has the greater "heat capacity." On the other hand, suppose the atomic structure of $A$ is less complex than that of $B$. Because of 
It is most convenient to use a thermometer as a direct reading instrument instead of by the substitution method. It must therefore be calibrated by adding energy, just as the spring scale described on page 31 was calibrated by added weights. But what is the condition which we are to call zero? Obviously the condition when the average kinetic energy of the molecules of its gas is zero. This condition means zero average velocity of the molecules and from equation (1) we see that it corresponds to the condition when the pressure exerted is zero.

In the development of science a knowledge of thermometry preceded by more than two centuries knowledge of any such behavior on the part of the gas molecules, as that which we have been describing. Furthermore, even to-day, it is impossible to subtract all the energy from a gas and thus reduce it to an absolute zero temperature. In the earlier years there were then two possibilities, either (1) the experimenter might assume that the lowest temperature he was able the partition of the energy added to a molecule between the degrees of freedom of translation and of internal motions the more complex molecule would require the addition of a greater amount of energy to produce an equal increase in its k.e. of translation. In other words, the heat eapacity per molecule is higher for $B$ than for $A$.

Suppose that $B$ has a heat capacity very much greater than the thermometer. If it is at a higher temperature, it will need to lose but little of its energy in order to bring the average k.e. of the molecules of the thermometer to an equilibrium value. On the other hand, if $A$ has a small heat capacity the amount of energy which it must transfer, to raise the temperature of the thermometer, may well result in a decided decrease in its own temperature. When an equilibrium has been reached between $A$ and the thermometer the indication of the latter represents a temperature below that which $A$ originally had. 
to obtain by the best means at his disposal was the lowest obtainable by any means and thus take that temperature as the zero of his scale, as did Fahrenheit, or (2) he might arbitrarily assume a zero. The latter course was followed by Celsius, who in $\mathbf{1 7 4 2}$ devised what we know to-day as the "Centigrade scale."

The zero chosen by Fahrenheit corresponded to the temperature reached by a mixture of sal ammoniac (ammonium chloride) and melting snow. In the Centigrade scale the zero is the temperature of melting ice and water. As a matter of fact it was Fahrenheit himself who had made this selection possible by showing, sometime previous to Celsius' choice, that the temperature of such a mixture is constant as long as the ice is not entirely melted. The difficulty previous to Fahrenheit's demonstration had been that it was known that water could be cooled below this temperature without ice forming. This is true, but the condition is essentially unstable, for if a small bit of ice is dropped into the water freezing occurs with great rapidity.

As an upper point on his scale Fahrenheit chose, unfortunately, the blood temperature of the human body. He then divided the interval into 96 equal divisions. Celsius, however, selected the boiling point of water at atmospheric pressure and divided the temperature interval between zero and this upper value into 100 equal degrees.

The positions of the liquid in the stem of a thermometer like that of Galileo, corresponding to the two arbitrarily assumed but easily reproducible temperatures of the Centigrade scale, may be marked and the 
intervening portion of the stem divided into 100 equal divisions. Such a thermometer is not, however, as satisfactory for use as that shown in Fig. 15. In this form ${ }^{1}$ the volume of the contained gas is kept constant. As the temperature changes corresponding changes occur in the pressure exerted by the gas and hence in the pressure required to maintain its volume constant. The volume is controlled by the mercury in the flexible tube and the pressure exerted on the gas is dependent upon the difference in levels of the mercury in the glass tubes forming the extensions of the flexible $\mathrm{U}$ tube.

To calibrate this thermometer the bulb is inserted in distilled water containing chipped ice. The mercury column is then adjusted so that the gas has a definite volume when it has reached a temperature equilibrium with the melting ice. Under these conditions let the pressure be denoted by $\mathrm{P}_{0}$. The ice bath is then replaced by a steam bath and the pressure, $\mathrm{P}_{100}$, which is required to reduce the volume to $\mathrm{V}$, is noted. The change in pressure which has been observed corresponds to $100^{\circ}$ Centigrade.

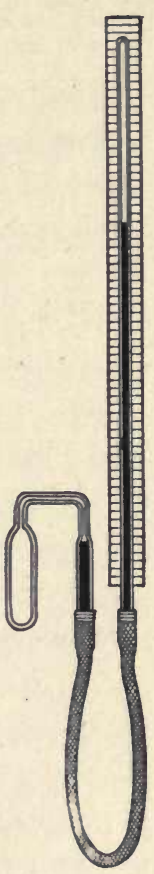

Fra. 15.

The change of pressure per degree Centigrade is then $\left(\mathrm{P}_{100}-\mathrm{P}_{0}\right) / 100$. The fractional increase in pres-

${ }^{1}$ Such a piece of apparatus is used as an instrument of precision for ealibrating the more convenient mercury and alcohol thermometers with which we are all familiar. The latter require calibration because equal intervals on the stem do not correspond exactly to equal increments in temperature. 
sure per degree represented by $\alpha$ is found by dividing by $\mathrm{P}_{0}$, thus

$$
\alpha=\frac{P_{100}-P_{0}}{100 P_{0}}
$$

Careful measurements have shown the numerical value of $\alpha$, the "pressure coefficient at constant volume," to depend somewhat upon the kind of gas. Hydrogen has therefore been adopted as the standard for the gas thermometer.

Returning to equation (2) we remember that the quantity $\frac{2}{3} N\left(\frac{m v^{2}}{2}\right)$ is constant if the temperature is constant and that we decided to measure temperature from an absolute zero corresponding to a value of $N m v^{2} / 2$ equal to zero. We are therefore interested in finding where our arbitrary reference point of zero degrees Centigrade may happen to be located in this absolute scale of temperatures.

Let us represent temperatures measured from this absolute zero by $T$. Since we do not as yet know the absolute temperature corresponding to $0^{\circ} \mathrm{C}$. let us represent it by $T_{0}$. In terms of absolute temperature a temperature of $t^{\circ} \mathrm{C}$. is expressed as $t=T-T_{0}$, since $T=T_{0}+t$. The value of the pressure, $P_{t}$, corresponding to $t$ is expressed in terms of the pressure coefficient and the pressure at $0^{\circ} \mathrm{C}$., namely $P_{0}$, as follows:

$$
P_{t}=P_{0}(1+\alpha t)
$$

Substituting for $t$, and for $\alpha$ its value for hydrogen of $0.00367=1 / 273$ gives

$$
P_{t}=P_{0}\left(1+\frac{T-T_{0}}{273}\right)
$$


When the absolute temperature is zero (i.e. $T=0$ ) the pressure is zero $\left(P_{t}=0\right)$. Substituting these values in (5) and solving for $T_{0}$ gives $T_{0}=\overline{2} \overline{7}$. The zero of the absolute scale of temperature is then $273^{\circ}$ below the arbitrary zero of the Centigrade scale. In other words the absolute zero is $-273^{\circ} \mathrm{C}$.

This absolute zero is probably never to be reached experimentally, although in recent years remarkably low temperatures ${ }^{1}$ have been obtained. As the temperature of a gas is decreased the molecules may be crowded closer and closer together, until they are so close that they are in the liquid rather than in the aëriform state. This crowding together and consequent liquefaction may not, however, be brought about merely by an increase of pressure. There is for each gas a certain definite temperature above which it is impossible to produce liquefaction by compression.

The liquid gas may be solidified by a further reduction of its temperature. The temperature at which this occurs is called the freezing point. We see, then, that gases like hydrogen or oxygen may assume any of the three forms solid, liquid, or aëriform, depending upon the temperature and pressure to which their molecules are subjected. This is the familiar action of water; but in the case of water the freezing point and the boiling point (that is, the temperature at which steam condenses under atmospheric pressure) are at temperatures within the range which we meet in our daily lives instead of only under laboratory conditions. In fact, from our ideas of the molecular construction

${ }^{1}$ The gas helium was liquefied at a temperature of $-271 .^{\circ} 3 \mathrm{C}$., that is, within two degrees of the absolute zero. 
of matter, we see that what we have been accustomed to consider solid substances are merely substances for which the melting point (i.e. the freezing point) is well above the temperatures which we meet under our climatic conditions. The characteristic of being solid is not one of the substance itself but is dependent upon the physical conditions of pressure and temperature under which it is at the time. Similar statements may be made as to substances which we are accustomed to consider liquid. Substances which we know as gases are of course those for which the boiling point (i.e. the liquefaction point) is well below ordinary temperatures. 


\section{CHAPTER XIV}

\section{MOTIONS OF ELECTRONS}

The phenomenon of the electrification of two dissimilar substances was explained in Chapter VIII as due to a redistribution of the electrons. The electrical charges thus produced might therefore be expressed as a definite number of electrons, that is, measured by counting the number of similar particles of electricity which were added or subtracted. Of course, the actual operation of counting would be impossible, because of the size and the large number. ${ }^{1}$ During the 120 years preceding the demonstration of the existence of the electron, knowledge of electrical phenomena and of methods for their measurement had developed rapidly. To make such measurements units were adopted which are not as logical as would be the electron for unit quantity. When the electron was recognized its electricity was measured and expressed in terms of a previously chosen unit. The units adopted are simpler than the more logical unit because they are defined in terms of magnitudes which are directly measurable and are also of convenient amount.

${ }^{1}$ In fact, if during the electrification the number transferred is such that as we separate the two bodies we find a force of 1 dyne when they are $1 \mathrm{~cm}$. apart, we know to-day that about $2.1 \times 10^{9}$ electrons have been transferred. 
The early study of electricity followed two lines because the investigators wrongly distinguished between "frictional" electricity and "galvanic" electricity. Electrification produced by friction had, of course, long been recognized. The quantitative law for the action of two charges produced in this way was stated in 1785 by Coulomb in a form similar to Newton's law of gravitation. The force acting between two charged bodies is proportional to their charges and inversely as the square of the distance between centers. This law leads to a unit for electricity since it may be written as

$$
F=q_{1} q_{2} / K r^{2}
$$

where $q_{1}$ and $q_{2}$ are the two quantities of electricity, $F$ is the force, $r$ is the distance (between centers), and $K$ is a factor of proportionality depending upon the choice of units and upon the medium. We must select some medium, as for example, air, and let $K$ be unity for this condition. Applying to equation (1) the method of Chapter X, it appears that unit electricity is such a quantity that when placed in air at a distance of $1 \mathrm{~cm}$. from an equal quantity it will repel it with a force of 1 dyne. This is now known as the electrostatic unit of electricity.

About 1780, Galvani, professor of anatomy in Bologna, observed a peculiar phenomenon in connection with the legs of some newly skinned frogs which were awaiting his examination. In the room there was a machine for producing electrification continuously by the friction of two dissimilar substances. When a sufficient charge had been accumulated a spark 
would pass through the air. This miniature lightning, Galvani noticed, caused twitchings of the muscles of the frogs' legs. This started him upon a series of experiments as to the effect of electricity upon vital actions, in the course of which he was rewarded by another accidental discovery. Some frogs' legs, hung by copper hooks from an iron railing, convulsed violently when they swung into contact with the railing. Guided by this he studied the effect further. He arrived, however, at a wrong explanation of it, assuming that at the junction of the nerve and the muscle there was a separation of electricities.

It remained for Volta, a professor at Pavia, to show about 1800 that the source of electrification was in the dissimilar metals and was made available for continuous effect if the two metals were separated by a liquid like salt water. From this accidental start there was developed the science of electricity as we know it to-day. Men have forgotten the original experiment, which Galvani had in mind to do, but the by-product has had far reaching effect. His name is preserved in science in the word "galvanometer," meaning an instrument for metering "galvanic" or "voltaic" currents.

Volta's first form of electric battery was the "pile," consisting of successive layers of copper, zinc, and wet cloth in the order named. A later arrangement was a series of glass vessels, each containing salt water and plates of copper and zinc. These plates did not make contact inside the vessels but were connected outside them from copper to zinc as illustrated schematically in Fig. 16. In each vessel the zinc plate was found to be negatively and the copper plate positively electrified. 
The series connection allowed the fact to be more easily observed with the apparatus then at the disposal of

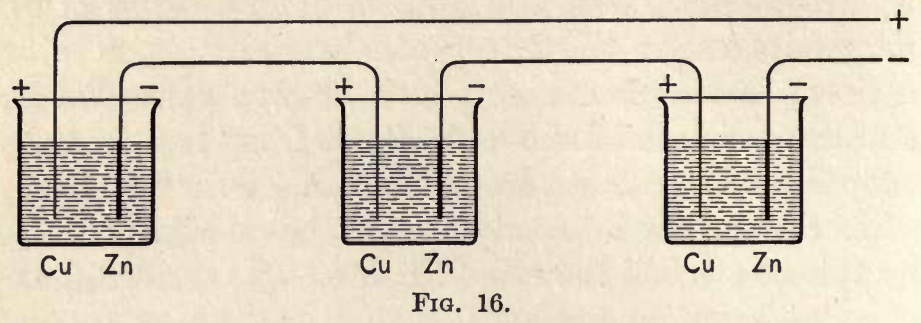

scientists. The galvanometer, of course, had not yet been invented and the forms of electroscopes in use were not particularly sensitive.

Volta's contribution to science, described in modern terms, was the discovery of a means whereby potential energy of chemical separation could be converted into kinetic energy of electrons. A definite connection between chemistry and physies was thus indicated. Just as there is a unity to physics, which was formerly violated by the attempt to classify phenomena under the five headings mentioned on page 60 , so there is a unity to chemistry and physics. Words, of course, change but slowly as time goes on, and too frequently establish artificial barriers to our mental development. In the formal education which we obtain in schools and from books these barriers remain even longer than they do in the education of our other daily experiences. In most school curricula physics and chemistry are considered so separate that they are studied in different years and from texts which carefully refrain from encroaching on each others' fields. Nevertheless, the subjects have an essential unity. An attempt to ap- 
proach one at a time instead of both at once frequently leads to a neglect of the fundamental realities and hence to a treatment of each subject as a group of apparently unrelated phenomena.

To designate the portions of the two subjects which are of importance to students of both a new name has come into use, that of Physical Chemistry. This treats of the portions of chemistry where energy relations, the behavior of molecules, and their electronic composition, are most evidently involved. As yet, however, this name and the unified treatment of these fundamental relations has been reserved for the occasional advanced student. In elementary treatments the subjects are still separated.

The phenomena of which Volta's batteries are an illustration classify under the title of physical chemistry. From the standpoint, however, of the engineer, who is interested in effects rather than causes, Volta's contribution to science may be described as the discovery of a source of continuous current at a low but fairly constant potential difference.

By current we mean the time rate at which electricity is transferred, that is, the number of electrons per second which move across any section of the conducting path. Thus if the zinc and copper plates of a voltaic cell are connected by a wire a stream of electrons flows through this wire from the negative zinc to the positive copper plate. Whatever units we use for measuring the quantity of electricity, unit current will be flowing in the wire when electrons are transferred at the rate of one unit of quantity per second. For example, using unit quantity as defined by reference to Coulomb's 
Law, we obtain unit current in the electrostatic system as 1 e.s. unit of quantity per second. Symbolically

$$
i=Q / t \text {. }
$$

The system formed by the plates of the battery has potential energy which may be converted into kinetic energy of electrons. A difference of gravitational potential, as we learned on page 108, is measured in energy per unit mass. In the similar case of the cell it would be logical to express the potential difference of the plates in ergs per electron. In general, a difference in electrical potential is expressed as so many units of energy per unit of electricity. Several units are therefore possible, depending upon the choice of units for energy and quantity. In the case of the unit called the volt (after Volta), the energy unit is the joule and the quantity unit is the coulomb. The latter, named after the scientist mentioned above, is the quantity represented by three thousand millions of the electrostatic units which were defined by using his law. The corresponding current unit, the coulomb per second, is called the ampere.

If we represent potential difference by $E$, quantity by $Q$, and energy or work done by the system as $W$, we have

$$
\begin{aligned}
E & =W / Q \\
\text { or } \quad W & =E Q
\end{aligned}
$$

as the defining equation for $E$. If the quantity $Q$ is expressed by equation (2) as it we may write

$$
W=\text { Eit. }
$$

In order that a body shall fall through the space intervening between the points of higher and lower 
gravitational potential it is only necessary that it be released. In its free fall it acquires kinetic energy which is available upon impact for conversion into other forms of energy. The larger portion of this energy is, of course, converted into heat, that is, the haphazard motion of the molecules of the partners to the collision. Some of the energy is, however, transmitted away through space in the form of a sound wave, the mechanics of which we have previously considered.

This case of free fall is one which is possible for electrons only under rather special conditions. We obtain it in the laboratory by using an evacuated vessel containing two metal plates which we connect to the positive and negative plates of the battery.

In all other cases with which we have to do the electrons are impeded in their fall. This is true whenever a "conductor" connects the two points of different potential. If the fall is impeded the energy is subtracted during it instead of entirely at its end. The difference between the two cases is much like that of a ball which is either dropped from the roof of a building or allowed to roll down the stairs. In the latter case its descent consists of a large number of free falls through short distances. It never, therefore, acquires the high velocity which is obtained in the other case. With each impact the kinetic energy acquired since the previous impact is converted into heat. This is essentially the phenomenon of the conduction of electricity through metallic conductors.

When the fall of electrons is not free but takes place through a gaseous medium an impact with a gaseous molecule may be sufficient to shake loose or otherwise 
free one of the component electrons of the molecule. If this is to be the effect, the electron, before its collision with the molecule, must have fallen through a sufficient difference of potential to acquire the amount of kinetic energy necessary for disrupting the system of nucleus and electrons which constitutes the molecule. When an electron has been shaken from a gas molecule, so that it is free to pursue an independent path and to have an individual existence, the molecule is said to be ionized. The two parts which are thus formed are called "ions," meaning "goers," but it is preferable to call the portion which is still of molecular size the ion and to speak of the other moving part as an electron, since that is what it really is.

As we shall see, the electron may later join company with a neutral molecule, that is, one which has not been ionized. In this case also we would speak of the new combination as an ion. We may thus have ions, positive or negative, depending upon whether they are formed from a neutral molecule by knocking off an electron or by combination with an electron. The electrons and the ions are "goers" whose motion is conditioned by the systems of potential energy which they form with the positive and negative plates.

Now in air at ordinary pressures and temperatures the mean free path ${ }^{1}$ is comparatively short. A moving

${ }_{1}^{1}$ The distance which a molecule in its haphazard motion would travel on the average between two successive impacts with its fellows is called its mean free path. This will be smaller the larger the number of molecules per unit volume, that is, the greater the density of the gas. The average distance through which an electron may move between successive impacts with the molecules of its gaseous path will depend upon the mean free path of the gas molecules. 
electron may therefore not acquire sufficient energy between successive impacts to admit of its ionizing the gas through which it bumps its way. Its ability to ionize depends upon its acquiring the necessary kinetic energy during a motion comparable with the mean free path of the gas. But this kinetic energy is equal to the change in potential corresponding to the distance which it moves along the path between the two plates. If this change is sufficient then ionization will occur.

The phenomenon when ionization occurs is that with which we are familiar on a large scale in the case of lightning. On a small scale it is illustrated by the spark discharge between the electrodes of a machine such as Galvani was using, or in the discharge between the electrodes of a so-called induction coil such as is used in the ignition system of an automobile. In all such cases the discharge starts because of the presence in the medium of a few electrons. These, by their collisions with neutral molecules, produce other electrons and also positive ions. The number of electrons which are traveling toward the positive electrode therefore increases rapidly. The positive ions which are formed by the collisions naturally move toward the negative electrode, where they combine with its excess electrons and neutralize not only their own deficiency of electrons but also the excess of the electrode.

Such recombination may also take place en route. In fact, during a continuous transfer of electricity through a gas it is possible for the same atomic nucleus to change partners several times. Thus, after a recombination with an electron has again made it neutral and while pursuing its own haphazard motions, it may 
be struck by another electron traveling at such a speed as to combine with it instead of again disrupting it. As a negative ion it would then take up a directed motion toward the positive electrode. The molecule has now in its group an extra electron. None of the electrons are therefore as firmly held as if the normal number had not been exceeded. An impact even with a neutral molecule may sometimes be sufficient to jar off an electron. Whether the electron jarred loose in this way is the latest addition or one of the original ones makes no difference and can probably never be determined, since they are all alike anyway.

Before discussing further the picture, which we have just obtained as to the mechanism for the conduction of electricity through gases, it is well to note that it is that of the general case. If all the molecules of the gas are removed, leaving a vacuum, the current can be carried only by electrons, since there are no molecules to form ions, and hence all the electrons must be supplied and released at the negative electrode. If electrons are not so released there can be no current. In the case of a gas, if there happen originally to be no free electrons between the electrodes, there can be no current, unless some electrons are released at the negative electrode. If, however, the potential difference is sufficiently high the presence or release of a few electrons will result in ionization, and hence in the selfperpetuation of the supply of carriers.

In conduction through solids, molecular motion is restricted and the entire transfer of electricity is due to the motion of the electrons. In this case combinations probably occur in much the same manner as 
in a gas, but the combinations are prevented by the other molecular masses from moving toward the electrodes. In the case of metals, which are the best conductors, there are always electrons moving about through the substance. Although the number per cubic centimeter is very large, it is small compared to the total number of electrons in this volume. A metal then consists of a large number of neutral molecules, a few positive molecules (they can hardly be called "ions" since they cannot "go"), a smaller number, perhaps, of negative molecules and a number of free electrons just equal at any instant to the difference between the number of positive and negative molecules.

In the case of those liquids which conduct electricity (pure water, for example, does not) we shall see later that there are positive and negative ions but no free electrons. The ionization of liquids is not the result of collisions with free electrons, since there are none present. It is in the nature of a spontaneous dissociation and depends only upon the chemical composition of the liquid. Of this phenomenon of "electrolytic dissociation" we shall have more to say later.

For the moment, the important matter is to obtain a general picture of the conduction of electricity. Conduction occurs as the result of the motion of electrons. This may be an actual motion or it may be a motion of what we might call "certificates of electronic indebtedness." A positive ion is essentially a certificate of electronic indebtedness which may be transferred at will and may be satisfied at any point in the universe where there is an excess electron. (Sometimes the certificate will call for more than one electron, as is true 
of the ions of some liquids.) In the transfer of electricity, therefore, between two plates, say $A$ and $B$, of which $B$ is positive and $A$ negative, it makes no difference whether the transfer is an actual one of electrons moving from $A$ to $B$, or is accomplished by the motion of certificates of electronic indebtedness from $B$ to $A$, or in part by each method.

In the case of conduction through a vacuum, or through any conductor if ionization does not occur, the transfer is entirely the result of motions of the electrons. In the case of gases the transfer is partly by individual electrons, partly by the certificates or positive ions, and partly by electrons which are combined with molecular masses. The latter are truly carriers in the sense in which a horse is a carrier of his rider, and they move in the direction in which the added electrons would move individually. The word "carrier" is, however, generally applied to both positive and negative ions. In the case of liquids, as we have noted, the transfer of electricity is brought about entirely by the motion of these carriers.

Of course the carriers may not share the burden of transfer equally, one kind being swifter than the other. In other words, the positive and negative carriers of an electrolyte may have what is called different "mobilities." The same is true of the carriers of a gas. A study of the mobility of the ions formed from various gases and also of their rates of diffusion yielded some of the earlier determinations of the value of the charge carried by the ions and hence of the amount of electricity corresponding to an electron.

So far we have considered only the mechanism 
whereby charges are transferred between two plates or electrodes which are maintained at different potentials. We have not as yet discussed the manner in which electrons may be released at the negative electrode. We have seen that in the case of metals the electrons are comparatively loosely held in the atomic or molecular structure with the result that they are always available for conduction. Free electrons, which may migrate within a metal body from one point to another, are the cause of the better electrical conductivity of metals and also of their better heat conductivity. Those substances which are good conductors of electricity are also usually efficient in transferring molecular energy from a point of high temperature to one of low temperature.

Increased temperature of a metal results in increased energy on the part of these free electrons, as we should expect from the idea of the equipartition of energy which was developed in the preceding chapter. From the standpoint of the kinetic theory we are not, therefore, surprised to learn that there comes a time, as the temperature of a metal is increased, when some of the electrons have acquired a sufficient kinetic energy to carry them beyond the influence of the molecules of the metal ${ }^{1}$ itself. In other words, we can picture to ourselves a phenomenon of the boiling of the electrons of a metal quite similar to the boiling of a liquid.

Because the electrons are of smaller mass than the molecules we should expect a very pronounced boiling of electrons long before the temperature of the metal

1 The phenomenon is essentially similar to that of surface tension, which is discussed on p. 221. 
reaches the melting point of the substance itself. This phenomenon is made of practical use in the socalled "audions," thermionic devices which have proved of great value in radio-communication.

As a metal is heated we may obtain through our physical senses an indication of its increased electronic activity, for we may feel the heat radiated to us through space. As the temperature rises still further we obtain a visual indication in the dull red color of the metal. The kinetic energy of the electrons has on the average been increased and hence their velocity. The frequency with which an electron, although bound within an atom, may move back and forth or once round its restricted path is thus increased. We thus associate the radiation of heat with slower vibrations than correspond to the radiation of light. Not all the electrons have the same frequency, since not all would have just the average value of kinetic energy. The result is that as the temperature rises some of the electrons reach the frequency at which they radiate red light before the others. As the temperature is still further increased the average frequency rises and more electrons emit red light. Those which are faster than the average now emit a yellow light while the slower ones still radiate heat. As the temperature rises the other colors of the spectrum are emitted and the metal becomes incandescent. ${ }^{1}$

The radiations of the fastest electrons are beyond the range of visibility, but they affect photographic plates and may otherwise be detected. We are accustomed to divide up this range of frequencies and to call those

${ }^{1}$ A more exact statement is beyond the scope of this chapter. 
which are too slow to give red light "infra-red" and those which are too fast to give the violet light which lies at the other end of spectrum "ultra-violet." The radiations of the ultra-violet range have only begun to be investigated, but we shall find several known facts of considerable interest.

For example, the ultra-violet radiations reaching us from the sun are the cause of those chemical transformations whereby the leaves of plants exposed to sunlight turn green, while the growth beneath the ground remains white. Ultra-violet radiations if not sufficiently reduced in intensity by the air through which they travel may also produce severe burns, particularly in the inner eye of a human being, as has been recognized by workers with electric arcs or oxyacetylene welding outfits. For this reason, where street railway rails are being welded electrically, goggles are worn by the workers and signs are displayed advising the passer-by not to look at the flame.

For our immediate purpose, however, the importance of ultra-violet light is its ionizing effect. Ions are produced in gases exposed to light, rich in ultra-violet radiations, as is easily verified by their increased ability to conduct electricity. Thus if the air between the charged leaves of a gold-leaf electroscope is exposed to ultra-violet radiations the leaves quickly collapse. The explanation lies in the formation in the air of positive and negative ions. Whether the leaves were charged positively or negatively, there are thus made available carriers of the opposite kind, which may move to the leaves and neutralize their charges, allowing them to collapse. 
These ultra-violet radiations may also serve to shake electrons loose from the metals on which they fall. In fact, the electrons of the surface of the metal are forced to vibrate with the same high frequency as do the electrons of the source of the ultra-violet light. The phenomenon of this radiation of energy is similar to that of sound, as discussed in Chapter VI, in the one respect that energy is transferred by a wave motion from a vibrating source and results in a similar vibration of a distant particle.

It is immaterial, so far as concerns merely the fact of shaking loose an electron, whether the electron acquires the necessary energy indirectly as its share of the total increase of energy received by the entire body in being heated, or directly by transmission from a distant electron. Of course the electron may also receive the necessary increase of energy by the direct impact of some molecular mass, as in the case of the conduction of electricity through gases, when the positive ions of the gas collide violently with the negative electrode toward which they naturally move.

The emission of light which accompanies ionization is well illustrated in the discharge which takes place

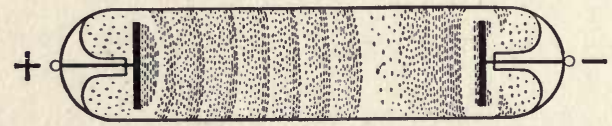

FIG. 17.

in a partially evacuated tube like that of Fig. 17. The appearance of the discharge depends upon the mean free path of the gas molecules in the tube and hence upon the evacuation. The form shown in the figure 
is merely typical of those which may be observed. Near the negative electrode, or cathode, ${ }^{1}$ the positive ions are ionizing the gas and combining with the excess electrons of the cathode, and a violet glow results. In the region of the so-called "positive column" there are striæ, indicating the successive layers of the gas where ionization and recombination occur. When the vacuum of the tube is carried further a condition is reached where, because of the small number of molecules available, but little ionization occurs and the effects are due largely to the electrons. These fly away from the cathode in radial lines. Their existence was first noted by Crookes in 1876, who spoke of them as "radiant matter." A brilliant phosphorescence indicates their impacts with the walls of the glass tube. The fact that they proceed radially is usually illustrated by interposing a piece of mica, as the Maltese cross of Fig. 18, and observing that it casts a well-defined shadow within which there is no phosphorescence. Some of the ex-

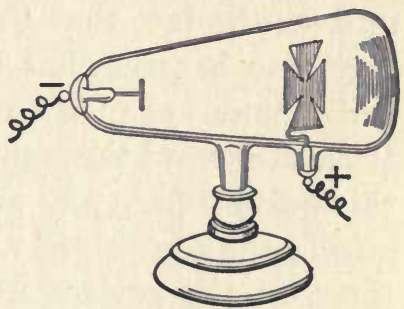

Fig. 18. periments by which it was proved that the phenomenon was one of corpuscles rather than of light rays, that is, the experiments which led to the identification of the electron, will be described in Chapter XXII.

${ }^{1}$ Current was considered to flow from a positive to a negative electrode before the electron was discovered. It was therefore spoken of as flowing from the "anode" to the "cathode." The tube which we are considering has had associated with it the names of various scientists. It is preferably described by the name of either Crookes or Geissler. 
When the electrons are allowed to strike a piece of platinum, as $A$ of Fig. 19, they give rise, under proper conditions of vacuum, to what have been called X-rays, since their discovery by Röntgen in 1895 . Their impacts with the platinum " anti-cathode" result in very

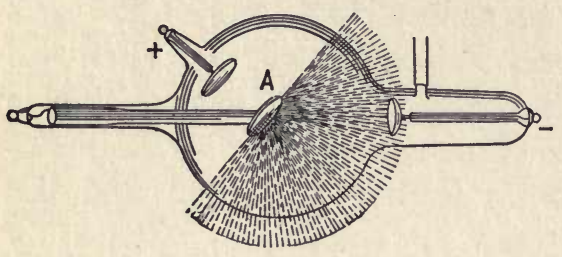

FIG. 19.

large changes in their momenta, since they are moving with velocities nearly that of light, for which the velocity is $3 \times 10^{10} \mathrm{~cm}$. per sec. Just as the periodic vibrations of electrons radiate energy so the sudden change in motion sends out energy in radial lines. Except for the enormous difference in the velocity and for the fact that the medium is different, the phenomenon is somewhat similar to the sharp crack which accompanies the blow of a baseball and a bat. There travels outward through the ether a sudden pulse. When this pulse strikes any substance it is so violent that it affects the atoms well within the body instead of merely those at the surface as does the energy of light and heat waves. In other words, these pulses have extreme penetration. The penetration depends upon the substance, and is much less for those denser substances like the metals and particularly for lead. A substance may partially absorb the pulses and hence cast a shadow depending upon its density and thickness. These X-rays therefore admit of our taking shadow pictures. The shadows may be observed by interposing the object, as for example the human body, between the source and a screen of zinc sulphide, or a 
photographic plate (since the pulses will affect it much the same way as does light).

The mechanism of the ether whereby energy may thus be transmitted through space from one electron to another is not as yet known, although we know many important quantitative laws as to such transmission. We have considered the unexplained realities which the physicist meets to be matter (i.e., electricity) and energy. The ether is sometimes taken as a third reality, but its explanation will probably be included in that of the other two. Thus, when we know why an electron and an atom which has lost an electron constitute a system the potential energy of which tends to decrease as the parts tractate, we shall probably know also the mechanism of the transfer of energy through space.

The fact that the motion of an electron anywhere in space may affect the motion of any other electron in space, except in so far as the energy which the first is transmitting is absorbed by intervening electrons, is the basis of all so-called "electromagnetic radiation" whether manifested to us as heat, light, X-rays, wireless telegraph radiations, or obscured to us because of our insufficient scientific knowledge and hence awaiting detection by future scientists. There is also another whole field of effects which moving electrons produce upon other electrons in their immediate neighborhood. These are the basis of the dynamos, motors, and transformers with which the electrical engineer deals. They are, however, but special cases of the more general phenomenon of the effect of an electron in motion upon other electrons. 
Before considering them let us summarize the factors that enter into the conduction of electricity between two plates or electrodes which are maintained by some means or other at a constant difference of potential. The current at any instant depends upon the number of carriers which are available and upon the velocity with which they are "falling." The velocity will depend upon the potential difference between the two electrodes, but the number of available carriers will depend upon several other factors. Thus it will depend upon whether or not the conducting path is ionized, and this in turn depends upon what the medium is and upon whether or not the potential gradient has been sufficient. If the path is ionized the number of available carriers will depend upon its previous history, for it was the carriers which were present in the preceding instant which were active in forming those now available. The number of carriers will also depend upon the character and electronic condition of the negative electrode and upon the energy which the electrode or the conducting path may be receiving in the form, for example, of ultra-violet radiations, or X-rays.

In the case of metals, however, the supply of carriers is apparently equal to any demand which may be made and, provided the temperature of a metal conductor, and hence the mean free path, is maintained constant, the current depends only upon the potential difference. An increase in the current is accomplished by increasing the average velocity with which the electrons travel toward the positive plate and hence the number per second which crosses any area of the conducting path. Let us see how the potential difference must 
be changed to produce for such a conductor a given change in current.

If the average velocity is doubled the same number of electrons will pass a cross section of the conductor in half the time previously required; that is, the current, or rate of transfer of electricity, is doubled. The kinetic energy of the electrons is, however, quadrupled, since it varies as the square of the velocity. This energy is dissipated in heat in the circuit, and thus we see that the energy required to force a current through a given circuit varies as the square of the current. This is known as Joule's Law and is usually expressed as

$$
W=R i^{2}
$$

where $R$ is a factor of proportionality, known as the resistance.

Returning to the numerical problem we see that the energy has been quadrupled by doubling the current, but that the quantity of electricity transferred has only been doubled. The energy per unit quantity, that is, the potential difference, has thus been doubled. The current and potential difference are therefore directly proportional. ${ }^{1}$

The fact that the current is directly proportional to the difference of potential is usually expressed in symbols as

$$
E=R i
$$

where $R$ may be shown to be the same factor of proportionality as was introduced into equation (5) above.

${ }^{1}$ This is also evident from equation (3), namely, $W=E Q$, since if $W$ is made four times as large, while $Q$ is made twice as large, then $E$ must be twice as large. 
This relation, which we have reached by considering the energy of the falling electrons, is known as Ohm's Law. It was announced in 1829, years before the more general aspects of electrical conduction were recognized. Covering as it does the special case of conduction through metals and through electrolytes, it has proved of great value to physicists and engineers in the development of the practical utilization of energy in the form of electricity in motion. To-day, however, the place of importance which it holds in most elementary presentations exposes students to the danger of considering the general phenomenon of conduction as an exception, instead of recognizing that those cases for which the law holds are special and simple cases of the general phenomenon. 


\section{CHAPTER XV}

INTERACTIONS OF MOVING ELECTRONS IN CONDUCTING CIRCUITS

WHEN two electrons tractate, the space rate at which their potential energy varies is given by Coulomb's Law. This law, however, holds only for electrons which are at rest, for even if the separation is constant the potential energy of the system will be constant only if its parts are not in motion. This phenomenon is the basis of those so-called electro-magnetic methods for converting mechanical energy and electrical energy which are utilized by the "electrical power" industry.

The reasoning which we shall follow in discussing this behavior of electrons may be illustrated by considering a somewhat similar problem of mechanics. A body resting on the surface of the earth is revolving about the terrestrial axis much like a bit of mud on an automobile tire. The tendency of the mud to fly off at a tangent is merely another instance of the inertia which Newton recognized. The greater the kinetic energy of the mud, the more pronounced is this tendency and the greater must be its adhesion to the tire, if it is not to fly off.

The body has potential energy with the earth and also its own kinetic energy. The latter is divided among two degrees of freedom, one along the line of centers, 
i.e. radial, and the other normal to this, i.e. tangential. Suppose the body, which is instantaneously at $p$ of Fig. 20, follows its tangential path to the point $p^{\prime}$. In this position its motion is partly away from the earth, along $O p^{\prime}$, and partly at right angles to this direction.

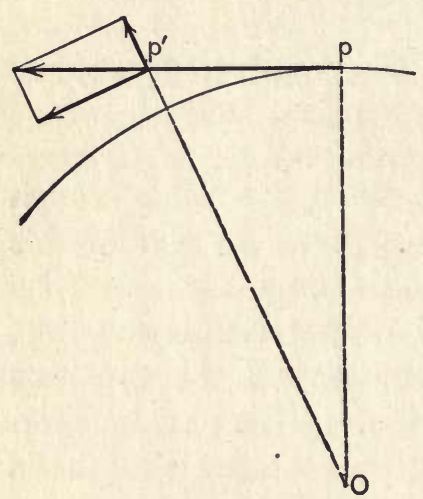

Fig. 20. There is now kinetic energy in both degrees of freedom, although in the previous position the radial k.e. was zero and the motion was entirely tangential. In departing from a circular path it acquires radial kinetic energy, and also increases the potential energy of the system. (The tangential k.e. is decreased.) The change in the p.e. is due to the increased separation from the earth, but that in the k.e. is due to the new angle which the direction of motion makes with the radial line. The radial k.e. and the p.e. do not necessarily, therefore, increase at the same rate with respect to the space over which the body moves. The radial energy is available for further outward motion and if it increases more rapidly than the potential energy, the body will continue to move away from the earth. Whether or not it does, depends upon the total kinetic energy and hence upon how fast the surface of the earth is rotating about its axis.

The limiting ${ }^{1}$ case occurs when the increase in radial

${ }^{1}$ Calculations show that for bodies on the surface of our earth this limiting value would be reached if the earth should revolve about 290 times as fast as at present. Bodies on the surface would 
k.e., in moving a small distance like $p p^{\prime}$, just equals the increase in p.e. Any such outward motion as that represented in the figure would then be impossible. On the other hand, even if not supported, it could not fall toward the earth. Under this condition the kinetic energy of the rotating body would have made unavailable the potential energy which it has by virtue of its position.

Below this critical speed, that is, under actual conditions, some of the gravitational potential energy will be unavailable. Such a reduction of available potential energy should be most pronounced at the equator, where the surface speed is greatest. Hence " $g$," the space rate of change of the available potential energy per gram, should be less $^{1}$ nearer the equator, as experiment shows it to be.

Suppose, however, that we had been born on an earth which was not revolving and that we had calibrated a number of spring balances after the manner described in Chapter III. Suppose that one night our hypothetical earth was set into a rotation like that which we now experience. All of our spring balances would register a little light. If then somebody told us that our earth was revolving we might say that such a rotation had resulted in a repulsion being exerted between the earth and all bodies on its surface.

In much the same way men became accustomed to electricity at rest, but following Volta's work they awoke suddenly to a world in which electricity is also moving.

then not show the phenomenon of weight at all. If it should revolve faster they would fly off into space.

1 This change in " $g$ " is in addition to the smaller change due to the increased separation, as discussed in Chapter XII. 
They had learned to speak in terms of force and to recognize that like charges repel, while unlike attract. A body which did not test as being either positive or negative, that is, a neutral body, contained equal and opposite charges. Such a body might, however, serve as a conductor of electricity. Two parallel conductors did not attract each other electrically, for the attraction of their unlike charges was balanced by the repulsion of their like charges. Nevertheless, when currents flowed through them in parallel directions they tractated. Therefore, men reasoned that electricities in motion attracted if going in parallel directions. When it came to electricity in motion they forgot Coulomb's law and treated it as a new entity, calling it "voltaic electricity," building up the subject of "electromagnetism," so called because such currents also affect magnets, and making new definitions for such electrical magnitudes as current, quantity, and potential difference.

Let us, however, express this phenomenon in terms of energy and electrons. Consider first two wires, say $A$ and $B$, which are not carrying currents. We analyze this system into four component systems, namely those comprised by (1) the free electrons of $A$ and of $B,(2)$ the positive molecules, (3) the electrons of $A$ and the positives of $B$, and conversely, (4) the electrons of $B$ and the positives of $A$. These potential energies exist but are absolutely not available, e.g. systems (1) and (3) are equal in their space rates, and the parts of (1) pellate while those of (3) tractate. If we could isolate one system we should find that the energy which we made available would just be equal to the work which we had done. 
If then the two wires are to tractate, energy must be given to the system from some outside source. If this condition is brought about by causing parallel currents we may justly consider it to be due to a decrease in the availability of the energy of system (1), for the molecules of the wires do not move more during conduction than before but the free electrons do. Individual electrons, of course, may start or stop; some may move with velocities higher than the average and some with less. The net effect, however, is just the same as if there was a stream of electrons formed by a definite number which move continuously with constant velocity. The available potential energy of a system of two electrons, moving in parallel paths, is less than if they were at rest by an amount equal to the work done in setting them into motion, that is, their own kinetic energy. Of course, because of the impacts which they make in their travel, energy must constantly be supplied equal in amount to the energy dissipated in heat in the conductors, if the condition is to be maintained.

We recognize, then, two expenditures of energy from the batteries which cause the streams of electrons. The first of these is equal to the kinetic energy of the electrons. It is made in the first few instants after the battery is connected. The second is the constant energy expenditure, the rate of which is expressed by Joule's Law. The current, which flows in the first moment or so before a steady condition is established, depends not only upon conditions in its own circuit but also upon those in the adjacent circuit. When the battery is removed from the circuit the moving 
electrons do not come to rest immediately, but only after they have expended the kinetic energy which was originally imparted to them.

In terms of energy we think of a system of electrons as having potential energy which is reduced if they are set in motion along parallel lines. The reduction will depend upon the velocity of the electrons. When will the p.e. be zero, and can two electrons ever attract? The answer to both questions comes in the statement that two electrons moving with the velocity of light do not pellate. The velocity of light is that with which all radiations from electrons are transmitted through a vacuum. It has the enormously high value of $3 \times 10^{10}$ cm. per sec., and appears to be the upper limit for velocity in our universe. Whatever the ether may be it cannot transmit disturbances faster than this. ${ }^{1}$ Of course, where electromagnetic disturbances are impeded in their passage through the ether by the presence of groups of electrons, as for example when light passes through a piece of glass, the velocity may be smaller than the value given above. The velocity of light represents the greatest velocity we can imagine in a universe built up, as is ours, of electrons. Two electrons, then, can never tractate but may be moving so fast that they do not pellate. Thus if an atom could be shot off through space with the velocity of light there would be no tractation of its nucleus and electrons. There would, then, be nothing to prevent the

${ }^{1}$ Media which transmit energy do so as a result of their elasticity, the velocity of propagation in each being determined by its constants of elasticity. For each substance there is therefore a definite velocity. The ether behaves like an elastic medium and transmits all disturbances at a definite rate. 
electrons flying apart, but they would have no tendency to do so.

If two equal circular loops are placed with their planes parallel as in Fig. 21, so that the distance between them is everywhere the same, then it is found that the force of attraction is proportional to the two currents and inversely as the distance between them and also directly proportional to the length of the current path. If one of the loops is formed of several turns of wire, since the same current will travel through each turn, the effect will be increased proportionately to the number of turns. If the current in one of the loops is reversed, then there is a repulsion

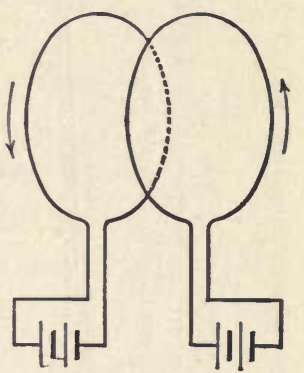

Frg. 21. equal to the former attraction. For convenience in determining for any pair of such circuits whether the action is one of repulsion or of attraction it is simplest to view both circuits from some point which is not between their planes. If the currents are in the same direction there is attraction, and if in opposite directions there is repulsion. Incidentally, it is obvious that in a coil of several turns the various turns are mutually attracted.

Consider the case of a fixed coil, $a b$, and a movable coil, $c d$, shown in Fig. 22, both carrying currents in the direction of the arrows. The interactions of the electrons in wires $a$ and $c$ cause them to pellate while wires $a$ and $d$ tractate. The result is that the coil $c d$ rotates in the direction of the heavy arrow. A rule may now be stated for the rotation of a movable coil 
with reference to a fixed coil. The former will turn until its motion has reduced the potential energy of the system to a minimum, in which condition the planes of the coils and the currents will be parallel. In

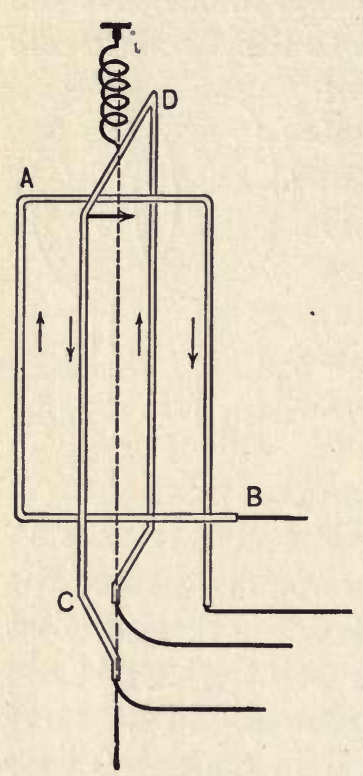

FIG. 22.

general, coils carrying currents, if free to move, will rotate so as to make their currents parallel and will also tractate, the resulting motion of each coil being a combination of the two.

If the coils are not single loops or bunched windings, but are solenoidal, we have a number of systems of single loops. Of course, each loop of a coil is not free to turn about its own axis, but all must turn about a common axis. The motion of translation is the same for all the loops of the same coil. Each of these systems tends by conversion into kinetic energy to reduce its potential energy, and the space rate at which that of the entire system reduces is the sum of the rates of the component systems; in other words, the force acting is the sum of the forces due to the several loops in all the combinations of two at a time which they can form.

In the solenoids which we have just considered the individual loops are mechanically connected and cannot revolve about axes lying in their own planes. Imagine one solenoid to be replaced by a large number 
of loops which are free to rotate about individual axes but have no individual freedom of translation. Suppose also that each loop is closed on itself instead of being connected in series with the others and that all are carrying equal currents. What would be the effect if such a group of loops were placed along the axis of a solenoid which is also carrying a current? Each loop will turn so as to reduce, as much as is possible, the potential energy of those similar systems which it forms with the loops of the solenoid, and then a further reduction will be occasioned by a translation of the group as a whole toward the solenoid.

The fact that a current is flowing in each loop means merely that electrons are rotating about its center. In the particular case under discussion such a rotation is accomplished by the motion, in the circumferential path formed by the metallic conductor, of its free electrons. The molecules of the metal do not move, and so far as concerns the effect in which we are interested the only function the metal serves is to keep the electrons in the path. Suppose, therefore, that a positive nucleus was located at the center of the loop. It would serve the same purpose. If, then, there are any substances the atoms of which are formed by electrons rotating in a plane about the positive nucleus, such atoms ought to act just like the single loops which we have been discussing.

What would be the test? Obviously if we bring long cylindrical pieces of different substances near to a solenoid which is carrying a current then those whose atoms are of this description will tractate toward it. In the case of iron and its compounds and also of 
nickel and cobalt this effect is very pronounced. In most other substances it is practically negligible. The substances in which there is any effect whatever are called "paramagnetic," while those like iron are known as "magnetic."

The group of loops which we have described is a model of a magnetic body. Since the loops are free to turn, thus reducing the potential energies of the systems they form with each other, and since the greatest reduction would have been made when the electrons were moving in parallel paths, we might expect that they would do so and hence that in a magnetic substance the molecules would naturally have assumed similar orientations. Such, however, is not the case. The molecules have haphazard orientations, as may be verified by placing the body near another similar body and noting that there is no attraction or repulsion, as would be the case if their molecular currents were not flowing "every which way." The explanation is that the molecules have already formed themselves into a large number of small and fairly stable groups.

When such a body is placed near a loop carrying a current some of these groups are disrupted, new groups being formed with more molecules oriented in the direction of minimum potential energy with respect to the magnetizing current. Two phenomena are now possible when the magnetizing coil is withdrawn or its current interrupted. Either these newly formed molecular groups may break down, due to their interactions with adjacent groups, or many of them may be so stable as to persist more or less permanently. In the latter case the magnetic body is said to be permanently magnetized and is 
called a magnet. The reason why two magnets attract or repel is to be found in the interactions of these oriented loops.

The discovery of electricity in motion by Galvani and that of a source by Volta was followed in 1820 by the important discovery of Oersted, a Danish investigator. His experiments showed that a magnet was deflected from the magnetic meridian by a conductor carrying a current when the latter was placed over the needle and parallel to it. The direction of deflection was reversed when that of the current in the conductor was reversed. This phenomenon came to be explained and stated in terms of force by saying that the current exerts a magnetic force. About the conductor there is said to be a magnetic field, that is, a region in which a magnetic force may act.

The intensity of this magnetic field at any point was quantitatively expressed in terms of the force which it would exert upon a so-called "unit magnetic pole" placed at the point. The direction of the field was taken as that in which a "north-seeking" pole would move under the action of this force. The forces exerted between magnets had already been investigated by Coulomb, who obtained a relation identical in form with that for electrical charges, namely,

$$
F=\frac{m_{1} m_{2}}{\mu r^{2}}
$$

where $m$ is the pole strength and $\mu$ is a constant of proportionality. Taking $\mu$ equal to unity for a vacuum (or air), the equation defines unit pole as one which will exert upon a like pole a force of 1 dyne at a dis- 
tance of 1 centimeter. The defining equation for field intensity, $H$, is then

$$
H=\frac{F}{m}
$$

where $F$ is the force in dynes which the field exerts on a pole of $m$ units.

Experiments during the years immediately following Oersted's discovery developed the fact that the magnetic field due to a current in a conductor is directly proportional to the magnitude of the current, to the length, $l$, of conductor if it is everywhere the same distance, $r$, from the point where the field is being measured, and inversely as $r$. A unit for current was therefore adopted as that current which flowing through $1 \mathrm{~cm}$. of the arc of a circle $1 \mathrm{~cm}$. in radius would establish at the center of the are a field of unit intensity. Such a current would then exert one dyne of force on a unit pole at the center. This is the electromagnetic unit of current in the C.G.S. system.

The action between such a current and the unit pole is, however, in the nature of a stress, and the pole reacts on the conductor pushing it sidewise with an equal and opposite force. The reaction on the conductor is therefore 1 dyne. The current is pushed sidewise by a magnetic field of unit intensity, for the unit pole at the center would exert 1 dyne of force on a similar pole anywhere on an are $1 \mathrm{~cm}$. from it. The field in which the conductor is placed is unity and the length of the conductor $1 \mathrm{~cm}$. If field, current, or length is increased, other things being equal, the force exerted on the conductor is proportionately increased. 
That is, a conductor of length $l$, placed at right angles to a magnetic field $H$, and carrying a current $i$, is pushed sidewise with a force of $F$. Hence

$$
F=i l H
$$

is the most convenient form for the electromagnetic relation defining current.

While this equation is peculiarly useful, it successfully obscures the energy relations. All ideas of the interactions of electrons in motion, of the relative motions of the two bodies containing these electron streams, of the decreasing potential energy which is the fundamental cause of the motion, are left without either expression or implication. It is impraticable, however, at this late date to rewrite this defining equation in terms of energy and electrons.

The laws for the motions of conductors carrying currents are all expressed in terms of the positive carriers, although this is the exact reverse of the actual mechanism of conduction in wires. In terms of electrons the laws might be expressed as follows: The direction of a magnetic field is that in which a so-called north pole would move. In any coil or magnet in which the direction of the rotating electrons is clockwise the field is directed toward the observer. Electron streams which are parallel, tractate. Streams which are in opposite sense pellate. The motion of a conductor at right angles to a magnetic field is at right angles to both the direction of the electrons and that of the field. These motions are related as the thumb, center finger, and forefinger respectively of the right hand. 
In 1831 Michael Faraday performed his simple, illuminating experiments on the production of currents by electromagnetic induction. These phenomena he pictured in terms of magnetic lines or tubes of force which extend through space from the north pole of a magnet to the south pole. Such lines, also, are imagined to form concentric circles in planes perpendicular to a conductor carrying a current. At any point in space their number is considered proportional to the strength of the magnetic field and their direction that of the field. If these lines are assumed to have two mechanical properties they may be used to explain all the attractions or repulsions of magnets and coils. The first property is that of contracting indefinitely. The second is that of exerting a pressure on each other which is perpendicular to their directions.

Faraday's discoveries are usually expressed by saying that a relative motion of a conductor and a magnetic line induces an electromotive force. ${ }^{1}$ An e.m.f. is induced only while the conductor crosses lines of force, and its amount depends upon the time rate at which the lines are cut. If the conductor forms a closed circuit, then an induced current flows in it provided that there is a net change in the number of magnetic lines threading it. It makes no difference whether the cutting is occasioned by the actual motion of the conductor relative to a current-carrying coil, or magnet, or is occasioned by changes in the current and hence

1 The term electromotive force originated in the days when the causes of motions were sought in forces, and persists to-day. It is essentially synonymous with "difference of potential " in the units of which it is measured. 
in the magnetic field of a coil which is fixed in space with reference to the conductor. In every case, as was first stated succinctly by Lenz, the direction of the induced current is such as to oppose the cause inducing it. This is, of course, an electrical statement of the principle of the equality and opposition of action and reaction which had been noted by Newton.

If in one of two parallel loops of wire a stream of electrons is started in a clockwise direction there is induced in the other loop a stream in a counterclockwise direction. The e.m.f. in the second circuit exists only while the current in the first coil is building up, that is, only while there are more electrons starting than stopping. The direction of the current in the second coil is obviously such that the coils tend to move apart. An induced current of the same direction would occur in the second coil if it were moved toward the first. Conversely if the second coil were moved away from the first the induced current would be in the opposite direction, that is, in the direction to oppose the motion inducing it. These phenomena are usually stated in terms of magnetic lines of force and the motion of positive charges. The idea of energy is frequently obscured thereby and the motion of electrons is entirely neglected.

In discussing energy we found that work results from a relative motion of the parts of a system to a configuration of smaller potential energy. Two parallel conductors carrying parallel streams of electrons tractate and may thus do work in the same manner as a gravitational system. We therefore say that the conductors move to a position of smaller potential energy, The 
potential energy of the system is not, however, as in a gravitational system, inherent in the separation of the two bodies. It is a potential energy of ponderable and visible masses by appearance only. In final analysis, it is a kinetic energy of the electrons within the conductors, for unless there are electron streams there is no potential energy. When motion is allowed, external work is done at the expense of the electrons.

The current is therefore reduced. This is not, however, the only reduction which occurs. Due to the relative motion of the two conductors, currents are induced in them in such directions as to oppose the currents which occasion this motion. The average velocity of the free electrons which are taking part in the conduction is therefore reduced. (An induced current occurs whether the motion inducing it is caused by an expenditure of mechanical energy or is the result of the mutual attraction of the two parallel currents.)

If the electron streams are not allowed to decrease, but are maintained at the expense of batteries or other sources of energy connected in the conducting circuits, then such sources must supply an amount of energy equal to the external work accompanying the motion, and also such energy as is required to restore the electrons to their former velocities. (We are neglecting any stopping of the electrons due to collisions in the conductors whereby energy is dissipated in heat.)

Let us state this phenomenon in a slightly different manner. Two conductors carrying parallel currents possess a potential energy which depends upon the currents and is less if the separation between the con- 
ductors is less. If we allow them to tractate we find the currents reduced, but when we attempt to restore them to their former value we have to supply a larger amount of energy than was derived in external work. In restoring the currents to their former value we have made the same number of electrons per second pass through a cross section of the conductor. If this represents the same kinetic energy as before it should have been necessary to supply to the system only an amount of energy equal to the external work. We have to supply as much again. ${ }^{1}$ It therefore appears that the same number of electrons moving with the same velocity now possess a greater kinetic energy. This conclusion we must reach if we accept the principle of the conservation of energy.

We are accustomed to consider the kinetic energy as $m v^{2} / 2$. Can the mass of the electron be different in the two cases? This brings us squarely against the question as to what we mean by mass. We have been using mass as meaning amount of matter, but we have had occasion to deal either with electrically neutral bodies or with bodies, like the pith balls mentioned in Chapter VII, which are composed of millions and millions of neutral molecules and comparatively few excess electrons. We have measured masses in terms of the standard kilogram by a comparison of the gravitational potential energies of the unknown and known mass. Or, by our own muscular sense, we have compared inertias and said that they were equal when equal forces produced equal accelerations. We have then said that the bodies of equal inertia had equal masses.

1 Cf. footnote of p. 215. 
The only conclusion at which we can arrive is that part or all of the mass of an electron is what we might call "electromagnetic" to distinguish it from the sort of masses with which we have so far had to deal. If we say that all of the mass of an electron is of this character, that is, not invariable in its inertia, then we are in accord with the modern theory.

Consider now the conditions of the conductors, which we were discussing, in order to determine what factors influence the effective inertia of an electron. We notice that the electrons are in motion. We also notice that the kinetic energy of two parallel electron streams is greater, even though the velocity remains the same, when the streams are closer together. The inertia or mass, as we prefer to say, of an electron depends, then, upon its velocity and upon the parallel streams of electrons in its neighborhood.

It has been found, however, that for velocities which are small as compared to that of light the mass of the electron is practically constant. If the mass at rest is represented by $m_{0}$, while that for motion with a velocity of $v \mathrm{~cm}$./sec. is represented by $m$, and the velocity of light by $c \mathrm{~cm}$./ sec. then

$$
m=m_{0} \frac{1}{\sqrt{1-v^{2} / c^{2}}}
$$

gives values for $m$ which have been checked by experiment for speeds from about 0.3 to 0.8 that of light. For experimental purposes electrons moving with these high velocities are obtained from X-ray tubes or from radioactive substances.

For velocities below about $0.1 c$. such as we meet in 
the mechanical problems of falling bodies, railroad trains, aëroplanes, the transmission of sound, or even molecular motions in gases and liquids, we may consider mass to be invariable. For such velocities as we meet in the transmission of electricity through metallic or electrolytic conductors the mass of the electron is invariable except as it may be influenced by the presence of other moving electrons. In the case of electrons emitted by radioactive substances we cannot consider the mass invariable, for it will depend upon its velocity.

As to the variation in apparent mass and hence in kinetic energy due to the motions of other electrons, we may say that it always requires more energy to impart a given velocity to an electron if it is set into motion parallel with that of another electron, but less energy if its direction of motion is parallel and opposite to that of another electron.

In establishing a current, say $i$, in a conductor of more than one turn, e.g. in a solenoid, the mass of each electron is dependent upon the existing motion of all the other electrons not only in its own loop but also in all the other loops. The calculation of the increase in mass of the electron under consideration is therefore rendered too difficult except in the case of a few circuits of simple geometrical form. The energy required to establish $i$ depends upon the mass and this in turn upon the configuration of the circuit and upon the current. For each electron the energy will be one half the product of its mass and the square of its velocity. In a circuit like that of a metallic conductor, where the number of free electrons available for transfer 
is constant, the current will depend only upon the velocity with which they move. In other words, velocity and current are proportional.

The total kinetic energy represented by a current, $i$, is therefore proportional to $i^{2}$. Let us write it as

$$
K . E .=\frac{1}{2} L i^{2}
$$

where $L$ is a factor of proportionality which depends upon the mass of the electrons and hence upon the geometrical form of the circuit. The factor, $L$, is usually called the coefficient of self-induction of the circuit, because it determines the currents induced in each part of the circuit by the changing electron streams in all the other parts. It is a measure of the retardation or negative acceleration of the electrons occasioned by their interactions.

The self-inductance takes into account only those interactions occurring between the electrons of its own circuit. If there is in the neighborhood of a circuit of inductance $L_{1}$, with a current of $i_{1}$, another circuit which is carrying a current, say $i_{2}$, then there are possible interactions between the two circuits which may either increase or decrease the energy required to establish the current $i_{1}$ in circuit 1 . Consider first a single loop and let its inductance be $L$. If a current of $I$ is flowing in it, the kinetic energy is $\frac{1}{2} L I^{2}$. Now suppose we divide this circuit lengthwise of the conductor by an imaginary plane so that on one side the current is $i_{1}$ and on the other side $i_{2}$, where $i_{2}=I-i_{1}$. The energy may now be expressed as

$$
\therefore \quad K . E .=\frac{1}{2} L I^{2}=\frac{1}{2} L\left(i_{1}+i_{2}\right)^{2}=\frac{1}{2} L i_{1}{ }^{2}+L i_{1} i_{2}+\frac{1}{2} L i_{2}{ }^{2}
$$


Let us now maintain the two currents by two separate batteries. The forms of the two circuits obtained by using the plane are identical and both have the same inductance. Let us, however, represent the inductance of each circuit by its proper subscript. The energy represented by $\frac{1}{2} L i_{1}^{2}$ above then becomes $\frac{1}{2} L_{1} i_{1}^{2}$; and similarly $\frac{1}{2} L_{2} i_{2}{ }^{2}$. These are evidently the energies which the circuits would possess if they were isolated in space.

But what about the energy represented by $L i_{1} i_{2}$ ? Is it intrinsic to circuit 1 or to circuit 2? Obviously it is a mutual energy. Let us therefore write it as $M i_{1} i_{2}$, indicating by the $M$ that it is mutual. The total energy of the system may now be represented as

$$
K . E .=\frac{1}{2} L_{1} i_{1}^{2}+\frac{1}{2} L_{2} i_{2}^{2}+M i_{1} i_{2}
$$

Which circuit has contributed this mutual energy? The answer is: both circuits. For example, if we allow the current to become established in circuit 1 and then attempt to establish the current $i_{2}$ we find that the acceleration of the electrons in circuit 2 has been accompanied by a retardation of those of circuit 1. Additional energy, therefore, must be supplied to circuit 1 to maintain the velocity of its electrons. The value of $M$ may, however, be negative, ${ }^{1}$ depend-

${ }^{1}$ If motion of the coils occurs, $M$ changes in value. If it does, the kinetic energy of electrons is converted into kinetic energy of the ponderable coils or vice versa. In the first case (that of p. 211) it may be shown that to maintain the currents the battery sources must supply an increase of k.e. of electrons equal to twice the external work done by the moving coils. In the second case the source of mechanical energy supplies twice the decrease in k.e. of the electrons. 
ing upon the relative directions of the two currents. If it is negative the energy expenditure, required to establish in the circuits the corresponding currents, is less than would have been required if they had been isolated.

An acceleration of the electrons in one circuit produces a retardation of those electrons in an adjacent circuit which are moving in a parallel direction. The interactions of two electrons in motion therefore constitute a stress. In other words, Newton's third law applies to electrons in motion. 


\section{CHAPTER XVI}

\section{THE CONTINUITY AND CORRESPONDENCE OF MOLECULAR STATES}

THE statement that matter is molecular in composition implies that no abrupt change takes place when a body of matter undergoes a change from one to another of the three forms - solid, liquid, and aëriform. The changes in state are successive and continuous. Many attempts were made during the latter half of the 19th century to formulate a relation which would represent all the possible states not only of a single substance but of all substances which are not mixtures of several kinds of molecules.

These equations were usually extensions of equation (2) of page 164 which expresses the relation between pressure, volume, and kinetic energy of translation, the latter being a measure of the absolute temperature. Let $w$ represent the average change in the kinetic energy of translation of a single molecule, when the temperature of the mass is changed by one degree. Then the average k.e. of translation of a single molecule in a mass, which is at an absolute temperature of $T$, will be $w T$. For $N$ molecules the energy will be $N w T$.

Hence

$$
P V=\frac{2}{3} N w T
$$


We may deal always with the same number of molecules, whatever the substance may be, by taking 1 mole of it as explained on page 85. The quantity $N w$ is then independent of the substance. Hence for 1 mole let us write $\frac{2}{3} N w=R$ where $R$ is constant. ${ }^{1}$

Hence

$$
P V=R T
$$

This equation gives the relation between the three variables of pressure, volume, and temperature which determine the "state" of a gas. For example suppose

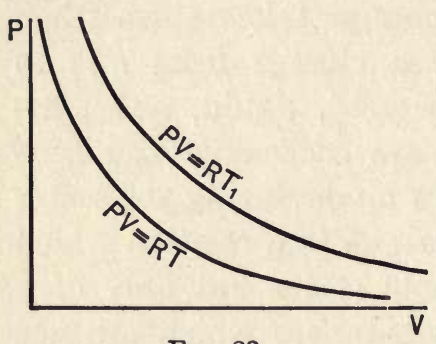

Frg. 23. the temperature is maintained constant at a value represented by $T$, then the points corresponding to all the possible pairs of values may be represented by a hyperbolic curve like that marked $P V=R T$ in Figure 23. If the temperature is increased to $T_{1}$ the values of $P$ and $V$ will lie on a new hyperbola like that marked $P V=R T_{1}$. These curves are called isothermals.

In developing equation (2) we tacitly assumed that the volume actually occupied by the molecules is small as compared to the volume $V$ in which they are

1 The numerical value of $R$ may be found from the following data: Under standard conditions of pressure and temperature, namely $76 \mathrm{~cm}$. of mercury and $0^{\circ} \mathrm{C}$., the volume of $2.016 \mathrm{gm}$., that is $1 \mathrm{~mole}$, of hydrogen is $22,410 \mathrm{c.c}$. Since the density of mercury is 13.6 and $g$ is 980 , the pressure in dynes of a column $76 \mathrm{~cm}$. high is $13.6 \times 76 \times 980$ or $1.013 \times 10^{6}$ dynes per sq. $\mathrm{em}$. The temperature $T$ is 273 . Substituting these values of $P, V$, and $T$ in equation (2) gives $R$ as $83.2 \times 10^{6}$ ergs per degree. 
contained. This assumption is, of course, not valid at high pressures. We also assumed that the molecules of a gas do not form with each other systems having potential energy, and hence that there are no attractions or repulsions between them.

If a body of gas for which there are no molecular attractions is allowed to expand, as for example by pushing a piston, it will do work at the expense of its molecular k.e. of translation. Its temperature will therefore fall. If it is then heated until its temperature is restored it will require from the source of the heat an amount of energy just equal to the external work done in the expansion. But if no external work is done during the expansion then no energy should be required to maintain the temperature. Thus consider two connecting vessels, $A$ and $B$, which are separated by a stopcock. Let $A$ be filled with a gas at a high pressure and let $B$ be practically a vacuum. Let the system be immersed in a vessel of water, changes in the temperature of which may be observed by a sensitive thermometer. After the temperature has become that of the bath, the stopcock is opened. The gas rushing from $A$ into $B$ does no external work. We should therefore expect no change in the average k.e. and hence no change in the temperature as indicated by the thermometer.

On the other hand, if the molecules form with each other systems the potential energy of which increases with their separation such an expansion involves an increase in their p.e. This increase can be obtained only at the expense of the kinetic energy of the molecules. The temperature of the gas will then fall. 
This method was first used by Joule, who found no change in temperature. The conclusion reached above, as to the equivalence between external work and energy input in the form of heat, when an expanding gas is maintained at constant temperature, is known as Joule's Law. Later and more precise experiments showed that all gases cool somewhat upon free expansion, except that for hydrogen there is an anomalous warming effect at ordinary temperatures.

If Joule's Law does not hold we are not at liberty to use the equation $P V=R T$ except as an approximation. It is convenient, nevertheless, in considering gases to discuss the "perfect gases," that is, imaginary gases, for which $P V=R T$ would always be true. Actual gases depart from this perfect gas relation not only because the molecules occupy some space, but also because the compression of a gas is not due solely to the externally applied pressure. The molecules are brought closer together by the tractation which accompanies the decrease in p.e. of the systems which they form. Except, however, for temperatures near that at which the gas liquefies the perfect gas equation may be used to determine the condition of an actual gas.

In liquids the molecules are very close together. A molecule in the body of a liquid moves without any effect from those molecular attractions which are due to its potential energy with the other molecules. This is because the other molecules are disposed about it in spherical shells. For any molecule of such a shell there is always diametrically opposite another molecule. With these two the particular molecule at the 
center forms two balanced systems of potential energy. For a molecule at the surface as in Fig. 24 it is evident that the systems are unbalanced, and hence it would move inward. (The systems which a surface molecule forms with other molecules on the surface appear in balanced pairs, and there is no tendency to move along the surface.) The p.e. of the liquid molecules is therefore decreased by such an inward motion

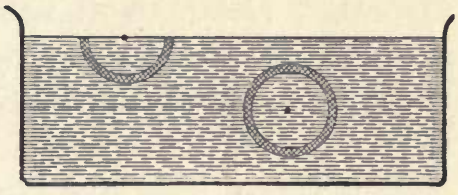

FIg. 24. until the surface is as small as is consistent with the volume which it must contain. The ratio of surface area to volume thus reduces to a minimum, and hence liquid drops are spherical unless affected by gravity. This phenomenon is known as "surface tension."

When a liquid "wets" a solid in contact with it, the molecules of the liquid and those of the solid form systems for which the potential energy is greater, other things being equal, than it is for the systems of molecules of the liquid alone. The liquid molecules tend to

FiG. 25. spread out over the surface of the solid, reducing as
much as possible their separation from those of the solid. Conversely if the liquid does not wet the solid it is unaffected by the latter. Thus a drop of mercury in contact with clean glass assumes the oblate ${ }^{1}$ spheroidal form shown in Fig. 25.

At the critical temperature at which liquefaction is

${ }^{1}$ The drop of mercury approaches the spherical form until a further increase in sphericity would cause an increase in gravitational p.e. greater than the decrease in molecular p.e. 
just possible the phenomenon of surface tension vanishes. For temperatures below this value the k.e. of the molecules is insufficient to render unavailable the p.e. and tractation occurs. As the temperature is decreased from the critical value the surface tension increases, although at first very slowly. Now water is ordinarily well below its critical temperature of $360^{\circ}$ C., and in it therefore we find a very noticeable surface tension.

Because of this p.e. between molecules and also because of the space occupied by molecules, the perfect gas equation does not apply to an actual gas except at temperatures well above the critical value. The process of liquefaction is obviously not taken into account by the perfect gas equation, for the molecules of a perfect gas could be compressed and cooled indefinitely without ever acting like a liquid, since they have no p.e. It would be convenient if we had an equation of state which was applicable not only to actual gases but also to the same molecules in a liquid state. One of the most successful attempts to develop such an equation was that of Van der Waals. We may consider his equation to be formed from the equation $P V=R T$, by the introduction of two correction factors.

The first of these is introduced to take into account the fact that the volume $V$ in the above equation is too large by an amount dependent upon the actual space occupied by the molecules. Let us represent this amount by $b$ and hence substitute $V-b$ for $V$. The second correction factor takes into account the p.e. of the molecules. Because this tends to decrease the molecules tractate and the effect is the same as if the 
pressure was greater. The pressure $P$ in the gas equation is therefore too small by an amount which depends upon the separations of the molecules, being inversely as the square of the volume. For $P$ we write the expression $\left(P+a / V^{2}\right)$. Making these substitutions, we have the equation of Van der Waals

$$
\left(P+a / V^{2}\right)(V-b)=R T
$$

or multiplying out

$$
V^{3}-\frac{R T+P b}{P} V^{2}+\frac{a V}{P}-\frac{a b}{P}=0
$$

The values of $a$ and $b$ may be determined by substituting in this equation the known value of $R$ and experimentally determined values of $P, V$, and $T$.

Equation (4) evidently states the physical relation by which we should expect to calculate the volume $V$ of a molecular mass upon which the pressure is $P$ and of which the absolute temperature is $T$. It is a general theorem of mathematics that there are three roots for an equation in which the highest power of the unknown magnitude is a cube. Since $V$ enters as a cube we expect to obtain three numerical values for it. But can a molecular mass under these conditions fill three different volumes? If we consider $V$ in the perfect gas equation to be the unknown there is only one possible value which it may have for any assigned values of $P$ and $T$. According to equation (4), under the same conditions of pressure and temperature there appear to be three different volumes, any one of which the molecules might occupy equally well, so far as concerns the physical conditions represented by the equation. 
We can conceive of three such volumes if we take into account that the molecular mass may be either a gas, a liquid, or part liquid and part gaseous. When a gas changes into a liquid we say it condenses, and conversely when a liquid changes into a gas or vapor we say it boils. This reversible phenomenon we shall need to discuss before considering further the roots of Van der Waals's equation.

The temperature at which this phenomenon occurs is the boiling point. The boiling point is raised if the liquid is subjected to an increased pressure. Water boils at $100^{\circ} \mathrm{C}$. under a pressure of $76 \mathrm{~cm}$. of mercury. In mountain districts, the pressure being less, boiling occurs at correspondingly lower temperatures. In a boiler of a steam-engine plant the boiling point of water may be very much higher than $100^{\circ} \mathrm{C}$. At the boiling point, however, the pressure exerted by the water vapor molecules is always just equal to that of the air or vapor molecules above them. If the molecules are not allowed to escape from the boiler, as is the case in "getting up steam," the increase of molecules in the space above the liquid results in an increase in the pressure against which those still in the liquid must escape. They must, therefore, have a higher kinetic energy, and when they do escape they increase still further the pressure exerted upon the liquid by its own vapor. The pressure of the steam (and water) thus rises. When it reaches the desired value steam may be withdrawn to run the engine, but the molecules thus withdrawn must be continuously replaced by others with the same average $k . e$. or the pressure will fall.

If the pressure exerted on a body of vapor in contact 
with its liquid is increased there will be a condensation unless the molecular k.e. is correspondingly increased, that is, unless the temperature of the liquid (and vapor) is raised to the new boiling point. Now we have seen that when the molecules of a substance are in the liquid state the potential energy of the systems they form with each other has been reduced. Obviously then, if an attempt is made to increase the pressure exerted upon a liquid and its vapor, the condensation which occurs will cause a reduction of this molecular potential energy. What becomes of the energy thus released? It is available for increasing the molecular kinetic energy and thus for opposing, by the pressure of these molecules, the very cause, namely increased external pressure, which induced the effect. ${ }^{1}$ An increase in molecular pressure thus occurs to meet the increase in the externally applied pressure.

Suppose, however, that as fast as energy is liberated by the condensing molecules of the vapor it is withdrawn from the system. That is, suppose the change in pressure is made isothermally. The slightest increase in pressure results in the condensation of a part of the vapor. The pressure exerted by the vapor does not rise because the energy released by condensation is immediately subtracted. Condensation, therefore, occurs at constant pressure and temperature until all the vapor is condensed. This phenomenon is usually shown in the laboratory by using a barometer tube, I, as in Fig. 26. A drop of liquid is released into the vacuum at the top by inserting the point of a medicine

1 This reminds us of "action and reaction." Later we shall discuss the principle of Le Chatelier which has to do with such eases. 
dropper into the mercury immediately under the column. Evaporation then takes place from this drop, which should be some highly volatile substance, like ether, so that the effect will be marked at ordinary temperatures. The evaporation continues until the number of molecules in the space above the liquid is

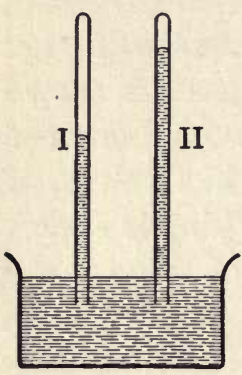

FIG. 26. such that at each instant just as many are condensing into the liquid form as there are evaporating from the surface. A statistical equilibrium is thus established between the liquid and its vapor. The pressure exerted by the vapor molecules plus that of the weight of the column of mercury (the weight of the drop of liquid is negligible) must balance the external atmosphere. The mercury in the column therefore falls. The amount that this column is reduced, as shown by a second barometer column, II, is the measure of the vapor pressure in centimeters of mercury.

If the barometer tube is pushed down into the mercury the liquid condenses. If the tube is moved slowly the temperature will remain constant, for the tube and its contents will lose energy to their surroundings as fast as it is released by the condensation. The reduction of the volume, occupied by the liquid and its vapor, will be found to occur at constant pressure, as will be evidenced by the constancy of the height of the mercury volume. Similarly, if the volume is increased by raising the tube it will be found that this also occasions no change in the pressure as long as any liquid is in contact with the vapor. After all the liquid is evap- 
orated the mercury column will rise as the tube is raised, indicating a reduction in the pressure of the vapor with increased volume. The volume and pressure will then be related practically as for a perfect gas.

Let us now make a plot to show these relations of $P$ and $V$ for a substance which is maintained at a temperature below its critical temperature, so that the liquid and its vapor may coexist in equilibrium. Let us start with the substance entirely in the form of vapor. Let this condition be represented by the point $a$ of Fig. 27. If the pressure is increased the volume decreases practically inversely, and successive states are represented by points along the hyperbolic curve $a b$. At $b$ the pressure is such that there is some condensation.

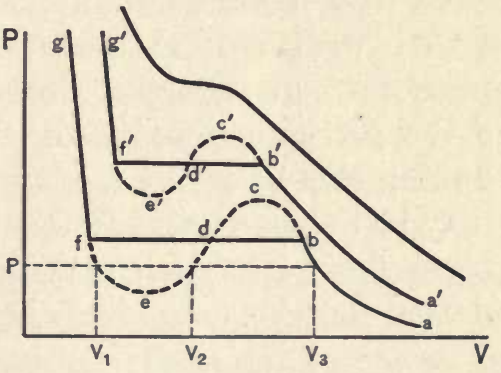

FIG. 27.

This pressure is the vapor pressure of boiling for the temperature of this isothermal. As we have just seen, this pressure cannot be increased as long as the substance is maintained at the same temperature. An attempt to increase the externally applied pressure merely results in a decrease in volume. The successive states of the substance are now represented by the solid line bf. When the vapor is all condensed the volume (represented at $f$ ) is merely that of the liquid. Further increase in the pressure compresses the liquid, as represented by the line $f g$.

These changes may be carried out in the reverse 
order, by starting with the liquid in the state corresponding to $g$, and following the isothermal in the order $g f b a$ by gradually reducing the pressure. Incidentally, it may be pointed out that in this reversible cyclic process such work as we did in compressing the substance is returned to us as it expands. Such energy as was imparted to the surroundings during compression is also returned during the expansion.

It does not always happen that the change follows exactly this isothermal, abfg. For example, it is possible with a pure liquid, free from dissolved air, in a vessel with smooth walls, to obtain the following phenomenon. Starting from the state indicated by $g$ the pressure is reduced. When $f$ is reached where boiling should occur, it may not occur. The pressure may be reduced well below this value without ebullition occurring. The $V-P$ plot then follows the partially dotted line gfe. Suddenly, however, ebullition occurs.

A somewhat similar phenomenon may occur if we start with the substance in the gaseous condition, as represented at $a$. As the pressure is increased the volume is decreased. This decrease may extend along the dotted line $a b c$ well beyond the point $b$. The molecules are thus compressed without aggregating into drops of liquid. Suddenly condensation takes place and the pressure drops to the boiling point pressure corresponding to the temperature of the isothermal. The state corresponding to $b$ is called that of saturated vapor. From $a$ to $b$ the vapor is below saturation, that is, the molecular density of the vapor is less than that of a vapor at the same temperature which is in contact with its liquid. 
Saturated vapor is in equilibrium with its liquid. Unsaturated vapor is not, for it tends to increase in number of molecules at the expense of the liquid. On the other hand, supersaturated vapor, such as corresponds to states represented by the curve $b c$, is in a decidedly unstable equilibrium. ${ }^{1}$ The slightest cause will result in a disproportionate effect. Such a cause may be furnished by inserting a drop of the liquid or by particles of dust and other impurities.

It has proved impossible as yet to penetrate very far into the region of instability, whether above $b$ or below $f$. It is usual therefore to follow the suggestion of James Thomson and draw a dotted line like cde to represent for an absolutely pure substance the part of the isothermal which we cannot follow experimentally. Somewhere between $b$ and $f$ the substance, which is a gas at $b$ and liquid at $f$, must change from one to the other. It seems reasonable to assume that such a change would occur continuously in some such way as that represented by cde. Thus the pressure rising above $b$ might ultimately reach a maximum at $c$. As it decreases it might well fall too low, reaching a minimum at $e$. Let us remember that the process of aggregation into a liquid is a contraction of the substance, that is, a motion of the molecules toward each other. Since they have inertia, or mass, such a motion might well result in an excessive contraction corresponding to the state $e$.

In the states represented by the line $b c$ the vapor is

${ }^{1}$ Similar phenomena of instability of state occur in the case of liquids cooled below the freezing point. For their observation laboratory conditions are usually required. 
compressed and has an excess of energy, for the molecules have not yet converted their p.e. into k.e. The contraction has consumed external energy instead of available internal energy. From $c$ to $d$ this molecular p.e. is released. When it is converted into k.e., the molecules may travel beyond their positions of stable equilibrium until their relative separations are too small, as represented by the point $e$. As the molecules return to a separation corresponding to stable equilibrium the pressure increases, as represented by the line $e f$. The molecules thus arrive at the same condition as if the successive states had been as represented by the line $b f$, and there had been no overshooting of the mark.

We cannot carry a substance through this hypothetical isothermal, for we cannot carry it as far as either the maximum or the minimum. Van der Waals's equation, however, indicates such a form for the isothermal of a pure substance. Thomson's hypothesis appears conceivable and is supported to some extent by the experimental entry into these regions of instability. The effects which scientists observe in pressure and temperature are, however, average effects of very large numbers of molecules. If we could only observe the interactions of individual molecules we should need no hypothesis. But if we could observe and direct the actions of individual molecules we could also make possible far more efficient utilization of molecular energy and even be able to alter the processes of life itself. It is the intuition of scientists, however, that it is impossible to control the action of molecules except in so far as their average effects are concerned. 
Returning to the hypothetical isothermal of Fig. 27 , we notice that for any pressure higher than that corresponding to the state $e$ and lower than that of $c$ there are three possible volumes, e.g. those marked $v_{1}, v_{2}$, and $v_{3}$ in the figure. In this figure are also plotted isothermals for higher temperatures. Consider for example that lettered $a^{\prime} b^{\prime} c^{\prime} d^{\prime} e^{\prime} f^{\prime} g^{\prime}$. At this higher temperature the molecules occupying a volume corresponding to $a$ are at the higher pressure corresponding to $a^{\prime}$. Because the temperature is higher, that is because of greater k.e.,

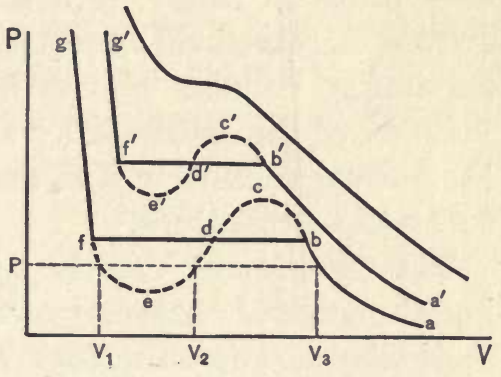

Fig. 27. the external pressure which must supplement the attractions due to molecular potential energy in order to cause condensation is greater. This is merely another statement of the fact that the boiling point increases with pressure. The volume of the liquid is now greater than at the lower temperature because liquids expand if the molecular k.e. is increased.

The distance $b^{\prime} f^{\prime}$ is therefore less than $b f$, and the dotted portions of the isothermal should be less pronounced. The range of pressures for which three volumes are possible is also reduced. The maximum volume occupied by the liquid, corresponding to $f$, increases as the temperature rises, while the minimum volume which can be occupied by the molecules in a stable gas condition, corresponding to $b$, decreases with the increase in temperature. (For some tempera- 
ture these two volumes are the same. For higher temperatures the substance cannot exist as a liquid and the isothermals are the hyperbolic curves of a gas.)

As the temperature rises the three volumes which Van der Waals's equation indicates (two of which exist only on the hypothetical portion of the isothermal) approach each other in value. For some particular values, say $P_{c}$ and $T_{c}$, they will be equal. This occurs when the maximum volume of the liquid and the minimum volume of the saturated vapor are equal. This is the critical volume, and $P_{c}$ and $T_{c}$ are the critical pressure and temperature.

The equation of Van der Waals has value as indicating the general character of the relations between the molecules of any substance and the fact that all substances behave essentially alike, but it gives only approximate relations. It fails particularly to give accurate values for the critical state.

It has been found, however, that an extension of this equation may be used to considerable advantage. Instead of using $P, V$, and $T$ to represent the actual pressures, volumes, and temperatures, there are substituted the fractions which these are of the critical values. For example, when two different substances are under pressures which are the same fractions of their respective critical pressures, they are said to be in corresponding states of pressure. Similarly there are corresponding temperatures and volumes. These substitutions give rise to an equation which should be applicable to all substances. All substances, since they are composed of molecules, provided the molecules do not change (chemically), should act in the 
same way, and pass through "corresponding states." Experiments and calculations have been made for a large number of substances to determine whether or not this is so, and it has been found very nearly true. The differences are small for substances which are somewhat similar chemically, but greater for other substances. 


\section{CHAPTER XVII}

\section{MOLECULAR MIXTURES}

The law for the pressure ${ }^{1}$ of a mixture of two or more gases resulted from experiments by Dalton which originated in his desire to explain the mixture of gases in which men were just realizing that they were living. In our study, some 120 years later, we may start from the concept of a molecular and atomic composition and thus obtain general expressions for the molecular condition of homogeneous substances. In this chapter we shall consider mixtures of molecules.

In the case of a mixture of a gas and a liquid it is usual to say that the gas is dissolved by the liquid. Consider the case where there is no chemical action between the two kinds of molecules. Let the liquid be contained in a cylinder which we then fill with gas and compress by a piston. Above the liquid surface there is a mixture of two aëriform substances, namely the gas and the vapor of the liquid, and below the surface the mixture of liquid and gas which we call a solution. $^{2}$ The pressure on the piston is the sum of

1 Dalton's law is obviously only an approximate relation. Chemically inert gases, provided their volumes are well above the critical volumes, act like perfect gases, in that the total pressure due to molecular impacts is the sum of the partial pressures which the molecules of each gas would exert.

${ }^{2}$ There is no hard and fast line between a mixture and a solution when the composition of the molecules is not altered. The substance of smaller amount is usually said to be dissolved in that of larger amount, - the solute in the solvent. 
those of the vapor and the gas. As the piston is moved into the cylinder the gas pressure rises. (The vapor pressure does not change at constant temperature.) Some of the gas molecules are thus forced into the liquid. At any instant and for any temperature there will be a definite number of them in each c. c., and this amount of dissolved gas is proportional to the "partial pressure" of the gas.

The surface of the liquid, which looks so smooth and continuous, is formed by moving molecules. There are always spaces through which a gas molecule may penetrate. The volume thus formed by the interspaces of the liquid molecules communicates at the surface with the volume occupied by the "undissolved" molecules of the gas. On the average the effect is that of two communicating vessels for the gas, one free from obstructions and the other much reduced in actual volume because of obstructions. That the latter are moving makes no difference on the average. The pressures in the two vessels are equal, for otherwise more molecules would pass from one vessel than enter it from the other. Since the pressures are the same, the number of molecules per c. c. of free space will be the same and will increase directly with an increase in pressure.

According to this picture the molecules of the dissolved gas behave exactly like the gas molecules which we discussed in arriving at the equation $P V=R T$. In applying this it is usual to measure the volume in liters (1000 c. c.) instead of c. c. and hence the value of $R$ must be $1 / 1000$ of its former value. We are of course dealing with 1 mole of the gas, and hence if the 
volume is 1 liter the "concentration" of gas molecules is $\mathbf{1}$ mole per liter. In general if the volume is $V$, the concentration, represented by $c$, is $1 / V$. In the equation $P V=R T$, if we substitute $c$ for $1 / V$ we have $P=R T c$, as the expression for the pressure of the dissolved molecules of the gas.

This equation is not limited to the case we have discussed. No matter how the molecules are introduced into the liquid we should expect this pressure. For example, the molecular weight of cane sugar, which has the formula $\mathrm{C}_{12} \mathrm{H}_{22} \mathrm{O}_{11}$, is $12(12)+22(1.008)+11(16)$ or 342.2. Ten grams of sugar in a liter of water is $10 / 342$ of a mole per liter. The value of $c$ is then 0.029 . Suppose the solution is at $30^{\circ} \mathrm{C}$. or approximately $300^{\circ}$ absolute. If we calculate the pressure which the molecules of the sugar would exert on each sq. cm. of a membrane inserted in the solution, we find it to be about 0.7 of an atmosphere or 10 pounds to the square inch.

In the case of a gas we can measure such a pressure directly by measuring that of the gas above the solu-

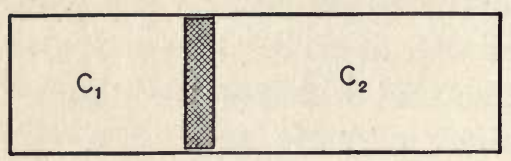

Frg. 28. tion, but it is necessary, if we wish to check these assumptions for the sugar solution, that we should measure the pressure in the solution. Imagine now a vessel like that of Fig. 28 to be divided by a membrane which separates solutions of the same character but of different concentrations. There will be a pressure of $p_{1}=R T c_{1}$ on the left of the membrane and of $p_{2}=R T c_{2}$ on the right. Assume that the membrane is movable 
as a whole and that it is permeable by the molecules of the solvent, but impermeable to those of the solute. The net pressure exerted on the membrane by the dissolved molecules is of value $p_{1}-p_{2}$, acting from left to right if $p_{1}$ is greater than $p_{2}$. The membranous piston will then move toward the right. As it does, molecules of the solvent pass through it, so that the number on the left increases while that on the right decreases. Since the number of molecules of the solute on each side of the piston remains fixed, the concentration on the left decreases and that on the right increases. $^{1}$ This will cease when the concentrations have been altered to such an extent that $p_{1}-p_{2}=0$, that is, when $c_{1}=c_{2}$.

In the case we have discussed there is no external opposition to the motion of the membrane, which will move into its final position without there being any work done. The case is similar to that of an expanding gas. If the two vessels in Joule's experiment (cf. page 219) were separated by a frictionless and weightless piston the piston would have moved without any work being done. It is only when a decrease in the concentration of the gas molecules takes place against an external force that work is done. Suppose, however, that we turn the vessel of Fig. 28 on end and oppose the motion of the piston by weights. The piston will move just as before, supposing that the weights are constantly reduced, being always just a

${ }^{1}$ It is customary to speak of this pressure which the molecules of a solute exert as the osmotic pressure of the solution. If the membrane is withdrawn the concentrations would be made alike by diffusion. In other words, osmotic pressure is the agency causing diffusion. 
bit less ${ }^{1}$ than the value which $p_{1}-p_{2}$ may have corresponding to each position. Then work will be done by the system composed of the two solutions. Of course, this work is at the expense of the molecular energy of the system, and the solutions will be cooled.

It is possible to obtain a semipermeable membrane which allows water molecules to pass freely but retains the solute. Of this character are the cell walls of plant and animal organisms ; in life the phenomena of osmosis are of great importance. Organic membranes are not, however, suitable for a laboratory experiment on osmotic pressures, but a convenient one may be obtained by the precipitate of copper ferrocyanide which results from the reaction of copper sulphate and potassium ferrocyanide. Since this will not stand large forces it is usual to cause the precipitation to take place in the pores of an unglazed earthenware vessel or cell. In this way a number of small membranes are obtained, the effect of which is the same as that of a single large surface.

The cell is partially filled with the solution of which we wish to measure the osmotic pressure and immersed in a vessel of pure solvent. In other words, we make the difference in concentration between the two solutions equal to that of the solution actually under test by making one of them pure solvent. Now we have seen that the two solutions tend to come to the same pressure for their dissolved molecules. The solvent, e.g. water, enters the cell, making the solution weaker

${ }^{1}$ This " bit less" is of course negligible, for it need only be enough to give a negligible acceleration to a weightless, that is, inertialess, piston. 
and, of course, increasing the height of the column. An equilibrium position is finally reached when, for a further increase, the work done by the solutions would be less than the corresponding increase in gravitational potential energy of the column of liquid. The osmotic pressure is then taken as equal to that of the column of liquid.

In a paper before the Swedish Royal Academy in 1885, Van't Hoff advanced the explanation of osmosis as due to the kinetics of the molecules themselves. He found confirmation of this theory not only in the experimental facts that osmotic pressure does vary directly as the absolute temperature and as the concentration of the solution, in other words in the same way as gaseous pressure, but also in previous experiments on the effect of dissolved substances in lowering the freezing point and in raising the boiling point of solutions.

As to the last of these phenomena, we have seen from the isothermals of page 231 that for any pressure there is a boiling-point temperature, namely that at which the pressure of the saturated vapor of the liquid equals the external pressure. The relation of boiling-point and pressure is illustrated for water in Fig. 29. Let

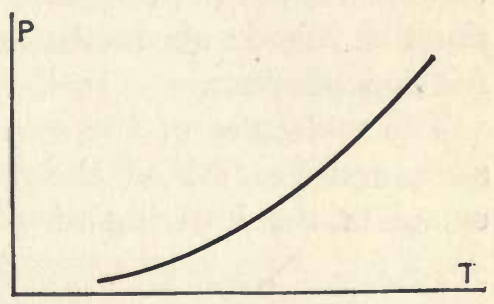

FIG. 29.

us now see how this temperature is altered by mixing with the liquid some other substance. The case of immediate interest to us in connection with osmosis 
is that of a pure liquid (a solvent) and a solid (the solute). The pressure exerted by molecules is always proportional to their number per unit volume and to their kinetic energy. Assume $N+n$ molecules per c. c. of the pure solvent. Let the pressure of its saturated vapor be $p$, then $p \propto N+n$. Now suppose $n$ molecules are replaced by those of a dissolved solid, and are incapable of existing in a vapor state at this temperature. The molecules available for producing the vapor pressure are now $N$ per c. c. and the resulting pressure $p^{\prime}$ is $p^{\prime} \propto N$. Hence $p-p^{\prime} \propto N+n-N$ and

$$
\left(p-p^{\prime}\right) / p=n /(N+n)
$$

This equation gives the fractional reduction in vapor pressure in terms of the molecules per c. c. of the pure solvent and of the solute. The reduction is seen to be independent of the substance which is dissolved, provided the number of molecules per c. c. is the same. If the vapor pressure is reduced the solution cannot boil against a given external pressure at the same temperature as would the pure solvent, and so its temperature must be raised ${ }^{1}$ above the normal boiling temperature for that pressure.

The molecules of the solute exert an osmotic pressure, and Van't Hoff showed that it was possible to calculate the lowering of the vapor pressure from a

1 This phenomenon has only recently entered quantitatively into the daily life of the home in the matter of making jellies and candies. While water will boil at $212^{\circ} \mathrm{F}$. under atmospheric pressure, the boiling point of a solution of sugar is higher, depending upon its concentration. Since other substances like fruit acids also enter into the solution, boiling temperatures furnish a convenient test of the concentration, and recipes are to-day expressed in such terms. 
knowledge of this pressure. He also developed, on the basis of a perfect gas relation for the dissolved molecules of a solution, an expression for osmotic pressure in terms of the lowering of the freezing point. This relation need not be derived, but the physical phenomenon illustrates some interesting principles.

Solid substances, like liquids, lose molecules as vapor although in most cases the vapor pressure ${ }^{1}$ is too small to be meas- $p$

ured. As the temperature increases the vapor pressure rises. We may plot pressure and temperature for a solid in equilibrium with its vapor, just as in Fig. 29 of page 239 we plotted the relation for the

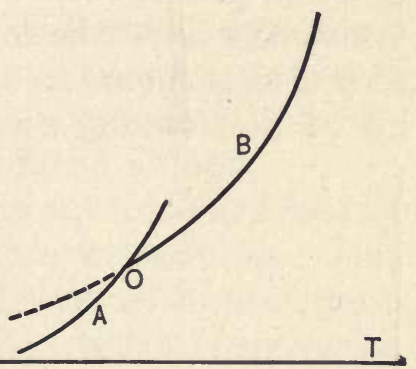

Fig. 30. liquid in equilibrium with its vapor. These two curves will intersect as at $O$ in Fig. 30 . Curve $A$ is for solidvapor equilibrium and $B$ is for liquid-vapor equilibrium. At $O$ is represented the condition at which all three states may coexist in equilibrium. $O$ is therefore called a "triple point."

This point is the freezing point (or the melting point, depending upon our point of view). Under the conditions it represents, the vapor arising from the solid is in equilibrium with that rising from the liquid. But suppose that the vapor pressure of the solid was not just equal to that of the liquid. Either the solid or

${ }^{\prime}$ For solid benzine at $5.5^{\circ} \mathrm{C}$. the pressure is $3.55 \mathrm{~cm}$. of mercury, and for ice at about $0^{\circ} \mathrm{C}$. it is $0.46 \mathrm{~cm}$. 
the liquid would grow at the expense of the other. Now this is exactly what does happen if the temperature is altered. Thus you notice that as the temperature falls below that of the triple point the pressure of the supercooled liquid, shown by the dotted extension of the curve $B$, is higher than that of the solid. Molecules leaving the surface of the water as vapor then serve to supersaturate the vapor above the solid and thus condense on it. In other words some of the water freezes. Conversely it may be seen that the curve $A$ is steeper at $O$ than is curve ${ }^{1} B$, so that if the temperature rises above the freezing point the solid loses molecules to

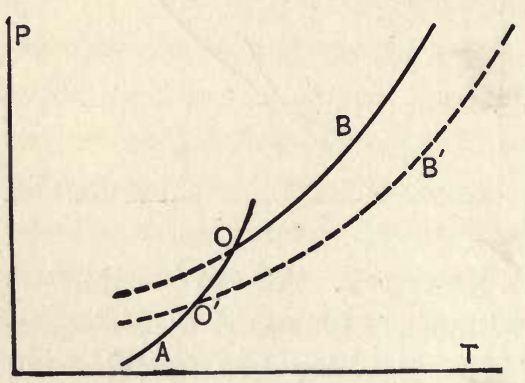

Frg. 31. its vapor more rapidly than it gains from it and there is thus an excess of molecules which condense as a liquid. Melting thus occurs.

If a substance is dissolved in the liquid, for which we have the curves in Fig. 31, its

vapor pressure is reduced according to equation (1). The vapor pressure curve $B^{\prime}$ corresponding to a solution is shown dotted. The intersection of $B^{\prime}$, with $A$

${ }^{1}$ Curves like $A$ and $B$ represent equilibrium conditions. Thus for any temperature greater than freezing there is one and only one pressure at which the liquid and its vapor may coexist in equilibrium, and that is the pressure corresponding to this temperature on the curve. We may use the term "reaction" to describe these actions and indicate by arrows the direction in which a reaction occurs. Thus for water we have $\mathrm{H}_{2} \mathrm{O}$ (liquid) $\rightleftarrows \mathrm{H}_{2} \mathrm{O}$ (vapor). The double arrows are made similar to indicate that this reversible reaction is in equilibrium. 
is evidently at a point corresponding to a lower temperature, that is, the freezing point of the solution is less than that for the pure solvent.

Let us now summarize as to molecular pressures in liquids. The lowering of the freezing temperature and the raising of the boiling temperature are both the result of the reduction in the vapor pressure of a liquid which occurs when some of the molecules are not available for producing vapor. Within the liquid those molecules which are not available for producing vapor exert a partial pressure known as the osmotic pressure of the solution. These phenomena depend upon the number of such molecules per unit of volume.

It is however more accurate to say that they depend upon particles of essentially molecular size. This allows for cases where the number of particles entering into the reaction differs from the number of molecules of the substances involved either because of a dissociation or of a polymerization of the molecules. Van't Hoff's equation, therefore, is usually written as $P=R T i c$, where the factor $i$ is unity for those cases like sugar solutions where there is a normal molecular condition. 


\section{CHAPTER XVIII}

\section{ELECTROLYTIC DISSOCIATION}

THE earliest indications of the electrical character of matter were obtained from studies of the conduction of electricity through solutions. To-day we know that such conduction is essentially a mechanical process of transferring electrons. In order that a medium which has no dislodged electrons shall serve to transfer through itself electricity, there must be brought about and maintained an abnormal electronic condition for some of its molecules. Normal molecules will not so serve.

This abnormality can only occur if the molecule is dissociated into parts which are abnormal. If there are thus formed two components they must depart equally but oppositely from normality, that is, they must be equally and oppositely charged. Even then conduction can occur through such a medium only if the abnormal particles are free to move, as would be the case if the medium were a liquid. Now pure liquids like water, alcohol, or hydrochloric acid are non-conductors. Solutions of substances which are chemical compounds, frequently but not generally, are conductors. Those which conduct are called electrolytes or sometimes "ionogens."

The simplest dissociation would be that in which a 
molecule formed two "ions,." one, the anion, being abnormal by an additional electron, and the other, the cation, abnormal by a corresponding deficiency. The anion of an electrolyte is not a discrete electron as in metals, nor is it formed by the addition of an electron to one of the original normal molecules as is sometimes the case in gases. In electrolysis both ions are molecular (or atomic) in size and in composition except for the abnormality in number of electrons. More than two ions may be formed from complex molecules, but only in a few of the simplest cases is the number equal to the number of atoms in the molecule. In general it is less than the number of atoms composing the normal molecule.

Consider, for example, hydrochloric acid. The pure acid and pure water are non-conducting, but a mixture of the two is conducting. This may be observed in a simple manner by inserting two chemically inert electrodes, e.g. platinum, and connecting a battery and a current-measuring instrument to the electrodes. Hydrogen gas will rise from the electrode connected to the negative terminal of the battery, that is, from the cathode. Chlorine gas will rise from the anode. We therefore conclude that the dissociation which has made conduction possible is that of the $\mathrm{HCl}$ rather than of the $\mathrm{H}_{2} \mathrm{O}$ of the solution. The gases which rise are the diatomic gases $\mathrm{H}_{2}$ and $\mathrm{Cl}_{2}$ and are composed of normal molecules.

This simple experiment raises four questions:(1) What causes the dissociation which is evidenced by the conductivity of the solution?

(2) How do the anion and the cation neutralize their respective abnormal- 
ities, that is, how do they deliver up their charges? (3) Why are these gases diatomic? and (4) Why do normal molecules instead of abnormal molecules compose the liberated gases? There is no question as to the mechanism of the transfer of the ions through the liquid, for that is the result merely of superimposing on their normal haphazard motions a directed motion due to the potential of the electrodes. The answers to these questions should be considered as indicative rather than conclusive, for there are many unsettled matters involved.

(1) The normal molecule in this case consists of two nuclei and their associated electrons. The two nuclei are not combined into one larger nucleus, but are the individual nuclei of hydrogen and chlorine atoms. About neither of them, however, is the configuration of electrons what it would be about isolated atoms of the two component elements. The nuclei pellate and the electrons pellate, but any electron tractates with either of the two nuclei. We are not yet able to form a geometrical picture of such a system, so let us draw an analogy from human relations. Let us consider a political coalition formed by two leaders of exceptional individuality and diverse tendencies. About them are a group of adherents, men who require leadership and are held in the coalition, despite their petty suspicions of each other, by the attraction of the leaders. The leaders, on the other hand, are kept from diverging by the group about them, whose adherence is to leadership itself rather than to any individual leader. Such a coalition may dissolve under the attraction of dissimilar groups and in so doing form two new groups. 
The adherents do not, however, necessarily apportion themselves to the individual leaders exactly in proportion to their relative strengths. In one of these new groups the adherents are in excess of the leader's capacity while in the other they are too few. The dissociated groups may later be thrown together and recombine. Similarly the dissociation of a molecule in a solution is the result of the formation of new systems of potential energy between the molecules of the solvent and the component ions of the solute molecules.

(2) The battery or other source of potential difference draws electrons from one platinum electrode, the anode, and forces electrons to the other, the cathode. The cation, or positive ion, on reaching the cathode receives from it an electron, thus becoming a normal molecular particle. The neutralization of its deficiency in electrons corresponds exactly to the neutralization of the positive charge of a pith ball when it is attracted to and touches a negatively charged ebonite rod. Similarly, the anion gives up an electron to the anode. The number of electrons in the solution is then unaltered on the average, and similarly as to the number in the part of the conducting circuit formed by the battery and its connecting wires.

(3) The electrolytic ions are not the particles into which the substance of the solute would decompose as a gas. For example, $\mathrm{NH}_{4} \mathrm{Cl}$ decomposes as a gas into ammonia $\left(\mathrm{NH}_{3}\right)$ and hydrochloric acid $(\mathrm{HCl})$. In solution the dissociation is into an ion formed by the atoms $\mathrm{NH}_{4}$, which is deficient by one electron, and an ion formed by a chlorine atom and one extra electron. 
These ions do not appear as vapor, for their existence is due to the potential energy of the systems which they form with the molecules of the solvent. The kinetic energy which would be required to move one of them beyond the influence of the molecules of the solvent is greater than that corresponding to the energy required to produce an evaporation of the solvent molecules. ${ }^{1}$

(4) At the instant that the ions neutralize, normal electronic groups are formed, atoms in this case of hydrochloric acid. Such neutralization means a new configuration of electrons. The hydrogen atom is therefore in a condition of changing electronic configuration which renders it peculiarly adaptable to the formation of larger aggregates. The aggregate formed by two such nascent hydrogen atoms appears to be very stable. Diatomic molecules are the product of the neutralization. These are the $\mathrm{H}_{2}$ molecules which we know as hydrogen gas. A similar formation of $\mathrm{Cl}_{2}$ occurs at the other electrode. These gases are not especially soluble at ordinary pressures and temperatures, and therefore they rise as gases above the liquid surface.

That there is an electrolytic dissociation we have reasoned from our knowledge of the mechanism of the conduction of electricity. Historically, however, the proof of the dissociation was largely the result of

1 The latter evaporate rather than the ions of the solute. If the temperature is increased the solvent molecules evaporate more rapidly, and after a time the concentration of the solute ions becomes such that normal molecules of the solute are formed in greater numbers each instant than they are dissociated. The result is a decrease in the total average number of ions in the solution, until finally when all the solvent is evaporated the original solute is left. 
measurements upon the osmotic pressure, the freezing point, and the boiling point of such solutions.

The amount of the dissociation may be conveniently calculated from such observations. Suppose that there are $N$ molecules of solute and that a fraction $a$ of these are rendered abnormal by dissociation. Then there are $(1-a) N$ normal molecules and $a N$ dissociated molecules of the solute. Let $n$ represent the number of ions into which each dissociated molecule has separated, then the total of molecular particles introduced into the solution by the solute is not $N$ but is

$$
(1-a) N+n a N=N(n a-a+1)=N[(n-1) a+1]
$$

A study of the conductivity of an electrolytic solution enables us to determine $a$ in a direct and very convenient manner. If the two electrodes of such an electrolytic cell as was described above are maintained at a constant potential difference while the concentration in moles per liter of the solution is altered, it is found that the current varies, indicating a variation in the ability of the solution to conduct electricity. The conductivity is the ratio of the current in amperes to the potential difference in volts. A solution would then have unit conductivity if it carried electricity at the rate of one ampere ${ }^{1}$ under a potential difference of one volt.

For any given electrolyte the conductivity will depend upon the dissociation $a$. At great dilution we may consider $a$ to be unity. Or, as it is usually expressed, the dissociation at infinite dilution is complete. Under these conditions, the ions, which are formed by the ac1 One coulomb per second. Cf. p. 178. 
tion of the solvent, in pursuing their haphazard motions through the liquid have but a negligible chance of colliding with ions of the opposite electrical sign. On the other hand, if the dilution is not infinite there will be collisions between ions of opposite sign, and hence at any instant a number of recombinations are taking place. Of course, a similar number of molecules are dissociating at this instant or otherwise the solution would be changing in its ionization. The number of molecules of the solute is increased if the concentration is increased. Unless therefore the dissociation $a$ decreases proportionately, the total number of ions available for transferring electricity will also increase. There will be a higher conductivity, as concentration increases, until a point is reached where the dissociation decreases equally. Then, for further increases in concentration the dissociation decreases even more rapidly, resulting finally in a solution of essentially zero dissociation and hence negligible conductivity.

The value of $a$ may be determined from measurements of the conductivity, or more strictly the molecular conductivity, which is the ratio of the conductivity to the concentration. The molecular conductivity is, then, an actual conductivity of the solute molecules and changes only as these molecules change by dissociation. Represent it by $L$ and let $K$ be the factor of proportionality. Then $L=K a$. Calling the maximum value $L_{\infty}$ corresponding to the dissociation $a=1$, we have $K=L \infty$. Hence the dissociation, $a$, corresponding to any observed molecular conductivity, $L$, is

$$
a=L / L \infty
$$


The value of $n$, the number of ions into which a molecule of the solute dissociates, is obtained from a study by weight of the substances liberated as gases or deposited on the electrodes, when different solutions transfer equal quantities of electricity. In the case of hydrochloric acid, a molecule dissociates into one anion and one cation and $n=2$. Each of these ions serves to transfer one electron. Whatever the division may be, the quantity of electricity transferred by each ion must be an integral number of electrons.

Other types of dissociation are possible giving higher values of $n$. Thus $n$ may be 3 , as is the case for barium hydroxide $\mathrm{Ba}(\mathrm{OH})_{2}$ which separates into the cation, $\mathrm{Ba}$, deficient by two electrons, and two anions of the composition, $\overline{\mathrm{OH}}$, each with a single excess electron. The converse may also happen ; for example sulphuric acid, $\mathrm{H}_{2} \mathrm{SO}_{4}$, separates into two cations of $\stackrel{+}{\mathrm{H}}$ and a single anion of the form $\overline{\mathrm{SO}}_{4}$ which carries two extra electrons.

In the case of those elements which have more than one valence, ions may be formed differing in their number of electrons, depending upon the compound from which they are derived. Thus iron may be divalent and form the ferrous chloride $\mathrm{FeCl}_{2}$, in which case the ions are $\stackrel{++}{\mathrm{Fe}}$ and two $\overline{\mathrm{Cl}}$ ions. On the other hand, in ferric chloride $\mathrm{FeCl}_{3}$ the iron atom is trivalent, and this molecule in solution splits into an iron ion $\mathrm{Fe}$, which is deficient by three electrons, and three ions of chloride, $\overline{\mathrm{Cl}}$, each with an extra electron. For this case $n=4$.

The same element may appear in one substance as 
an anion and in other substances as a cation, thus in ferrocyanide of potassium, $\mathrm{K}_{4} \mathrm{Fe}(\mathrm{CN})_{6}$, there are formed four positive ions of potassium, $\stackrel{+}{\mathrm{K}}$, and one complex anion, $\overline{\mathrm{F}} \mathrm{e}(\overline{\mathrm{CN}})_{6}$, composed of an iron atom and six molecular groups called cyanogen, each composed of an atom of carbon and one of nitrogen. The cyanogen ion consists of thirteen atoms and carries four extra electrons. The iron atom in this case is not a cation but a component part of the anion, and thus does not enter into the characteristic chemical reactions which distinguish it in those cases where it is a cation.

When an ion is neutralized at an electrode, there are three possible effects; thus it may be liberated as a gas, be deposited on the electrode, or enter into a reaction with the solvent. The electrolysis of $\mathrm{HCl}$, of silver nitrate, $\mathrm{AgNO}_{3}$, and the decomposition of water are examples respectively.

Consider a solution of silver nitrate between electrodes of silver. When the silver ions are neutralized at the cathode they are deposited, granules of pure silver being formed on the surface of the plate. At the anode the neutralization of the radical $\overline{\mathrm{NO}}_{3}$ takes place by its combination with a silver ion, $\mathrm{Ag}^{+}$, which is released by the anode itself. Thus silver is transferred from the anode to the cathode. We may consider $\mathrm{NO}_{3}$ to react with the silver of the anode to form $\mathrm{AgNO}_{3}$, or better we may consider that the silver dissolves as silver ions, that is, atoms deficient by one electron each. A surplus of electrons is thus left on the anode just as if the nitrate radicals had given up to it their excess electrons. 
This excess is withdrawn by the action of the battery. This process is evidently the basis of electroplating, whereby silver is deposited upon a baser metal, which is used as the cathode. Similarly, the electrolysis of copper sulphate is used commercially either for copperplating or for the refining of copper derived from ores.

In the third case the products which appear are the results of secondary reactions at the electrodes. In the case of a solution of sodium hydroxide, $\mathrm{NaOH}$, the ions are $\stackrel{+}{\mathrm{Na}}$ and $\overline{\mathrm{OH}}$. Now, metallic sodium enters into a vigorous reaction with water, forming hydrogen gas and sodium hydroxide, $2 \mathrm{Na}+2 \mathrm{H}_{2} \mathrm{O}$, giving $\mathrm{H}_{2}+2 \mathrm{NaOH}$. In conduction through sodium hydroxide, when the sodium ion has neutralized its deficiency of one electron, it is in a condition to enter into this reaction. The formation of electrically neutral atoms of sodium is followed, then, immediately by the decomposition of water and the liberation of molecules of hydrogen gas. At the anode the neutralized hydroxyl ions $(\overline{\mathrm{OH}})$ form water and liberate oxygen, thus $4(\mathrm{OH})=\mathrm{O}_{2}+2 \mathrm{H}_{2} \mathrm{O}$. It was this secondary reaction which in the earlier days of the investigation of electrolysis obscured to some extent the actual process and resulted in the idea that an electric current decomposed ${ }^{1}$ water. The more nearly free

${ }^{1}$ A similar secondary reaction is obtained if a dilute acid is used, as for example sulphuric acid. In that case hydrogen is liberated at the cathode in the primary reaction. At the anode the water is decomposed by the neutralized sulphate radical and oxygen is liberated, thus

$$
2 \mathrm{H}_{2} \mathrm{O}+2 \mathrm{SO}_{4}=2 \mathrm{H}_{2} \mathrm{SO}_{4}+\mathrm{O}_{2}
$$


the water can be made of impurities the more nearly is it non-conducting, and the less it is decomposed.

Whether or not the liberated product is the result of the primary or the secondary reaction there is in the product of electrolysis one univalent atom for each electron transferred through the solution, or in general a number of atoms equal to the quotient of the number of electrons which have been transferred divided by the valence of the product. The masses of the products produced by the transfer through different electrolytic solutions of equal numbers of electrons should therefore be proportional to the so-called "electrochemical equivalents" of the individual products, i.e. to their molecular weights per unit of valence.

Now these conclusions, although not expressed in terms of electrons, were obtained experimentally by Faraday in 1834 and are known as his first and second laws of electrolysis. To-day, it is partly a convenience to speak of them by this name and partly a matter of justly honoring the name of one of the most fruitful investigators in the early development of electricity. The conclusions are, however, inevitable as soon as we accept as facts the hypotheses of atoms and electrons.

The disadvantage, in this instance and in other similar cases, which is attached to the retention of the names of the laws, is that it results usually in their acceptance by the beginner in science as empirical laws rather than as the logical consequence of the structure of matter. In treating electrolysis we have in this chapter deliberately inverted the historical order so as to emphasize the essential unity of ap- 
parently discrete phenomena. The number of laws and concrete facts which the student of science needs to remember are fewer than the names which have become associated with them in their evolutionary development. If the reader obtains a correct concept of molecules, atoms, and electrons, many important laws will appear to him as deducible.

In electrolysis the number of electrons leaving the solution at the anode is equal to that entering at the cathode. In conduction through an electrolytic solution it may however happen that the anion and the cation move through the solution at different speeds. The result will be a different concentration of anions near the anode than of cations at the other electrode. This is evidenced in cases like that of copper sulphate $\mathrm{CuSO}_{4}$ by a paling of the color near the anode, but it may always be found by a chemical analysis of samples of the liquid taken from near the two electrodes.

In a dilute solution, where dissociation is essentially complete, we should expect the behavior of an ion to be characteristic and not dependent upon the particular substance from which it was derived. Thus all hydrogen ions are alike whether they are obtained from $\mathrm{HCl}, \mathrm{HNO}_{3}, \mathrm{H}_{2} \mathrm{SO}_{4}$, or some other acid. The molecular conductivity of a dilute solution will, therefore, depend upon the individual characteristics of its anion and its cation. Since the amount of electricity transferred across a solution is the sum of that transferred by the two kinds of ions, the conductivity should be the sum of the conductivities of the two kinds of ions. These conductivities are called their "mobilities." Now, an acid is an electrolyte which 
gives a hydrogen cation; a base, one which gives an hydroxyl anion $(\mathrm{OH})$; and a salt is an electrolyte which has neither of these ions. The mobility of the hydrogen ion is the highest of all, $\mathrm{OH}$ is next, and other ions much less. In these individual mobilities, therefore, we see the explanation of the physical fact that acids are better conductors than bases and the latter better than salts.

Chemists are most generally interested in acids as sources of the $\mathrm{H}$ ions which cause the characteristic effects. For this reason they are accustomed to speak of acids, like $\mathrm{HCl}$, which, in a solution of one tenth mole per liter, dissociate more than 70 per cent, as "strong." If the dissociation of a decinormal solution of the acid lies between 10 and 70 per cent it falls into a second group of strong acids. On the other hand, acids like acetic, which in similar concentrations have dissociations of 1 to 10 per cent, are "weak," and those like carbonic acid, which have even smaller values, are "feeble." In the same way the chemist divides bases into two groups; those like sodium hydroxide with large dissociations are called "strong," while those which, in a decinormal solution, form hydroxyl ions from less than two per cent of the molecules are weak bases. Of the latter ammonium hydroxide is an example. Salts may be formed by weak acids and strong bases and vice versa; thus sodium acetate is the salt of a weak acid and a strong base. 


\section{CHAPTER XIX}

\section{EQUILIBRIA FAND THEIR DISPLACEMENT}

The idea of a statistical or mobile equilibrium we have met in considering a system of two phases, e.g. a liquid and its vapor. When the system is in equilibrium there are just as many molecules of the liquid evaporating from the surface each instant as there are molecules of vapor condensing into the liquid. If the temperature is raised evaporation increases until the vapor density corresponds to the new temperature. As the density of vapor molecules increases there is a corresponding increase in the number of them which strike back into the liquid surface. When the rate at which molecules condense has increased sufficiently to be equal to the rate at which they evaporate a new equilibrium is reached. The proportions of liquid and vapor have meanwhile been altered, in this case the vapor gaining at the expense of the liquid.

The term "equilibrium" must of course be understood in a statistical sense. The balance is between the rates at which two different molecular reactions occur. It is the results of these reactions which we consider as opposing. In effect we use the word "equilibrium" much as if the amounts of liquid and vapor formed opposite ends of a lever, the position of the fulcrum representing the condition of equilibrium between the two 
phases. This position is determined in the present case by the temperature. Increasing the temperature means shifting the equilibrium in a direction corresponding to increased vapor.

In an electrolyte at a given temperature there is equilibrium between the rate at which molecules are dissociating and that at which they are recombining due to collisions. Let us represent the molecule by $A C$, where $A$ stands for anion and $C$ for cation. There are taking place in the solution two reactions, $A C \longrightarrow A+C$, and $A+C \longrightarrow A C$ or $A C \longleftarrow A+C$, that is, the dissociation of molecules and the recombination of ions. Let the rates be expressed in molecules per second as $k_{d}$ and $k_{c}$, respectively. When the solute is added to the solvent, $k_{c}$ is zero and $k_{d}$ is a maximum. As ionization occurs the number of normal molecules decreases and hence $k_{d}$, the number ionized per second, also decreases. On the other hand $k_{c}$ increases. When the two rates become equal equilibrium ${ }^{1}$ results. Thereafter dissociation and recombination occur, but the average number of dissociated molecules remains constant unless we change some of the conditions, e.g. the temperature or the concentration.

The rate of recombination will obviously depend upon the frequency of collision of the ions which are necessary to form a molecule, and hence upon the concentration of each of these ions. Thus in the present

${ }^{1}$ In the case of a solution the equilibrium is reached very quickly provided that the solute is either in a liquid form or finely powdered. If the solute is in the solid form it is evident that but few of its molecules are accessible for reaction with those of the solvent, and hence that the value of $k_{d}$ will be limited by the supply of dissolved molecules. 
case if we represent the concentrations of the ions by $(A)$ and $(C)$ respectively, we have $k_{c} \propto(A)(C)$. For example, if there are no ions of one type present there can be no recombinations, and $k_{c}$ is zero. On the other hand, doubling the number of either kind of ion will double the number of collisions of this kind of ion with the other.

In the same way the rate at which molecules dissociate will be proportional to the concentration of the normal molecules. Thus $k_{d} \propto(A C)$, where the brackets represent the concentration of the substance included by them.

In equilibrium $k_{d}$ and $k_{c}$ are equal. Let the corresponding value of the concentrations be represented by a subscript $e$. Then, since $k_{d} / k_{c}=1$ we have

$$
\left.K=(A)_{e}(C)_{e} /{ }^{\prime} A C\right)_{e}
$$

In this particular case the ratio $K$, which is called the "equilibrium constant," is a constant expressing the equilibrium conditions for ionization and is therefore frequently called the "ionization constant."

The idea that the rate at which a substance reacts is proportional to its molecular concentration was formulated in a law by Guldberg and Waage in 1864 . We may express it in a general form by saying that if $A$ and $B$ are the reactants in a reaction which gives the products $C$ and $D$, then we may write the rate at which the reactants disappear as $k_{1}(A)(B)$ or at the equilibrium point as $k_{1}(A)_{e}(B)_{e}$. Similarly if the substances $C$ and $D$ may enter into a reverse reaction then the rate at which they disappear is $k_{2}(C)(D)$ or at the equilibrium point $k_{2}(C)_{e}(D)_{e}$. At the equilib- 
rium point the rate of disappearance of $A$ and $B$ must be equal to the rate at which they are formed by the disappearance of $C$ and $D$. Therefore

$$
\frac{(A)_{e} \times(B)_{e}}{(C)_{e} \times(D)_{e}}=K
$$

where $K$ is the equilibrium constant of the reaction.

This law is commonly known as the law of "mass action" because originally the words "active mass" were used in place of the modern term "concentration." The equilibrium constant will depend upon the temperature and may also depend upon pressure. For this reason whenever an equilibrium constant is given in numerical value it is necessary to state the other conditions. For very many reactions, on the other hand, no equilibrium point may be reached, for they are not reversible. For example, there is no equilibrium point for a liquid above its critical temperature, and if this temperature is exceeded the reaction occurs in one direction only and goes to completion.

In the reactions of electrolytes this law of mass action is of 'greatest convenience, since the ionization constants may be easily measured and tables of them prepared. These data, with tables of solubility, permit the chemist to foretell the results of the reactions of mixtures of electrolytes and hence to make efficient use of them in the quantitative analysis of unknown mixtures.

If both components of such a mixture are soluble and also have appreciable dissociations, chemical reactions are possible, that is, neutral molecules may be formed by the collisions of the anion of one component with the 
cation of the other. If these resultants are also highly soluble and ionizable there will be no evident chemical reaction. Suppose, however, that one resultant is practically insoluble. In so far as it is, it will be precipitated and thus remove two of the products of the ionization of the original electrolytes. This will displace the equilibrium and will result in further ionization. These new ions will collide sooner or later and form the insoluble product. This process continues until all the ions of one kind derived from one of the original substances have been removed from the solution.

On the other hand, suppose that one of the resultants is soluble but is almost negligibly ionized. So far as removing ions from participation in those combinations and dissociations, which would occur if the cross products were highly soluble and ionizable, this inability to dissociate is effective in the same way as is insolubility.

The extreme instance of the displacement of the equilibrium due to the failure of one of the cross products to ionize is found in the neutralization of an acid by a base. By definition an acid has a cation of $\mathrm{H}$, and a base has an anion of $\mathrm{OH}$. The two combine to form water. Strictly speaking, water is not entirely free from ionization, but the amount possible is for all ordinary purposes entirely negligible. The neutralization ${ }^{1}$ of an acid by a base therefore results

${ }^{1}$ Certain substances known as indicators are peculiarly useful in quantitative work for determining whether or not neutralization has been complete. For example, if it is desired to determine the percentage of a given acid in an unknown mixture, the acid may be 
in water as one product and a salt for the other. (The latter, if soluble, is present partly as dissolved molecules and partly as ions, namely the anion of the acid and the cation of the base.)

We have already mentioned the equilibrium between the two phases, liquid and vapor, of a system with only one component, e.g. water. We have seen that the condition is determined by two variables, namely the temperature and the volume. If either of these two conditions is altered the equilibrium is disturbed and the proportions of water and vapor are varied. Thus an increase of temperature causes an increased vaporization and a consequent reduction, of the portion which the water is of the entire volume. Similarly if the volume is varied, as for example decreased, there is a change in the proportions of the two phases, vapor being condensed.

In both cases we notice that the change is of such a nature as to oppose the cause. Thus in the case of increased temperature there is an increase in the kinetic energy of the molecules of the system, and this results in a separation of more molecules from the liquid. This increased molecular separation means a greater potential energy for the molecules. In so far as the potential energy is increased the kinetic energy is reduced. The change occurring is therefore of such a character as to reduce the molecular kinetic energy neutralized by the addition of a base of known concentration and hence known ionization. An indicator, e.g. methyl orange, litmus, or phenolphthalein, is used to show when the amount of the base which is being added is just sufficient to neutralize all the $\mathrm{H}$ ions. The amount of acid may then be calculated from the required amount of the base. 
and hence the temperature. Similarly, in the case of the reduced volume, there is a decrease in the molecular potential energy, which is thereby converted into kinetic energy and thus increases the pressure exerted by the vapor molecules. This change or reaction is also such as to oppose the action.

In Newton's third law of motion we have the expression of the physical fact that every action is accompanied by an equal and opposite reaction. We are accustomed, however, to consider this generalization as referring specifically to the interactions of matter in bulk. In an earlier chapter we met the same generalization, as expressed by Lenz, for the interactions of moving electrons. In the case of molecular reactions this important idea awaited expression until the work of Le Chatelier in 1884 and Braun in 1887.

Their principle is, that any external action upon a system produces a change of such a character (in such a sense) that the resistance which the system offers to the external action is increased. In quantitative form this principle is embodied in the second law of thermodynamics. The latter, however, involves some of the most difficult abstract reasoning to be found in physical science. Its mathematical expression also does not lend itself to simple verbal interpretation in elementary treatments of science. In the principle of Le Chatelier-Braun, however, we are fortunate in having a non-mathematical expression of marked simplicity which indicates the character of the reactions, the quantitative relations of which are expressed by the mathematical forms of the second law. This principle is not restricted by any assumptions as to 
molecular structure, and like the second law is perfectly general. It serves admirably either in lieu of this law for students whose mathematical training is insufficient, or as an introduction to the law.

From our study of continuity of state we recognize that the molecular state of a body or system is determined by various conditions, of which temperature, pressure, and volume are the three so far considered. ${ }^{1}$ These conditions, or parameters, are variable at the will of the experimenter. The behavior of the molecules of the substance is not directly controllable, however, but only indirectly as one or the other of these factors may be varied by an external action. The principle of Le Chatelier-Braun enables us to predict in any case what the character of the effect upon the molecules will be when one of these parameters is varied.

For example, consider the case of a gas under a given pressure and occupying a definite volume at a definite temperature. If the external pressure is increased, the effect is to decrease the volume. The equilibrium which the moment before existed between the external pressure and the opposing pressure of the gas molecules has been disturbed. The volume is reduced. Now, the principle tells us the compensating change which occurs within the system. The change in $V$ is accompanied by a change in one of the other variables, in this case $T$, of such a character as to oppose the change in $V$. That gases expand with increased tem-

${ }^{1}$ Electromotive force, that is, a difference in electrical potential energy, is obviously another factor. The ions which take part in chemical reactions do so as the result of the potential energy of the electronic systems which they form with one another. 
perature, is an experimental fact, independent of any theories as to molecular behavior. If the change in temperature is to oppose a decrease in volume the temperature must increase. That the temperature of a gas increases as the volume is decreased is the simple observation of every one who has pumped a bicycle or automobile tire.

We may express this principle, then, by saying that when a parameter, e.g. $x$, which is one of those determining the equilibrium of a system, is altered, another parameter, e.g. $y$, changes in such a manner as to diminish the direct effect of the external cause. It is, of course, necessary, if we are to foretell the result of a change in $x$, that we should know how $x$ and $y$ are related. In the particular case just studied we know that $V$ is proportional to $T$. The change in $T$ must be that corresponding to a change in $V$ opposite to that which actually takes place. Hence, since $V$ actually decreases, $T$ must increase.

The principle is not, however, limited in its applications to the phenomena of gases and vapors. Consider the case of an elastic wire at a definite temperature and having a certain length under a definite tension. What will be the effect of stretching the wire still further? The parameter which is changed by the external cause is the length. The other parameter is the temperature. Now, we know that metal wires are elongated by an increase in temperature. The increase in length will then be accompanied by a change in temperature in such a direction as would normally produce the opposite effect. Hence the wire is cooled by stretching. 
Consider for example an illustration in the case of surface tension which, we have seen, decreases with an increase in temperature. If the surface of a liquid is increased, what will be the nature of the effect on the temperature of the liquid? The temperature must change in such a direction as to increase the surface tension and thus to resist the increase in surface area. Hence, the temperature must decrease. From our considerations of molecular potential energy (see page 221) we arrived at the same conclusion. Thus, an increase in surface means an increase of p.e. due to the increased separation of the molecules, and hence a decrease in the k.e., that is, a decrease in the temperature.

Suppose the temperature of a two-phase system, e.g. water and ice, is kept constant, how will the equilibrium be affected by the introduction of a soluble solid, e.g. a salt? The salt dissolves, in part at least. Its introduction increases the concentration of salt molecules from the original value of zero. The change which takes place in the mixture must then be of such a character as to oppose this change in concentration. The equilibrium between the ice and the water is, therefore, altered in such a manner as to tend to reduce the concentration of the salt solution. Hence the ice melts so as to increase the amount of the solvent water.

An interesting comparison has been suggested between the principle of Le Chatelier-Braun and the principle in organic life which is illustrated by the "faculty of accommodation." This is the faculty by virtue of which external actions upon a living organism produce changes which tend to increase its power of resistance to such external actions. Of this phe- 
nomenon the development of muscle by exercise is a familiar illustration. We might, therefore, look upon the principle of Le Chatelier as an extension to inanimate substances of the faculty of accommodation.

We may also express the principle by saying that every system, chemical or physical, which is in equilibrium is conservative, that is, tends to remain unchanged. In the world about us, however, changes are constantly occurring in the molecular systems. We conclude, therefore, that they are not in equilibrium. Certain transformations are taking place in these systems naturally, that is, without external cause. Such a system, for example, is the solar system, in which we live, where the transformations take place "of themselves," as we might say.

What are the typical transformations which take place naturally? We have progressed far enough in our study to realize that the production of molecular motions, or "heat," at the expense of work is a natural process, as in the phenomenon of friction. Similarly the mixing of gases by diffusion is a natural process. The transfer of energy from molecules with high kinetic energy to those of low is also natural, that is, the transfer of heat from a hot body to a cold body. The radiation of energy of which light is an example is another natural process.

What is the result of these natural transformations? We notice that they tend toward a dead level of molecular energy. The faster moving molecules lose energy to the slower. The final condition of equilibrium toward which the universe tends in these natural processes is then one of uniform temperature. The 
temperature will be the lowest possible. The ratio of all the energy in the universe to its absolute temperature will then be as large as it can become. Now this quotient of heat energy and absolute temperature is usually called "entropy." The natural processes or transformations of the universe tend to increase the entropy.

The processes mentioned above are natural much as it is natural for water to run down hill. We can make water go up hill, but it is not natural and we have to do work. In the same way we can separate the molecules of gases which have mixed by diffusion, we can produce work from heat, and we can transfer energy from cold bodies to hot ones, making the former colder and the latter hotter, but these are not natural processes. In every instance we have to do work to accomplish the result. We can only do the necessary work at the expense of some other energy transformation which is natural. Those processes, which are the reverse of the natural ones, have never been known to occur of their own accord and scientists are agreed in believing that they never will. They may be produced, but only when a transformation which is natural supplies the energy.

These statements are the sense of the Second Law of Thermodynamics. The mathematical statement of the law is usually made in terms of that ratio of molecular kinetic energy or heat to absolute temperature which we have just called "entropy." The law says that all natural transformations in the universe result in an increase in entropy. The student of thermodynamics, however, finds it a great convenience to reason about 
ideal and limiting cases of transformations where there is no increase in entropy. The most famous case is known as the Carnot cycle which is typical of heat engines or internal combustion engines. The conclusion reached by Carnot and by Clausius is that the maximum efficiency of such a cycle is independent of the working substance, e.g. water, or air, and depends only upon the extremes of temperature to which the substance is subjected. The efficiency will be much less than this in all but the ideal case. 


\section{CHAPTER XX}

\section{MOLECULAR MAGNITUDES}

Evidence as to the reality of the molecular and atomic structure, which we have been discussing, is to be found in the agreement between the values obtained for various molecular magnitudes from entirely different experimental determinations. The most important magnitudes are (1) the number per mole under standard conditions of pressure and temperature, (2) the mass of each molecule, (3) its diameter, and (4) its kinetic energy of translation. A knowledge of these is desirable in order to obtain a fairly complete picture. In addition we shall need to consider later the total energy possessed by a molecule at a given temperature and its partition among the degrees of freedom.

Many attempts have been made to determine the number of molecules in one mole. The earlier values were obtained indirectly from an estimate of the diameter of a molecule. For example, Lord Rayleigh made use of the fact that the surface tension of a liquid is greatly affected by the presence of impurities. A particle of camphor placed on a water surface jerks about due to variations in the surface tension about it. Oil spread on the water reduces these motions and Rayleigh determined the critical thickness of an oil 
film which would just cause them to cease. He found that a layer of approximately $1.6 \times 10^{-7} \mathrm{~cm}$. was sufficient. Since the layer cannot be less than one molecule in thickness the diameter of a molecule is not greater than this distance.

Somewhat similar values were obtained by various investigators using soap films. We have all noticed that as a soap bubble drains, its iridescent colors change and a black spot appears at the point where it ultimately breaks. Measurements of this thickness are possible by optical means and another value of the upper limit for the diameter of a molecule has thus been obtained.

Some of the most consistent values of the number of molecules per mole were obtained by Perrin. He used small granules of gamboge or of mastic, substances which do not dissolve in water but form emulsions. Such particles he sorted into uniform size by centrifuging. The average kinetic energy of these is the same ${ }^{1}$ as that of a molecule of the liquid in which they are placed. But it is this energy which accounts for the osmotic pressure and brings about a diffusion of the particles when the liquid is not agitated.

In a liquid the osmotic pressure will depend at each point upon the concentration of the particles. If there is no external cause like gravity the concentration will be the same at all points when the liquid has reached a state of equilibrium. Because of gravity,

1 That is, there is an equipartition of k.e. between the particles and the molecules of the liquid. It is this equipartition which makes such Brownian movements so valuable in the study of the invisible molecules. 
however, the particles in Perrin's experiment fell until the concentration at each level in the liquid became such that a further decrease in the gravitational p.e. of the particles would have occasioned a greater increase in osmotic energy due to the increased concentration. Figure 32 represents a vertical section of an emulsion in equilibrium. Perrin, therefore, was able to obtain a relation between the decrease in gravitational energy, occasioned by a particle in moving from one level to a new level, $h \mathrm{~cm}$. lower, and the corresponding change in the energy which the particle possessed as a result of its inclusion in a group of greater concentration and hence of greater osmotic pressure.

If each particle is spherical, of radius $r$ and of density $D$, its mass is $4 \pi D r^{3} / 3$. The decrease in gravitational potential energy of the particle considered by itself is $4\left(\pi r^{3} D h g\right) / 3$. Its movement downward results in the movement upward of a similar volume of the liquid, that is, it may be considered to change places with an equal volume of

Fig. 32. change places with an equal volume of the liquid of density $d$, which therefore gains in potential energy the amount $4\left(\pi r^{3} d h g\right) / 3$.

The corresponding increase in energy on the part of the average particle is expressed as $K w T$, where $w T$ is the average kinetic energy of translation of a liquid mole- 
cule. The factor $K$ involves the ratio ${ }^{1}$ of the concentrations at the two levels, and hence may be expressed in terms of the number of particles in equal areas at these levels. These numbers, $n$ and $n_{0}$, Perrin determined by direct count, viewing different layers of the emulsion through a microscope.

The kinetic energy of translation, $w T$, may be expressed by using the perfect gas equation, which we saw from our study of osmosis is applicable to such cases. From page 218 we have $w=3 R / 2 N$. Using these values of $K$ and $w$ in the expression of the energy relations at equilibrium, gives.

$$
\frac{4}{3} \pi r^{3} g h(D-d)=\frac{R T}{N} \log \frac{n_{0}}{n}
$$

where $N$ is the number of molecules per mole. The other terms on the right-hand side of this equation are known. The density, $d$, was easily measured. The density, $D$, of the mastic Perrin determined from a solid piece before forming the emulsion and checked after the main experiment by evaporating the liquid and measuring the density of the residue. The distance, $h$, was directly measured. There remained to be determined only the radius $r$. The granules which he used were about $2 \times 10^{-5} \mathrm{~cm}$. in diameter, much too small for an accurate direct measurement. The radius was obtained by making use of an equation developed by Stokes which states the rate at which small spherical

${ }^{1}$ This factor, which is conveniently derived by using integral calculus, involves the logarithm of the ratio $n_{0} / n$. The expression is $K=(2 / 3) \log _{\epsilon}\left(n_{0} / n\right)$. A "calculus dodging" derivation is given by Perrin in "Les Atomes," an interesting book, published in translation by D. Van Nostrand Company, 1916. 
particles will fall under gravity through a viscous fluid. The emulsion was therefore shaken until thoroughly mixed and a measurement was made of the rate at which the upper layers cleared of particles.

The phenomenon of viscosity, sometimes spoken of as molecular friction, is most easily described in the case of the flow of a liquid through a pipe. Suppose the liquid wets the walls, then the layer of molecules immediately adjacent to the walls is at rest and the next layer slides by it. In terms of the kinetics of molecules we say that there is now a "mass motion" in addition to the haphazard molecular motion. The mass motion of the inner streaming layer is, however, interfered with by the absence of such motion on the part of the outer layer. The molecular motion of the streaming molecules causes some of them to collide with those of the fixed layer and they are thus retarded. Layers farther from the stationary layer will be retarded less by such collisions. (The effect, being due to collisions and not to attractions, takes place in all aëriform substances, including perfect gases. It is viscosity which retards the motion of bodies through the air and of which we have spoken as air friction.) In terms of force it is measured by the number of dynes which must be applied tangentially to each square centimeter of the surface of one layer of the fluid to cause this layer to move with a velocity of $1 \mathrm{~cm}$. per second with reference to a parallel layer which is $1 \mathrm{~cm}$. away. This ratio is the coefficient of viscosity. This quantitative definition is concerned only with relative velocities and is not limited to the special case which we described where one layer is at rest. 
For the case of a sphere it was calculated by Stokes that the reaction due to viscosity is $6 \pi r c u$, where $r$ is radius, $v$ is the velocity, and $c$ is the coefficient of viscosity of the fluid. The acting force which occasions the fall is the space rate of change of the energy and therefore equals the quotient of the left-hand side of equation (1) and $h$. Hence equating action and reaction gives

$$
(4 / 3) \pi r^{3}(D-d) g=6 \pi r c v
$$

The coefficient $c$ is obtainable from tables of previous determinations or may be found by a separate experiment. Stokes' Law, therefore, enabled Perrin to

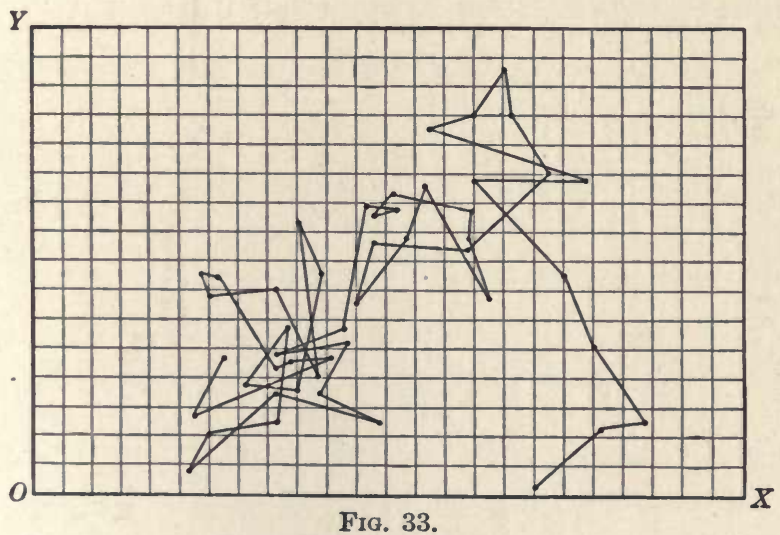

determine $r$ from his observations of $v$. Substitution of this value in equation (1) then gave $N$. By this experiment he found $N=6.83 \times 10^{23}$.

Although this method makes use of the kinetics of visible particles it considers the average particle rather than the Brownian movement of a particular particle. 
Another series of Perrin's experiments dealt with individual motions. If one of the particles is observed in a microscope its motion will be of the character illustrated by the diagrams of Fig. 33. Its position is observed and recorded every $t$ seconds ( $t$ was 30 in this instance). It is by such irregular motions that the diffusion of the particles takes place. Einstein had shown a relation between the coefficient of diffusion and the average square of the displacements of a particle. The diffusion is expressible in terms of $R T / N$ and the viscosity of the liquid if the radius of the particle is known. If $X^{2}$ represents the average square of the displacements along the $x$-axis for times of value $t$ seconds, then it was shown that

$$
X^{2}=R T t / 3 N \pi c r
$$

where the other terms have their previous meanings. Perrin observed several thousand displacements and obtained as his average value for $N, 6.88 \times 10^{23}$.

The most reliable determination of the number of molecules in a mole, is the work of Millikan. It is essentially a by-product of his determination ${ }^{1}$ of the amount of electricity represented by an electron. You will remember that the electrostatic unit of quantity was defined (on page 174) in terms of the repulsion of two unit charges at unit distance, and the electromagnetic unit (on page 206) in terms of the repulsion exerted on a unit magnetic pole at the center of a unit arc of unit current. The practical unit of current is the ampere and is nominally one tenth of the latter unit. Because of its importance in the arts the ampere ${ }^{1}$ To be described in Chapter XXII. 
has been legally defined as the steady current which in 1 second will transfer 1 coulomb of electricity. The coulomb, which is defined as one tenth of the quantity transferred in 1 second by one absolute e.m. unit of current, is legally defined as the quantity of electricity which is transferred in electrolysis between two silver plates in a slightly acid solution of $\mathrm{AgNO}_{3}$ when 0.001118 gram of silver is deposited on the cathode. Since the atomic weight of $\mathrm{Ag}$ is commonly accepted to be 107.88 , it follows that the deposition of 1 mole of silver represents the transfer of $107.88 / 0.001118$ or 96500 coulombs, or 9650 absolute e.m. units.

The value of the charge carried by the electron is, however, usually expressed in electrostatic units. Represent the value of the electron in these e.s. units as $e$. The e.m. unit of quantity is $3 \times 10^{10}$ times the e.s. unit, as may be determined experimentally by measuring the same charge of electricity first in one unit and then in the other. ${ }^{1}$. By 1 mole of silver there is, then, transferred $9650\left(3 \times 10^{10}\right)$ or $28,950 \times 10^{10}$ absolute electrostatic units of electricity. If $N$ represents the number of silver atoms (strictly ions) which are in the mole, then in e.s. units this amount of electricity is $N e$. Millikan's value for $e$ is $4.774 \times 10^{-10}$, and hence his value for $N$ is $60.65 \times 10^{22}$.

The mass of a molecule of any substance is to be found as the quotient of its molecular weight in grams and $N$. Thus for hydrogen the mass is $2.016 / 60.65 \times 10^{22}$

1 The ratio is the velocity of light. This experimental fact was one piece of evidence substantiating Maxwell's theories, which were referred to on p. 124 as anticipating Hertz's discovery of electromagnetic waves of frequencies much smaller than those of light. 
or $3.33 \times 10^{-24}$ gram per molecule. For oxygen it is $32 / 2.016$ times as large or $52.8 \times 10^{-24}$ gram per molecule.

The root mean square velocity of a gaseous molecule may be obtained without a knowledge of $N$ by considering equation (2) of page 164. Thus

$$
p=N m v^{2} / 3 V=d v^{2} / 3
$$

where $d$ is the density. Then $v$ is the square root of $3 p / d$ or

$$
v_{a}=0.921 v=0.921 \sqrt{3 p / d}
$$

where $v_{a}$ is the average velocity. The factor, 0.921 , is to be obtained only by a mathematical analysis beyond the scope of this book. For hydrogen under standard condition $p=1.013 \times 10^{6}$ dynes/sq.cm., and $d=2.016 / 22410$ g./c. c., hence $v_{a}=169,200 \mathrm{~cm}$. $/ \mathrm{sec}$., that is, of the order of one mile a second.

The velocity of any other gas will be less than this, being inversely as the square root of its molecular weight. Oxygen will have an average molecular velocity, under the same conditions of temperature and pressure, of one fourth this amount or $42,500 \mathrm{~cm}$. $/ \mathrm{sec}$. If the temperature is not $0^{\circ} \mathrm{C}$. the velocity will be to the velocity under standard conditions in the ratio of the square roots of the absolute temperatures. Since pressure is directly as density, the velocity will not vary with the pressure.

The mean free path of a gaseous molecule may be obtained by measurements of its viscosity. We have seen that a force is required to maintain a difference in mass motion of two parallel layers of a gas because of the collisions which occur between molecules of originally different layers and hence of different mass 
velocities. The greater the number of such collisions the greater will be the tendency of the molecules of all the layers to come to a common speed and hence the greater must be the force ${ }^{1}$ which maintains the desired difference. Other things being equal we should expect that the greater the density, the greater will be the viscosity. If tha molecules of a fast-moving layer may travel, before collision, only to a near-by layer, the molecules of which are moving with a speed but slightly different, then the effect of the collisions is not so great as it would be if the molecules move past several layers and collide with those of a much slower mass motion. Similarly we expect the effect of the slow moving molecules to be less if they do not move into far distant and rapidly moving layers and hence that the greater the mean free path of the molecules the greater will be the viscosity. These hypothetical effects are not independent, for greater density means smaller mean free path. The effect will also depend upon the average molecular velocity. It may be shown by reasoning similar to that followed in Chapter XIII, that

$$
c=v L d / 3
$$

where $d$ is density, $v$ is average velocity, $L$ is the mean free path, and $c$ is the coefficient of viscosity. For example at $0^{\circ} \mathrm{C}$. for hydrogen $c=0.0000889, v=169,200$, $d=0.0000898$, and hence $L=1.76 \times 10^{-5} \mathrm{~cm}$.

${ }^{1}$ It is evident that energy is expended in maintaining this difference in mass velocity between two layers. The external energy imparted to the molecules in a mass motion is thus seen to be constantly degrading into molecular kinetic energy of haphazard motion. The average molecular velocity, and hence the temperature, of the gas therefore increase. 
Expressions have been derived for the diameter of a molecule in terms of its mean free path. We shall only indicate the line of reasoning which has been followed in such derivations. If all the molecules in a c.c. of gas are imagined to be evenly spaced there will be in each row or column of the cube $\sqrt[3]{N_{0}}$ molecules, where $N_{0}$ is the total number per c. c. The distance

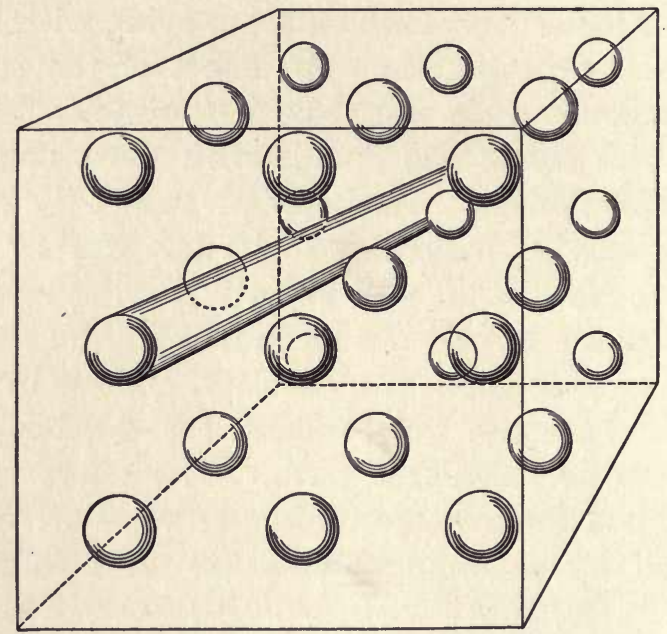

Frg. 34.

between the centers of two adjacent molecules will then be $D=1 / \sqrt[3]{N_{0}}$. Now imagine all the molecules except one to be stationary in this configuration. This molecule will trace out a cylinder having the same diameter as itself, as illustrated in Fig. 34. The average length of all the possible circumscribing cylinders which just fall short of inclosing a portion of another molecule, is therefore the mean free path 
of a molecule under the condition that its neighbors are stationary.

Now Clausius showed that

$$
L^{\prime} / D=D^{2} / 4 \pi r^{2}
$$

where $L^{\prime}$ is this mean free path, $r$ is the radius of the molecule, and $1 / D$ is the cube root of the number of molecules per c. c. As a matter of fact all the molecules are in motion with different velocities, so that the problem is not quite as simple as the case we have just considered. The mean free path is shorter than $L^{\prime}$ and is $L^{\prime} / \sqrt{2}$. Hence if we express the diameter in terms of the mean free path we have

$$
(2 r)^{2}=D^{3} / \pi \sqrt{2} L=1 / \pi \sqrt{2} N_{0} L
$$

Substituting for $N_{0}$ its value of $60.65 \times 10^{22} / 22410$ and for $L$ the value found above, we find for hydrogen $2 r=2.17 \times 10^{-8} \mathrm{~cm}$. Similarly for oxygen $2 r=2.99 \times 10^{-8}$ $\mathrm{cm}$.

There are other methods by which these molecular magnitudes may be obtained. For example, the constants of Van der Waals's equation furnish an indication of the molecular diameter. This method is not, however, as accurate as some others, e.g. that of viscosity discussed above, but it leads to results of the same order of magnitude. For example, Van der Waals found $2 r$ for hydrogen to be $1.04 \times 10^{-8} \mathrm{~cm}$., while a more recent determination using the same method more carefully gave $1.26 \times 10^{-8} \mathrm{~cm}$.

Knowing the mean free path and the average velocity we may calculate the average number of collisions per second as $v / L$. Thus for hydrogen there are about 
$10^{10}$ and for oxygen approximately half as many collisions per second under standard conditions.

The mean translational kinetic energy of a molecule per degree is found by the equation $w=3 R / 2 N$ as $3(83.2) \times 10^{6} / 2(60.65) \times 10^{22}$ or $2.06 \times 10^{-16} \mathrm{ergs}$.

As an illustration of the variations in the determination of molecular magnitudes and also of the remarkable consistency of the values obtained by widely different methods, consider the following table ${ }^{1}$ :

\section{TABLE II}

Phenomena Observed . . . . . . . . . . . . . $N \div 10^{22}$

Viscosity of gases (Van der Waals's equation). . . . . 62.

Brownian Movement - Distribution of Grains . . . 68.3

Brownian Movement - Displacements . . . . . . . 68.8

Brownian Movement - Rotations . . . . . . . . 65.

Brownian Movement - Diffusion . . . . . . . . 69.

Irregular Molecular Distribution - Critical Opalescence . 75.

Irregular Molecular Distribution - The Blue of the Sky . 55.

Black Body Spectrum . . . . . . . . . 64 .

Charged Spheres (in a gas) . . . . . . . . . . 68

Radioactivity - Charges Produced . . . . . . . . 62.5

Radioactivity - Helium engendered . . . . . . . . 64 .

Radioactivity - Radium Lost . . . . . . . . 71.

Radioactivity - Energy Radiated . . . . . . . . 60.

Millikan's Value - Charged spheres in a gas : . : . 60.65

The agreements are more remarkable than the discrepancies when we stop to realize what an enormous number of molecules there are in a mole. The fundamental assumptions of the kinetic theory cannot be doubted in the light of this evidence. This does not mean, however, that certain assumptions which are sometimes made for convenience of mathematical analysis are verified. For such analysis it is usual to assume that the molecules behave like hard elastic

${ }^{1}$ From Perrin's “Atoms" except for the addition of Millikan's value and the value obtained from the blue of the sky. 
spheres. But as we shall see in considering the motion of the helium ions, which are shot off from radium, the molecule is more like a solar system with relatively large spaces between the electrons and the nucleus which compose it. That matter is composed of finite particles which are in constant motion, and that phenomena like gaseous pressure, osmotic pressure, and viscosity are due to motions and impacts of these small particles is verified by this remarkable evidence.

Two practical applications of the fundamental facts of the kinetics of gases are illustrated in the pumps for obtaining high vacua in the manufacture of vacuum devices such as X-ray tubes and thermionic vacuum tubes for radio-communication. The vacua to be obtained to-day are far in excess of those obtained by Torricelli. ${ }^{1}$

Consider for example a rotating drum. Molecules of the adjacent gas, which impinge upon it, have superimposed upon their natural molecular motions a mass motion in a direction tangential to the drum. If the mean free path is small they will lose this

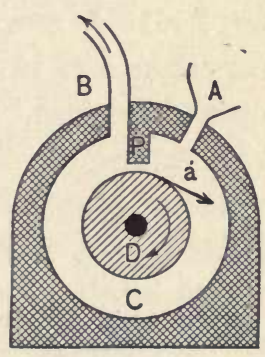

Fig. 35. forced motion by collisions with other molecules, but if it is comparatively large they will maintain it during an appreciable travel. In the Gaede molecular pump the drum rotates inside a hollow cylinder, as shown in cross section in Fig. 35.

The vessel to be exhausted is connected at $A$. An

1 Above the mercury in his barometer there was, of course, the vapor of the mercury. In accurate readings of a mercury barometer an allowance is always made for this fact. 
ordinary air pump, connected to $B$, maintains the pressure within the cylinder low enough to permit the desired action. Molecules, due to their natural motions, enter $C$ from $A$ and impinge on the drum $D$. They leave $D$ with a component motion in the tangential direction of the small arrow $a$. Because the mean free path is large few of them encounter other molecules. Striking against the walls of $C$, they are reflected back on to the drum but farther along. In this way they are impelled around $C$ from $A$ to $p$. The number of molecules at the exit $B$ is therefore maintained greater than at $A$. The action of the "rough" pump constantly removes some of these excess molecules.

With such a molecular pump ${ }^{1}$ vacua corresponding to $2 \times 10^{-8} \mathrm{~cm}$. of $\mathrm{Hg}$ have been obtained. This represents a pressure of about three ten-thousandths of a dyne $/ \overline{\mathrm{cm}}{ }^{2}$ In oxygen the mean free path corresponding to this pressure is $76 / 2 \times 10^{-8}$ times the value of page 279 , or $35,400 \mathrm{~cm}$. The number of molecules per c.c. is directly as the pressure and is approximately $7 \times 10^{9}$. The number of collisions per second per molecule is the quotient of the average velocity, which has not been altered by a reduction of the pressure, and the mean free path, or about one

${ }^{1}$ In the actual pump there is a series of chambers like $C$. The first of these connects at $A$ to the vessel to be exhausted and the last connects at $B$ to the backing pump. The outlet $B$ of the first chamber connects at $B$ with the intake $A$ of the succeeding chamber, and so on. The result is equivalent to that which would be produced by a drum of much larger diameter. The molecules which are impelled around toward $B$ have, therefore, smaller chance of diffusing back to $A$. The actual pump runs in oil so arranged that by the rotation the oil is thrown outward against the clearance spaces at the end of the drums and thus seals them very effectively. 
collision per second. This gives an interesting picture of the spatial relations of the molecules in a c.c. of highly rarefied gas. Although there are about seven thousand million, they are so widely separated, relative to their size, that each molecule travels on the average about a third of a kilometer between collisions and makes but one collision a second with another gas molecule.

The principle of the other pump is somewhat similar, but the mass motion of the molecules which are to be exhausted is due to impacts with directed molecules. The system is shown in Fig. 36. The rough pump is connected at $B$ and the vessel, which is to be evacuated, at $A$. The reservoir $R$ contains mercury which is heated and boils.

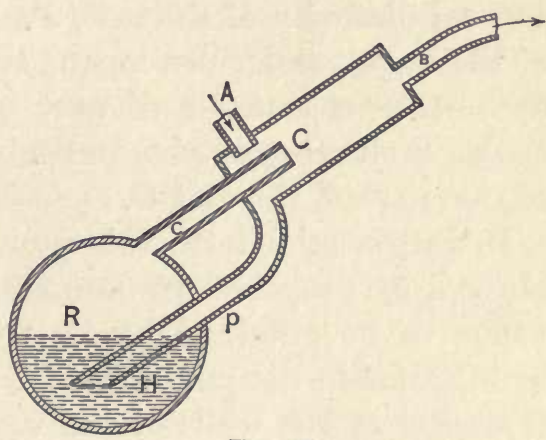

Frg. 36. The mercury molecules rise in a dense stream and shoot through the tube $c$ into the chamber $C$. Molecules of the gas entering at $A$ get in the way of this stream, and receive a mass motion toward the outlet at $B$. The chamber $C$ is cooled, usually by a water jacket (not shown in the sketch), and hence the vapor molecules condense on its sides and trickle down again into the reservoir $R$.

The kinetic energy of the mercury vapor molecules is in part transferred to the gas molecules with which they happen to come into collision, but in greater part 
is removed by this cooling. At the upper end of the chamber $C$ there are some molecules of the vapor, but these are much reduced in velocity by the cooling and but few of them find their way back, against the stream, into the region $A$. The stream of molecules from $c$ spreads out somewhat as a result of the haphazard motions of its individual molecules. The mass motion given to the gas molecules may therefore be lateral in part, in which case they may bounce a few times from the walls of $C$, but the motion is nevertheless in the general direction of the exit, $B$. The lateral spreading of the vapor molecules means collisions with the walls and hence a transfer of part of their energy to the cooler molecules of the walls. In this way but few of them reach the exit $C$.

In commercial form this pump has been developed along lines proposed by Langmuir. The limit of the vacua to be obtained by its use does not appear to be inherent in the pump itself but to depend upon the character of the walls of the vessels, particularly that which is to be exhausted. We recognize that these walls are not smooth and solid but are a granular structure of glass molecules. Within the spaces between these molecules there may be numbers of gas molecules. These diffuse into what we usually consider the free space of the vessel, but do so comparatively slowly because of the network of glass molecules past which they must thread their way. Gas, which is thus occluded by the walls of the vessel, is probably the real limit of the vacuum which may be obtained, for otherwise, sooner or later, every gas molecule of the vessel at $A$ would find its way into the chamber $C$. 
Modern methods which are used for measuring small gaseous pressures also illustrate the reality and the fundamental facts of molecular kinetics. A typical pressure gauge consists of a chamber which is connected to the vessel containing gas at the unknown pressure. It contains a small strip of platinum and a movable vane. The strip is heated electrically. The deflection of the vane is manifested by the rotation of a beam of light reflected from it. The vane turns as a result of its bombardment by molecules which have been heated by contact with the platinum strip. The pressure at the vane is therefore higher than elsewhere in the vessel. The uniform pressure in the rest of the vessel may be expressed in terms of the pressure on the vane and the temperatures of the vane and the platinum strip. With a gauge of this type pressures have been observed as small as $5 \times 10^{-10} \mathrm{~cm}$. of $\mathrm{Hg}$ (i.e. 7 millionths of a dyne per sq. cm.). 


\section{CHAPTER XXI}

\section{MOLECULAR ENERGY}

THE value of the kinetic energy of translation of all the molecules in a mole has been shown to be $3 R T / 2$. To raise the temperature of a mole one degree therefore requires $3 R / 2$ ergs to supply the increases in energy of translation of the molecules, that is, $R / 2$ ergs for each degree of freedom. (If the molecule has other degrees of freedom additional energy will be required.) If expansion is allowed and external work done by the gas, still more energy is required to heat the mole one degree. Represent this energy by $A$.

In considering the amount of energy required per degree of temperature per mole we therefore distinguish two cases, namely, (1) the energy required when the volume is maintained constant, and (2) that required when the volume is allowed to increase but the external pressure is maintained constant. The first of these is the "specific heat at constant volume," denoted by $C_{v}$, and the second is the "specific heat at constant pressure," $C_{p}$. We may write an expression for $A$, the external work per mole per degree of temperature, and these specific heats as

$$
C_{p}=C_{0}+A
$$

These magnitudes are conventionally expressed in other units than the erg. The usual unit is the calorie, 288 
which is equal to an odd multiple of an erg, namely, $4.19 \times 10^{7}$, or 4.19 joules. The calorie is a relic from the days of the phlogiston theory, which has become firmly fixed in the literature.

It was adopted at a time when heat appeared or disappeared from the view of experimenters in a most mysterious manner, and was a measure of that "imponderable fluid." It was and is, however, a very convenient unit in many ways. For example, it was found that if two masses of water, $m_{1}$ and $m_{2}$, at temperatures of $t_{1}$ and $t_{2}$ respectively, are mixed the mixture comes to a temperature, $t$, given by the relation ${ }^{1}$

$$
m_{1}\left(t_{1}-t\right)=m_{2}\left(t-t_{2}\right)
$$

It is convenient to take unit heat as that lost or gained when 1 gram of water changes $1^{\circ} \mathrm{C}$. This is the calorie. In calories, then, the "specific heat" of water is unity. We now see that what Joule (cf. page 112) really measured was the specific heat of water. Up to his time its absolute value was unknown. The calorie is merely an arbitrarily chosen unit for measuring energy. It is therefore usual to write 1 calorie $=J$ ergs, where $J$ is sometimes incorrectly called the "mechanical equivalent of heat."

This "method of mixture" which led to the adoption of the calorie as a unit of "heat" was easily extended.

${ }^{1}$ This equation means that the molecules of the mass $m_{1}$, which have a kinetic energy of translation corresponding to $t_{1}$, arrive at an equilibrium with the molecules of mass $m_{2}$, which are at the lower temperature $t_{2}$, when both groups of molecules have the same average kinetic energy of translation and hence a common temperature $t$. The energy transferred from the molecules of the first mass is $m_{1}\left(t_{1}-t\right)$ and in a conservative system equals that gained by the other molecules, namely $m_{2}\left(t-t_{2}\right)$. 
For example, if a mass of some substance other than water was heated and mixed with a mass of water at a lower temperature, the final temperature was found to be lower than equation (2) indicated. The substance was, therefore, said to have a smaller capacity for the intangible fluid. For calculations the mass of the substance was therefore reduced to that of an amount of water, equivalent in heat capacity, by multiplying it by a factor called its specific heat. The general relation of which equation (2) is a special case is then

$$
M_{1} S_{1}\left(t_{1}-t\right)=M_{2} S_{2}\left(t-t_{2}\right)
$$

where $S_{1}$ and $S_{2}$ are the specific heats ${ }^{1}$ in calories per gram.

It is convenient in discussing gases to deal with the molecular specific heat, that is, the heat per degree per mole, as we have in equation (1). Let us retain the same symbols but express $C_{v}$ and $C_{p}$ in calories; since $A$ equals $R,{ }^{2}$ we have

$$
C_{p}=C_{v}+R / J
$$

1 The calorists found a curious state of affairs when one of the components of the mixture passed through a change of state. For example one gram of steam at $100^{\circ} \mathrm{C}$. in changing from steam to water without change of temperature would liberate about 536 calories. To-day we recognize in this change a conversion of potential energy into kinetic. The calorists, however, considered that there was a hidden store of the fluid which was released when steam condensed and called the amount per gram the "latent heat of vaporization." Similarly when water freezes about 80 calories per gram are released merely by the change of state. This they called the "latent heat of fusion." These two unfortunate terms remain in the literature to-day.

${ }^{2}$ Consider 1 mole, at pressure $p$ and temperature $T$, to be heated $1^{\circ} \mathrm{C}$, and to do external work, $A$, against a piston of area, $a$. Let 
Let us now see what value of $C_{v}$ we should expect for various types of molecules. In addition to translation a monatomic molecule should have three degrees of rotation, that is of spin, about three mutually perpendicular axes through its center. With the fact that a body has such degrees of freedom we are familiar from our experience with golf balls. ${ }^{1}$ Unless the centers of two molecules are moving along the same line or unless they are perfectly smooth spheres, a collision results in a change in their rotation. In an impact the points of contact come to rest relatively. The centers, and in fact all other points, do not, but continue in their original directions because of their inertias. If the impact is elastic the molecules bounce apart, but their rotational speeds will have been altered.

The k.e. of rotation of the various molecules of a gas will, therefore, be different and that of the same molecule will vary from time to time. It will, however, have an average value just as in the case of translation. According to the conclusions of the mathematicians the two average values will be equal, that is, there will be equipartition between translation and rotation and hence between all the degrees of freedom.

Corresponding to an increase of $1^{\circ} \mathrm{C}$. in a mole of gas each degree of freedom of translation is increased by $R / 2$ ergs. From page 218 we have $R=83.2 \times 10^{6}$

the initial and final volume be $V_{1}$ and $V_{2}$, respectively. The piston moves $\left(V_{2}-V_{1}\right) / a$ against a force, $p a$, and hence $A=p\left(V_{2}-V_{1}\right)$. But $p V_{1}=R T$ and $p V_{2}=R(T+1)$, hence $A=R$.

${ }^{1}$ In this case we usually recognize the existence of a spin by a deflection of the ball from its rectilinear path due to the difference in air pressure on the two sides, which is occasioned by its rotation in combination with its translation. 
ergs, and hence $R / 2 J$ is 0.99 calorie. For convenience ${ }^{1}$ in discussion we shall use the approximate value of 1 calorie. We then expect the specific heat, $C_{v}$, to be $(3+n) R / 2 J$ or $(3+n)$ calories, where $n$ is the number of degrees of freedom which the molecule has in excess of the three of translation. For a monatomic molecule, therefore, we put $n=3$ and expect $C_{v}$ to be $(3+n)$ or 6 calories.

Specific heat, we notice, is merely the name for a rate, that of change of the total molecular energy per degree of temperature. We expect this rate for a monatomic molecule to be 6 calories, independent of the temperature. Now, what are the facts? In the first place, we find that specific heats are not in general independent of the temperature, as we shall see in more detail later. In the second place, we find that the specific heat of monatomic gases is practically 3 instead of 6 calories. For argon it has been measured over a very wide range of temperature and found to be constant and of value $2.98 \mathrm{cal}$. Apparently all the energy required to raise a mole of argon $1^{\circ} \mathrm{C}$. is that needed to increase its kinetic energy of translation. According, however, to the simple mechanical considerations of the last few pages any impacts, except head-on, must cause some rotation of the molecules unless the latter happen to be smooth spheres. Of course, if the argon atom was practically a geometrical point, that is, infinitely small, it could not rotate. But

1 This convenience may not be eredited to the calorists. In this connection it is interesting to note that before Joule's classical experiments on the "mechanical equivalent of heat," J. R. Mayer had reasoned from the relation, $C_{p}-C_{v}=$ external work, and had obtained a value of the calorie in mechanical units. 
we know that, although it is small, it is finite in diameter. Helium and mercury vapor, which are both monatomic gases, also have values of molecular heat of about 3 calories and behave as if there was no energy of rotation.

In the case of a diatomic gas there are five degrees of freedom, if the distance between the centers of the atoms remains fixed. The position of one atom is then determined with reference to the other by two angles which are formed by the connecting line and two reference planes, one angle giving the bearing or "azimuth" and the other the height or "elevation" as measured from a plane perpendicular to the first reference plane. Such a system, therefore, has five degrees of freedom, and we should expect its specific heat to be 5 calories.

Many of the diatomic gases have molecular heats of about this value. For example, oxygen has the following values: $C_{v}$ is 5.17 at $300^{\circ}$ C., 5.35 at $500^{\circ}$, and 6.00 at $2000^{\circ} \mathrm{C}$. It will be noticed that although in one instance $C_{v}$ has about the expected value, it does vary and is higher at the higher temperatures. At the higher temperatures oxygen seems to be more nearly in the condition of the gases which we know dissociate. For such gases we find the value of the molecular heat about 6 at ordinary temperatures and higher than that at still higher temperatures. It seems as though the bonds which maintain the distance between the two atoms were gradually weakening, allowing an oscillation of the atoms in the case of more and more molecules as higher temperatures are reached. If there is a motion of one atom relative to the 
other there are six degrees of freedom, namely, three of translation, two of rotation, and one of oscillation. In an oscillation, however, there is a continuous change of kinetic energy into potential and then of potential into kinetic. According to the generalization of the equipartition of energy the kinetic energy of this oscillation is on the average 1 calorie. Now the average value of the potential energy must be the same. ${ }^{1}$ There should then be required an average of 1 calorie of kinetic and 1 calorie of potential energy, or a total of two calories for this degree of freedom. The molecular heat should then be 7 calories and not 6 . We, therefore, expect the molecular heat of a diatomic molecule to be either 5 or 7 calories, depending upon whether or not there is freedom of oscillation, but we do not expect intermediate values. Such, however, are found in actual experiment.

The idea of an equipartition of energy among the degrees of translation was seen in Chapter XIII to lead to a correct expression of the kinetic relations for gas molecules. An equipartition between translation and rotation (or internal oscillations) would seem from page 291 to be physically necessary for granular atoms composed of electrons. As a matter of fact, one of the methods employed by Perrin in determining the value

${ }^{1}$ For convenience in this relative motion consider that one atom oscillates about a mean position with reference to the other. The oscillating atom has its maximum k.e. while passing through this unstressed position. At the turning points, both nearer and farther from the other atom, there is zero k.e., but in these positions it has a potential energy equal to its maximum k.e. The result is that the k.e. varies from a maximum to zero while the p.e. is varying from zero to an equal maximum. The average values of the p.e. and the k.e. are then equal. 
of $N$ involved Brownian rotations ${ }^{1}$ of spherules of mastic. The equation which he used to interpret his observations was correct only if there was on the average an equipartition of energy between rotation and translation for these spheres. Of course, the latter had to be large enough so that he could observe any markings on them and thus detect and measure the angular displacements of such markings. He used spheres of diameter $13 \mu\left(13 \times 10^{-3} \mathrm{~mm}\right.$.), which were therefore about 100,000 times as large in diameter as a molecule. For particles at least as small as this, therefore, equipartition holds.

From the values of the specific heat of monatomic gases it appears that the degrees of freedom of rotation, which we should expect the molecules to have, are effectively ankylosed ${ }^{2}$ at all temperatures to which they have yet been subjected. It further appears from the values for other gases that as the temperature increases there is an increasing number of molecules for which there is no longer ankylosis. There is also reason to believe that collisions of the molecules result in the acquisition of energy in these degrees of freedom only if a definite quantity of energy is made available by the impact. If, at the temperature represented by the average molecule, the velocity of translation of the fastest molecules is too small for a collision to result in this quantum of energy, then none of the k.e. of translation is absorbed by other degrees of freedom.

1 Cf. Table II, p. 282.

2 The term "ankylosis" entered the language of statistical mechanies from medicine, where it represents a stiffening or fixation of a joint. 
The more thoroughly one is accustomed to the scientific formulation of the laws of matter and energy which hold for visible masses, the more impossible seems such a phenomenon as has been suggested. We expect that a system will absorb energy in any amount and increase continuously in its energy, and we cannot as yet visualize a molecular mechanism of the sort we have implied above.

In the case of solids the principle of equipartition is even farther from representing the facts. The molecule of a solid cannot leave its boundaries and must have all its energy in oscillation about a mean position. As it departs from that position it forms with adjacent molecules systems of increasing potential energy. As it returns toward the mean position this potential energy is converted into kinetic energy. Heating the solid increases the kinetic energy of the "oscillators," as we might call them. The average potential energy, however, increases equally with the kinetic. There are three mutually perpendicular axes along which the molecule may vibrate and there will be required one calorie of p.e. and one of k.e. for each of these three degrees of vibrational freedom. We should therefore expect a total of 6 calories.

The molecular heat of monatomic solids, that is, the atomic heat of elementary substances, is in many instances about 6 calories, as is evident from the following values: carbon 5.5 , boron 5.5 , sodium 6.7 , magnesium 5.9, phosphorus 6.2, sulphur 5.9, silver 6.0, copper 5.9, iron 6.4 , nickel 6.3 , aluminium 5.9, zinc 6.1 , platinum 6.2 , gold 6.2 , cobalt 6.0 . In the early days of calorimetric measurements (1818) Dulong and 
Petit noticed the fact that the product of the specific heat per gram and the atomic weight was approximately 6.4 calories. They announced the fact as an empirical law, years before the idea of an equipartition had been developed.

More recent measurements have shown that this relationship is the accidental result of the temperatures of their experiments, for as the temperature is decreased the specific heat is found to have lower values, approaching zero at the absolute temperature of zero. Thus $C_{v}$ for carbon (from measurements on a diamond) is 5.51 at $1258^{\circ}$ absolute; 5.29 at $880^{\circ} ; 3.63$ at $520^{\circ}$; 2.12 at $358^{\circ} ; 1.35$ at $283^{\circ}\left(10^{\circ}\right.$ C. $) ; 0.76$ at $222^{\circ}$, and practically zero at $50^{\circ}$ absolute.

As a solid is heated, its changes in temperature are manifested to our senses by the radiation of heat, and later by luminous radiations, first dull red, but finally all those of the spectrum, in which condition the solid is incandescent. According to the modern theory, this light is due to the oscillations of the electrons. These electronic oscillators we should expect to be displaced from their equilibrium positions by collisions or by interactions with the electrons of atoms in their immediate neighborhood. According, however, to the theory advanced by Planck, they will be caused to oscillate only by the receipt of a definite amount of energy, a quantum. The quantum is not necessarily the same for two different oscillators, but depends upon their natural ${ }^{1}$ frequencies, being $d=h f$, where $f$ is the frequency and $h$ is known as "Planck's constant."

${ }^{1}$ The natural frequency of a system is the frequency at which it will oseillate if displaced from its equilibrium, and then left free 
The total energy possessed by the oscillators of one mole of a substance will then depend upon their natural frequencies, upon the number of molecules in the mole, $N$, and upon the absolute temperature, $T$. As the temperature is changed the energy changes and the ratio of the change in energy to the change in temperature is, of course, the specific heat. In terms of $h, f, N$, and $T$ both the average energy and the specific heat ${ }^{1}$ have been expressed by Einstein. These formulæ do not give calculated values of the specific heat exactly in accord with the experimental values, although the agreement-is sufficient over a wide range of temperatures to indicate that in the concepts of energy quanta and of electronic oscillators, scientists have much more than a hopeful clew to follow in their study of matter and energy. Some modifications of Einstein's equation have been suggested which adapt it more nearly to the observed facts as to the specific heat of solids, but these we shall not consider.

To apply such a formula it is necessary to have numerical values for $h$ and $f$. The value of Planck's constant, $h$, has been determined several times and is fairly accurately known, as we shall see in the succeeding chapter. As to the frequency, $f$, of the natural oscillation it should be noted that in general there would be more than one natural frequency. (The total

of external influences to dissipate the energy contributed to it in producing the displacement. The opposite of a "natural" vibration is a "forced" one. A violin string when bowed receives energy and vibrates at its natural frequency, but the drum of the ear of the listener undergoes a forced vibration.

1 Thus

$$
C_{v}=3 N \frac{h^{2} f^{2}}{R T^{2}} \frac{\epsilon^{h / R T}}{\left(\epsilon^{h / R T}-1\right)^{2}}
$$


specific heat would then be the sum of the specific heats as found for each of the types of oscillators.) The determination of these frequencies may be made by several methods, of which two will be described.

It is found that substances absorb the same frequencies as they naturally emit. Thus glass which transmits red light absorbs blue; when heated it will be found to give off a blue light, not a red light. The frequencies which are reflected from the surface are found to be those which are most strongly absorbed in transmission. Thus for this case, blue light will be reflected from the outer surface.

To determine what frequencies are reflected from a substance it is then only necessary to illuminate it by a source containing all frequencies ${ }^{1}$ and to observe the reflected light. Now, at first thought, this does not seem reasonable, for we know if we observe the image of an incandescent electric lamp as reflected by a sheet of red glass that the lamp appears white, exactly as well as if viewed directly. In this particular case there happens to be reflected from the polished surface enough light of all the frequencies which compose white light so that we do not observe the expected effect. But let us arrange other mirrors of red glass and see the lamp by reflection from several surfaces instead of only one. Each successive reflection results in purer and purer light "of the natural frequencies of the red glass." The rays of light which survive a number of such reflections are called "re-

1 A "full radiator," containing all frequencies from zero to infinity, sometimes called a "black body," since the ideal black body would absorb all frequencies. 
sidual rays." It is not correct to say "of the natural colors," for some of the "rays" may be of frequencies too low to be visible and others too high.

The phenomenon of residual rays is one of "resonance," of which many illustrations are to be found. Consider a case in sound. If all the keys of a piano are depressed so that the strings are free to vibrate and if then a person sings some note, the string corresponding to this note is set into "sympathetic vibration." The energy of the sound waves is not absorbed by the other strings to an appreciable extent, although they are all forced to move somewhat. In the case of the string of the proper natural frequency, each succeeding displacement which the wave causes is in just the same direction as the string would naturally move as a result of the energy imparted during the preceding displacement. The energy of the wave train is, therefore, always available for increasing the displacement of the string. In other cases this energy is obviously not always so available. The greater the musical interval between the natural frequency of the string and the impressed frequency of the wave train, the more nearly will it be true that energy is available alternately, and in equal amounts, for reducing the natural motion of the string and for increasing it. Under these conditions the string will have no motion.

Looking at this matter from a slightly different viewpoint, we see that this means that the string of the wrong frequency does not absorb energy from the wave train. All the energy of the wave train passes by such strings. We, therefore, do not expect a 
medium to transmit a wave train without absorption when the natural frequency of its oscillators is the same as that of the waves. Those oscillators of a medium which are nearest the source of the radiation absorb the most and those farthest away the least of the energy. For this reason a thin sheet of black paper may prove insufficient to protect photographic films in strong sunlight when a sheet of double the thickness may do so.

The oscillators of a medium which are absorbing radiation are vibrating with the increased amplitudes. Now, it makes no difference how they were set into vibration, they will also radiate energy. (It is immaterial, for example, whether a piano string is set into vibration by a wave train or by a blow on the proper key, it will send out a wave train of its own frequency.) The absorbing oscillators, at and near the surface, thus act as radiators. ${ }^{1}$ The frequency of the radiation, which is "reflected," must then be that which is absorbed. Reflection is really "re-radiation."

In the other method for obtaining the natural frequencies it is assumed that at the melting point of a solid the amplitude of vibration of the atoms is practically equal to the average distance between the centers of adjacent molecules. At the melting point of all

${ }^{1}$ The reason that a mirror surface must be plane and smoothly polished is now apparent. It must present to the impressed radiation a smooth front of oscillators so that the energy which they radiate may all be available at some distant point. If the surface is irregular the energy radiated by some of the oscillators will render unavailable at the desired distant point some of the energy radiated by the other oscillators. Or, as it is more usually said, there will be a scattering and an interference of the reflected waves. Scattering is negligible if the irregularities are small as compared to the wave length of the incident radiation. 
solids the atomic heat is practically 6 calories, that is, Dulong and Petit's law holds for these high temperatures. (It might be noted that we should expect the physical behavior of molecules to be alike at "corresponding states.") An expression may then be written for the frequency in terms of known constants of the substance under examination. The values obtained by this method are not sufficiently accurate, however, to warrant their use in calculations, but they do serve as checks on those obtained by other methods.

In the matter of electronic oscillators and their ability to absorb energy we have reached a pivotal position of modern science. The earlier idea as to the equipartition of the energy of a molecule is no longer tenable. For the oscillators assumed by Einstein we have the evidence that equations derived upon that assumption indicate variations in specific heat in the direction and of the magnitude confirmed by experiment. The further assumption of Einstein's equation, that energy may be absorbed only in quanta, was originally advanced by Planck to explain certain phenomena of radiation. The success of the application of this concept of quanta to the phenomena of specific heat is at once a confirmation of the "quantum theory" and a promise of an ultimate explanation of these phenomena. At present, however, it is not possible to picture with definiteness the electronic construction or behavior of these oscillators. The quantum theory is in the hands of the future, but its fundamental assumption is completely verified: energy may only be absorbed or transferred in discrete quanta. 
Matter and energy, the two realities of science, are both "granular."

In this theory we have the modern meeting point of physics, chemistry, and physical chemistry. Originally derived to explain certain difficulties met by older theories in the electromagnetic radiation of light, it has been applied to the quantitative expression of specific heats of solids in an equation involving the physical constants met with in the study of gases. This equation may therefore be applied to the determination of the number of molecules per mole. The method used consists first in determining from the relations expressed in the laws of thermodynamics an expression for the energy of radiation of a "black body" in terms of the total energy of the body. For the total energy the value expressed in terms of electronic oscillators is then substituted. The actual radiation is measured by observing its heating effect. The value of $N$, thus determined, is quoted as $64 \times 10^{22}$ in the table of page 282 . 


\section{CHAPTER XXII}

\section{ELECTRONIC MAGNITUDES}

IN Chapter XIV the conduction of electricity through highly rarefied gases was explained in terms of electrons. The phosphorescence of the sides of a glass tube in which such conduction is taking place is due to the impacts of electrons proceeding with high velocities away from the cathode. ${ }^{1}$ Before it was proved that this stream was corpuscular it was assumed that it was a new kind of "light," that is, an electromagnetic radiation, and hence the misnomer "cathode

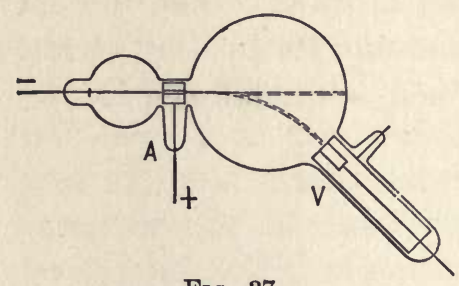

Frg. 37.

rays." For experimental purposes the stream may be made a band (indicated by the dotted line in Fig. 37) by arranging the anode $A$ as a hollow cylinder. A magnetic field at right angles to this ray was found to bend it in the same direction as we would now expect with our knowledge that it is a stream of electrons. By deflecting it into the metal vessel $V$, which was connected to an electroscope, it was found that the ray carried a negative charge. That it is a stream of negative particles was further indicated by the fact that it undergoes a deflection in the proper

${ }^{1}$ Or in some cases to ultra-violet light produced at the cathode. 
direction when a transverse electrical field is impressed upon it.

The force deflecting the stream, when it is subjected to a magnetic field of intensity $H$, is obtained from equation (3) of page 207 as $F=q v H$ if $q$ represents the total quantity of electricity transferred along a length $L$ of the path in a time $t$ (and hence with a velocity of $v=L / t)$. Similarly if the electrical field intensity is $E$ the force acting on the quantity $q$ which is contained by this length of beam is $F=E q$. The velocity of the particles was measured by J. J. Thomson by opposing the actions of these two fields and adjusting their values until there was no deflection, in which case $H v q$ equals $E q$ and $v$ is $E / H$.

Having determined in this way the velocity of the electrons in a particular cathode ray it was possible to find the ratio of the charge, $e$, on each electron to its mass, $m$, by the deflection of the ray under the action of an electrical field only. The case is exactly analogous to that of a bullet shot in a horizontal line with a velocity of $v$, except that the medium in this case is ether and offers no friction. If the acceleration at right angles to this motion is $a$, then in a time $t$ the bullet will travel downward the distance $s=a t^{2} / 2$ and horizontally the distance $L=v t$, following a parabolic path. Now $a$ is always $F / m$, and this was $E e / m$ in the experiment and hence $s$ was

$$
s=\frac{1}{2} \frac{E e L^{2}}{m v^{2}}
$$

Of these terms $s$ and $L$ are directly observable and $v$ is known from the preceding experiment; hence $e / m$ 
was obtained. The numeric representing it is the number of units of quantity per gram. It was found to be about $1.7 \times 10^{7}$ when the quantity was measured in electromagnetic units.

Upon the assumption that the ion of hydrogen in electrolysis is essentially the mass $m^{\prime}$ of a hydrogen atom and represents an equal (but opposite) charge of electricity, the value of $m$ was obtained. In electrolysis one e.m. unit of quantity is transferred by $(1.008)(0.01118) /(107.88)$ or about $10^{-4}$ gram of hydrogen. Hence $e / m^{\prime}$ is $10^{4}$ and a value of $m$ as approximately $1 / 1700$ part of $m^{\prime}$ was thus obtained.

Methods for determining the charge $e$ were soon devised. One of these, by Townsend, proved to be basic to most of the subsequent determinations. In Chapter XVIII we spoke as though all the molecules of gas which rise from the electrodes of an electrolyte were neutral. As a matter of fact, perhaps, one in a million may carry a charge. The sign of the latter depends upon the electrolyte from which the gas rises. Now these charged molecules, when in air containing water vapor, become nuclei of small drops, aggregating to themselves water molecules and forming a visible cloud. The natural assumption is that in such a condensation the number of droplets is equal to the number of unneutral gas molecules. The charge per unit volume Townsend found by allowing the gas to give up its charge to an electrometer (a calibrated electroscope). The average radius of the droplets he found by observing the time it took the cloud to settle, under the action of gravity, through a known distance and then applying Stokes's Law. The weight 
of the cloud per unit volume was obtained by passing it through drying tubes and observing their increase in weight. From this and the size of the particles he found the number, and upon the assumption that each is abnormal by only one electron he obtained from his electrometer reading the value of $e$.

The most exact determination of the electronic quantity is that of Millikan. ${ }^{1}$ The method which he devised involved the observation of the motion of a small particle of oil (about $10^{-4} \mathrm{~cm}$. diam.) under the action of gravity and of an electrical field. The particle usually carried an electrical charge produced "by friction" in its own formation, for the drops were obtained by blowing carefully filtered air through an ordinary atomizer eon-

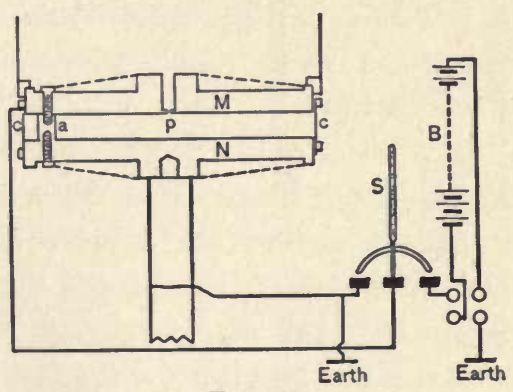

Fic. 38. taining the oil. The electrical field was maintained between two parallel plates, $M$ and $N$ of Fig. 38, by means of the battery $B$. The switch $S$, if to the right, permitted the plates to be raised to the difference of potential of the battery or to discharge through the connecting wires in case it was moved to the left. The four circles at the right of the figure represent a commutator, a device of four mercury cups, two of which connect to the battery and the other two to the parallel plate condenser (in one case through the earth). These mercury cups could be connected in any desired way

${ }^{1}$ Cf. Millikan, "The Electron," Univ. of Chicago Press, 1917. 
by short wires and thus the polarity of the condenser could be reversed.

Above the plates was a closed chamber, which received the spray from the atomizer; and occasionally a small drop would find its way through the pinhole, $p$, in the center of the upper plate and thus be available for observation. Powerful beams of light were directed through the space between the plates from the windows $c$ and $c$ on the right and left. The illuminated drop was observed by a small telescope through a window in the apparatus. In the eyepiece of the telescope were small parallel hairs which served as fixed reference lines for noting the position of the "droplet." This droplet appeared merely as a speck of light, like a bright star on a black background.

If it was desired to alter the charge on an oil drop the air between the plates was ionized by exposure to some ionizing agent, either X-rays or radium. If it was desired to give a drop an additional negative charge it was arranged that it should be near the positive plate of the condenser while the air was being ionized. Toward this plate there came, of course, a shower of electrons produced from the air by the ionization. Conversely, when it was desired to give the droplet an additional positive charge it was held near the negative plate, and thus it suffered collisions from positive ions.

The position of the drop could be controlled at will because it was so small that it fell very slowly indeed. For example, a matter of ten or twelve seconds would be required for the droplet to fall under the action of gravity through the distance of about one centimeter 
between the plates. On the other hand, if it carried a negative charge, it could be made to move up by making the upper plate positive with respect to the lower (by the proper motion of the switch and the commutator). Similarly, if the droplet were positive, the upward motion would be accomplished by reversing the battery connection.

We must remember that the little drops with which Millikan worked were so small that they would only fall about a millimeter a second and yet they were a thousand times or more the diameter of the molecules of the air through which they fell. The change in the inertia of the drop due to its picking up a molecule of the air in a collision would then be negligible. Now Millikan observed thousands of these drops at various times and would sometimes observe the actions of a single drop for hours. By allowing it to fall and then by applying the potential and moving it up again he could keep it in the field of his telescope. When he wanted it to fall he short-circuited the plates, thereby destroying the electrical field between them. He made observations of the time of fall and the time of rise consecutively.

The time of fall for a given droplet, when there was no electrical field, was found to be always the same, within the limits of the experimental error involved in observing the times when it passed the cross hairs of the telescope. The effect of the charges which the drop carried in increasing the resistance of the gaseous medium was therefore inappreciable. There was no appreciable acceleration under the action of gravity, and the motion of the drop was that of a body in a 
viscous fluid, where the velocity is proportional to the force. In the case of the fall, the velocity, $v_{1}$, was therefore directly proportional to $\mathrm{mg}$, the force of gravitation.

The time of rise would be found to be the same for several trips and then suddenly it would change, indicating a change in the charge carried by the droplet. The velocity $v_{2}$ of the motion upward is also proportional to the force. This force is $F n e-m g$, where $F$ is the force due to the field maintained by the battery upon one electrostatic unit of quantity, $e$ is the charge in e.s. units of an electron, and $n$ is the number of electrons carried by the droplet. If the number of electrons is altered to $n^{\prime}$, then the velocity $v_{2}$ will be altered, say to the value $v_{2}{ }^{\prime}$. Thus

$$
\begin{aligned}
& v_{1} \propto m g \\
& v_{2} \propto F n e-m g
\end{aligned}
$$

but

Hence

$$
v_{2}^{\prime} \propto F n^{\prime} e-m g
$$

$$
\left(n^{\prime}-n\right) e=\left(v_{2}^{\prime}-v_{2}\right) m g / F v_{1}
$$

That is, the change in the number of electrons carried by the droplet should be proportional to the change in the velocity which is thereby occasioned, provided that the value of $F$ is maintained constant.

The changes in velocity which Millikan observed always bore simple ratios to each other. He found, in other words, that there was one minimum value for $\left(v_{2}{ }^{\prime}-v_{2}\right)$ and that all the other values were simple multiples. That could only mean that the change in charge. was due to the additions or subtractions of a definite 
amount of electricity or of some whole number of times this amount. His observations are, therefore, to be taken as a final demonstration of the existence of electricity only in definite amounts. This definite amount of electricity he found to be independent of the manner in which it was produced, as for example by friction, or by the ionization of gases. It is independent of the substance from which it is obtained or with which it is later associated, since he used for his drops conductors like mercury, poor conductors like glycerin, and non-conducting oil.

If for $\left(n^{\prime}-n\right)$ there is substituted unity, and for $\left(v_{2}^{\prime}-v_{2}\right)$ the smallest change in velocity due to a change in charge, the value of $e$ may be computed from equation (4) above, providing $m$ is known. Stokes's Law for a falling drop, as given in equation (2), page 275, may be solved to give the radius of the drop in terms of the velocity and viscosity, as follows :

$$
r=\left(\frac{9 v_{1} c}{2(D-d) g}\right)^{\frac{1}{2}}
$$

Now the numerator of the expression given in Stokes's equation is $m g$, since $4 r^{3}(D-d) g / 3$ is the weight of the sphere in a vacuum less the weight of the liquid displaced. Hence, making this substitution in equation (4) and also substituting $r$ from equation (5), gives

$$
e=\frac{4}{3}\left(\frac{9 c}{2}\right)^{\frac{3}{2}}\left(\frac{\pi}{g(D-d)}\right)^{\frac{1}{2}}\left(\frac{\left(v_{2}-v_{2}\right) v_{1}}{F}\right)^{\frac{1}{2}}
$$

Millikan, however, found that the values he obtained for $e$ by using this equation depended upon the size of the drop, being larger as the drop experimented with 
was smaller. He therefore doubted the applicability of Stokes's Law to spheres of such a small size. One of his students, Arnold, tested Stokes's Law for a wide range of diameters by using small spheres formed of rose-metal, a substance with a low melting point. The velocity was found to be correctly expressed by Stokes's Law only when the radius $r$ of the sphere was large as compared to the mean free path of the molecules of the air. The mean free path being inversely as the pressure of the air the true velocity was found to be expressed as

$$
v_{1}\left(1+\frac{A}{p r}\right)
$$

where $p$ is the pressure, $A$ is a constant, and $v_{1}$ is the velocity of fall as calculated by Stokes's Law.

Millikan therefore determined the value of $e$ by using droplets in air under various pressures, and thus found not only the value of the correction factor $A$ but also the true value of $e$. As a further check he repeated his experiments with drops so large that Stokes's Law would hold for fall through air at atmospheric pressure. He then obtained $e$ by substituting directly in equation (4).

The value of $e$ as obtained by this method is $4.774 \times 10^{-10}$ electrostatic unit or $1.591 \times 10^{-20}$ electromagnetic unit. This determines Avogadro's constant, $N$, as $6.065 \times 10^{3}$. From this the mass of a hydrogen atom is obtained as $1.662 \times 10^{-24}$ gram. Using the best value of $e / m$ for the electron and the above value of $e$ gives the mass of the electron as 1/1845 part of the hydrogen atom, or $9.01 \times 10^{-28}$ gram. Upon the assumption that the entire mass is electromagnetic and 
that this charge is uniformly distributed over a sphere, the radius of the electron is indicated as about $2 \times 10^{-13}$ $\mathrm{cm}$. Such magnitudes are quite beyond our comprehension except by analogies, such as a statement of how long it would take if every man in the world should count before the total number counted equaled the number of electrons equivalent in inertia to one gram. They may be more nearly visualized after considering some phenomena of ionization of gases.

For experiments involving ionization $\mathrm{X}$-rays may be used (cf. page 190) or the gas may be exposed to a radioactive substance. The radiations from the latter are of three types, although all three do not usually occur in the case of a single substance. They are usually designated by alpha, beta, and gamma respectively. In this case also the terms "radiation" and "rays" are misnomers, at least as far as concerns the first two, for the $a$ rays are formed of a stream of positively charged helium atoms and the $\beta$ rays by electrons. The $\gamma$ rays are really a radiation, being a penetrating radiation of the nature of a pulse like the X-rays.

The disintegration of an atom of radium, for example, results in the projection in opposite directions of a helium atom (deficient by one electron) and a niton atom, with velocities inversely as the masses. The lighter $a$ particles have about 100 times the greater velocity, and travel about seven tenths as fast as does light. The niton atoms, themselves, disintegrate further and after successive changes in which further $a$ particles are lost, as well as electrons, a more stable resultant of polonium is reached. 
All three types of rays produce ionization. The rays themselves may be separated by subjecting them to a transverse electrical field, for they consist of streams of positive and negative corpuscles, which will be oppositely deflected, and a true radiation which suffers no deviation. Their ionizing effects are easily traced in a gas containing water vapor by the phenomenon of condensation about the newly formed ions. The paths may therefore be photographed. Fig. 39 illustrates the case of $a$ particles projected from radium through air and Fig. 40 is an enlargement of a portion of the preceding figure. Fig. 41 shows the path of a $\beta$ particle.

The paths shown by the $a$ particles are from 3 to 7 cm. long. Now in each cubic centimeter of air there are about $2.7 \times 10^{19}$ molecules, so that each of the particles traced by the photograph must have ionized millions of air molecules. Through the electronic systems which form these molecules each $a$ particle passed so rapidly as not to be deflected although it repeatedly knocked off electrons. In two cases in Fig. 40 there may be seen sharp changes in the direction, when one probably collided head-on with the massive nucleus of an air molecule. These paths would indicate that the nucleus of a molecule is relatively very small indeed, for otherwise, in all probability, there would have been many more such collisions.

In Fig. 41, from bottom to top, we trace the ionization of a high speed electron ( $\beta$ particle). It does not ionize as frequently but it also follows a straight line. Its velocity is obviously so high that it does not remain long enough within the neighborhood of the 

individual systems which it passes to receive by interaction a component of velocity. On the other hand, in Fig. 42 are given the paths of some electrons with smaller velocities which ionize more frequently but are also deflected. The slower speed electron ionizes a larger number of molecules per centimeter than does the higher speed particle. ${ }^{1}$ Both are gradually retarded, and below a certain speed ionization does not occur.

In the cases of Fig. 40 and Fig. 41 the electrons which are knocked off from the molecules leave at such small speeds that they may not themselves serve for ionizing agents (unless accelerated by an impressed electrical field as was discussed in Chapter XIV). In Fig. 42, however, is shown the trace of an X-ray. This radiation does not merely jar loose electrons as did the $a$ and $\beta$ particles, but seems to shake them loose with such violence that each electron leaves behind itself a trail of ionization.

The ability of electromagnetic radiations to shake out electrons is not limited to $\mathrm{X}$-rays and $\boldsymbol{\gamma}$ rays but, as we saw in Chapter XIV, is characteristic also of ultra-violet radiations. Metals, especially zinc and the alkali metals, emit electrons when exposed to ultra-violet light. The effect, known as photoelectric, was recognized, before the theory of electrons was so fully developed, by the fact that under these conditions the metal acquires a positive charge.

In this phenomenon are some curious facts which have supported Planck's suggestion that energy (in this

1 Millikan estimates that this particle (Fig. 41) on the average passed through 10,000 gas molecules for every time it reacted sufficiently to jar loose an electron. Cf. Millikan, "The Electron," p. 186. 
case radiant) is absorbed only in discrete quanta. It is found that if the frequency of the light is maintained constant the number of electrons emitted increases with the intensity of the illumination, but that the speed, and hence the energy, of each electron is independent of this intensity. In other words more quanta are received if the light is more intense, and hence more electrons can be emitted, but each can only absorb the same quantum as before and hence must possess only that amount of energy. On the other hand, if the intensity of the light is kept constant and the frequency is increased, the quanta are greater, as is manifested by the increased velocity of the emitted electrons.

The photoelectric effect, therefore, offers a very convenient method of determining Planck's constant, $h$, by which the frequency must be multiplied to obtain the quantum ${ }^{1}$ of energy corresponding to that frequency. The determination involves a knowledge of the charge on the electron. This constant was therefore redetermined by Millikan using his value for e. He found it to be $6.56 \times 10^{-27}$.

${ }^{1}$ A frequency of about $1.5 \times 10^{14}$ is that at which a heated body radiates the maximum energy. This corresponds to a wave length of $\left(3.0 \times 10^{10}\right) / 1.5 \times 10^{14}$, or about two thousandths of a millimeter, or $2 \mu$ as it is abbreviated. The quantum is then $\left(1.5 \times 10^{14}\right)$ $\left(6.56 \times 10^{-27}\right)$ or $9.9 \times 10^{-13} \mathrm{erg}$. The lowest frequency visible as red light is $3.75 \times 10^{14}$, of wave length $\lambda=0.8 \mu$, and its quantum is $2.5 \times 10^{-12} \mathrm{erg}$. The highest frequency visible as violet light is $7.5 \times 10^{14}$, that is $\lambda=0.4 \mu$, and the quantum is $5.0 \times 10^{-12} \mathrm{erg}$. Ultraviolet light is not transmitted by ordinary glass as well as by quartz. About the highest frequency the latter transmits is $1.5 \times 10^{15}$, that is $\lambda=0.2 \mu$, and the corresponding quantum is $9.9 \times 10^{-12}$ erg. 


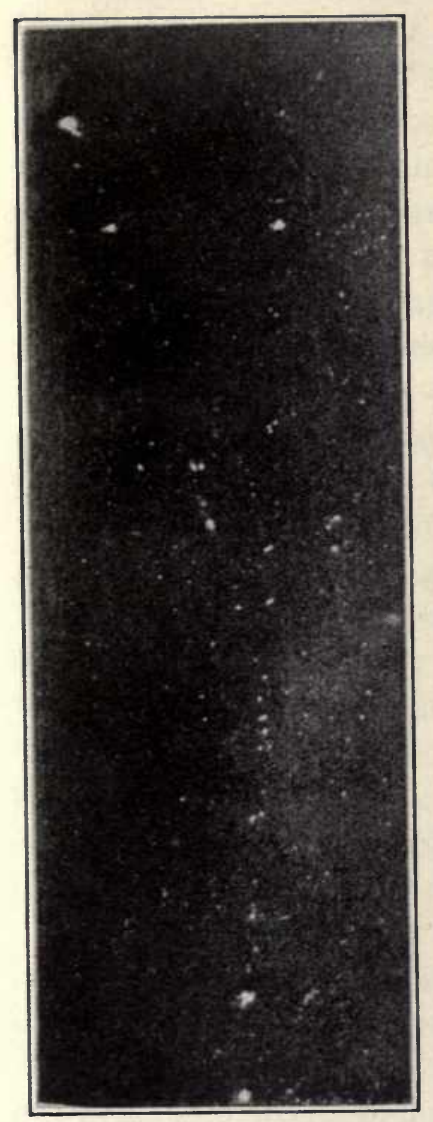

FIG. 41.

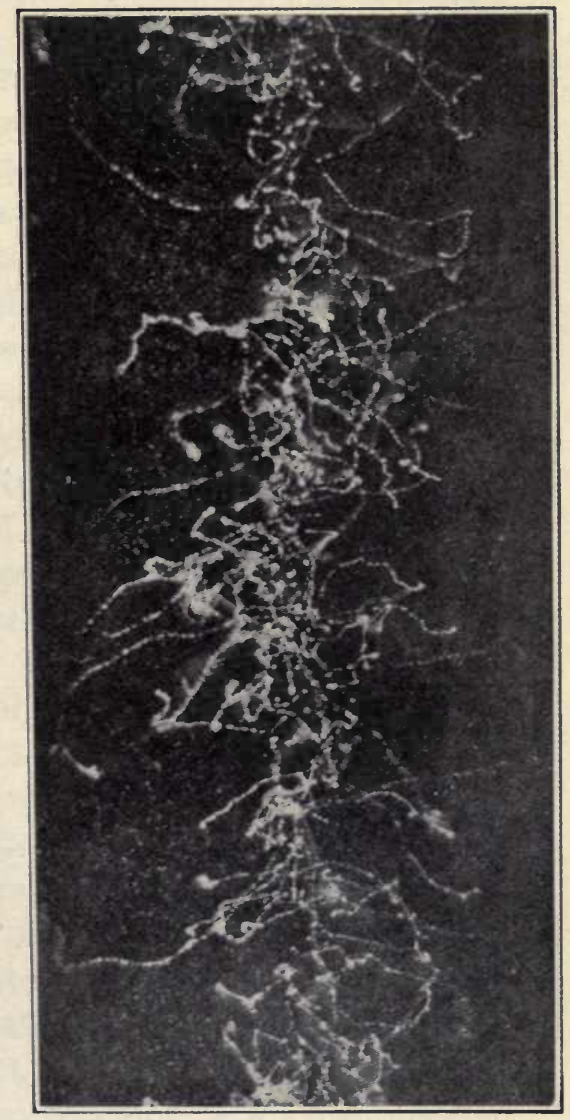

Fig. 42 . 

What might be called the classical theories of radiation have been upset by the remarkable accumulation of evidence indicating the correctness of Planck's hypothesis that energy is absorbed only in definite quanta, each of value $h f$ where $f$ is the frequency. The fact that it is so absorbed is evident from the photoelectric effects, but the mode of its emission, transmission, and absorption is as yet in the domain of speculative physics. For that reason we shall not attempt a further discussion of radiation. Future scientific investigations and analyses will ultimately reconcile the quantum theory with the portion of the classical theory which is supported by direct experiment. One of the difficult points is to reconcile the idea of interference of wave trains of continuous energy with the present evidence of the granular nature of the energy. The phenomenon of interference was responsible for overturning that earlier corpuscular theory of light which had the influential support of Newton. That theory pictured light as a stream of corpuscles, while the present theory may only definitely assert that the energy which we recognize as light is to be received by an electron oscillator only in definite quanta.

With one application of the phenomenon of interference we are immediately interested because it is involved in the determination of the electron numbers which are referred to in Chapter VIII. Interference, however, is a phenomenon common to all instances of the transmission of energy from periodic sources. It occurs in molecular media as well as in the ether. Consider for example a row of similar sources as indicated in Fig. 43. Along the line ad the magni- 
tude of the effect of these will differ from point to point. Thus suppose that at $a$ the disturbance is a maximum. At some point like $b$, however, it will happen that the disturbance received from any source, as $s_{1}$, will be just opposite in its effect to that received from the adjacent source, $s_{2}$. Similarly for other

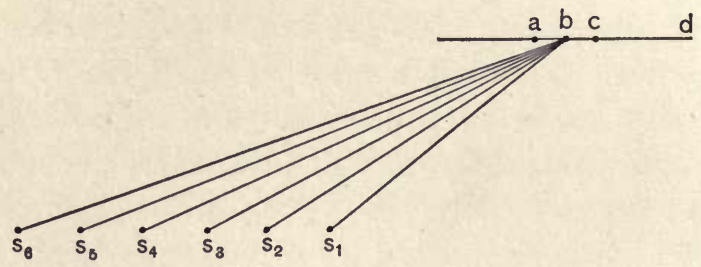

Fig. 43.

pairs of sources. At $b$ there is therefore complete interference. At another point, as $c$, the effects will again be in phase and there will be reënforcement and a consequent maximum. The distance $a c$ is dependent upon the frequency of the several identical oscillators. If these individually give rise to more than one frequency there will be a different series of points like $b$ and $c$ for each frequency, with the result that the location of the maximum will no longer be a point but will appear as a spectral band. ${ }^{1}$

1 The phenomenon is easily observed if one makes in a visiting card two small pinholes separated by about half the diameter of a pinhead. Holding this card close to the eye and observing a distant and intense source of light, e.g. a street lamp, the two holes act like two sources in the diagram of Fig. 43 and the line ad is the retina. A series of spectral bands should then be observed. If it is not, the pinholes are probably too large or too far apart, or both. The pattern seen through the meshes of an umbrella while looking at a distant light is a familiar illustration. 
The sources of Fig. 43 may be secondary sources, all receiving energy from some distant source. If they are excited by monochromatic light its frequency may be determined, provided the separation of the sources $s_{1}, s_{2}$, the distance $s_{1} a$ and the separation of the bands are measurable. This principle has been applied to the measurement of the frequency of visible light by using the so-called diffraction grating, a smooth surface of speculum metal upon which are ruled equidistant scratches. When this is illuminated by a beam of light, the intervening spaces act by reflection as sources. These sources are lines and not points and result in spectral bands parallel to themselves, as may be seen by considering the sources of Fig. 43 to be points in a cross section of such a grating. The grating thus serves to resolve light which is not monochromatic into its monochromatic components, since the location of each band will depend upon its frequency.

Conversely, if the primary source is monochromatic, an indication of the spacing of the point sources is obtained from the separation of the bands. If these point sources do not lie in the same line, as we have so far assumed, but are in three dimensions, the resulting interference bands will form a complicated pattern from which, however, some indication of the configuration of the sources may be obtained. Of course, the spacings of the sources must be regular, and not haphazard, if this is to be done. Such a regular structure is afforded by the atoms of crystalline substances, but their separations are very small and a diffraction pattern is impossible, unless the wave length of the light which is used is smaller than that of visible light. In 
X-rays, however, sources of short wave length are available, and for such radiations crystals act like diffraction gratings, the interference patterns of which may be made visible by photographing.

If various crystals are thus examined under excitation by a given source of X-rays, very definite indications of their molecular structure are obtainable. ${ }^{1}$ Conversely, if a given crystal is used as a grating and is illuminated by $\mathrm{X}$-rays from different sources, indications may be obtained as to the frequency of the sources.

The principle was employed by Moseley to determine the characteristic radiations of various substances when used as the anti-cathode of an X-ray tube. $^{2}$ In other words, the sources were the electronic oscillators of the substance. These were excited by a bombardment of electrons from the cathode of a highly evacuated tube. The spectral bands obtained in this way are illustrated in Fig. 44. As the substance of the anti-cathode is changed from arsenic $(A s)$ to selenium $(S e)$ or from rubidium $(R b)$ to strontium $(S r)$ there occurs the same shift of the characteristic spectrum shown in the figure. This indicates that the group of oscillators, constituting the atom, changes, as the substance is changed to that next in the series of elements, by the addition of the same number of oscillators, that is by the same charge. The number of positive electrons in the nucleus of the atom of any element is thus to be determined from the number in that of any other element by counting the number of

${ }^{1}$ Cf. W. H. Bragg and W. L. Bragg, "X-rays and Crystal Strueture," G. Bell \& Sons, Ltd., London, 1915.

${ }^{2}$ Cf. Kaye, "X-Rays." Longmans, Green and Co., 1914. 


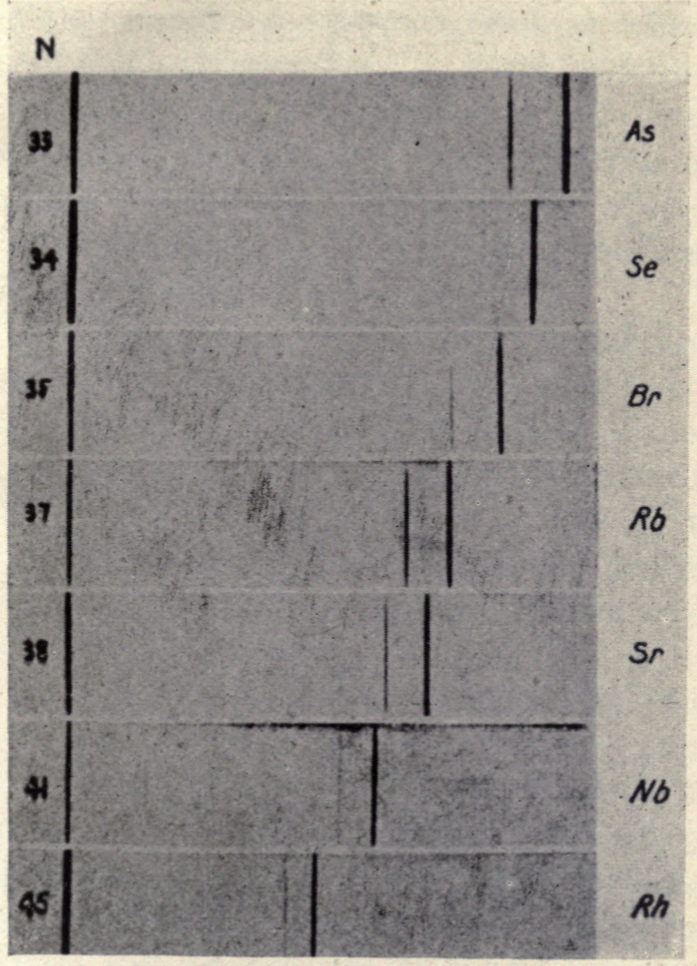

FIg. 44. 

steps required to displace the spectrum of the second to coincide with that of the first. The characteristic lines of the hydrogen atom appear displaced in the spectra of the other elements. (This is evidence in favor of the concept of a positive electron which is the nucleus of the hydrogen atom.) Starting with hydrogen as unity the atomic numbers of a large number of elements have been obtained by the analysis of these and similar experiments. The method offers a precision in excess of that of preceding methods and has definitely established these numbers.

Earlier experiments indicating atomic numbers made use of the deflection of an $a$-ray due to collisions (cf. page 314). Calculations may be made of the charge of the nucleus of a molecule from the scattering of $a$ particles (or of $\beta$ particles) in their passage through solids. Using thin films of metals Rutherford ${ }^{1}$ determined some atomic numbers which are in general agreement with more recent values.

The concept of an electronic constitution of matter, which we have sketched in the preceding chapters, is to-day commonly accepted. Its development has been so rapid that few scientists besides those actively engaged in its research have as yet adopted its terminology and the necessary point of view. In terms, however, of electrons and quanta, the scientific progress of the next few years will undoubtedly be expressed.

${ }^{1}$ Cf. Rutherford, "Radioactive Substances and Their Radiations." Cambridge University Press, 1913. 



\section{INDEX}

absolute motion, 64

absolute zero, 167, 171

acceleration, 134, 144

acid, 255

actinium, 92

action and reaction, 148

active mass, 260

Ahmes papyrus, 120

alchemy, 73, 85, 152

Alexandria, 50

alpha rays, 313

ampere, 178

amplitude, 33

angle of repose, 17

anion, 245

ankylosis, 295

anode, 189

anti-cathode, 190

Arabs, 50, 73

Archimedes' principle, 41

Aristotle, 34, 40, 52

Arnold, 312

Assyrians, 27

atomic numbers, $91,92,320$

atomic size, 90

atomic weight, $84,91,99$

atomists, 85

atoms, $71,72,78,80$

attraction of currents, 198, 201, 207

availability of energy, 105, 153

Avogadro, 80, 83, 84

Avogadro's constant, 312

Babylonians, 10

Bacon, Roger, 41

balance, 28

base, 256

Berzelius, 78, 84

beta rays, 313

Black, 74, 76

black body radiation, 299

boiling point, 171, 224, 239

Boyle, 54, 74, 77, 78

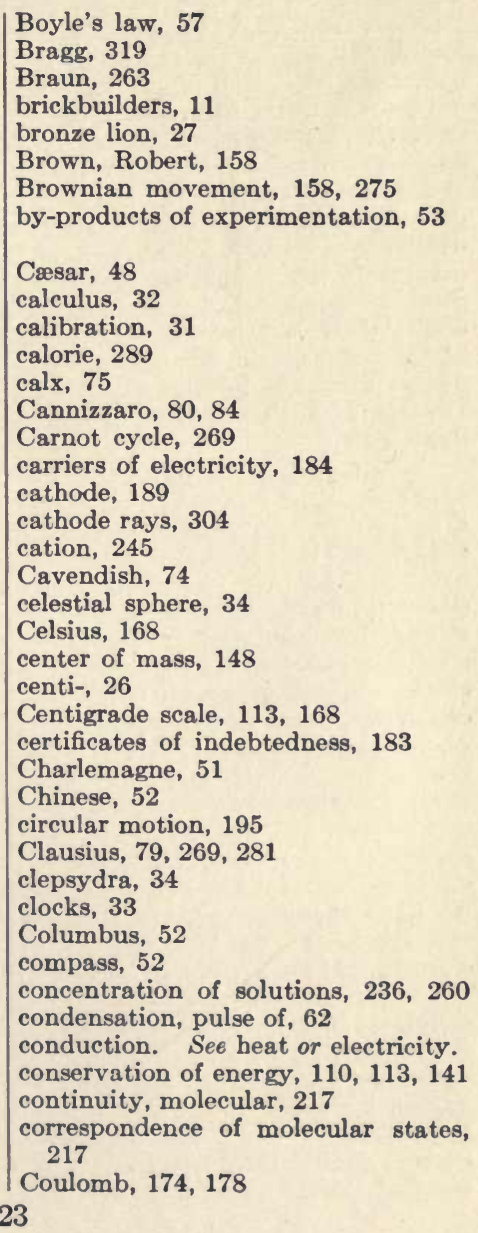


Coulomb's law, 174

critical pressure, 233

critical temperature, 221, 232

critical volume, 232

crystal structure, 319

Curie, 92

current, electrical, 192

Dalton, $72,74,78,79,81,82$

Dalton's laws, 79, 234

Davy, 73

day, solar, 34

days of the week, 11

deductive reasoning, 47

degrees of freedom, 165

Democritus, 70

derived units, 119, 121

diameter of molecule, 281

diffraction grating, 319

dissociation, electrolytic, 248

dog, attitude toward fire, 1

Doppler's principle, 65

double weighing, 28

Dulong and Petit's law, 296, 302 dyne, 145

e, 307

$\mathrm{e} / \mathrm{m}, 305$

efficiency, 21

Einstein, 298

elasticity, 30

elastic limit, 31

electricity, 88, 94, 174

electricity, conduction of, 182,184

electricity, positive and negative, 93

electricity, units of, 177, 178, 206, 277

electrification, 95, 173

electrochemical equivalent, 254

electrolytes, 183, 244, 253

electromagnetic mass, 212

electromagnetic units, 277

electromagnetic waves, 124

electromotive force, 208

electron, $88,90,97,304$

electronic oscillators, 297, 302

electrons, interactions of, 195

electrons, motions of, 173,179

electron, theory, 34

elements, chemical, 72, 91

e.m.f., 208

energy, 8, 101, 114

energy in electrical currents, 199, 209 energy, molecular, 161, 303

engineer, 126

England, 27

entropy, 268

equilibrium, $227,229,257,259,261$

equipartition of energy, 165,271 ,

294,296

equipotential surface, 107

erg, 144

ether, $90,191,200$

Euclid, 44

evaporation of solutions, 248

faculty of accommodation, 266

Fahrenheit, 168

Fahrenheit scale, 113

falling bodies, 46,135

Faraday, 208, 254

Faraday's laws of electrolysis, 254

feudalism, 22

fire, 2,3

fire machine, 6

fluxions, 32,124

foot, 25

force, 139

forced vibration, 298

Franklin, 93, 94

freezing point, $171,239,242$

French Revolution, 122

frequency, 61

friction, 17,113

full radiator, 299

fundamental units, 123

"g," 135, 147, 197

Gaede molecular pump, 283

Galileo, 32, 46, 54, 110, 135, 136, 166

Galvani, 174

gamma rays, 313

gas constant, $\mathrm{R}, 218$

gas equation, 163

gas pressures, low, 284, 287

Gay-Lussac, 83

Geissler tube, 189

Gilbert, 54, 57

Gizeh, 22

gram-centimeter, 108, 145

gram-molecule, 85

gravitational units, 143

Greeks, 11, 85

Gresham's law, 21

Guldberg, 259

gunpowder, 52 
heat eapacity, 166

heat conduction, 161,185

heat dissipation, electrical, 193

heat, specific, 288, 290, 292

Hebrews, 22

helium, 97

Hertz, 124

Hiero, 42, 50

Hippocrates, 85

Hooke, 54

Huyghens, 35

hydraulic press, 59

ideal problems, 18

inclined plane, 17

India, 27

indicators, 261

induced currents, 208

inductive reasoning, 47

inertia, 101

infinitesimals, 130

infra red, 187

intra-molecular motions, 162

inventor, 126

ionization, 180, 181, 314

ionization constant, 259

ionogen, 244

isothermal, 218, 227

\section{J, 289}

Joule, 70, 112, 289

joule, 145

Joule's laws, 193, 220

Karlsruhe, 80

kilo-, 26

kilogram, 27, 123

kinetic energy, 102

kinetic energy, electronic, 214

kinetic energy, molecular, 153, 217

Langmuir, 286

latent heat, 290

laughing gas, 74

Lavoisier, 70, 74, 76

Le Chatelier's principle, 263

Lenz's law, 209

lever, 15

light, 60

light, velocity of, 279

lines of force, 208 liquefaction of gases, 171, 222

Lodge, 127

machine, 8,153

magnetism, 32, 47, 204, 205

man, 1

manometer, 57

Marconi, 124

mass action, 260

mass of electron, 211

mass of molecules, 277

mathematical physicist, 126

mathematics, 115

matter, 114, 303

Maxwell, 124

mean free path, 278

measurement, methods of, 29

mechanical equivalent, 113, 289

Mendelejeff, 100

mercury vapor pump, 285

meridian, 34

meter, 122

metric units, 26, 123

Michelson, 123

milli-, 26

Millikan, 276, 307, 316

mina, 12

mixtures, method of, 289

mobility, 184, 255

mole, 85

molecular conductivity, 250

molecular energy, 270

molecular impacts, 160

molecular mixtures, 234

molecular motions, 155

molecules, 34, 71, 80, 82, 246, 291, 293

molecules, number per mole, 282

momentum, 147, 148

Moseley, 320

motion, 64

musical note, 63

mutual energy, electrical, 215

natural transformations, 267

natural vibrations, 298

Newlands, 100

Newton, $54,79,124,137,141,148$

Newton's laws, 139, 141, 147, 148

neutralization of acid and base, 261

niton, 313

Nobel prize, 123

nucleus, 88,96 
null method, 29

numeric, 119

objective reality, 60

Oersted, 205

Ohm's law, 194

opposition method, 29

oscillators, 296

osmotic pressure, 237,271

$\pi, 44$

pace, 25

paramagnetic, 204

partial pressure, 235

Pascal, 54, 56

Pascal's law, 58

pellate, 146

pendulum, 32

perfect gas, 220,222

period, 33

periodic series, 91, 99

perpetual motion, 152

Perrin, 271, 276

Petit, 297

phlogiston, 75, 77

photoelectric, 315

physics, classification, 60

physical chemistry, 177

pile, Volta's, 175

Pisa, 32, 135

pitch, 61,63

Planck's constant, 297, 315, 316

Pliny, 49

polonium, 92, 313

pontifex, 49

power, 145

powers of ten, 71

potential, 102, 106

practice, 45

pressure coefficient of gas, 170

pressure of gas, 156

pressure of dissolved gas, 235

pressure gauge, 287

pressure head, 136

Priestley, 74, 76

probability, 159

prototype, 27

Ptolemy, 50

pulley, 19

pulse, 62

pyramids, 21

Pythagoras, 28 quantum, 295, 316

$\mathrm{R}$, gas constant, 218

radial energy, 196

radiant matter, 189

radiation, 191

radioactive, 92,313

radium, 97

rarefaction, pulse of, 62

rates, 128

Raleigh, 270

realities of science, 60

recombinations in electrolysis, 250

reflection, 301

relative motion, 64

Renaissance, 51

research physicist, 126

residual rays, 300

resonance, 300

Roman Empire, 48

Romans, 22

Röntgen, 93, 190

roots of cubic, 223

Rutherford, 321

salt, 256

Samothrace, 40

saturated vapor, 229

scaffolding, 21

scattering of alpha rays, 320

Scheele, 74, 76

screw, 19

second, 34

self-induction, coefficient of, 214

sexagesimal system, 12

shekel, 12

Skeptical Chemist, 74

slavery, 22

slope, 130

solenoid, 202

solute, 234

solvent, 234

sound, 60,61

span, 25

spectral lines, 319

spectrum, continuous, 186

speed, 128, 129, 134

statistical method, 159

stone, 27

strain, 30

stress, 30

Stokes's law, 273, 312 
subjective reality, 60 substitution method, 28 supersaturated vapor, 228 surface tension, 221 symbolized logic, 115 sympathetic vibrations, 300 Syracuse, 44

talent, 12

tangential energy, 196

terrella, 47

Thales, 13, 34

theory, 34,45

thermionic emission, 185

thermodynamies, laws of, 114, 263, 268

thermometer, 166,170

Thomson, 229, 230

thorium, 92

time, 32

tool, 1,4

Torricelli, 54, 137

Townsend, 306

tractate, 146

train of waves, 65

transit, 34

translation, motion of, 7

triple point, 241

ultraviolet, 187

ultimate strength, 31

United States, 27 units, 24, 123. See also electricity, units of

universal gravitation, 141, 142

uranium, 92

vacuum, 54, 90

valence, 86

Van't Hoff, 239, 243

Van der Waals's equation, 222, 224, 230,281

vapor pressure, $225,239,240$

variable mass, 213

variable standards, 25

velocity, 134

Vesuvius, 49

vibration of elastic system, 66

viscosity, 274

Vitruvius, 42

volt, 178

Volta, 86, 175, 197

Waage, 259

water, decomposition of, 253

watt, 145

wedge, 18

weighing, 27

weight, 147

wheel and axle, 21

wireless telegraphy, 124

work, 8. See energy

work principle, 20,153

$\mathrm{X}$-rays, 91, 190 

THE following pages contain advertisements of a 1 few of the Macmillan books on kindred subjects 



\section{A Short History of Science}

\section{By W. T. SEDGWICK}

Head of the Department of Biology

AND

W. H. TYLER

Head of the Department of Mathematics, Massachusetts Institute of Technology

With Appendices and Illustrations Cloth, 8vo, \$2.50

The history of science is as engrossing as the history of Greece and Rome and gives as sure an indication of the growth of civilization as does the history of philosophy, art, literature, or music. The literature of science has always been more or less technical both in the subject matter and the form of its presentation, and Professors Sedgwick and Tyler have rendered a great service to the lay reader as well as to the student in writing a history of the development of science from its remotest period, through the romance of mediæval astrology and alchemy to the tremendous achievements of the last two centuries. "A Short History of Science" is one of the first books of its kind in English and is the result of the authors' many years of joint teaching of the subject. It is a book which will prove of the greatest value to Universities, Colleges, Scientific and Technical schools, and is especially adapted to general reading and reference.

"It is a wonderful record of human progress, a record of the things by which the real progress of mankind has been achieved. ... Admirably arranged, with a series of bibliographies and illustrations." - San Francisco Chronicle.

"Both as a textbook and as a reference book, this volume deserves a place in every well-balanced library."

- The Evening Sun.

\section{THE MACMILLAN COMPANY}




\section{The Adventure of Life}

\section{By ROBERT W. MAcKENNA}

Cloth, $12 m o, \$ 1.25$

This book is the work of a doctor who has been serving with the British army. In the form of fiction and with vivid description and illustration, there is presented the scientific interpretation of life. As the reflections of a man scientifically trained who has been for four years in the presence of much suffering and death and can still believe in a just God who is not only the First Cause, but also the loving Father of mankind, the volume is of deep significance and import. The author's style is attractive and often eloquent. What he has to say has a special appeal at this time when the questions which he raises are being brought home afresh to many a bereaved family.

\section{Education by Violence}

\section{BY HENRY S. CANBY}

Cloth, I2mo, $\$ 1.50$

Professor Canby here deals with the effects of the war and the rehabilitation of society at home and in Europe. Among the specific topics taken up are the conditions in England and France, the racial and spiritual differences and agreements between the Allies and the prospects of a peace which shall finally end war. As the reflections of the mind of an American scholar when he comes into contact with the realities of the war and its changes, the book is certain to have a wide interest in this country.

\section{THE MACMILLAN COMPANY}




\section{Reconstruction and National Life}

\section{By CECIL FAIRFIELD LAVELL}

Cloth, remo

The purpose of Professor Lavell's new volume is, primarily, to suggest and illustrate an historical approach to the problem of reconstruction in Europe. Professor Lavell will be remembered as author, with Professor Charles E. Payne, of "Imperial England," published in the fall of last year.

\section{Problems of Reconstruction}

\section{By ISAAC LIPPINCOTT}

Associate Professor of Economics, Washington University

Cloth, I2mo, \$I.6o

"From an industrial point of view the nations at war are confronted with two groups of problems. Stated briefly, the first group contains questions of concentrating industrial effort largely on war production, of diverting men, materials and financial resources to the essential industries and of curtailing the operations of all the rest, of regulating commerce with foreign countries, and of formulating policies and methods for the accomplishment of these ends. In short, this is principally a question of development of war control with all that this implies. The second group of problems arises out of the first. It involves such questions as the dissolution of the war organization, the removal of the machinery of control, the restoration of men, funds, and materials to the industries which serve the uses of peace, and the reëstablishment of normal commercial relations with the outside world. The latter are post-war problems. Their prompt solution is necessary because the war has turned industrial and social life into new channels, and because it will be necessary for us to restore the normal order as quickly as possible. These brief statements outline the task of this volume."

\section{THE MACMILLAN COMPANY}




\title{
THE WORLD'S PEACE PROBLEMS
}

\section{The Great Peace}

\author{
By H. H. POWERS
}

Author of "America Among the Nations," "The Things Men Fight For," etc.

Cloth, $12 m o, \$ 2.25$

"The terms of peace to be agreed upon must be based on the fullest recognition of the special problems and wishes of the associated nations. The problem of problems is the control of the sea.... These questions are discussed with thoughtfulness and clarity, and a wide grasp of circumstances and difficulties."-The Detroit Free Press.

\section{National Governments and the World War}

\author{
BY FREDERIC A. OGG
}

Professor of Political Science in the University of Wisconsin

$$
\text { AND }
$$

CHARLES A. BEARD

Director of the Bureau of Municipal Research, New York City

$$
\text { Cloth, } 8^{\circ}, \$ 2.50
$$

In this new volume Professors Ogg and Beard give us a fuller realization of the bearings of governmental organization and practice upon public well-being, a better knowledge of the political experience and problems of other peoples, and a new enthusiasm for national and international reconstruction on lines such as will conserve the dearly bought gains of the recent conflict.

\section{The End of the War}

By WALTER E. WEYL

Author of "American World Policies," "The New Democracy," etc. Cloth, $12^{\circ}, \$ 2.00$

"Mr. Weyl says sobering and important things. ... His plea is strong and clear for America to begin to establish her leadership of the democratic forces of the world ... to insure that the settlement of the war is made on lines that will produce international amity everywhere." $-N$. Y. Times.

\section{THE MACMILLAN COMPANY}

Publishers 64-66 Fifth Avenue New York




\section{TWO NEW BOOKS ON CHINA}

\section{China and the World War}

By W. REGINALD WHEELER

Cloth, I2mo, $\$ 1.75$

This is a clear and succinct account of affairs in China since the outbreak of the war.

Among the events which the author discusses are the relations of Japan and China; political conditions in China with the conflict between republicanism and the monarchical form of government; the American-Japanese agreement, and the Chinese-Japanese alliance for intervention in Siberia. Dr. Wheeler sets these matters forth in a simple, straightforward fashion with many citations from Chinese papers and documents which provide most interesting reading for Westerners.

The author is a professor in Hangchow Christian College, is a friend of the Chinese Republic, and writes with sympathy and understanding of Chinese affairs.

\section{Foreign Financial Control in China}

BY T. W. OVERLACH

Cloth, $12^{\circ}, \$ 2.00$

This is a careful study of British, Russian, French, German, Japanese, and American financial intervention and financial operations in China. It is well documented and clearly written. It treats of a pressing issue in the Orient - one which involves the United States deeply and will press to the front after the war. It is the first consistent account of the origin and development of foreign control in China. In view of our interests there, both practical and political, and especially on account of the present crisis and further impending crises, there is significance in Mr. Overlach's authoritative.

THE MACMILLAN COMPANY

Publishers 64-66 Fifth Avenue New York 






THIS BOOK IS DUE ON THE IAST DATE STAMPED BELOW

AN INITIAL FINE OF 25 CENTS WILL BE ASSESSED FOR FAILURE TO RETURN THIS BOOK ON THE DATE DUE. THE PENALTY WILL INCREASE TO 50 CENTS ON THE FOURTH DAY AND TO $\$ 1.00$ ON THE SEVENTH DAY OVERDUE.

NOV 12

NOV 121932

SEP 171933

FEB 111998 
Yr. 73104

U. C. BERKELEY LIBRARIES

|| || || || ||| || || || ||||||

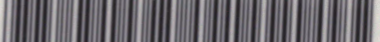

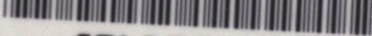
C니라859

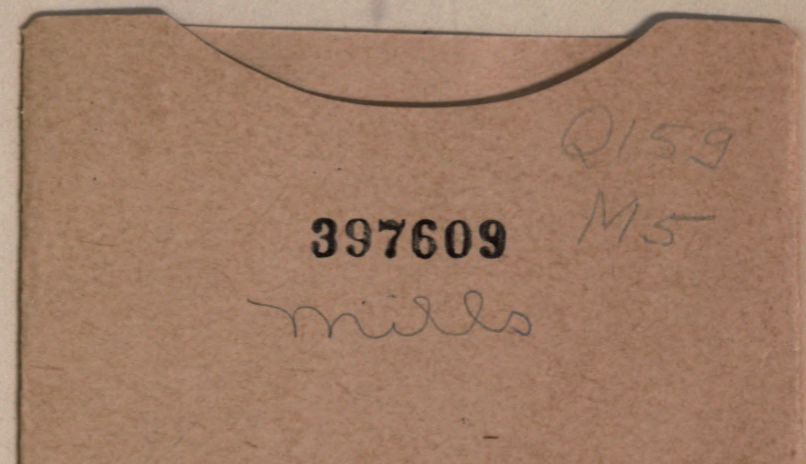

UNIVERSITY OF CALIFORNIA LIBRARY 
